Uma abordagem de apoio a boas práticas para desenvolvimento de aplicações Web acessíveis 



\title{
Uma abordagem de apoio a boas práticas para desenvolvimento de aplicações Web acessíveis
}

\author{
Thiago Jabur Bittar
}

Orientadora: Profa. Dra. Renata Pontin de Mattos Fortes

Tese apresentada ao Instituto de Ciências Matemáticas e de Computação - ICMC-USP, como parte dos requisitos para obtenção do título de Doutor em Ciências - Ciências de Computação e Matemática Computacional. VERSÃO REVISADA 
Ficha catalográfica elaborada pela Biblioteca Prof. Achille Bassi e Seção Técnica de Informática, ICMC/USP, com os dados fornecidos pelo(a) autor(a)

Jabur Bittar, Thiago
J318a Uma abordagem de apoio a boas práticas para
desenvolvimento de aplicações Web acessiveis / Thiago
Jabur Bittari orientadora Renata Pontin de Mattos
Fortes. -- São Carlos, 2013.
255 p.
Tese (Doutorado - Programa de Pós-Graduação em
Ciências de Computação e Matemática Computacional) --
Instituto de Ciências Matemáticas e de Computação,
Universidade de São Paulo, 2013.
1. Acessibilidade. 2. Web. 3. Interação Humano-
Computador. I. Fortes, Renata Pontin de Mattos,
orient. II. Título.




\section{Agradecimentos}

Agradeço a Deus, em primeiro lugar, que me deu saúde, serenidade, força de vontade e colocou-me ao lado das pessoas certas para ajudar-me neste trabalho.

A minha família, em especial ao meu pai Gilberto, a minha mãe Fátima e aos meus irmãos Luciana e Rafael, verdadeiros amigos, por me apoiarem e entenderem a necessidade de minha ausência em muitos momentos para o desenvolvimento deste trabalho. Neles eu tive a base forte para minha caminhada!

A professora Renata Fortes, minha orientadora, que sempre acreditou em mim e me conduziu com bons conselhos, compartilhando seus conhecimentos para ultrapassar os desafios encontrados ao longo do trabalho. Sua serenidade, disponibilidade e boa vontade foram fundamentais para a conclusão da pesquisa.

Aos amigos e colegas que foram muito importantes durante essa trajetória: Eduardo Pezutti, Willian Watanabe, Filipe Grillo, David Neto, Luciano Paranhos, João Henrique (Pirão), Márcio Fabrício e Alexandre Petersen. Em especial a Leandro Agostini e Daniel Lucrédio que tiveram paciência para me ajudar efetivamente em muitos momentos. A Luanna Lobato pela sua grande ajuda, carinho incondicional e positividade que sempre teve comigo, me inspirando para condução deste trabalho.

Ao professor e amigo Elson Longo pelos conselhos e apoios demonstrados durante todos esses anos.

Aos amigos da Aptor Software pelo grande aprendizado que tive enquanto estava junto a eles e pela confiança e entendimento que tiveram comigo.

A todos do ICMC/USP, professores, colaboradores e amigos que contribuíram para que este trabalho fosse realizado. Aos amigos da UFG, Campus Catalão, pelo apoio concedido.

Por fim, agradeço a todos aqueles que sempre se dispuseram e atenderam as minhas solicitações de colaboração com esta pesquisa.

Muito obrigado! 
"By creating we think, by living we learn"

Patrick Geddes 



\section{Resumo}

A interação com aplicações Web está se tornando cada vez mais presente no dia-a-dia das pessoas, sendo útil para a disponibilização de recursos que permitem a realização de serviços, estudos ou entretenimento. Porém muitos dos recursos disponibilizados apresentam barreiras em relação à acessibilidade, impedindo que usuários finais, com algum tipo de deficiência, possam utilizá-los de forma eficiente. Como solução para esse problema, têm sido propostas diretrizes para o desenvolvimento de aplicações Web acessíveis. Entretanto, apesar da existência dessas diretrizes, o cenário atual ainda mostra que há dificuldades em relação ao desenvolvimento considerando requisitos de acessibilidade. Neste sentido, esta tese está calcada na criação de uma abordagem que permita o apoio efetivo a boas práticas para desenvolvimento Web, a partir da aproximação de tais diretrizes ao ambiente das equipes de desenvolvimento. Para tanto, são definidas atividades separadas em 3 eixos de preocupações: Treinamento em Acessibilidade, Gerência de Decisões e Desenvolvimento e Ferramental. Para validação da concepção inicial da proposta desta tese, estudos de caso são detalhados, demonstrando como o desenvolvimento Web pode ser beneficiado com melhor apoio ferramental, que incluem o uso de técnicas de modelagem e de padrões para geração de código acessível. São ainda verificados os benefícios da colaboração de experiências e treinamento da equipe de desenvolvimento, para tanto foi desenvolvida a ferramenta AccessibilityUtil. Posteriormente é descrita a abordagem e validada em um experimento controlado em que existiram grupos de participantes utilizando a abordagem e outros que não fizeram uso da mesma. Com isso, observou-se que, com a utilização da abordagem, houve melhor apoio a boas práticas de desenvolvimento em relação à aplicação de requisitos de acessibilidade, o que ocasiona em melhores resultados de qualidade para as aplicações Web. 



\section{Abstract}

The interaction with Web applications is becoming increasingly present daily, being useful to provide resources that allow the execution of services, education or entertainment. But many of the resources present barriers in relation to accessibility, hindering disabled users use them efficiently. As solution to this problem, guidelines to develop accessible Web applications have been proposed. However, despite the guidelines definition, the current scenario shows that there are difficulties related to the development considering accessibility requirements. Thus, this thesis focus on proposing an approach to support good practices for Web development, based on the use of these guidelines to the development team environment. Therefore, activities are defined on 3 layers: Accessibility Training, Decisions Management, and Development and Tooling. In order to validate the initial design of this thesis proposal, case studies were detailed, presenting how the Web development can be benefited through the tool support, including the use of modeling techniques and patterns for accessible code generation. Additionally, the benefits with the experience collaboration and training of the development team are also verified, to allow this the tool AccessibilityUtil was developed. After this, the approach is described and validated in a controlled experiment, where groups were defined with and without the approach use. As conclusion, we verified benefits using the approach, since that was identified a better support on development best practices regarding to the use of accessibility requirements, which results in a better quality for accessible Web applications. 



\section{Sumário}

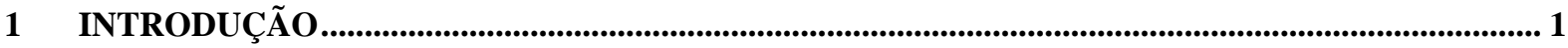

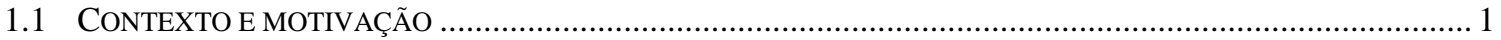

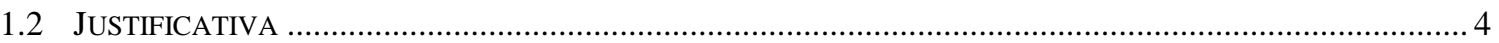

1.3 A TESE

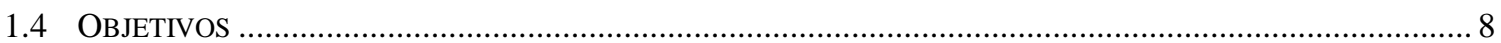

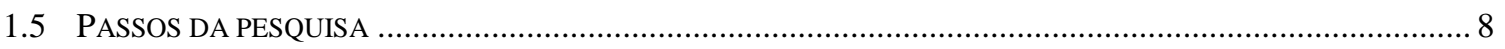

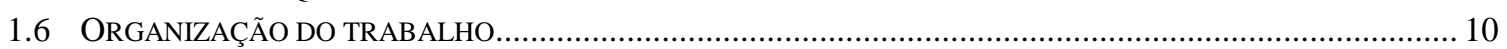

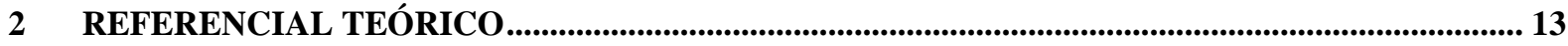

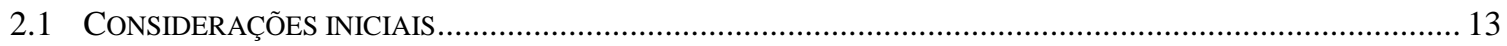

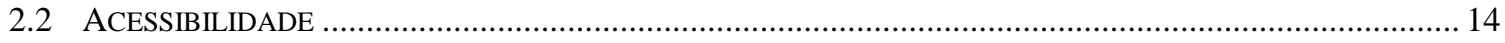

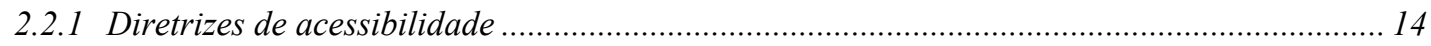

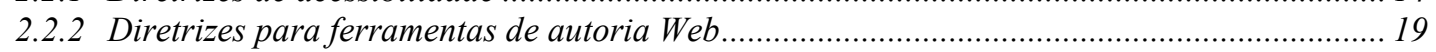

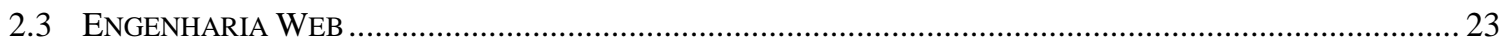

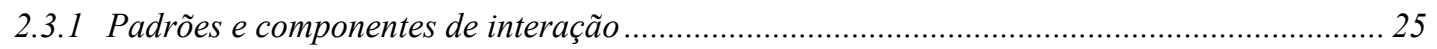

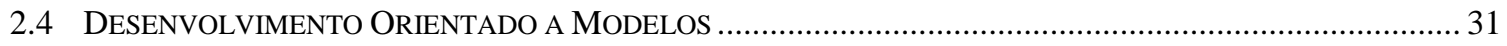

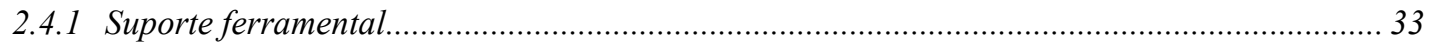

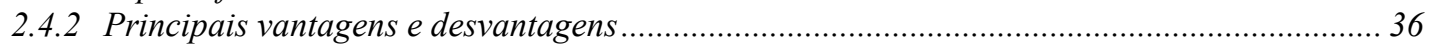

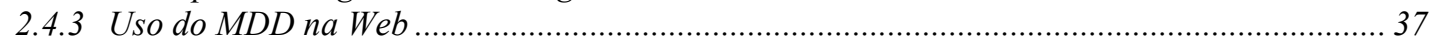

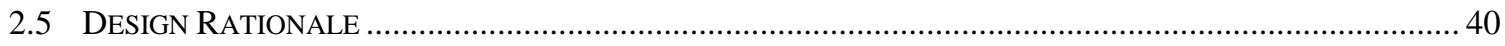

2.5 .1 Colaboração

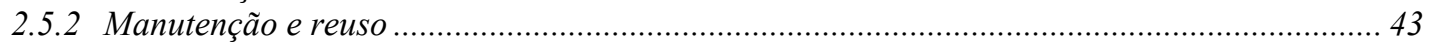

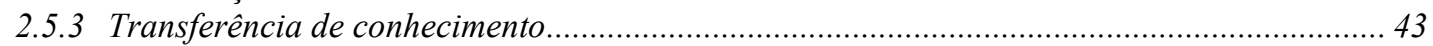

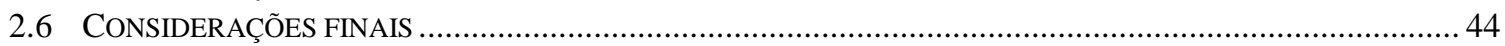

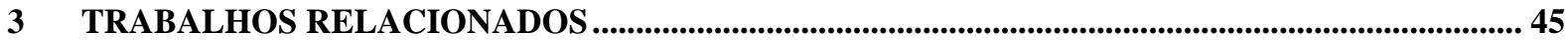

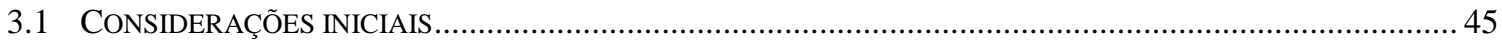

3.2 UMA ABORDAGEM PARA ANOTAÇÃO SEMÂNTICA DE ELEMENTOS PRESENTES EM PÁGINAS DA WEB ... 46

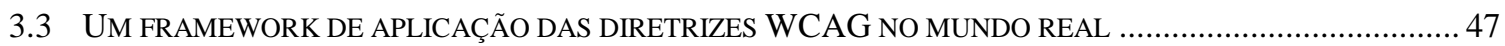

3.4 UM MODELO DE PROCESSO PARA DESIGN INCLUSIVO DE SISTEMAS DE INFORMAÇÃO NA WEB ............. 48

3.5 UM MODELO DE DESENVOLVIMENTO FOCADO NA AVALIAÇÃo CONTÍNUA DE ACESSIBILIDADE..............49

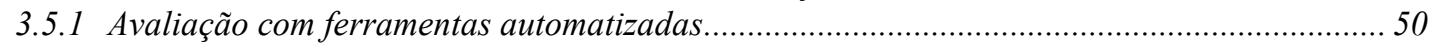

3.5.2 Inspeção manual realizada por especialistas em acessibilidade Web ......................................51

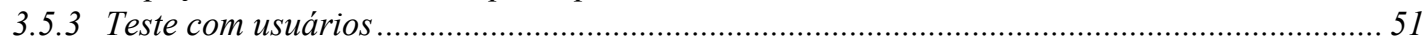

3.6 UM PROCESSO PARA O DESENVOLVIMENTO DE APLICAÇÕES WEB ACESSÍVEIS ........................................ 52

3.7 UMA ABORDAGEM COLABORATIVA PARA TESTES E MELHORIAS DE ACESSIBILIDADE EM SITES

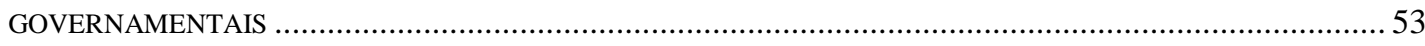

3.8 AWA, UM SUPORTE METODOLÓGICO FLEXÍVEL PARA DESENVOLVIMENTO DE APLICAÇÕES WEB

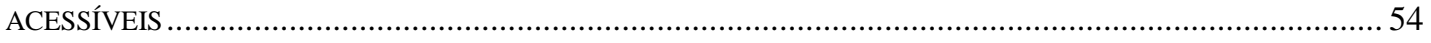

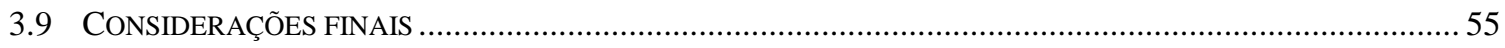

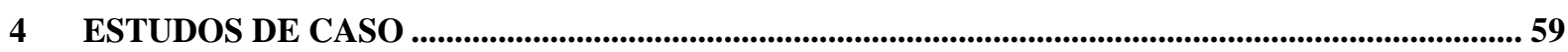

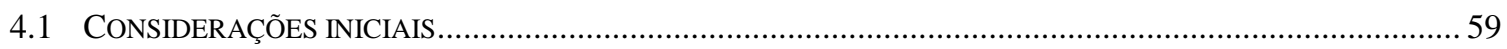

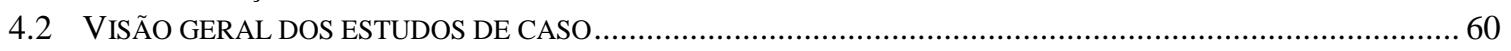

4.3 ESTUdO DE CASO 1 - DiAGNÓSTICO DE ACESSIBILIDADE EM SITES DAS PREFEITURAS MUNICIPAIS

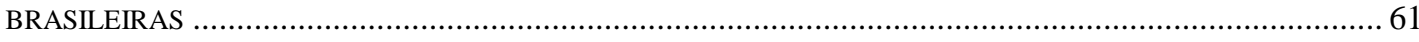

4.4 ESTUDO DE CASO 2 - EDITOR GRÁFICO, USANDO MDD, COMO PROVA DE CONCEITO PARA APOIO

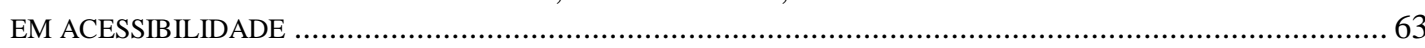

4.4.1 Editor gráfico para modelagem com recursos de validação.................................................... 66

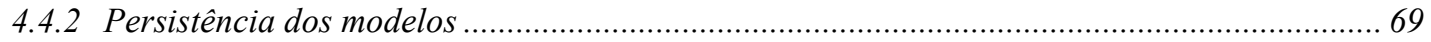


4.5 ESTUdo DE CASO 3 - USO DE MDD NA ESTRUTURAÇÃO DE UMA WIKI COM GERAÇÃO DE CÓDIGO

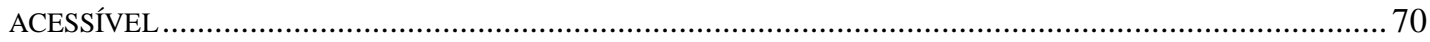

4.5.1 Estruturação em Wikis e a problemática envolvida ...................................................... 72

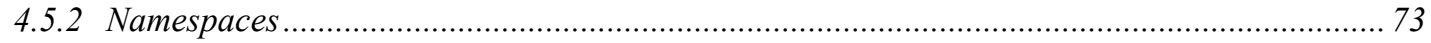

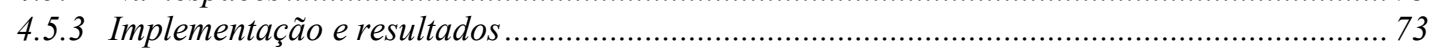

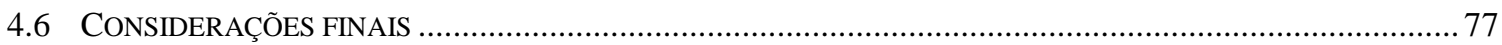

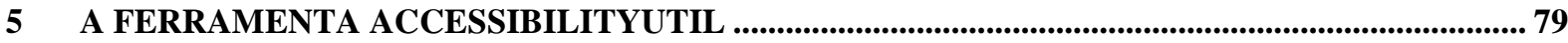

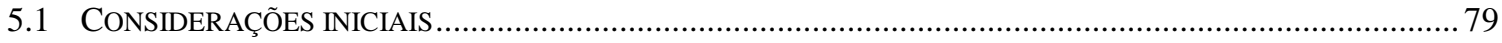

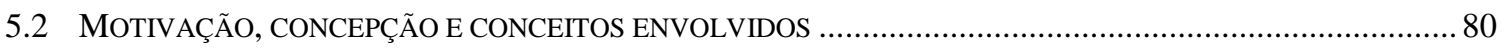

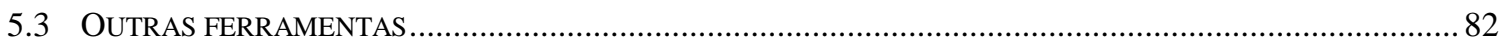

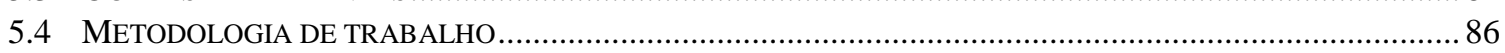

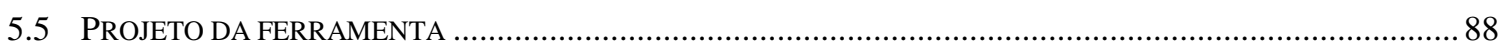

5.5.1 Moderação do conteúdo .................................................................................................. 95

5.5.2 Gestão de decisões de acessibilidade em projetos ......................................................... 97

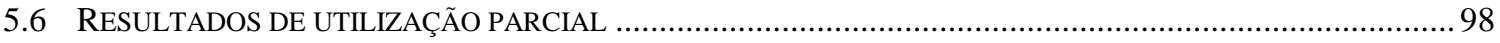

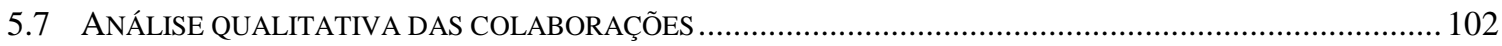

5.7.1 Seleção de trechos de contribuições e considerações ........................................................... 102

5.7.2 Verificação de concordância nas discussões ..................................................................... 105

5.7.3 Considerações gerais ..................................................................................................... 107

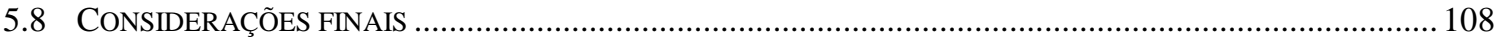

6 UMA ABORDAGEM DE APOIO A BOAS PRÁTICAS PARA DESENVOLVIMENTO DE

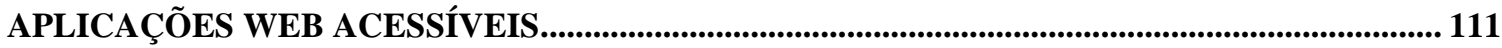

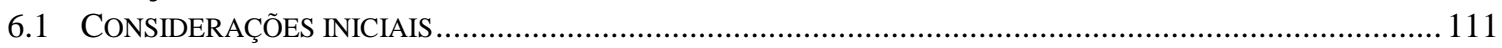

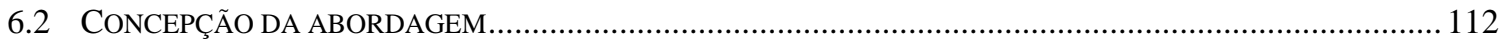

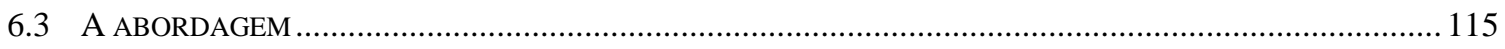

6.3.1 Descrição de papéis e suas responsabilidades..................................................................... 118

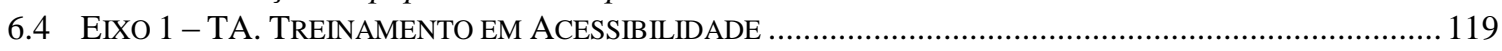

6.4.1 Atividade TA.1. Planejamento do treinamento em acessibilidade ........................................ 122

6.4.2 Atividade TA.2. Execução do treinamento em acessibilidade .............................................. 124

6.4.3 Atividade TA.3. Verificação de aprendizagem em acessibilidade ..................................... 125

6.5 EIXO 2 - GD. GERÊNCIA DE DECISÕES ............................................................................... 125

6.5.1 Atividade GD.1. Planejamento da gerência de decisões ................................................... 128

6.5.2 Atividade GD.2. Tomada de decisões.................................................................................. 129

6.5.3 Atividade GD.3. Consolidação das decisões ..................................................................... 130

6.5.4 Atividade GD.4. Difusão das decisões ...................................................................... 131

6.6 EIXO 3 - DF. DESENVOLVIMENTO E FERRAMENTAL ................................................................. 131

6.6.1 Atividade DF.1. Planejamento do desenvolvimento e ferramental ...................................... 136

6.6.2 Atividade DF.2. Elicitação de requisitos.......................................................................... 139

6.6.3 Atividade DF.3. Seleção e uso de componentes acessíveis ................................................. 140

6.6.4 Atividade DF.4. Verificação de referência aos modelos de desenvolvimento anteriores....... 142

6.6.5 Atividade DF.5. Utilização de recursos no apoio a boas práticas de desenvolvimento......... 142

6.6.6 Atividade de apoio DF.AP.1. Gerenciamento de configuração ........................................ 144

6.6.7 Atividade de apoio DF.AP.2. Monitoramento de acessibilidade ........................................ 145

6.6.8 Atividade de apoio DF.AP.3. Documentação de acessibilidade ........................................ 147

6.7 INTEGRAÇÃO COM O MODELO DE PROCESSO DA NORMA ISO/IEC 12.207 ...................................... 147

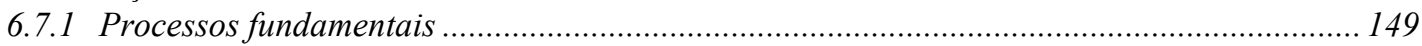

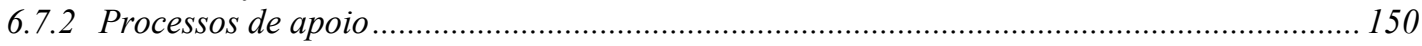

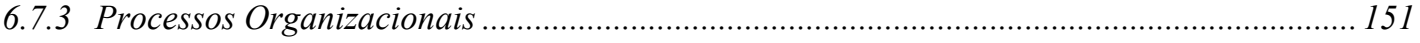

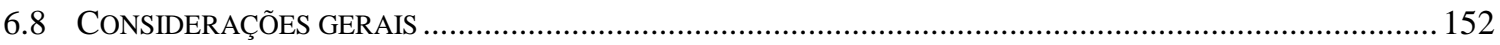

6.8.1 Ameaças e dificuldades para aplicação da abordagem ..................................................... 153

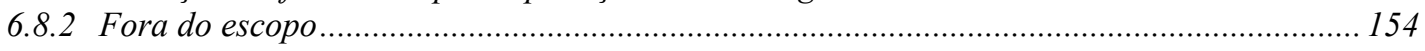

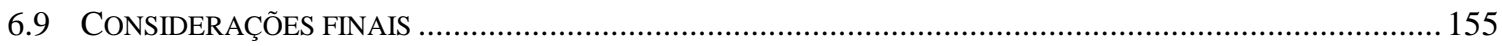

7 EXPERIMENTO PARA VALIDAÇÃO DA ABORDAGEM PROPOSTA .................................... 157 


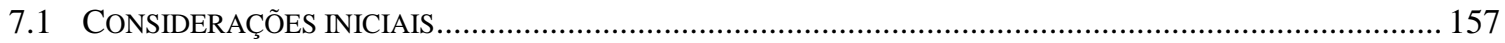

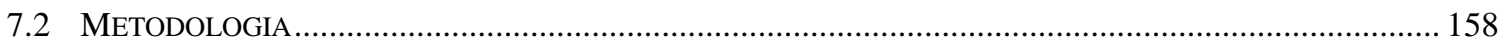

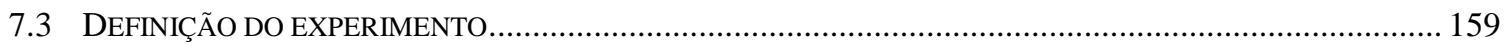

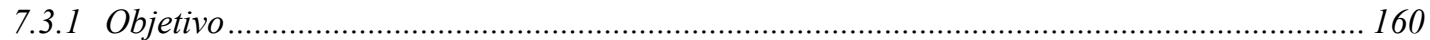

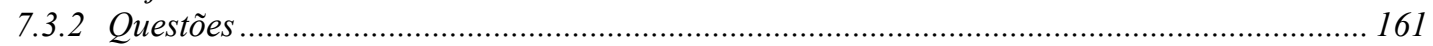

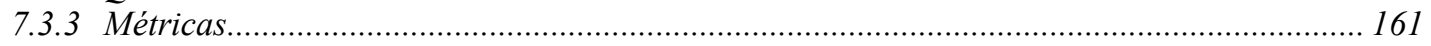

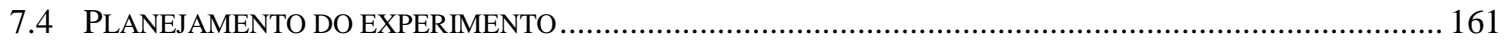

7.4.1 Seleção do contexto ............................................................................................. 162

7.4.2 Formulação das hipóteses.............................................................................................. 162

7.4.3 Seleção de variáveis ............................................................................................. 163

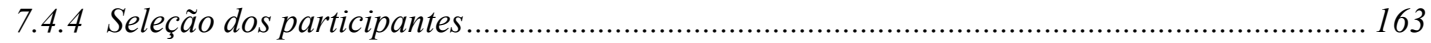

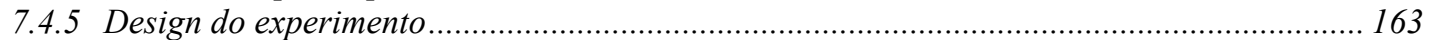

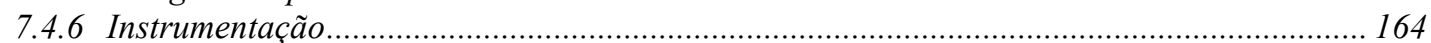

7.4.7 Avaliação da validade ................................................................................................... 164

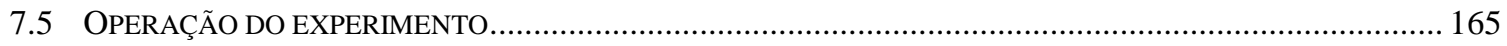

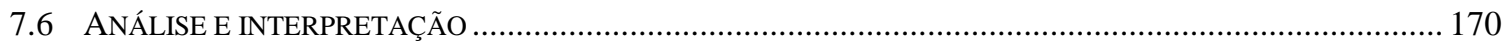

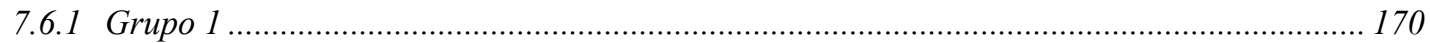

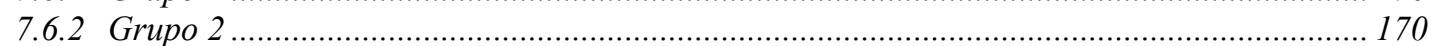

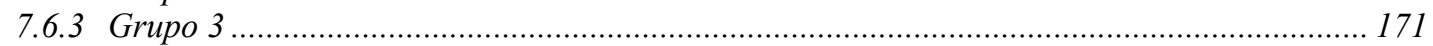

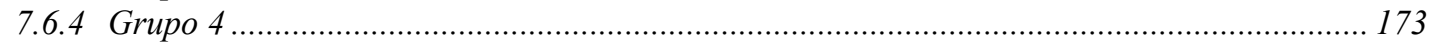

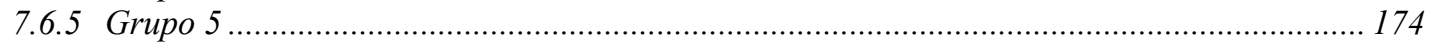

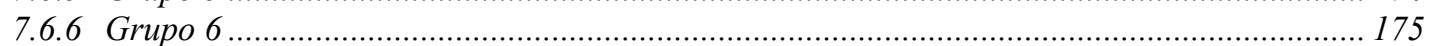

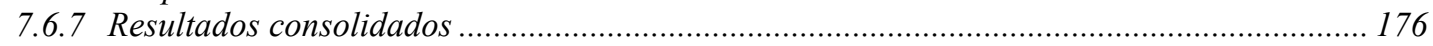

7.7 LEVANTAMENTO DE DADOS SOBRE O DESENVOLVIMENTO EFETUADO .......................................... 179

7.7.1 Análise de dados da experiência - Questionário 1 ......................................................... 181

7.7.2 Análise de dados do desenvolvimento efetuado - Questionário 2........................................ 181

7.7.3 Análise de dados do uso da abordagem - Entrevista ......................................................... 187

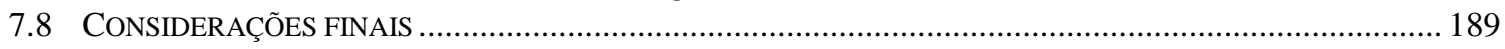

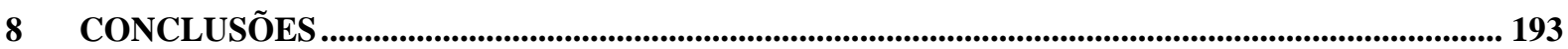

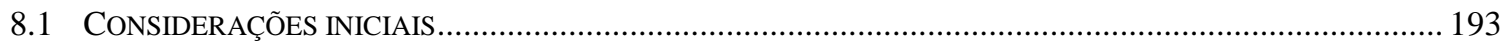

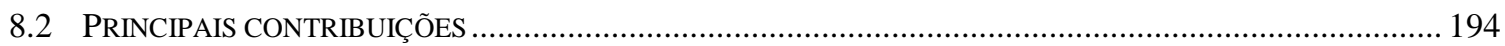

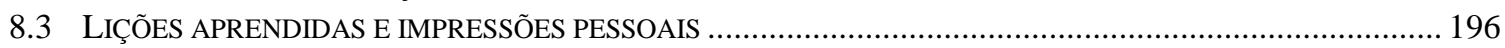

8.4 PREMIAÇÃO DA FERRAMENTA ACCESSIBILITYUTIL ….................................................................. 197

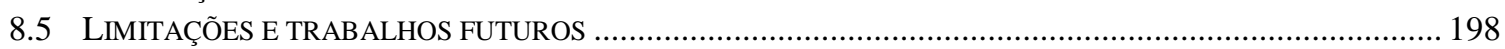

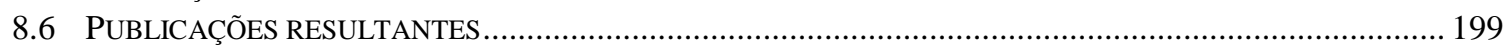

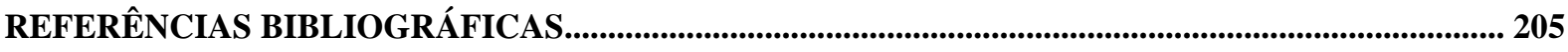

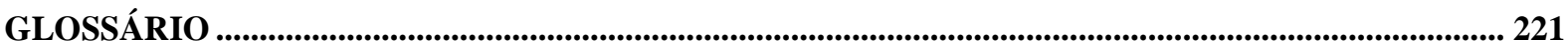

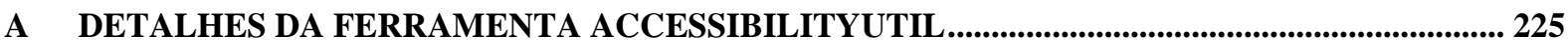

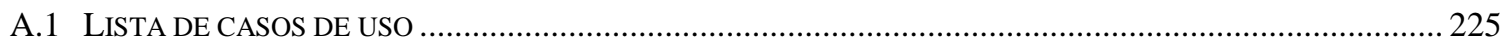

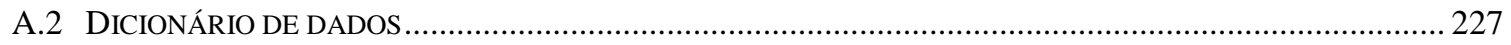

A.3 LISTAGEM DE ORGANIZAÇÕES E NÚMERO DE USUÁRIOS …........................................................ 231

B DETALHES SOBRE O EXPERIMENTO REALIZADO ................................................................. 233

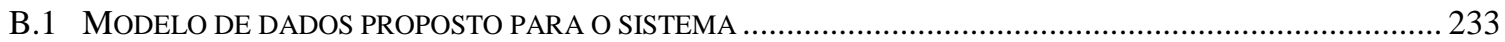

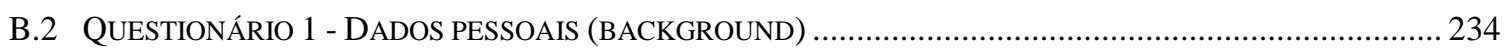

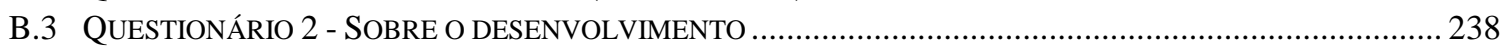

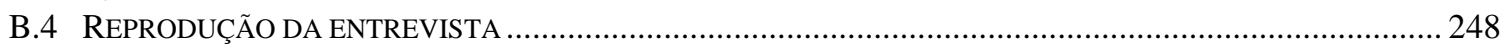

C TÉCNICAS, CRITÉRIOS DE SUCESSO E CHECKPOINTS DE DOCUMENTOS DO W3C...... 253

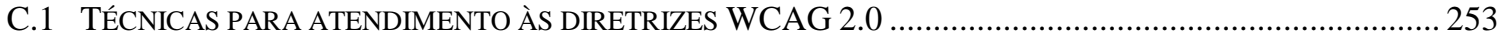

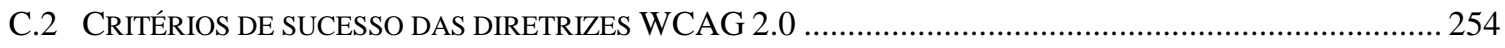

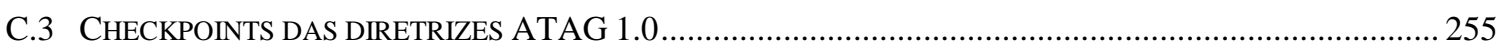




\section{Lista de figuras}

FIGURA 1.1 - FORMA TRADICIONAL DE DESENVOLVIMENTO WEB EM QUE NEM SEMPRE DIRETRIZES DE ACESSIBILIDADE SÃO CONSIDERADAS

FIGURA 1.2 - DESENVOLVIMENTO WEB COM ADOÇÃO DE BOAS PRÁTICAS .................................................... 6

FIGURA 1.3 - LINHA DO TEMPO DOS TRABALHOS EFETUADOS................................................................ 9

FIGURA 2.1 - MODELO DE DIRETRIZES DE ACESSIBILIDADE DA WAI, ADAPTADO DE W3C (2008B) ..................... 15

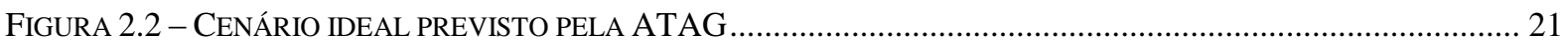

FIGURA 2.3 - SÍNTESE GRÁFICA (EM ADAPTAÇÃo AO ORIGINAL) DE ALGUNS DOS PADRÕES WEB DE

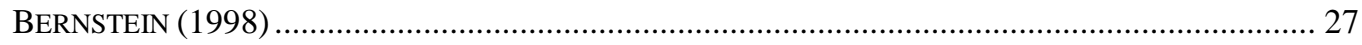

FIGURA 2.4 - EXEMPLO DO PADRÃo WEB “DOUbLE TAB NAVIGATION” DE VAN WELIE..................................... 29

FIGURA 2.5 - CICLO DE VIDA DO MDD DESDE O RECONHECIMENTO DE REQUISITOS ATÉ A IMPLANTAÇÃO ........... 32

FIGURA 2.6 - CICLO BÁSICO DE TRANSFORMAÇÕES NO DESENVOLVIMENTO ORIENTADO A MODELOS .................. 33

FIGURA 2.7 - REPRODUÇÃO DO CICLO DE DESENVOLVIMENTO DO GMF A PARTIR DE SEU GUIA DASHBOARD ....... 34

FigurA 2.8 - DiAgRAMA ECORE DA IAML (A) COM DESTAQUE PARA UM DE SEUS PONTOS (B) E SUA

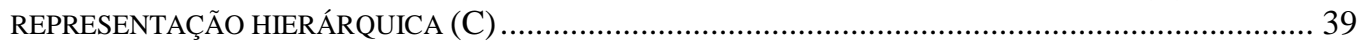

FIGURA 2.9 - SERVIÇOS PROVIDOS POR SISTEMAS DE DR, ADAPTADO DE LEE (1997) ......................................41

FIGURA 4.1 - ESTRUTURAS EM ÁRVORE HIERÁRQUICA DE ELEMENTOS EM METAMODELOS ECORE ........................64

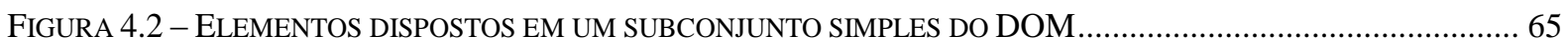

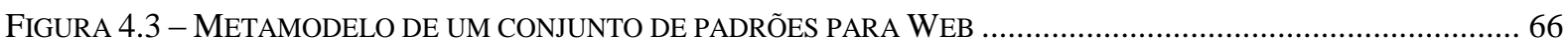

FIGURA 4.4 - EDITOR DE DIAGRAMAS PARA O MODELO SIMPLEDOM, MOSTRANDO O PRIMEIRO NÍVEL DE

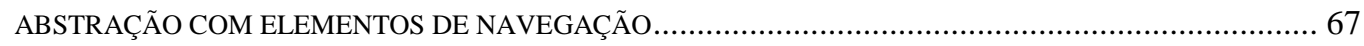

FIGURA 4.5 - EXEMPLO DE VALIDAÇÃO DO MODELO PARA CHECAGEM DE UMA DIRETRIZ DE ACESSIBILIDADE .... 68 FIGURA 4.6 - VALIDAÇÃO EM TEMPO DE DESENVOLVIMENTO EMITINDO UMA MENSAGEM DE VIOLAÇÃO DA

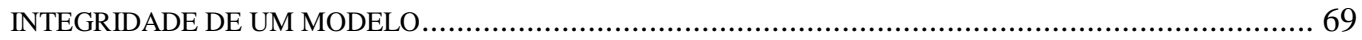

FIGURA 4.7 - VISUALIZAÇÃO GRÁFICA DO MODELO PERSISTIDO EM XMI E SEU MAPEAMENTO EM CÓDIGO ......... 70

FIGURA 4.8 - METAMODELO DE ESTRUTURAÇÃO DE MENUS FEITO NA PLATAFORMA ECLIPSE GMF .................... 74

FIGURA 4.9 - MODELO COM DADOS DE UM MENU EXEMPLO ......................................................................... 74

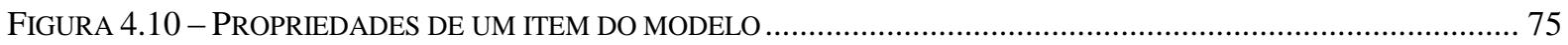

FIGURA 4.11 - MENU HIERÁRQUICO GERADO PARA A WIKI ....................................................................... 75

FIGURA 4.12 - VISÃO DA WIKI GERADA COM LINKS PARA A ESTRUTURA PLANEJADA NO MODELO....................... 76

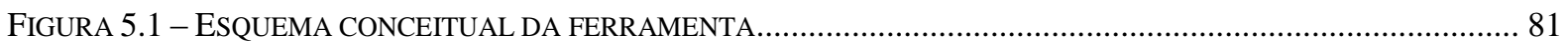

FIGURA 5.2 - PÁGINA INICIAL DA FERRAMENTA ACCESSIBILITYUTIL ..............................................................90

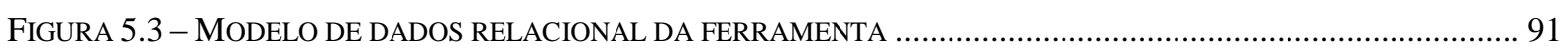

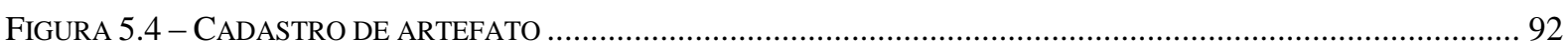

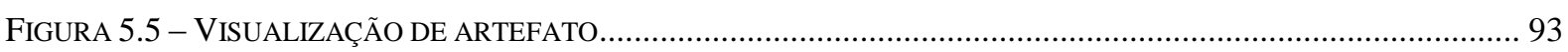

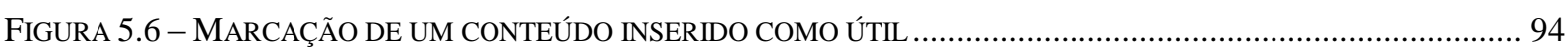

FIGURA 5.7 - LINKS E FORMULÁRIO PARA INDICAÇÃO DE CONTEÚDO A ANALISADO POR UM ADMINISTRADOR ....996

FIGURA 5.8 - VISUALIZAÇÃO DE UM TÓPICO DE UM PROJETO E A DISCUSSÃO REALIZADA ....................................98

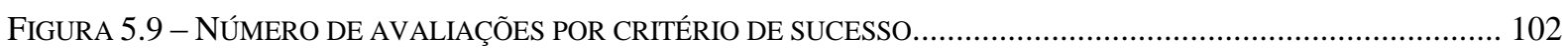

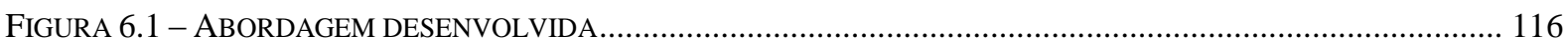

FIGURA 6.2 - LEGENDA PARA OS DIGRAMAS DE FLUXO DE ATIVIDADES ...................................................... 121

FIGURA 6.3 - FLUXO SIMPLIFICADO DE ATIVIDADES SUGERIDO PARA O EIXO 1 - TA ....................................... 121

Xvii 
FIGURA 6.4 - FLUXO SIMPLIFICADO DE ATIVIDADES SUGERIDO PARA O EIXO 2 - GD ........................................ 128

FIGURA 6.5 - FLUXO SIMPLIFICADO DE ATIVIDADES SUGERIDO PARA O EIXO 3 - DF ….................................. 135

FIGURA 6.6 - NÍVEL CONCEITUAL E CONCRETO PARA FORMAÇÃO DE UM COMPONENTE ACESSÍVEL .................... 140

FIGURA 6.7 - POSSÍVEL FLUXO DE SELEÇÃO, USO, CONSTRUÇÃO E TESTES DE COMPONENTES ............................ 141

FIGURA 6.8 - POSSÍVEL INTEGRAÇÃO DA ABORDAGEM APRESENTADA COM O MODELO DE PROCESSO DA

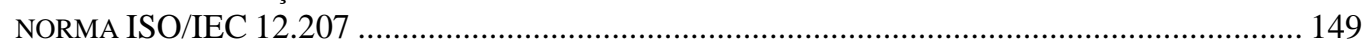

FIGURA 7.1 - VISÃO GERAL DA FASE DE PLANEJAMENTO DO EXPERIMENTO (WOHLIN ET AL., 2000) ................ 162

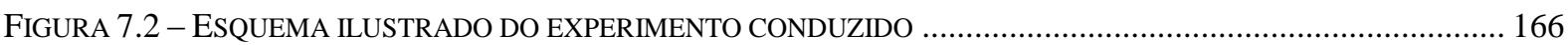

FIGURA 7.3 - DESIGN DO GRUPO 1 COM APONTAMENTO DE PROBLEMAS ...................................................... 170

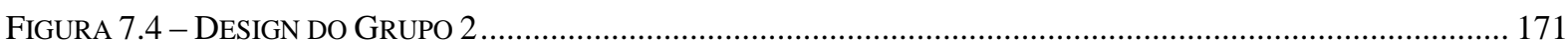

FIGURA 7.5 - H1 PARA TÍTULO CORRETO, PORÉM HÁ PROBLEMA DE CONTRASTE DE COR NO CABEÇALHO........... 172

FIGURA 7.6 - USO DE RECOMENDAÇÕES DE ACESSIBILIDADE PARA A TABELA, MAS COM LAY-OUT POBRE ......... 173

FIGURA 7.7 - VALIDAÇÃO DE CAMPOS DE ENTRADA DE TEXTO ................................................................. 174

FIGURA 7.8 - MENU ACESSÍVEL E USO CORRETO DO ELEMENTO H1 …......................................................... 174

FIGURA 7.9 - USO CORRETO DO ELEMENTO H1, MAS A TABELA APRESENTA PROBLEMAS DE ACESSIBILIDADE ... 175

FIGURA 7.10 - GRÁFICO DE BARRAS COM A PONTUAÇÃO TOTAL DE CADA GRUPO ........................................... 177

FIGURA 7.11 - DISTRIBUIÇÃO DE DADOS DE TODOS OS GRUPOS EM UM GRÁFICO BOX-PLOT .............................. 177

FIGURA 7.12 - DISTRIBUIÇÃO DOS DADOS SEPARADOS POR GRUPOS USANDO OU NÃO A ABORDAGEM ................178

FIGURA 7.13 - GRÁFICO DA QUESTÃO 1 SOBRE DIFICULDADE ADICIONAL EM DESENVOLVER COM PREOCUPAÇÃO EM GARANTIR ACESSIBILIDADE ................................................................ 182

FIGURA 7.14 - GRÁFICO DA QUESTÃO 3 SOBRE A PERCEPÇÃO DE CADA PARTICIPANTE SOBRE A IMPORTÂNCIA DE COMPONENTES ACESSÍVEIS .................................................................................. 183

FIGURA 7.15 - GRÁFICO DA QUESTÃO 4 SOBRE A CONSIDERAÇÃO SOBRE SER FÁCIL E VIÁVEL APLICAR AS

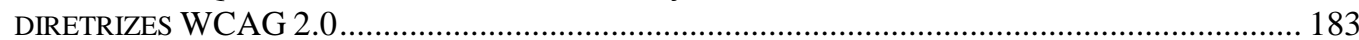

FIGURA 7.16 - GRÁFICO DA QUESTÃO 6 SOBRE A IMPORTÂNCIA DO USO DE DR PARA REGISTRO DE DECISÕES DO PROJETO.

FIGURA 7.17 - GRÁFICO DA QUESTÃo 8 SOBRE O AUXÍlIO DAS FERRAMENTAS DE DESENVOLVIMENTO NO TRABALHO EM ACESSIBILIDADE

FIGURA 7.18 - GRÁFICO DA QUESTÃO 9 SOBRE O FATO DAS FERRAMENTAS DE DESENVOLVIMENTO PODEREM APOIAR MAIS NO DESENVOLVIMENTO COM ACESSIBILIDADE.

FIGURA 7.19 - GRÁFICO DA QUESTÃO 11 SOBRE QUAIS UTILIDADES O DESENVOLVEDOR ACREDITA SEREM IMPORTANTES EM FERRAMENTAS DE DESENVOLVIMENTO PARA APOIO EM ACESSIBILIDADE ..... 187

FIGURA B.1 - MODELO DE DADOS PROPOSTO PARA O SISTEMA …................................................................. 233 


\section{Lista de tabelas}

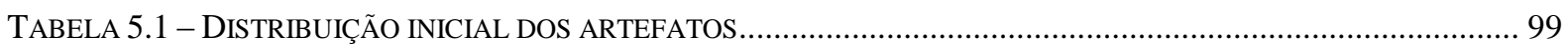

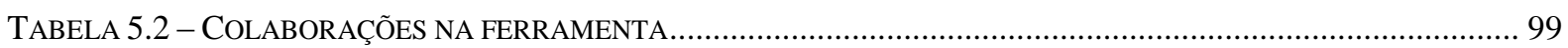

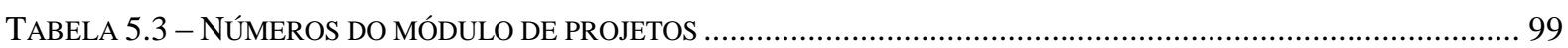

TABELA 5.4 - RESULTADOS DE DIFERENTES MÉTRICAS DE UTILIZAÇÃO DA FERRAMENTA ACCESSIBILITYUTIL . 100

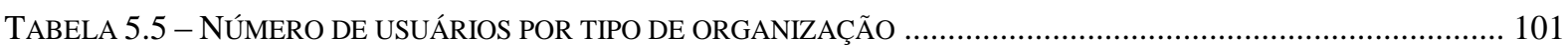

TABELA 7.1 - RESULTADO DA AVALIAÇÃO DE ACESSIBILIDADE NOS DESENVOLVIMENTOS EFETUADOS .............. 176

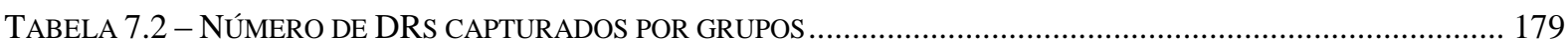

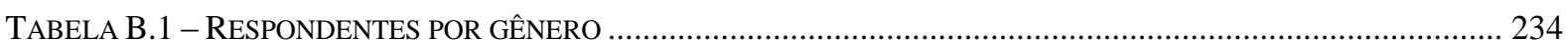

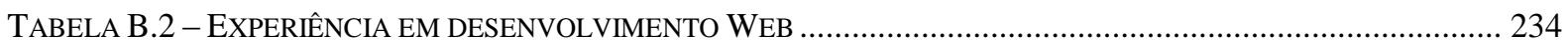

TABELA B.3 - EXPERIÊNCIA EM ACESSIBILIDADE NA WEB …………………………….............................. 236

TABELA B. 4 - SE O RESPONDENTE CONHECE ALGUÉM COM DIFICULDADE OU QUE ENFRENTA BARREIRAS EM

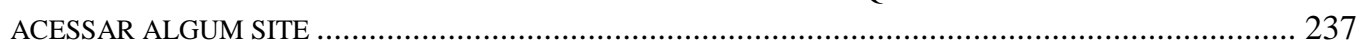

TABELA B.5 - DIFICULDADE ADICIONAL EM DESENVOLVER COM PREOCUPAÇÃO EM GARANTIR

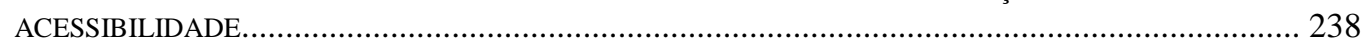

TABELA B.6 - SE COMPONENTES ACESSÍVEIS PODEM MELHORAR OS DESENVOLVIMENTOS ................................. 241

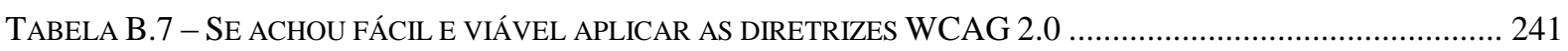

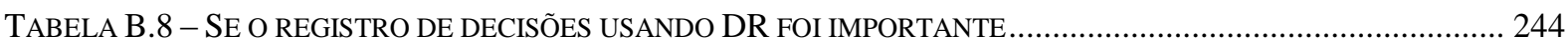

TABELA B.9 - FERRAMENTAS UTILIZADAS PELOS GRUPOS QUE USARAM A ABORDAGEM.................................... 244

TABELA B.10 - FERRAMENTAS UTILIZADAS PELOS GRUPOS QUE NÃO USARAM A ABORDAGEM ........................... 244

TABELA B. 11 - SE AS FERRAMENTAS APOIARAM NO DESENVOLVIMENTO COM ACESSIBILIDADE......................... 245

TABELA B. 12 - SE AS FERRAMENTAS PODEM APOIAR MAIS NO DESENVOLVIMENTO COM ACESSIBILIDADE ........ 245

TABELA B.13 - UTILIDADES IMPORTANTES CONSIDERADAS IMPORTANTES EM FERRAMENTAS DE DESENVOLVIMENTO PARA APOIO EM ACESSIBILIDADE ………………………………........... 247 



\section{Lista de quadros}

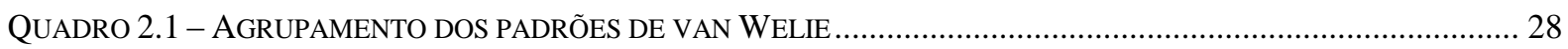

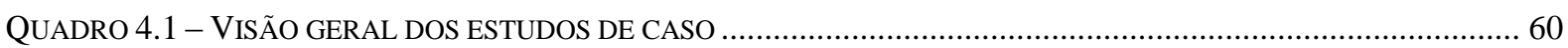

QUADRO 5.1 - DIFERENCIAÇÕES DAS FERRAMENTAS APRESENTADAS ……......................................................... 85

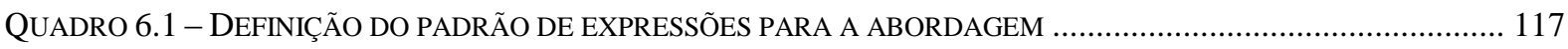

QuADRO 6.2 - ATIVIDADES DO EIXO 1 - TA. TREINAMENTO EM ACESSIBILIDADE........................................... 120

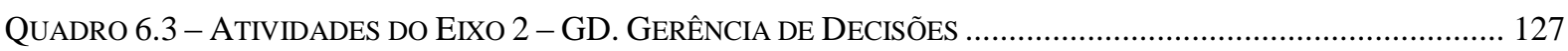

QUADRO 6.4 - ATIVIDADES DO EIXO 3 - DF. DESENVOLVIMENTO E FERRAMENTAL........................................... 134

QUADRO 6.5 - ATIVIDADES DE APOIO DO EIXO 3 - DF. DESENVOLVIMENTO E FERRAMENTAL ........................... 134

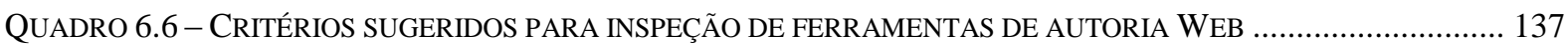

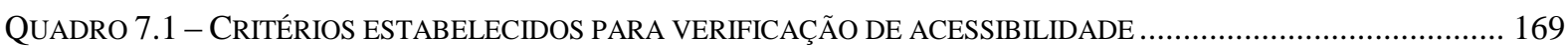

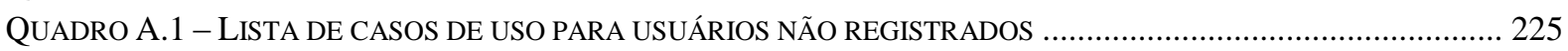

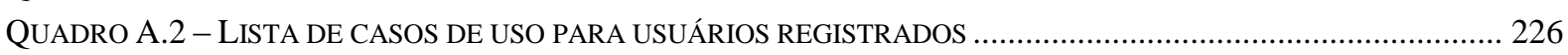

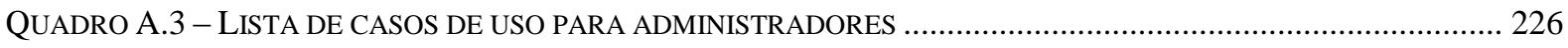

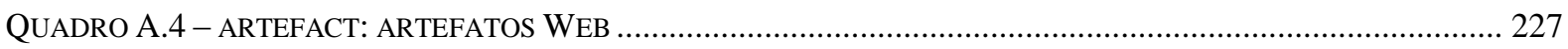

QUADRO A.5 - ARTEFACT_IMAGES: IMAGENS RELACIONADAS AOS ARTEFATOS WEB ...................................... 227

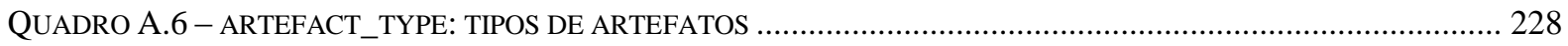

QUADRO A.7 - COMMENTS_EVALUATION_SUCCESS_CRITERIA: COMENTÁRIOS PARA CADA AVALIAÇÃO DE UM CRITÉRIO DE SUCESSO LIGADA A UM ARTEFATO............................................................... 228

QUADRO A.8 - CONTENT_ANALYSIS: ANÁLISE DE CONTEÚDO, ONDE UM USUÁRIO PODE REPORTAR UM ABUSO. 228

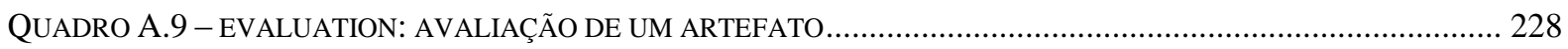

QUADRO A.10 - EVALUATION_SUCCESS_CRITERIA: AVALIAÇÃO DE UM ARTEFATO EM RELAÇÃO A UM

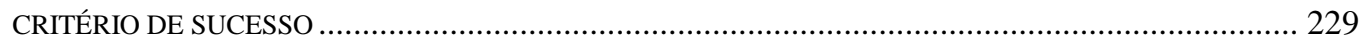

QUADRO A.11 - EVALUATION_SUCCESS_CRITERIA_UTIL: SE UM USUÁRIO ACHA ÚTIL UMA DETERMINADA

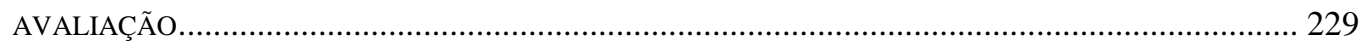

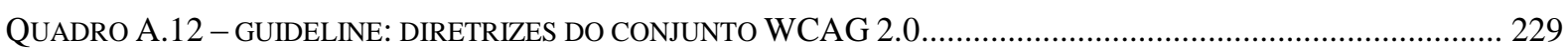

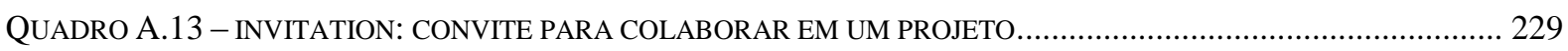

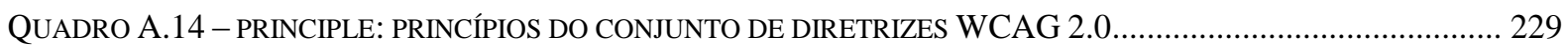

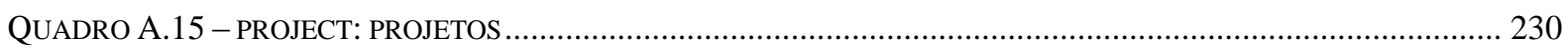

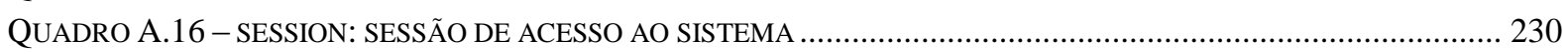

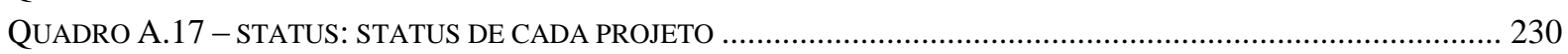

QUADRO A.18 - SUCCESS_CRITERIA: CRITÉRIOS DE SUCESSO DO CONJUNTO DE DIRETRIZES WCAG 2.0 ........... 230

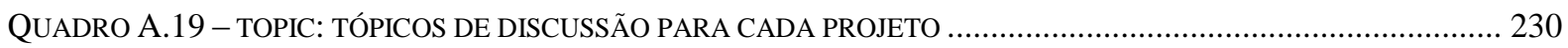

QUADRO A.20 - TOPIC_COMMENT: COMENTÁRIOS PARA CADA TÓPICO DE UM PROJETO...................................... 231

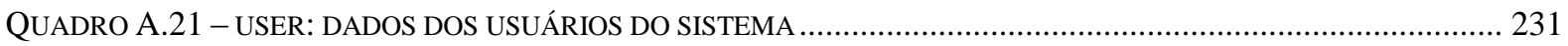

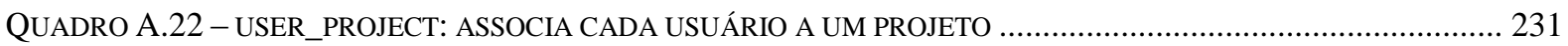

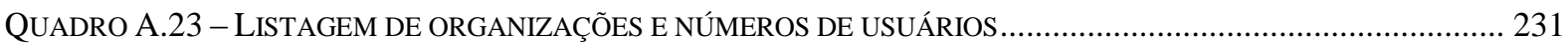

QUADRO C.1 - SELEÇÃO DE TÉCNICAS PARA ATENDIMENTO ÀS DIRETRIZES WCAG 2.0 ….............................. 253

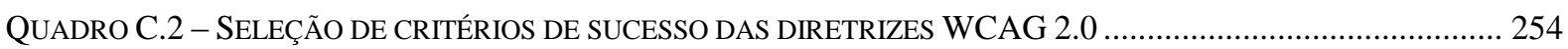

QUADRO C.3 - SELEÇÃO DE CHECKPOINTS DAS DIRETRIZES ATAG 1.0............................................................ 255 



\section{Lista de acrônimos}

Ajax - Asynchronous Javascript And XML

ATAG - Authoring Tool Accessibility Guidelines

CIM - Computation Independent Model

CMS - Content Management System

CSS - Cascading Style Sheets

DOM - Document Object Model

EMF - Eclipse Modeling Framework

GEF - Graphical Editing Framework

GME - Generic Modeling Environment

HTML - HyperText Markup Language

IHC - Interação Humano-Computador

JET - Java Emitter Templates

MDA - Model Driven Architecture

MDD - Model Driven Development

MOF - Meta-Object Facility

OCL - Object Constraint Language

OMG - Object Management Group

PIM - Platform Independent Model

PSM - Platform Specific Model

RCP - Rich Client Platform

RIA - Rich Internet Application

SPL - Software Product Line

SQL - Structured Query Language

UAAG - User Agent Accessibility Guidelines

UML - Unified Modeling Language

UWE - UML-based Web Engineering

URL - Uniform Resource Locator

WAI - Web Accessibility Initiative

WCAG - Web Content Accessibility Guidelines

WebML - Web Modeling Language

WYSIWYG - What You See Is What You Get

xxiii 
XMI - XML Metadata Interchange

XML - EXtensible Markup Language 


\subsection{Contexto e motivação}

A interação com aplicações Web está se tornando cada vez mais presente no dia a dia das pessoas, seja para a realização de serviços, estudos ou entretenimento. Ao fazer um retrospecto sobre a Web, pode-se observar que a mesma evoluiu da simples exibição de páginas estáticas para o processamento de páginas dinâmicas e interativas, permitindo agregar mais facilidades e recursos no oferecimento de conteúdos (JAZAYERI, 2007).

Além dessa evolução tecnológica, verifica-se que os conteúdos disponibilizados na Web estão em constante modificação e crescimento, existindo um considerável aumento em relação ao número de temas abordados e quantidade de material disponibilizado, os quais abrangem os mais diversos assuntos e perfis de usuários. 
No entanto, quando analisado o cenário em relação aos avanços de acessibilidade na Web o mesmo progresso não é encontrado, pois estudos mostram que muitos dos conteúdos disponibilizados apresentam barreiras em relação à acessibilidade, impedindo que usuários com algum tipo de deficiência possam ter acesso aos mesmos. Adicionalmente, considerando as diversas tecnologias existentes, tais como computadores e dispositivos portáteis, a aplicação da acessibilidade torna-se mais complexa e, frequentemente, não é considerada e tratada efetivamente pelas equipes de desenvolvimento (POWER e PETRIE, 2007; LAZAR et al., 2004; FREIRE et al., 2008).

Um exemplo que corrobora os estudos, são os dados apontados pelo Comitê Gestor da Internet (CGI) ${ }^{1}$ do Brasil (CGI.BR, 2010, p. 50), de que somente $2 \%$ das páginas Web governamentais brasileiras são acessíveis (de acordo com uma avaliação automática para o censo da Web do Brasil de 2010, envolvendo mais de 6 milhões de páginas).

Neste sentido, várias soluções têm sido propostas para reduzir os problemas encontrados pela falta de consideração sobre $\mathrm{o}$ uso e apoio a boas práticas de desenvolvimento de aplicações Web acessíveis. Dentre as soluções propostas, pode-se citar a disponibilização de diretrizes, como, por exemplo, as disponibilizadas pelo World Wide Web Consortium (W3C) $)^{2}$ em sua Web Accessibility Initiative (WAI).

No entanto, apesar da existência de diretrizes de acessibilidade, poucos sites atendem aos requisitos mínimos que são descritos nas mesmas (LÓPEZ, 2010; FREIRE et al., 2008; KANE et al., 2007; GILBERTSON e MACHIN, 2012). Tal deficiência pode ser justificada uma vez que tornar o conteúdo de um site acessível demanda tempo, esforço e conhecimento por parte da equipe de desenvolvimento e muitas organizações não ponderam sobre os benefícios de Inclusão que podem ser atingidos considerando e apoiando boas práticas para desenvolvimento de aplicações Web acessíveis (LAZAR et al., 2004).

Observa-se ainda, que há lacunas em relação à disponibilização de mecanismos eficientes que auxiliem o desenvolvedor durante o projeto de aplicações Web acessíveis, informando-o e apoiando-o a utilizar efetivamente as considerações identificadas em

\footnotetext{
${ }^{1}$ http://www.cgi.br/

${ }^{2}$ http://www.w3.org/
} 
experiências anteriores (TREWIN et al., 2010; SCHULZ e PIEPER, 2006; POWER e PETRIE, 2007).

Assim, o apoio a boas práticas para desenvolvimento com acessibilidade requer a conscientização dos indivíduos envolvidos no processo de desenvolvimento e implantação de software. Tal conscientização da equipe deve advir de treinamentos e criação de incentivos, no intuito de guiar e facilitar os esforços para a aplicação de boas práticas e oferecer recursos eficientes que auxiliem na tarefa de desenvolvimento. $\mathrm{O}$ processo ainda tem que ser ágil e eficiente, visando suprir a alta demanda de soluções e oferecer qualidade e precisão no contexto dos serviços disponibilizados (JACOBSON et al., 2012). Desse modo, a consideração e apoio a práticas de desenvolvimento com acessibilidade devem ser feitos com planejamento e competência, de modo a não atrasar os processos de Engenharia de Software envolvidos ou prejudicar o desenvolvimento de aplicações Web, em termos de usabilidade e outros atributos de qualidade.

Neste sentido, o desenvolvedor deve se preocupar e ter auxílios práticos para realizar um desenvolvimento que atenda as necessidades dispostas nos requisitos funcionais, bem como prover meios de tornar acessíveis os serviços oferecidos pelas aplicações, uma vez que diferentes modalidades de usuários (com preferências, necessidades e habilidades particulares) poderão acessá-los.

Segundo Freire et al. (2008), apesar dos esforços na elaboração de diretrizes de acessibilidade, os desenvolvedores frequentemente não as conhecem, as organizações não se dedicam em aplicá-las como requisito durante o desenvolvimento do software e as ferramentas de autoria não dão o suporte adequado às questões relacionadas à validação e aplicação de acessibilidade. Tal estudo descreve uma pesquisa sobre a aplicação de um questionário com participação de 605 pessoas envolvidas no desenvolvimento de projetos Web. Como resultado foi verificado que $39 \%$ dos respondentes não detêm conhecimento sobre as diretrizes de acessibilidade do W3C e 30\% responderam que têm somente conhecimentos básicos sobre questões de acessibilidade.

Tendo sido verificada a relevância pela consideração de boas práticas para desenvolvimento de aplicações Web acessíveis, foi também observada a necessidade de utilização de eficientes ferramentas de autoria, visto que a maioria do conteúdo Web, 
atualmente disponível, é criado a partir delas. Para tanto, deve-se considerar ainda as diretrizes de desenvolvimento de ferramentas de autoria.

Essa problemática caracteriza a motivação para a pesquisa, sendo que nesta tese são investigadas as possíveis soluções para a consideração efetiva de questões de acessibilidade pela equipe de desenvolvimento. Assim, é então proposta e formalizada uma abordagem para apoio a boas práticas para desenvolvimento de aplicações Web acessíveis. Para tanto, fez-se uma análise da literatura, sob a forma de uma detalhada revisão bibliográfica, e estudos de caso foram desenvolvidos, visando coletar dados empíricos para proposta da abordagem. Tais estudos são detalhados nos próximos capítulos, bem como são mostrados os resultados identificados.

De modo a manter a padronização das informações durante toda a tese, fez-se menção à "aplicação Web”, pois o foco compreende a consideração de acessibilidade em complexos conjuntos de artefatos Web, que atualmente formam verdadeiros sistemas de informação, sendo mais do que simples sites informativos, possibilitando cadastros e recuperação da informação usando ricos mecanismos de interação. Foi utilizado, ainda, o termo “diretriz”, visto que se fosse referenciado como "recomendação", esse poderia ser considerado como "recommendation" da língua inglesa, não se referindo bem a "guidelines", que representam o foco de estudo deste trabalho. E, por fim, o uso da expressão "boas práticas" é justificado devido a essa referir a uma forma flexível e abrangente de se referenciar às atividades voltadas ao desenvolvimento com consideração de questões de acessibilidade que devem ser executadas, sendo essa expressão também utilizada com sucesso em outros contextos, como, por exemplo, em Patel et al. (2007) e van der Duim (2007).

\subsection{Justificativa}

Como previamente apresentado, o uso de boas práticas é um fator importante para o desenvolvimento de aplicações Web acessíveis, uma vez que os desenvolvedores são guiados em relação às atividades que devem ser executadas e às decisões que devem ser tomadas para alcançar a acessibilidade. De modo a retratar o cenário em relação às perdas pela falta de apoio a boas práticas e, consequentemente, pelos ganhos com o seu uso, neste trabalho é 
descrito um ambiente em que esses pontos são enfatizados, conforme apresentados nas Figura 1.1 e Figura 1.2.

Na Figura 1.1 tem-se uma representação da forma tradicional de desenvolvimento Web, em que os desenvolvedores devem conhecer e utilizar uma vasta gama de diretrizes de acessibilidade, sem o apoio ideal de abordagens para o desenvolvimento das aplicações. Dessa maneira, os desenvolvedores, frequentemente sem treinamento e motivação para o desenvolvimento atendendo requisitos de acessibilidade, encaram a consideração de diretrizes como um processo adicional que irá demandar significativo esforço para seu entendimento e aplicação.

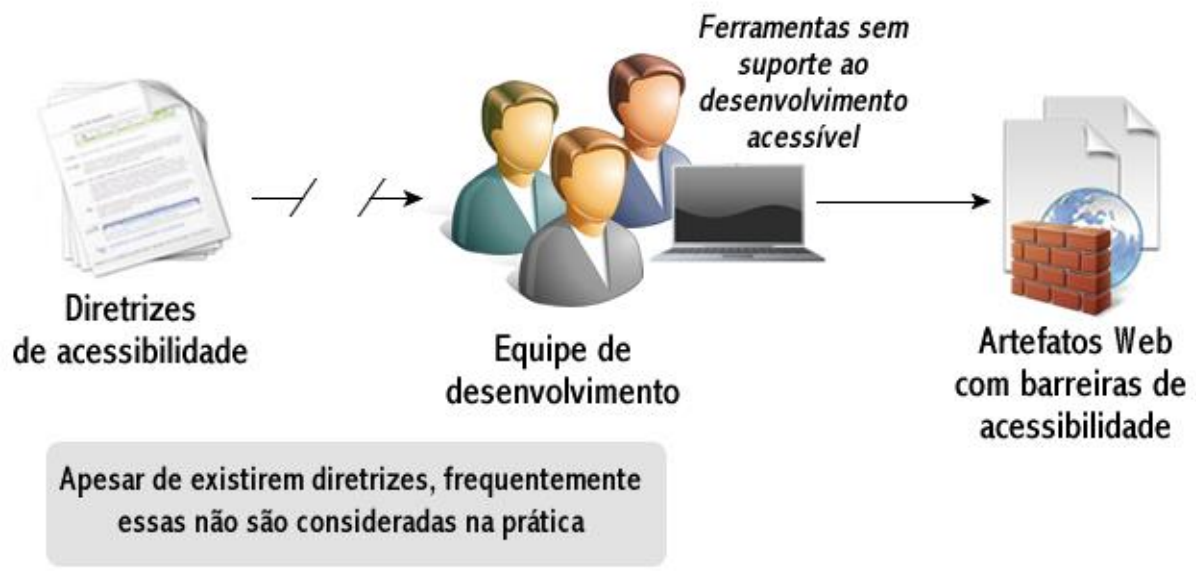

Figura 1.1 - Forma tradicional de desenvolvimento Web em que nem sempre diretrizes de acessibilidade são consideradas

Como apresentado na Figura 1.1, quando a equipe de desenvolvimento não está familiarizada com diretrizes de acessibilidade, provavelmente essas não serão utilizadas durante o desenvolvimento das aplicações. Assim, se o conhecimento não chega à equipe de desenvolvimento, dificilmente os ganhos com a aplicação de tal conhecimento chegarão ao resultado final. Com isso, as ferramentas utilizadas como suporte ao desenvolvimento acessível irão gerar artefatos que apresentam barreiras para os usuários com algum tipo de deficiência.

De modo a contrapor o cenário apresentado, na Figura 1.2 é retratada a forma de trabalho sugerida nesta tese. Para tanto, durante o desenvolvimento de aplicações Web são sugeridas as seguintes preocupações: i) treinamentos para a equipe de desenvolvimento, 
relacionados à acessibilidade; ii) possibilidade de reuso de componentes; iii) meios de colaboração para possibilitar a disseminação do conhecimento adquirido sobre boas práticas de desenvolvimento; iv) verificação e formação de uma base histórica para apoio à tomada de decisões e, v) provimento de um melhor apoio ferramental para adoção adequada de boas práticas, de acordo com as diretrizes de acessibilidade existentes.

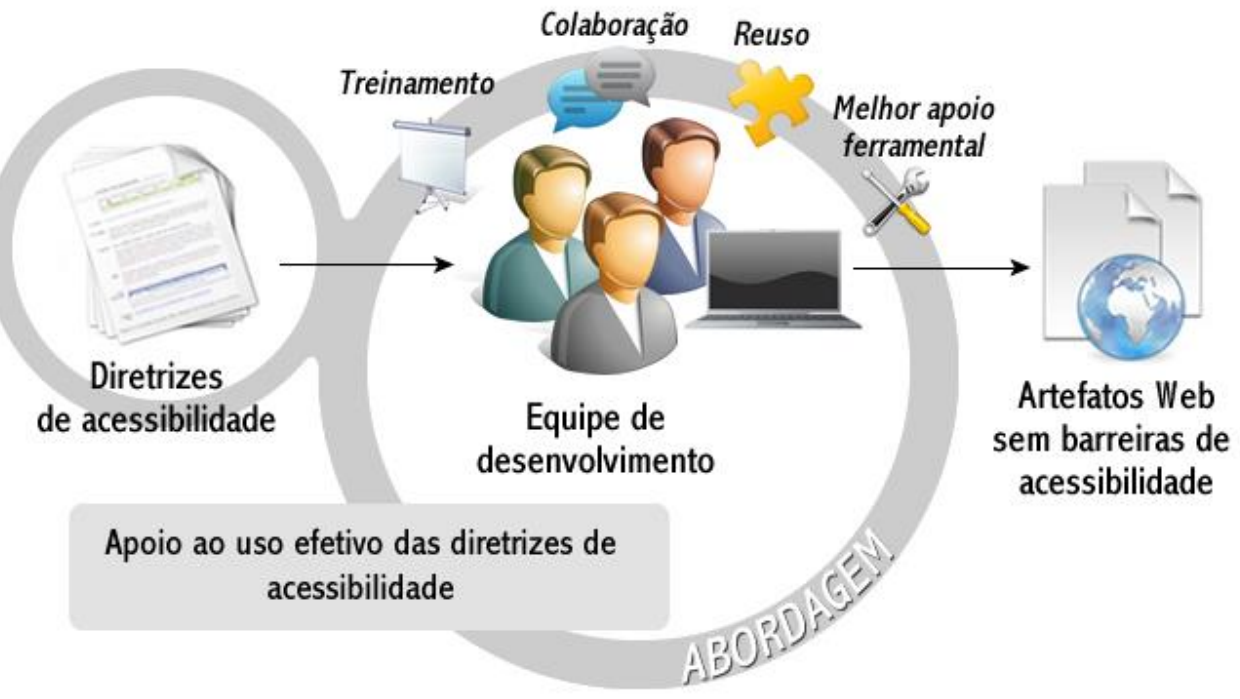

Figura 1.2 - Desenvolvimento Web com adoção de boas práticas

Observa-se que, uma vez que se tenha definido passos que devem ser seguidos para a execução de tarefas, a dificuldade de consideração das diretrizes é minimizada. Assim, nesta tese são propostos meios para nortear e facilitar a aplicação de boas práticas para desenvolvimento de aplicações Web acessíveis. Para tanto, as questões de acessibilidade são contrapostas aos conceitos de colaboração, desenvolvimento baseado em componentes e modelos por meio do reuso das práticas, com foco na documentação e reutilização de soluções de sucesso que privilegiem a qualidade, em termos de acessibilidade, dos artefatos Web desenvolvidos.

O desafio nessa área é projetar funcionalidades voltadas para a acessibilidade na Web, de modo que qualquer usuário possa entender e interagir com ela, bem como possibilitar que os desenvolvedores criem e desenvolvam conteúdo relevante que pode ser reutilizado em outros projetos (BAILEY e PEARSON, 2010). Para enfrentar esse desafio, existem inúmeras decisões que devem ser tomadas pela equipe de desenvolvimento Web relacionadas à consideração de diretrizes de acessibilidade. Essa questão é também abordada nesta tese por 
meio da verificação de diretrizes com o apoio de Design Rationale (DR), o qual auxilia na gerência dessas decisões de forma colaborativa.

De modo adicional, a Engenharia Web vem como fundamentação ao desenvolvimento, em que o foco deste trabalho está diretamente relacionado à interação com o usuário, envolvendo padrões de interação (considerando o reuso) para estrutura de navegação e composição de aplicações acessíveis.

Resumidamente, de modo a abordar os temas considerados como fundamentais para desenvolvimento desta tese, desenvolveu-se alguns estudos relacionados à fundamentação teórica e prática em relação à necessidade de se desenvolver técnicas sistemáticas para facilitar a adoção de boas práticas para desenvolvimento de aplicações Web acessíveis. Assim, são apresentadas soluções com o desenvolvimento de estudos empíricos, por meio dos quais foi possível construir cenários para aplicar boas práticas para desenvolvimento e, com isso, coletar resultados, sendo esses utilizados como apoio para a criação da abordagem apresentada nesta tese.

\subsection{A tese}

A tese sendo defendida é a de que "uma abordagem sistemática, com treinamento da equipe de desenvolvimento, colaboração para a gerência de decisões e uso de ferramentas eficientes, permite o apoio a boas práticas para desenvolvimento de aplicações Web acessíveis".

Para o desenvolvimento e validação desta tese, de acordo com as considerações expostas na seção anterior, as seguintes perguntas específicas nortearam a execução dos passos da pesquisa realizada:

- É possível e importante um melhor apoio de ferramentas para o desenvolvimento Web com acessibilidade?

- O compartilhamento e reuso de experiências de desenvolvimento é importante e eficaz no apoio ao desenvolvimento Web com acessibilidade? 
- Reunir considerações para nortear o desenvolvimento Web, incluindo ações de treinamento de equipe, gerência de decisões e apoio ferramental, resulta na criação de artefatos com menos barreiras de acessibilidade?

Tendo sido definidas as questões a serem analisadas nesta tese, foram então detalhados os objetivos do estudo proposto, como apresentado a seguir.

\subsection{Objetivos}

Como objetivo primário desta pesquisa tem-se a definição de uma abordagem de apoio a boas práticas para desenvolvimento de aplicações Web acessíveis.

Como objetivos secundários, podem ser citados:

- O estudo e a criação de mecanismos para aproximação de diretrizes de acessibilidade ao cotidiano das equipes desenvolvimento, de forma prática, provendo checagens integradas nos ambientes de desenvolvimento; e

- A investigação de resultados sobre o quão é interessante e viável o reuso de soluções de acessibilidade, o compartilhamento de experiências entre a equipe e o uso de DR no apoio à gerência de decisões para facilitar e apoiar o desenvolvimento com acessibilidade.

Para alcançar esses objetivos, muitos desafios devem ser vencidos, principalmente os relativos à dificuldade em se treinar equipes de desenvolvimento Web e se ter ferramentas que os apoiem eficientemente na geração de artefatos com menos barreiras de acessibilidade.

O público alvo desta tese é a comunidade de pesquisa em Engenharia Web e Interação Humano-Computador (IHC), os profissionais envolvidos em projetos Web, além de estudantes em nível de graduação e pós-graduação em Ciência da Computação e áreas afins.

\subsection{Passos da pesquisa}

Passos metodológicos foram seguidos para a condução dos estudos empíricos e concepção da abordagem, os quais são esquematizados na Figura 1.3. Na sequência, esses passos são apresentados de forma resumida, possibilitando uma visão geral do trabalho realizado. 


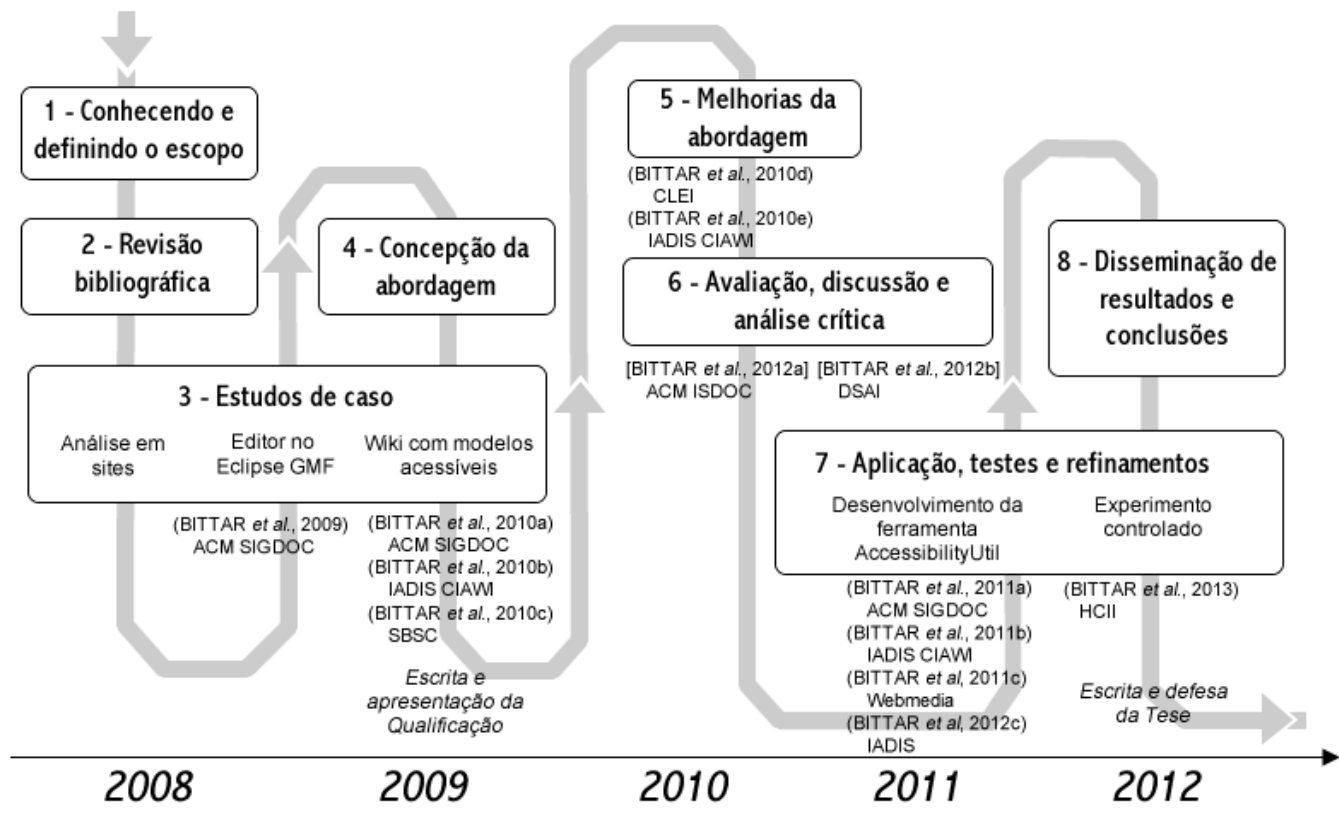

Figura 1.3 - Linha do tempo dos trabalhos efetuados

Na Figura 1.3 têm-se uma linha do tempo contendo os passos que subsidiaram o desenvolvimento da tese, como descrito a seguir:

1) Conhecendo e definindo o escopo:

- Verificação das lacunas da área para proposta da tese;

- Definição do foco da pesquisa no apoio aos desenvolvedores que frequentemente não aplicam as diretrizes existentes;

2) Revisão bibliográfica:

○ Verificação de estudos bibliográficos em acessibilidade na Web;

3) Estudos de caso:

- Análise em sites de prefeituras municipais para verificação do uso de acessibilidade;

- Proposta e prova de conceito para geração de um editor com apoio a modelos de navegação e composição de páginas, sendo esse desenvolvido no Eclipse Graphic Modeling Framework (GMF);

- Teste do uso de modelos em Wikis para estruturação de elementos de forma acessível;

4) Concepção da abordagem: 
o Desenvolvimento inicial e definição de eixos e atividades para nortear o desenvolvimento com acessibilidade;

5) Melhorias da abordagem:

- Verificação e relacionamento com a literatura e com os estudos de caso desenvolvidos;

- Refinamentos com definição mais detalhada dos eixos e atividades, bem como as entradas e saídas;

6) Avaliação, discussão e análise crítica:

○ Reuniões com grupo de pesquisa em acessibilidade da USP/ICMC Laboratório Intermídia, onde houve apresentações do trabalho desenvolvido e dos resultados obtidos;

7) Aplicação, testes e refinamentos:

○ Fundamentação sobre a base de conhecimento em acessibilidade com o planejamento e definição da ferramenta AccessibilityUtil;

○ Experimento controlado, desenvolvido em ambiente acadêmico, para análise da abordagem proposta;

8) Disseminação de resultados e conclusões:

○ Tabulação e análise dos resultados obtidos, refletindo em melhorias identificadas para a abordagem;

○ Conclusões e definição de trabalhos futuros.

$\mathrm{Na}$ Figura 1.3 foram apresentadas algumas publicações, resultantes do trabalho desenvolvido, utilizadas como meio de validar os passos executados. No entanto, a listagem completa das publicações obtidas, com os resultados coletados com o desenvolvimento da pesquisa, é mostrada nas conclusões (último capítulo). Observa-se, por meio da Figura 1.3, que a abordagem foi proposta, desenvolvida e validada baseada em estudos empíricos desenvolvidos, seguindo um desenvolvimento em top-down (o qual é explicado em mais detalhes na medida em que os capítulos são introduzidos e apresentados).

\subsection{Organização do trabalho}

Este trabalho está organizado da seguinte maneira: no Capítulo 2 apresenta-se o referencial teórico que inclui uma revisão sobre conceitos de Acessibilidade, Engenharia 
Web, Desenvolvimento Orientado a Modelos e Design Rationale. Ainda são apresentados os conceitos sobre diretrizes e padrões para o projeto Web, com o objetivo de fundamentar a reflexão dos requisitos necessários para contemplá-los no projeto de utilização de boas práticas para o desenvolvimento de aplicações Web acessíveis.

Os trabalhos relacionados são apresentados no Capítulo 3, em ordem cronológica, referentes às estratégias que podem ser utilizadas para o desenvolvimento Web com acessibilidade, tais como abordagens, métodos e frameworks. Tais estudos refletem o uso da acessibilidade na Web, com diferentes tipos de pesquisas desenvolvidas, visto que não foi encontrado nenhum estudo que enfatize completamente a abordagem apresentada neste trabalho. Assim, são apontadas diferenças conceituais destes trabalhos relacionados frente aos conceitos que permearam a proposta desta tese.

No Capítulo 4 são detalhados os estudos de caso, desenvolvidos com o objetivo de descrever cenários de análise sobre como a acessibilidade é considerada. Neste sentido, busca-se verificar a possibilidade de um melhor apoio ao desenvolvedor, sobre como devem ser consideradas as diretrizes de acessibilidade no desenvolvimento das aplicações Web.

Em seguida, no Capítulo 5, é apresentada a ferramenta Web desenvolvida, nomeada como AccessibilityUtil, incluindo detalhes de seu projeto e aplicação. Tal ferramenta objetiva promover o compartilhamento organizado de experiências e considerações sobre o desenvolvimento de artefatos Web com acessibilidade. Já no Capítulo 6 é apresentada a abordagem desenvolvida nesta tese, sendo introduzidos seus eixos e detalhadas as atividades, as quais devem ser seguidas a produção de artefatos Web com acessibilidade.

Com vistas a verificar benefícios e desvantagens do uso da abordagem desenvolvida, é apresentado, no Capítulo 7, o planejamento e os resultados da aplicação de um experimento controlado, executado em um ambiente acadêmico. Tal estudo foi relevante para identificação de melhorias na abordagem. Por fim, no Capítulo 8, são discutidos os resultados obtidos em todos os estudos realizados para tecer as conclusões do trabalho. Adicionalmente, neste capítulo são apresentadas a listagem de publicações e uma premiação obtida, as quais representam algumas das contribuições alcançadas com esta tese. As lições aprendidas e propostas para futuras pesquisas correlatas também são descritas. 


\section{Referencial teórico}

\subsection{Considerações iniciais}

Este capítulo tem por objetivo apresentar, de maneira sucinta, os conceitos envolvidos na área de trabalho desta tese, de modo a permitir o embasamento teórico para as ações de planejamento e concepção de uma abordagem de apoio a boas práticas para desenvolvimento de aplicações Web acessíveis.

O capítulo está dividido da seguinte maneira: na Seção 2.2 são apresentados conceitos sobre acessibilidade, incluindo detalhes sobre as principais diretrizes que devem ser consideradas. Na Seção 2.3 são abordadas questões e práticas da Engenharia Web, utilizadas como apoio ao trabalho proposto. Na Seção 2.4 tem-se a apresentação do Desenvolvimento Orientado a Modelos e seu ferramental, já na Seção 2.5 tem-se o delineamento de Design Rationale como base conceitual para o registro de decisões e razões para desenvolvimento de 
um projeto Web. E por fim, na Seção 2.6 são apresentadas as considerações finais do capítulo.

\subsection{Acessibilidade}

Acessibilidade pode ser interpretada como a possibilidade de utilização de recursos de maneira universal, sem barreiras ou utilizando vias alternativas para seu acesso e utilização. No contexto Web, os conteúdos de sites formam esse recurso, sendo a acessibilidade relacionada à possibilidade de que qualquer usuário, utilizando qualquer agente (software ou hardware que recupera conteúdo Web), possa entender e interagir com o conteúdo disponibilizado (THATCHER et al., 2002; THATCHER et al., 2006).

Várias ações devem ser consideradas para a adoção de boas práticas de desenvolvimento de aplicações Web acessíveis, dentre as quais é necessário que as pessoas envolvidas tenham consciência dos benefícios alcançáveis com essa adoção.

Assim, espera-se que, com a adoção de boas práticas para desenvolvimento de aplicações Web acessíveis, os benefícios relatados sejam atingidos e os problemas por falta de acessibilidade sejam minimizados, de modo a guiar as atividades de desenvolvimento, bem como, atingir os resultados esperados. Para tanto, nas próximas subseções são apresentadas as diretrizes de acessibilidade que devem ser aplicadas durante $\mathrm{o}$ desenvolvimento e, ainda, são ressaltadas considerações para ferramentas de autoria na Web, as quais devem ser observadas para o desenvolvimento com acessibilidade.

\subsubsection{Diretrizes de acessibilidade}

De acordo com Kelly et al. (2005), ao considerar as questões de acessibilidade na Web, uma das referências de maior importância é o documento "Web Content Accessibility Guidelines" (WCAG), elaborado pela Web Accessibility Initiative (WAI) ${ }^{3}$. A iniciativa WAI é formada por um grupo de trabalho criado pelo W3C, que tem como missão definir princípios e regras de desenvolvimento para que os recursos disponíveis na Web sejam acessíveis a pessoas com algum tipo de deficiência. Para esse fim, foi estabelecido um

\footnotetext{
${ }^{3}$ http://www.w3.org/WAI/
} 
modelo de conformidade com três conjuntos de diretrizes agregadas nos seguintes documentos:

- "Web Content Accessibility Guidelines" (WCAG) (1999), com foco no desenvolvimento do conteúdo Web. Atualmente está na segunda versão (2008);

- “Authoring Tool Accessibility Guidelines 1.0" (ATAG) (2000), com foco em ferramentas de autoria de conteúdo Web; e

- “User Agent Accessibility Guidelines" (UAAG) (2002), com foco no desenvolvimento de agentes de usuários (navegadores).

Esse modelo de acessibilidade é esquematizado na Figura 2.1.

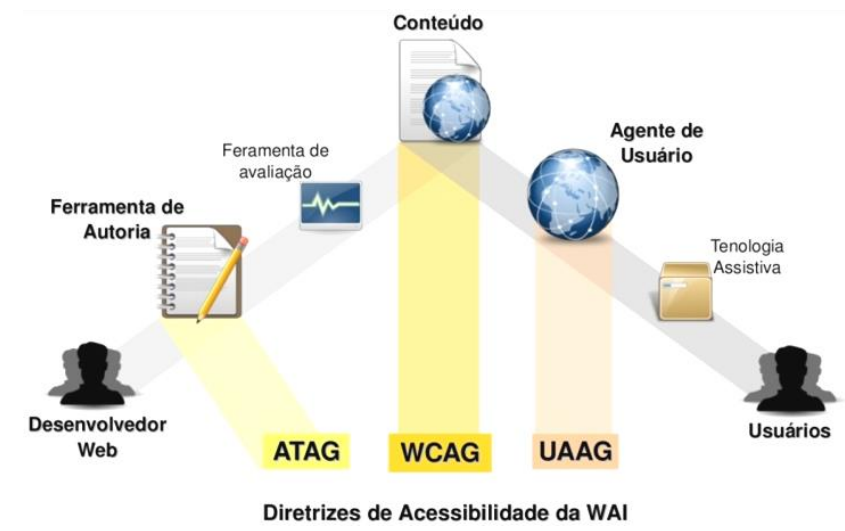

Figura 2.1 - Modelo de diretrizes de acessibilidade da WAI, adaptado de W3C (2008b)

Pode ser observado que esse modelo é dependente do desenvolvimento de agentes de usuários (navegadores) e ferramentas de autoria de conteúdo que sigam as diretrizes determinadas nos documentos UAAG e ATAG. No entanto, uma vez que os desenvolvedores de aplicações Web não possuem o controle sobre o desenvolvimento nessas áreas ou sobre as escolhas de utilização de navegadores e tecnologias assistivas utilizadas pelos usuários (KELLY et al., 2005; KELLY et al., 2007), um maior enfoque e importância, com relação à acessibilidade na Web e design universal, é atribuído ao documento WCAG.

O documento WCAG é composto por um conjunto de diretrizes que explicam como tornar o conteúdo Web acessível para indivíduos com deficiências, a partir dos mais diversos tipos de agentes de usuário (navegadores desktop, navegadores por voz, celulares, entre outros) e restrições de operações (ambientes com muito ruído, com pouca iluminação, entre outros). A primeira versão desse documento foi apresentada em 1999, em que para cada 
diretriz são descritos checkpoints que definem etapas ou partes de um projeto que podem apresentar barreiras a usuários com algum tipo de limitação (indivíduos cegos, surdos, com problemas cognitivos, entre outros).

A cada um desses checkpoints é determinado um valor de prioridade de 1 a 3 , de acordo com seu impacto na acessibilidade e conformidade com o documento, sendo que o valor de prioridade 1 denota um checkpoint de maior importância, seguido por checkpoints de prioridade 2 e 3.

A relativa simplicidade do modelo de acessibilidade, proposto pela WAI, ajudou a aumentar a popularidade da acessibilidade na Web. Suas diretrizes são reconhecidas como a principal referência para a elaboração de recursos acessíveis (KELLY et al., 2005).

Nessa primeira versão do documento WCAG, grande parte das páginas eram implementadas utilizando o padrão HTML de forma simples, sem o uso intensivo de linguagens de processamento do lado do servidor. Desse modo, as recomendações foram desenvolvidas com enfoque nessa tecnologia, de modo a torná-la acessível (KELLY et al., 2005; REID e SNOW-WEAVER, 2008).

No entanto, atualmente, para o desenvolvimento dos sites é utilizada uma maior diversidade de tecnologias. A nova geração da Web (conhecida como Web 2.0), juntamente com a implementação de aplicações e serviços ricos na Web (RIA - Rich Internet Applications) possuem um nível de interação mais dinâmico (GIBSON, 2007; WRIGHT e DIETRICH, 2008) e podem requerer tecnologias como: ECMAScript, XMLHTTPRequest, Scalable Vector Graphics (SVG), Flash, Java Applets, entre outras (MUNSON e PIMENTEL, 2008). Para essas e outras tecnologias devem ser considerados os impactos e necessidades em relação à acessibilidade (KELLY et al., 2005).

Outro fator limitante na utilização das diretrizes WCAG 1.0 está relacionado à subjetividade de determinados checkpoints (CENTENO et al., 2005). Essa característica torna difícil uma avaliação total de conformidade com suas diretrizes (REID e SNOWWEAVER, 2008). Fator, inclusive, determinante na decisão dos Estados Unidos de não adotar a WCAG 1.0 como padrão (seu desenvolvimento Web segue a Section $508^{4}$ ).

\footnotetext{
${ }^{4}$ http://www.section508.gov/
} 
Considerando isso, a WAI desenvolveu o documento WCAG 2.0, baseado na primeira versão. O objetivo é que suas diretrizes devam ser aplicáveis ao maior número de tecnologias, no âmbito atual e no futuro, sendo tecnologicamente neutras e testáveis, de maneira objetiva, com uma combinação de testes automáticos e avaliações humanas (REID e SNOW-WEAVER, 2008; W3C, 2008; KELLY et al., 2007). Essa nova versão também auxilia no desenvolvimento de conteúdo mais acessível e usável para indivíduos de idade avançada, no entanto, apesar de avanços nessa área, Lara et al. (2010) sugerem uma extensão das diretrizes WCAG 2.0, com inclusão de critérios de sucesso específicos de atendimento a demandas de acessibilidade desse público.

As diretrizes WCAG 2.0 não descrevem condições tecnológicas para satisfação dos requisitos de acessibilidade, mas disponibilizam informações a respeito dos métodos conhecidos para o desenvolvimento em conformidade com as diretrizes (REID e SNOWWEAVER, 2008). Esse documento é complementado por uma seção não normativa que descreve detalhes específicos de como as tecnologias devem ser utilizadas (KELLY et al., 2007). Manter, separadamente, as informações a respeito das técnicas do documento WCAG 2.0 permite que alterações e atualizações sejam feitas sem a necessidade de alterar o documento principal (REID e SNOW-WEAVER, 2008).

Diferentemente da WCAG 1.0, na versão 2.0 as diretrizes são divididas em quatro princípios que servem como características necessárias ao conteúdo Web, sendo eles:

1) Perceptível: os usuários devem ser capazes de perceber a informação apresentada (o conteúdo não pode ser invisível a todos os seus sentidos);

2) Operável: os usuários devem ser capazes de operar a interface, a qual não deve exigir interações que um usuário não possa realizar;

3) Compreensível: os usuários devem ser capazes de entender a informação e as operações da interface (o conteúdo e as operações não podem ir além do conhecimento deles); e

4) Robusto: os usuários devem ser capazes de acessar o conteúdo conforme a tecnologia avança (mesmo com a evolução tecnológica e dos agentes de usuário, o conteúdo deve permanecer acessível). 
Cada diretriz apresenta um determinado número de critérios de sucesso, que descrevem especificamente o que deve ser alcançado, considerando:

- Problemas de acessibilidade que afetam pessoas com deficiência, diferentemente dos problemas de usabilidade que podem ser apresentados a todos os usuários; e

- Aspectos testáveis na interface, ou seja, deve ser possível determinar, objetivamente, se a interface satisfaz ou não o critério de sucesso.

As prioridades, presentes na WCAG 1.0, também foram alteradas na evolução da versão desse conjunto de diretrizes. Cada critério de sucesso na versão 2.0 é classificado em níveis de relevância entre $\mathbf{A}, \mathbf{A A}$ e AAAA, em que o nível A representa os critérios de maior importância. Essa classificação de níveis foi determinada por meio da avaliação de acordo com os seguintes fatores: i) possibilidade da tecnologia assistiva tornar o conteúdo acessível; ii) aplicabilidade a todos os sites e tipos de conteúdo; iii) facilidade de compreensão por autores de conteúdo; iv) limitações na apresentação, funcionalidade, liberdade de expressão e estética; e v) existência de outros meios para solucionar o problema.

Essa evolução também resultou na necessidade de alteração significativa nas ferramentas de avaliação e de apoio na reparação de problemas de acessibilidade, conforme apresentado por Mbipom e Harper (2009). Esses autores relatam ainda que existem diretrizes cuja avaliação automática é difícil ou inviável, como, por exemplo, as verificações de: i) presença de jargões e palavras não usuais (critério de sucesso 3.1.3) e ii) oferecimento de símbolos gráficos na linguagem de sinais para a totalidade do áudio pré-gravado existente (critério de sucesso 1.2.6).

Adicionalmente, nas diretrizes WCAG 2.0 é apresentada uma grande variedade de técnicas que auxiliam no desenvolvimento, em conformidade com os critérios de sucesso, as quais são classificadas como suficientes para satisfação do critério de sucesso e complementares.

Um importante reconhecimento do documento WCAG 2.0 ocorrido recentemente, em outubro de 2012, foi a sua normatização como sendo um padrão ISO/IEC de identificador 40500:2012 (ISO/IEC, 2012) pelo Comitê Técnico Conjunto JTC 1 (Tecnologia da 
Informação) da Organização Internacional de Normalização (ISO) e da Comissão Eletrotécnica Internacional (IEC).

No entanto, apesar da disponibilização de todas essas diretrizes, os problemas de acessibilidade ainda são recorrentes nas aplicações Web. Frequentemente o conteúdo das diretrizes é desconhecido pelos desenvolvedores e as organizações acham difícil essa aplicação (POWER e PETRIE, 2007; FREIRE et al., 2007; LAZAR et al., 2004). Assim, novos estudos são requeridos visando prover soluções para apoio a boas práticas para desenvolvimento de aplicações acessíveis, e, consequentemente, minimizar os problemas existentes.

Os problemas de acessibilidade ocorrem nos mais diversos domínios de aplicação, no entanto, existe um nicho de aplicações Web em que a acessibilidade é especialmente importante, devendo ser cuidadosamente considerada, o de Governo Eletrônico (E-GOV). Nesse nicho, a deficiência sobre a observação de problemas de acessibilidade durante o desenvolvimento resulta na dificuldade de acesso a serviços e informações sobre recursos públicos, afetando diretamente na cidadania. Nesse domínio, Freire et al. (2008) verificaram, por meio do uso de um robô de acesso (crawler), que a maioria dos sites municipais apresenta significativos problemas de acessibilidade.

\subsubsection{Diretrizes para ferramentas de autoria Web}

O foco desta subseção é apresentar os conceitos sobre diretrizes para ferramentas de autoria Web, com especial atenção ao apoio oferecido em relação às questões de acessibilidade. Uma ferramenta de autoria pode ser definida como uma aplicação de apoio que permite habilitar, encorajar e auxiliar usuários (autores) na criação de conteúdo (BULTERMAN e HARDMAN, 2005; W3C, 2000).

O conteúdo Web é compreendido por diferentes tipos de mídias (texto, áudio, vídeo, entre outros) e suas relações que formam um espaço de navegação. Essas mídias são dispostas de acordo com um esquema de apresentação que envolve tipografias, espaçamentos de parágrafos, margens e os mais diversos tipos de efeitos (aparecimento de elementos, deslocamentos, entre outros) que podem ser alterados por eventos (cliques de mouse, temporizadores, focos em formulários, entre outros). Essas características demonstram a 
complexidade que permeia as funcionalidades das ferramentas de autoria Web, porém muitas pessoas têm uma visão simplista de tais ferramentas, pois acreditam que o conteúdo Web é apenas composto por textos, gráficos e vídeos desprezando as relações com o todo e a forma de apresentação, estruturação e navegação.

Ainda devem ser consideradas as reais diferenças entre ferramentas que permitem a composição e edição do conteúdo final a ser visualizado e ferramentas de desenvolvimento (em relação ao código fonte) no domínio Web. Tal diferença é relevante, devendo-se haver atenção ao fato de que vários conteúdos apresentados ao usuário atualmente advém de resultados de processamento que, por sua vez, são originados da atividade de programação. Assim, uma ferramenta de autoria Web refere-se a uma ampla gama de softwares usados para criar conteúdo hipermídia com diferentes ênfases (W3C, 2000), incluindo:

- Editores desenvolvidos especificamente para produção de conteúdo Web (por exemplo: editores visuais WYSIWYG - What You See Is What You Get);

- Ferramentas que oferecem a opção para salvar um material em formato Web (por exemplo: processadores de texto);

- Ferramentas para gerenciamento de layout (por exemplo: formatação em folhas de estilos em cascata - Cascading Style Sheets - CSS);

- Ferramentas que transformam ou auxiliam na produção de documentos Web, inclusive resultantes de edição multimídia; e

- Ferramentas que gerenciam sites dinamicamente, incluindo aquelas com apoio de bases de dados (por exemplo: sistemas gerenciadores de conteúdo Content Management Systems - CMS e Wikis).

Nesse contexto, o W3C constituiu uma recomendação oficial chamada "Authoring Tool Accessibility Guidelines" (ATAG), cuja versão 1.0 é datada de 3 de fevereiro de 2000. De acordo com esse documento, ferramentas de autoria estão próximas da origem dos "problemas" de acessibilidade, tendo dois propósitos básicos: auxiliar usuários a produzir conteúdo acessível e apoiar a criação de interfaces de autoria acessíveis. É nesse último propósito que entram as considerações úteis para os desenvolvedores de ferramentas de autoria. 
Apesar dessa recomendação oficial, pouco se tem visto de sua aplicação. Power e Petrie (2007) examinaram a acessibilidade de uma coleção de ferramentas de autoria Web não profissionais, voltadas ao público sem conhecimento técnico aprofundado em linguagens computacionais para esse domínio. Como resultado, verificaram que existem várias oportunidades ainda não aproveitadas para prover conteúdo acessível, sobretudo em sites pessoais (blogs, álbum de fotos, agendas, entre outros). Essa pesquisa também demonstrou que diversos problemas de acessibilidade podem ser tratados com relativamente pouco esforço, inclusive no contexto da Web 2.0.

Na Figura 2.2 é ilustrado o cenário ideal previsto nas diretrizes ATAG, em que as ferramentas de autoria são acessíveis (possibilitando utilização não só por especialistas na área), incluindo o apoio à incorporação desse atributo também nos conteúdos.

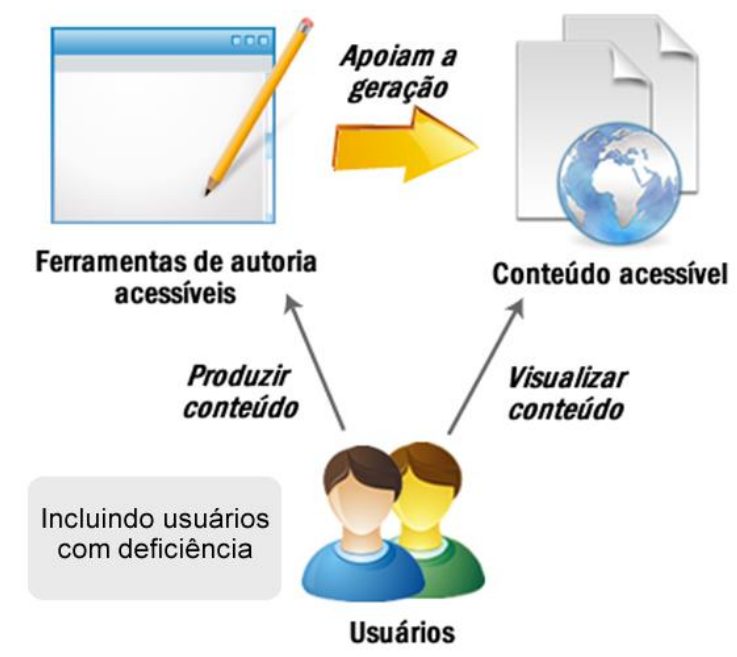

Figura 2.2 - Cenário ideal previsto pela ATAG

É importante ressaltar que, conforme visto na Figura 2.2, a incorporação de mecanismos de apoio para consideração de diretrizes de acessibilidade nessas ferramentas permite que usuários com algum tipo de deficiência possam atuar no processo de autoria, inclusive produzindo conteúdos para outros tipos de usuários que não necessitam de tecnologias assistivas.

Assim, se por meio das ferramentas de autoria pudessem ser automaticamente produzidos códigos válidos, com o uso das janelas para informações de acessibilidade fosse provida ajuda na acessibilidade de forma integrada e verificações de acessibilidade na pré- 
publicação, as pessoas, não necessariamente conhecedoras ou treinadas em acessibilidade, teriam maior facilidade em produzir conteúdos acessíveis (W3C, 2000).

De uma forma mais concreta, na ATAG 1.0 são apresentadas sete diretrizes de acessibilidade com 28 checkpoints para o desenvolvimento adequado de ferramentas de autoria. Cada diretriz inclui seu número identificador, orientações para aplicação, a lógica envolvida e definição de uma lista de checkpoints.

Um documento separado, intitulado "Techniques for Authoring Tool Accessibility Guidelines 1.0" (ATAG10-TECHS) (W3C, 2002b), provê sugestões e exemplos práticos para que cada checkpoint possa ser satisfeito. A seguir, são descritas, resumidamente, as sete diretrizes propostas na ATAG 1.0:

1. Apoiar práticas de autoria acessíveis: se a marcação é gerada de forma automática, muitos autores não visualizam a acessibilidade incorporada no produto final. As ferramentas de autoria devem ser responsáveis por gerar marcação de forma acessível e guiar o autor na produção de conteúdo acessível;

2. Gerar marcação padrão: a conformidade com padrões promove a interoperabilidade e acessibilidade por facilitar a criação de agentes de usuários especializados em usuários com deficiências;

3. Apoiar a criação de conteúdo acessível: informações bem estruturadas com alternativas equivalentes são fundamentais para um desenvolvimento acessível, permitindo assim que a informação seja apresentada da maneira mais apropriada às necessidades do usuário;

4. Prover meios para verificação e correção de conteúdo inacessível: muitas ferramentas permitem ao usuário criar documentos com pouco ou nenhum conhecimento sobre desenvolvimento Web. Para assegurar a acessibilidade, as ferramentas de autoria devem ser desenvolvidas de forma a identificar (quando possível automaticamente) um conteúdo inacessível e permitir sua correção, incluindo os casos em que a marcação não esteja visível ao autor;

5. Integrar soluções de acessibilidade no modo de "ver e sentir" (look and feel): quando uma nova funcionalidade é adicionada em uma ferramenta existente, sem a devida integração de aparência e modo de interação, o resultado é a dificuldade de utilização e entendimento por parte do usuário. Desse modo, 
diferentes esquemas de cores, tipologias e estilos de utilização podem prejudicar a aceitação da nova funcionalidade e possíveis alterações em elementos relativos à acessibilidade devem ser naturalmente integrados;

6. Promover a acessibilidade na ajuda e documentação: guias de auxílio e informações de desenvolvimento devem incluir explicações de problemas e demonstrar soluções com exemplos; e

7. Assegurar que a ferramenta de autoria seja acessível a autores com deficiências: uma boa acessibilidade nessas ferramentas permite a inclusão de pessoas com deficiência no processo autoral.

\subsection{Engenharia Web}

Outro conceito envolvido no desenvolvimento desta tese é a Engenharia Web, a qual, de acordo com Deshpande et al. (2002), pode ser caracterizada como o conjunto de abordagens sistemáticas, disciplinadas e quantificáveis para desenvolvimento, operação e manutenção de aplicações Web. De forma sucinta, ela pode ser descrita como a forma de se desenvolver para Web, desde a análise até a execução do projeto, visando alcançar a qualidade dos sistemas desenvolvidos. Para isso, é importante que sejam utilizadas boas práticas para apoio ao desenvolvimento, como as apresentadas anteriormente, e que métodos auxiliem na orientação das atividades e artefatos desenvolvidos.

A Engenharia Web surgiu como uma iniciativa disciplinada para apoiar e otimizar os esforços frequentemente exigidos nos processos de criação, gerenciamento, manutenção e controle de qualidade de aplicações Web. Ela se refere ao estabelecimento e uso de conceitos científicos, técnicas de engenharia e de princípios de gerenciamento para, de forma sistemática, desenvolver, tornar disponível e efetuar a manutenção de sistemas e aplicações Web de alta qualidade (PRESSMAN, 2006; PRESSMAN e LOWE, 2008).

De acordo com Pressman (2006), um método para desenvolvimento Web deve compreender as seguintes fases: i) formulação; ii) planejamento; iii) análise; iv) design; v) geração de páginas e teste; e vi) avaliação do usuário. 
Esse método, então, objetiva desenvolver aplicações Web usáveis, acessíveis, funcionais, confiáveis, manuteníveis, escaláveis e seguras. Deshpande et al. (2002) apresentam uma categorização de aplicações Web e alguns de seus exemplos como:

- Orientadas a informação: jornais, catálogos, manuais de serviços e livros;

- Interativas: formulários, jogos e apresentações customizadas;

- Transacionais: lojas virtuais e organizações financeiras;

- Workflow: sistemas com fluxos como planejamento, agendamento de atividades e monitoração de status;

- Ambientes de colaboração: sistemas de autoria distribuída;

- Comunidades on-line: grupos de bate-papo e sistemas de recomendação;

- Portais Web: agrupamentos de notícias, vendas e outros serviços, e

- Serviços Web: aplicações corporativas com informações de negócios.

A Engenharia Web utiliza vários conceitos da Engenharia de Software tradicional, entretanto existem diferenças e necessidades inerentes das aplicações Web. Desse modo, métodos têm que ser adaptados ou criados para atender essas novas demandas (DESHPANDE et al., 2002; GITZEL et al., 2007).

Deshpande et al. (2002), nesse sentido, apresentam 16 principais diferenças entre as aplicações Web e as convencionais. Eles ainda relatam sobre a natureza dos usuários finais da Web, que podem ser dos mais variados perfis e de diferentes localizações geográficas, ao contrário dos sistemas convencionais desktops que têm grupos de usuários mais específicos, geralmente dentro de uma organização.

Segundo os mesmos autores, as aplicações Web têm ficado cada vez mais complexas, tanto em relação ao desempenho (número de acessos ou sessões instanciadas por segundo), quanto em termos de natureza dinâmica da informação, com uso de técnicas de multimídia e gestão da informação proveniente das mais variadas formas de colaboração.

Em relação aos pontos chave no desenvolvimento para Web, deve-se tratar a elicitação de requisitos, sendo possível identificar e resolver muitos problemas atuais nas especificações de requisitos que estão em constante evolução. Deve-se também considerar as necessidades de uma significativa faixa de perfis de usuários, com entradas de dados claras e organizadas. 
Outro ponto chave está relacionado aos testes, os quais têm uma dimensão adicional ao teste convencional de software. Cada parte da aplicação Web, como página, caminhos de navegação e requisitos legais, precisa ser testada. Assim, engenheiros Web precisam criar estratégias de teste explícitas para incluir testes relevantes. Já a manutenção desse tipo de aplicação também merece um enfoque especial e deve ser uma atividade contínua que, dependendo da natureza da aplicação, pode ser complexa.

\subsubsection{Padrões e componentes de interação}

Além das diretrizes de acessibilidade já apresentadas, existe uma técnica utilizada para representar e comunicar o conhecimento na área de Interação Humano-Computador (IHC), conhecida como padrões de projeto, que podem ser aplicados para o desenvolvimento Web.

O conceito original de padrões, que é a base bibliográfica para os estudos atuais, foi concebido pelo arquiteto e urbanista Christopher Alexander na década de 1970, por meio do desenvolvimento de documentos em formatos similares com soluções para construções urbanas. Em seus escritos, foi exposta uma aproximação do desenvolvimento e projeto, codificada em padrões, que focava em interações entre a forma física de construções e a maneira que influenciava, inibindo ou facilitando, vários comportamentos pessoais e sociais (FINCHER et al., 2003).

Nessa definição original é relatado que padrão pode ser entendido como uma solução de sucesso para um problema recorrente em um determinado contexto (ALEXANDER et al., 1977). Assim, seu uso pode ser entendido como uma maneira de capturar e apresentar conhecimento de projeto na resolução de problemas, atuando como um meio de divulgação de conhecimento entre projetistas especialistas e novatos, e de comunicação entre os indivíduos da equipe.

No campo da computação, o conceito de padrões foi inicialmente definido com sucesso pelos esforços da comunidade de Engenharia de Software (ES). A prática de documentar problemas recorrentes e suas soluções foi uma maneira conveniente de registrar técnicas de programação repetitivas. Adicionalmente, o conceito de associar os padrões em uma estrutura hierárquica, a Linguagem de Padrões, traduziu-se em um interesse paralelo 
para o projeto de software orientado a objetos, cuja obra mais conhecida é Design Patterns (GAMMA et al., 1995).

De acordo com Gamma et al. (1995), padrões proveem um esquema para refinar os elementos de software e as relações entre esses, descrevendo uma estrutura comum de comunicação entre os elementos que resolvem um problema recorrente dentro de um contexto particular. Com o uso de padrões têm-se uma técnica para representar, compartilhar e descrever a estrutura e execução de softwares (por exemplo, identificando classes com inter-relações e mensagens entre objetos).

No domínio de IHC, um dos desafios recorrentes está relacionado ao desenvolvimento de técnicas eficientes para documentar e compartilhar o conhecimento em relação à interação com o usuário, que os projetistas adquiriram, e aplicá-las em determinadas circunstâncias (FINCHER et al., 2003; ANACLETO et al., 2004).

De acordo com van Welie e van der Veer (2003), não é difícil identificar padrões na interface com o usuário, mas é difícil identificar os padrões que realmente beneficiam o usuário, focando aspectos de usabilidade. Por exemplo, propagandas (banners) e telas de abertura (splash screen) são implementações comuns, por razões comerciais, e não por diretrizes de usabilidade.

Outra possibilidade no uso de padrões para beneficiar a interação do usuário é a disponibilização e pesquisa daqueles relacionados a boas práticas no desenvolvimento do conteúdo a ser apresentado, de forma que tais padrões sejam claros, compreensíveis e com atributos de apreensibilidade. Isso é importante, sobretudo em aplicações Web de educação, em que a qualidade do material instrucional é parte essencial do processo de ensinoaprendizagem (TALARICO NETO et al., 2005).

Van Welie e van der Veer (2003) afirmam que os padrões para projeto de interface com o usuário devem incluir em sua estrutura um tópico chamado "Raciocínio", na seção de "Solução", para explicar como sua adoção pode levar a uma melhora nos indicadores de usabilidade. As soluções descritas nesse tipo de padrões devem contemplar em seus indicadores os atributos de aprendizagem, memorização, desempenho e satisfação do usuário.

No contexto de padrões para Web, Bernstein (1998) apresenta uma das ideias precursoras, discorrendo sobre a complexidade do desenvolvimento Web, especialmente na 
estrutura de links. Assim, vê-se a necessidade de se ter um vocabulário de conceitos e estruturas para entender a maneira que os sites funcionam, sendo, para isso, importante analisar e conhecer os melhores trabalhos existentes na área. Em seu trabalho é descrita uma coleção de padrões de relacionamentos em hipertextos, em que é feita uma aproximação do uso de padrões como componentes, assim, páginas típicas contêm instâncias de diferentes padrões e frequentemente um único nó ou link pode participar em várias estruturas de intersecção.

Na Figura 2.3, a título de exemplificação, é feita uma síntese de alguns desses padrões para Web, na forma de desenhos que representam estruturas de navegação.

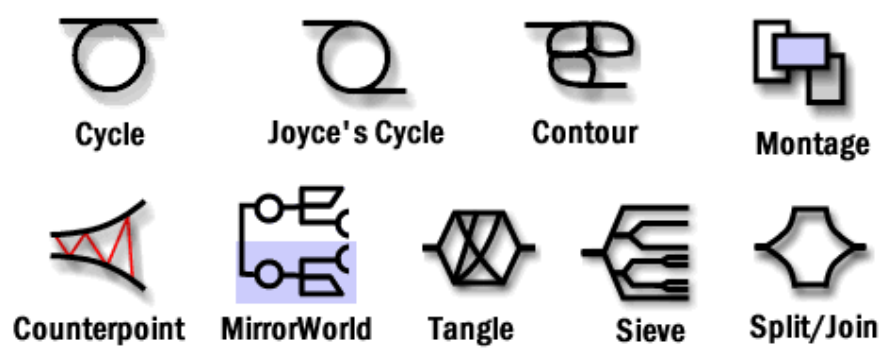

Figura 2.3 - Síntese gráfica (em adaptação ao original) de alguns dos padrões Web de Bernstein (1998)

No padrão Cycle há uma reflexão sobre o usuário regressar a um nó visitado anteriormente (como um ciclo) e, eventualmente, sair ao longo de um novo caminho. Ciclos criam recorrência e, portanto, expressam a presença de estrutura. $\mathrm{O}$ autor ainda infere a possibilidade de quebrar um ciclo usando ligações condicionais ou no uso do recurso "migalhas de pão" (breadcrumbs), tão conhecidas e utilizadas atualmente. São também mostradas variações desse padrão, como em Joyce's Cycle.

Garzotto et al. (1999) e Rossi et al. (1999) destacam que é possível a obtenção de benefícios usando padrões Web, principalmente no auxílio à arquitetura de navegação, especificação de requisitos e modelagem conceitual. Assim, uma linguagem de padrões para Web é substancialmente importante para desenvolvedores inexperientes, pois existem muitos princípios, diretrizes, regras de ouro e outros conhecimentos no campo de desenvolvimento Web e a utilização desses pode não ser trivial (MONTERO et al., 2002).

Montero et al. (2002) apresentam uma linguagem de padrões para Web, que possui três níveis de escala (site, homepage e detalhes de ornamentação). Adicionalmente, van 
Welie apresenta, em seu site ${ }^{5}$, uma coleção de padrões para desenvolvimento Web categorizados de acordo com a tarefa e o tipo de problema de utilização, capturando o ponto de vista do usuário. Essa categorização é feita em três grandes grupos:

- necessidades dos usuários;

- necessidades das aplicações; e

- contexto do design.

Cada um desses grupos ainda tem subdivisões, como pode ser visto no Quadro 2.1, em que a quantidade em cada grupo é apresentada entre parênteses.

Quadro 2.1 - Agrupamento dos padrões de van Welie

\begin{tabular}{|l|l|l|l|}
\hline \multicolumn{2}{|c|}{ User needs (84) } & \multicolumn{1}{|c|}{ Application needs (12) } & $\begin{array}{c}\text { Context of design } \\
\text { (35) }\end{array}$ \\
\hline $\begin{array}{l}\text { Navigating around } \\
(25)\end{array}$ & Making choices (5) & Feedback (2) & Site types (14) \\
\hline Searching (13) & Giving input (3) & Simplifying interaction (2) & Experiences (8) \\
\hline Shopping (9) & Miscellaneous (5) & Drawing attention (8) & Page types (13) \\
\hline Basic interactions (7) & Personalizing (3) & & \\
\hline Dealing with data (14) & & & \\
\hline
\end{tabular}

Como observado no agrupamento de padrões de van Welie, percebe-se uma significativa preocupação do autor com os padrões relacionados às necessidades dos usuários, sendo que esse aborda o maior número de padrões (84). Na Figura 2.4 pode ser visualizado um padrão Web de van Welie do grupo "Navigating around”.

\footnotetext{
${ }^{5}$ http://www.welie.com
} 


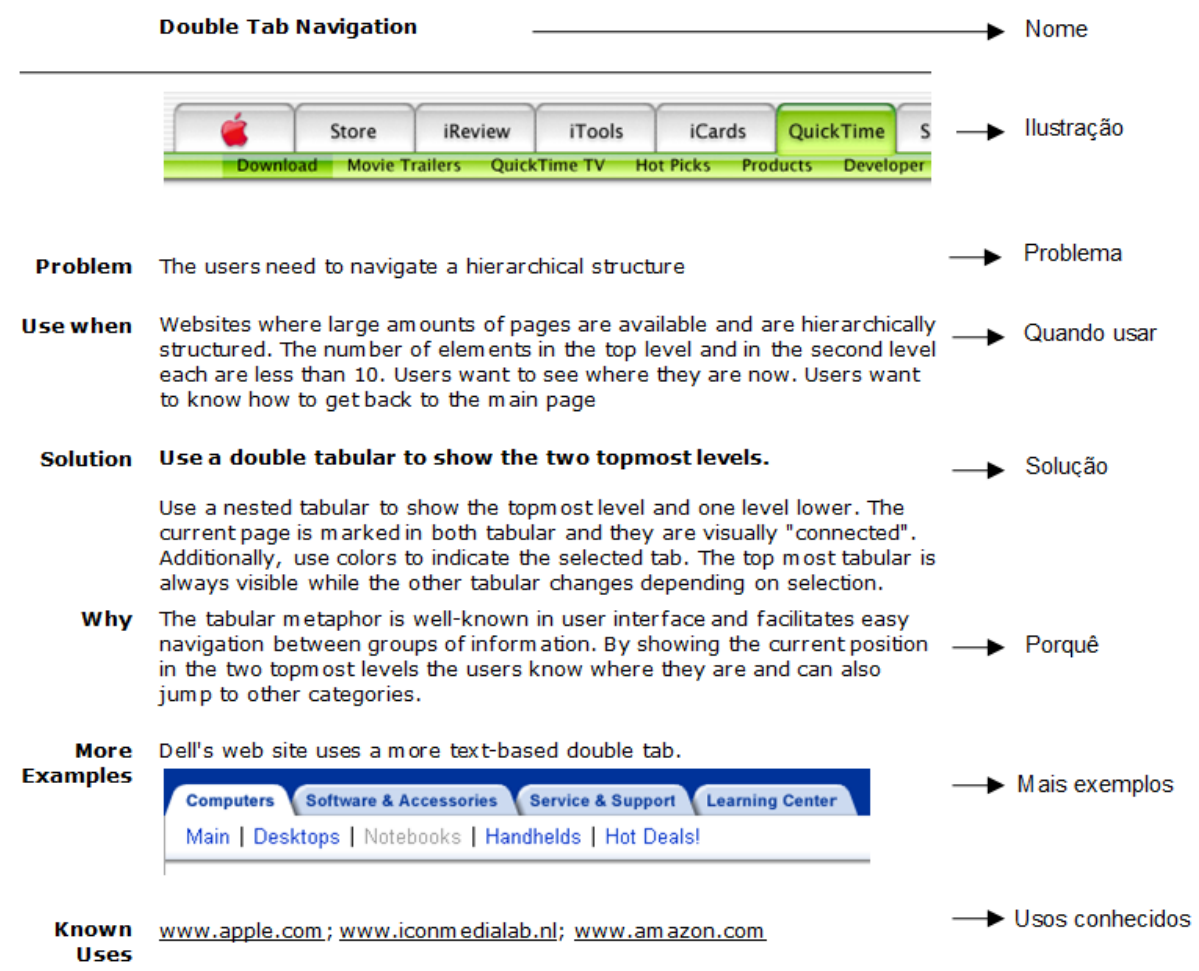

Figura 2.4 - Exemplo do padrão Web “Double Tab Navigation” de van Welie

No padrão "Double Tab Navigation" é relatado que os usuários necessitam navegar em uma estrutura hierárquica em que é sugerida a utilização de uma composição de menu com abas duplas, podendo ser utilizadas cores e efeitos de destaque para indicar a aba selecionada.

Em relação à acessibilidade, van Welie trata algumas questões em seus padrões, como por exemplo em "Font Enlarger", em que é ressaltada a importância de personalizar o tamanho da tipografia de acordo com as preferências e necessidades do usuário. No padrão “Captcha”, é mencionado o documento do W3C (2005) que trata da acessibilidade, ressaltando a importância em proteger formulários e serviços do acesso de robôs Web.

No padrão "Fly-out Menu”, que faz parte da categoria "Navigating around", a questão de acessibilidade é abordada na utilização do menu, sem a necessidade do uso de funções auxiliares na linguagem Javascript, possibilitando também a indexação por mecanismos de busca. Entretanto, é importante ressaltar que a acessibilidade na Web não é uma preocupação descrita em todos os padrões desse autor. 
Outra coleção interessante de padrões para Web é a Yahoo! Design Pattern Library ${ }^{6}$ que é dividida em cinco seções: busca, navegação, recuperação de informação, seleção e questões sociais. Cada padrão dessa coleção apresenta um resumo do problema, os padrões relacionados, onde foram usados no portal Yahoo!, quando esses devem ser utilizados e a solução para a aplicação do padrão. A ilustração com exemplos de telas auxilia significativamente os desenvolvedores, que podem visualizar melhor os detalhes da aplicação de cada padrão.

O uso de padrões também se faz presente na Web 2.0, relacionado à aplicação desses em uma nova visão de chamadas dinâmicas a eventos em diferentes tipos de interação no lado do cliente com o uso de Ajax (MAHEMOFF, 2006; GARRETT, 2005).

Os padrões de Ajax identificados por Mahemoff (2006) se dividem em quatro categorias, apresentadas a seguir, em que o número entre parênteses indica o número de padrões da categoria:

- Tecnologia básica (11): aborda as tecnologias puras, necessárias para o desenvolvimento do Ajax;

- Programação (22): apresenta técnicas direcionadas a desenvolvedores e como assegurar que as aplicações com Ajax sejam passíveis de manutenção;

- Funcionalidade e usabilidade (28): mostra os tipos de interfaces de usuário em aplicações com Ajax, inclusive com detalhes de funcionalidades permitidas por essa tecnologia, e

- Desenvolvimento (8): descreve os processos usados para monitorar, depurar e testar aplicações com Ajax.

Para esses padrões, o autor infere o quanto da evidência do mundo real existe e utiliza uma escala gráfica de três pontos para essa indicação. Tal escala vai de nenhum ponto marcado, ideia puramente especulativa, até todos os pontos marcados para informar que o padrão está em ampla aceitação e utilização (MAHEMOFF, 2006).

No tocante a padrões de usabilidade para Web é interessante citar o trabalho de Graham (2003) que define 79 desses padrões relacionados em uma linguagem. A intenção é

\footnotetext{
${ }^{6}$ http://developer.yahoo.com/ypatterns/
} 
auxiliar os desenvolvedores na criação de sites que atendam às expectativas dos clientes, satisfaçam os usuários e evitem erros de omissão.

Assim, os padrões Web são fortes aliados do desenvolvimento de aplicações Web, uma vez que esses, para se tornarem padrões, já foram verificados e testados, em relação à sua utilidade e real relevância. No que concerne à acessibilidade, devem ser consideradas as diretrizes para o bom desenvolvimento e isso deve ser incorporado nos padrões, para que seu uso seja útil para que menos barreiras sejam encontradas no desenvolvimento final.

\subsection{Desenvolvimento Orientado a Modelos}

Nesta seção é apresentado o conceito do desenvolvimento orientado a modelos (Model Driven Development - MDD), bem como as vantagens de sua utilização e sua relevância para o trabalho desenvolvido nesta tese, enfatizando os benefícios de sua utilização para o apoio a boas práticas para desenvolvimento de aplicações Web acessíveis.

No MDD os diagramas conceituais não são somente a referência que os desenvolvedores usam para produzir o código executável, sendo também artefatos "vivos", servindo como entrada para as ferramentas de geração de código (KLEPPE et al., 2003; AMBLER, 2003).

Assim, modificações feitas nos modelos são automaticamente refletidas no código, facilitando a manutenção e evolução dos sistemas. O conceito central é fazer com que os desenvolvedores foquem em modelar um problema do domínio e não programar uma possível solução, geralmente específica de uma plataforma.

Venkatesan (2006) ressalta que gerar código a partir de modelos é um objeto da indústria há anos, visto que modelos servem como um mecanismo para facilitar o entendimento e documentação de um projeto. No MDD há os conceitos de Computation Independent Model (CIM) (ou Modelo Independente de Computação), Platform Independent Model (PIM) (ou Modelo Independente de Plataforma) e Platform Specific Model (PSM) (ou Modelo Específico de Plataforma). Tais conceitos se baseiam em transformações para elevar o nível de abstração durante o desenvolvimento de software. 
Na Figura 2.5, adaptada de Kleppe et al. (2003), é ilustrado o ciclo de desenvolvimento de software com um processo MDD em contraposição ao tradicional.

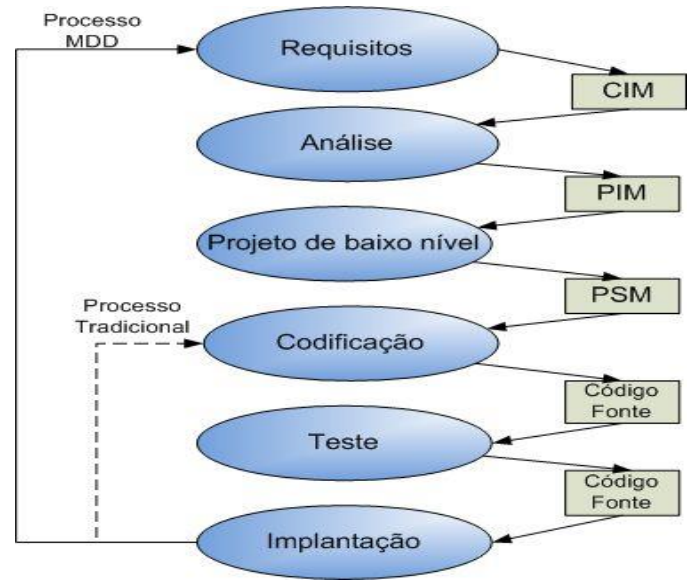

Figura 2.5 - Ciclo de vida do MDD desde o reconhecimento de requisitos até a implantação

O processo começa com a identificação dos requisitos que produz o CIM, o qual descreve a situação de utilização do sistema. Tal modelo é independente de como o sistema será implementado. O próximo passo consiste da análise de requisitos que produz o PIM, que é uma representação de como os requisitos serão satisfeitos, mas sem detalhar características de plataforma.

No projeto de baixo nível, o PIM é transformado em PSM, considerando-se a plataforma sobre a qual o software funcionará. O conceito é que um mesmo PIM possa dar origem a vários PSMs. A partir do PSM o processo segue normalmente, com a codificação, em que o modelo e os transformadores dão origem ao código executável.

Em uma primeira análise, esse modelo não difere muito do modelo tradicional de desenvolvimento de software. No entanto, no MDD, um modelo é uma descrição formal, que pode ser compreendida por computadores. Enquanto no modelo tradicional as transformações entre modelos são manuais. Assim, a ideia é automatizá-las usando ferramentas.

Em particular, no MDD se tem o preenchimento de atributos, associações e transformações de acordo com regras expressas em modelos, havendo a integração nos projetos especificada por meio de um PIM e, posteriormente, para cada dispositivo pode ser definida a geração de código para uma plataforma específica. Assim para possibilitar a geração de um modelo específico para uma plataforma é utilizada uma transformação, que funciona como uma caixa preta, transformando um modelo PIM em diferentes modelos PSM. 
Na Figura 2.6 é ilustrado, de maneira resumida, como são utilizadas as ferramentas de transformação.

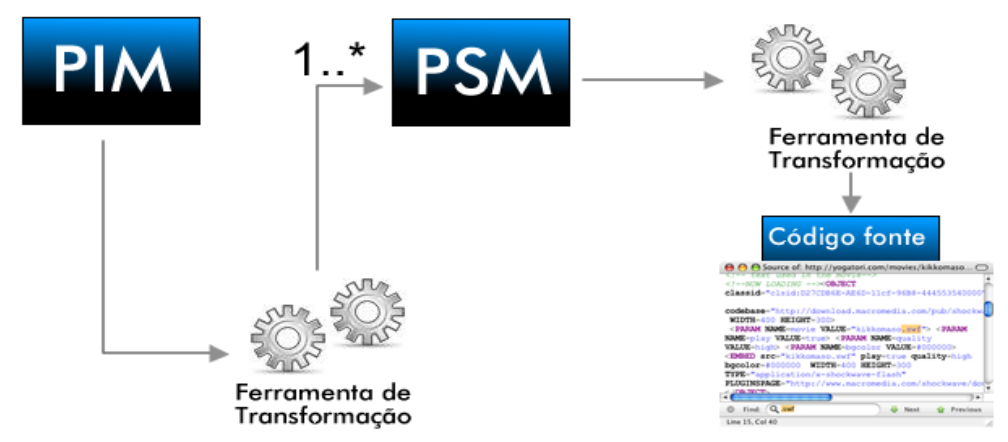

Figura 2.6 - Ciclo básico de transformações no desenvolvimento orientado a modelos

Transformações são operações que se encarregam de converter um ou mais modelos de entrada para outros de saída, que por sua vez podem servir de entrada para outra transformação.

Uma vez que o MDD está diretamente relacionado aos conceitos que permeiam o desenvolvimento desta tese, nas seguintes subseções é detalhado o suporte ferramental para seu uso, bem como suas principais vantagens e desvantagens, seguido pela sua utilização na Web.

\subsubsection{Suporte ferramental}

O suporte ferramental ao MDD é composto por diferentes ferramentas que vão desde a definição e edição de metamodelos de forma gráfica e textual até a geração do código fonte final da aplicação. Nesta subseção são detalhados três importantes ambientes de suporte ferramental ao MDD.

O primeiro ambiente a ser detalhado é o Eclipse $^{7}$, que é gratuito e bem utilizado no mercado e academia. Ele é baseado na linguagem Java, sendo um projeto com bastante atividade de desenvolvimento para expansões e melhorias (ECLIPSE, 2012).

Em suas versões disponibilizadas há a divisão em pacotes de funcionalidades, sendo o Modeling o pacote que oferece o suporte ao MDD. Tal pacote é caracterizado por um modo de distribuição que contempla uma gama de plug-ins para modelagem e geração de código.

\footnotetext{
${ }^{7}$ http://www.eclipse.org/
} 
Para suporte gráfico tem-se o Graphical Modeling Framework (GMF) que provê a infraestrutura gráfica de tempo de execução para desenvolvimento de editores gráficos, baseados em Eclipse Modeling Framework (EMF) e Graphical Editing Framework (GEF).

Na Figura 2.7 é apresentado o "GMF dashboard” que é um guia interativo de ajuda do Eclipse para a geração de editores gráficos.

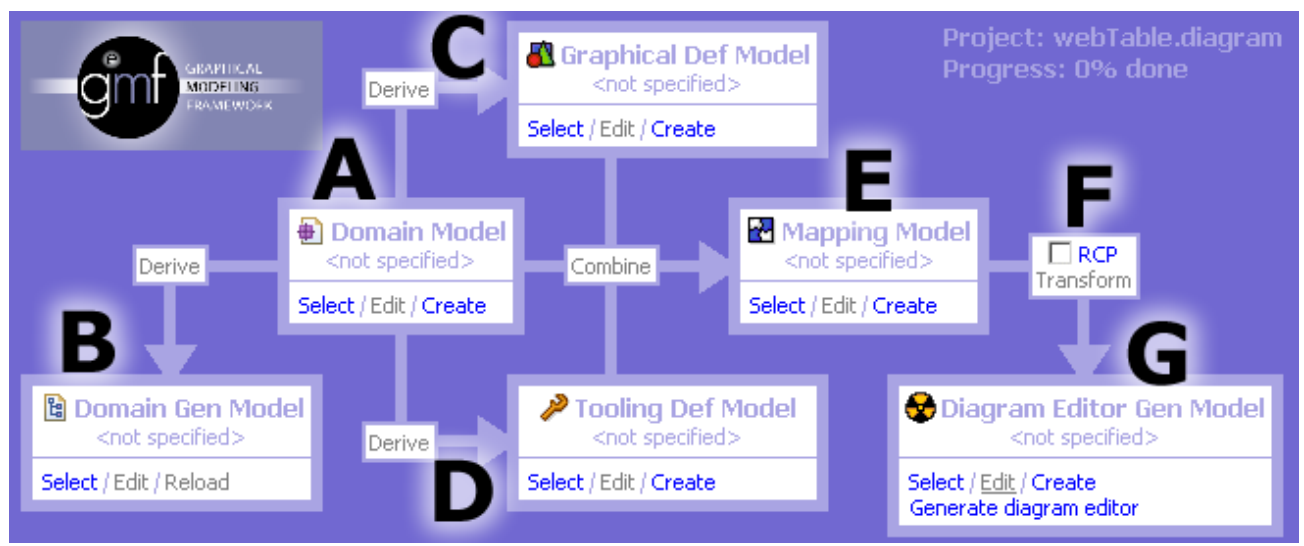

Figura 2.7 - Reprodução do ciclo de desenvolvimento do GMF a partir de seu guia dashboard

Os pontos marcados na figura representam diferentes resultados de passos do processo e são descritos a seguir: A - seleção ou criação de um modelo de domínio em EMF para dar início ao processo; B - derivação do modelo de domínio para um que contenha detalhes da geração; $\mathbf{C}$ - especificação dos elementos gráficos que formarão o modelo; D definição das ferramentas que formarão parte da paleta do editor; $\mathbf{E}$ - combinação do modelo de domínio, gráficos e ferramentas em um modelo de mapeamento; $\mathbf{F}$ - transformação para se chegar ao modelo final, deve-se marcar a caixa de seleção para criação de um cliente independente do tipo Rich Client Platform (RCP), e G - finalização com geração do código para o editor gráfico que criará outro projeto que pode ser executado via plug-in do Eclipse ou via RCP.

O EMF é utilizado para declaração de modelos de geração e provê um mecanismo de serialização para persistir modelos em tempo de execução, facilitando a interoperabilidade entre plug-ins. Seu metamodelo interno é chamado de Ecore, sendo um subconjunto da Meta Object Facility (MOF), que é uma linguagem padronizada pelo Object Management Group (OMG) que provê facilidades de metamodelagem.

O Ecore é um formalismo de notação para metamodelagem que pode ser descrito graficamente ou em forma de árvore hierárquica de elementos, não podendo gerar código 
sozinho, representando a caracterização de como será um modelo. Um modelo derivado do Ecore é pré-requisito para um gerador de código EMF, que nessa plataforma utiliza duas principais ferramentas para geração, o Java Emitter Templates (JET) e Java Merge (JMerge).

O JET é um transformador genérico que possui sintaxe simples, baseada em Java Server Pages (JSP), facilitando a escrita de máscaras de mesclagem conhecidas como templates. Um template JET é um arquivo de texto que contém uma estrutura pré-definida que representa o artefato final semiconcluído, com pontos em aberto que podem ser preenchidos por meio de variáveis especificadas pelo desenvolvedor. Esse transformador pode ser utilizado para gerar qualquer saída de um template, seja SQL (Structured Query Language), XML (EXtensible Markup Language) ou código fonte de alguma linguagem. Por convenção, sugere-se para a formação do arquivo template concatenar antes do "jet" o que será gerado, exemplos: i) .javajet - gera código Java; ii) .xmljet - gera código XML e iii) sqljet - gera código de consultas SQL.

Já o GEF permite que o desenvolvedor crie, a partir de um modelo de aplicação existente, um rico editor gráfico. Nele estão disponíveis funcionalidades comuns esperadas em editores, como: de impressão, ligação entre elementos, “copiar e colar", desfazer, dentre outras. O GEF utiliza a arquitetura MVC (Model-View-Controller) que possibilita que mudanças sejam aplicadas ao modelo, a partir da camada de visualização.

A plataforma Eclipse ainda traz a possibilidade de criação de editores gráficos de modelos independentes, baseados na tecnologia estrutural RCP. Com essa tecnologia os editores podem ser distribuídos e executados sem que o usuário tenha instalado anteriormente o Eclipse.

Outra ferramenta importante para o domínio de MDD é a Generic Modeling Environment (GME) ${ }^{8}$, a qual é formada por um ambiente de metamodelagem que permite a criação de ferramentas de modelagem específica de domínio. A GME é desenvolvida pela Vanderbilt University no âmbito do projeto Model Integrated Computing (MIC), que pesquisa três elementos principais relacionados ao MDD: i) tecnologias para modelagem

\footnotetext{
${ }^{8} \mathrm{http}: / / \mathrm{www}$. isis.vanderbilt.edu/projects/gme/
} 
específica de domínio; ii) ferramentas para modelagem, e iii) um framework para análise formal, verificação e transformação de modelos.

Sua linguagem de metamodelagem é baseada na notação do diagrama de classes UML e em regras na linguagem Object Constraint Language (OCL). Para sua integração e extensão é possível o uso de componentes no modelo Component Object Model (COM) que podem ser escritos nas mais diversas linguagens como $C++$, Visual Basic, C\# e Python.

Um ponto importante a se ressaltar é que o GME possui um gerenciador de regras para checagem orientada a eventos. Dependendo da prioridade da regra, a operação que causou a sua violação é abortada. Para violações de baixa prioridade esse gerenciador apenas exibe uma mensagem de alerta.

Outra ferramenta, que cabe ser citada, é a openArchitectureWare (oAW) ${ }^{9}$ que contempla um ambiente e um framework desenvolvido em Java, estruturado em módulos de geração para MDD. A oAW suporta a leitura de modelos arbitrários e de uma família de linguagens para checagens e definição de transformações.

A oAW oferece suporte a modelos baseados em EMF mas também trabalha com outros tipos de modelos, como por exemplo UML, XML e JavaBeans. Em seu núcleo existe um motor para a definição de fluxos de geração e transformação. Vários componentes de fluxo preconcebidos podem ser usados para leitura e instanciação de modelos, checando-os por violação de restrições, transformando-os em outros modelos e finalmente para geração de código (OPENARCHITECTUREWARE, 2011).

\subsubsection{Principais vantagens e desvantagens}

As vantagens do MDD envolvem a capacidade de evitar que o desenvolvedor execute tarefas repetitivas e manuais de transformação de modelos para o código final executável. O tempo gasto nessas tarefas pode ser significativamente reduzido com a automatização da geração de código.

O fato dos modelos serem computacionalmente compreensíveis e servirem de entrada para transformações, faz com que até mesmo atividades de manutenção, como correção de erros, possam ser executadas sem produzir inconsistência com os modelos, mantendo-os

\footnotetext{
${ }^{9}$ http://www.openarchitectureware.org/
} 
atualizados. A manutenção é facilitada também pelo desprendimento das camadas de alto nível com detalhes técnicos de plataforma. Essas camadas ainda auxiliam no entendimento do projeto por stakeholders e outros envolvidos.

Entretanto, há diversos aspectos que devem ser considerados para a aplicação com sucesso do MDD. Uma das principais críticas em relação a esse desenvolvimento é a dificuldade e complexidade de produção de modelos computacionalmente completos, ao ponto de gerar o código executável final. Em relação à Web, a dificuldade é ainda maior pela necessidade de modelagem de navegação e projeto do comportamento da interação, em que se têm vários estados e possibilidades.

Fowler (2004) ressalta que detalhar um comportamento usando um diagrama de sequência não é tão fácil quanto escrever um código executável em linguagens de programação modernas. O MDD demanda maior investimento inicial, visto que o desenvolvimento de uma infraestrutura orientada a modelos requer mais tempo e esforço. Porém, os ganhos posteriores são significativos, fazendo com que esse investimento possa ter retorno, sobretudo em organizações com alta escala de desenvolvimento.

Outra dificuldade está em manter a consistência entre o modelo e o código gerado. Em muitos casos, como a implementação de regras de negócios, um modelo não é hábil a capturar a lógica de negócios completamente. Dessa maneira, é necessário que sejam inseridas modificações e detalhes diretamente no código gerado, o que eventualmente causará inconsistências.

\subsubsection{Uso do MDD na Web}

Na prática, verifica-se que não é uma tarefa trivial utilizar orientação a modelos no desenvolvimento de aplicações Web, seja na composição de elementos de linguagens para Web já conhecidas e em suas transformações ou relacionado a como utilizar um ambiente de desenvolvimento eficaz que suporte esse tipo de desenvolvimento.

Uma característica do MDD, especialmente importante para Web, está na possibilidade de fornecer mapeamento de um modelo em transformações para diferentes plataformas. Isso pode ser justificado devido a tendência de ubiquidade cada vez maior no uso de navegadores Web em vários dispositivos, como celulares e tablets, sendo que o 
conteúdo e outros itens de interface das aplicações precisam ser adaptados em relação a características específicas de tamanho de tela e tipos de interação (muitos já permitem uso via touch screen).

Como exemplo dessa adaptação das aplicações Web por dispositivos podem ser citados portais de grande repercussão no país e sites de instituições bancárias que já possuem interfaces Web adaptadas para dispositivos da Apple, como iPad, iPod e iPhone. É interessante ressaltar que, mesmo a plataforma sendo Web, existem considerações que devem ser vistas para cada dispositivo, para esse exemplo o fabricante dos dispositivos disponibiliza uma série de diretrizes para interação Web, intitulada "iOS Human Interface Guidelines for Web Applications", em Apple (2011).

Trujillo et al. (2007) apresentam um trabalho de modelagem de features ${ }^{10}$ para uso na Web. Para tanto é proposto o mapeamento de portlets, que são componentes que oferecem funcionalidades específicas ao usuário. Os passos propostos envolvem: i) definição de controladores de portlets; ii) mapeamento em uma linguagem específica de domínio chamada "Domain Specific Language for Portlets" (PSL) e iii) criação das transformações para a geração dos produtos finais.

Outro caminho para o uso de MDD na Web é o da realização de avaliações automáticas de artefatos Web utilizando modelos, com a execução de validações e apresentação de sugestões para melhorias. Atterer (2008) apresenta essa visão, no intuito da checagem de diretrizes de usabilidade com o uso de modelos. Nesse caso, o foco não é o desenvolvimento a partir de transformadores e sim a leitura de modelos e validações automáticas com o uso de parsers.

Ciccheti et al. (2007) apresentam suas experiências de suporte a customização de software para o desenvolvimento Web orientado a modelos. É relatado que modificações para customização são atividades necessárias, mas que devem ser feitas com a preocupação em se manter os modelos íntegros e atualizados. Para tanto, nessas experiências, é mostrado como marcar pontos (chamados “injection points”) nos modelos, permitindo a inserção manual de código para customização da aplicação que será gerada.

\footnotetext{
${ }^{10}$ Uma feature pode ser definida como um conceito ou característica de um domínio, sendo perceptível ao usuário e stakeholders (LEE, KANG e LEE, 2002)
} 
Para aplicações ricas na Web a modelagem torna-se mais complexa e, nesse campo, Wright e Dietrich (2008) verificam requisitos para metodologias de desenvolvimento e apresentam uma linguagem que permite o desenvolvimento orientado a modelos chamada Internet Application Modelling Language (IAML) ${ }^{11}$.

Na Figura 2.8 é apresentada uma parte do diagrama de metamodelo Ecore da IAML em três pontos de visões distintas, os quais estão sendo representados pelas letras destacadas na figura.

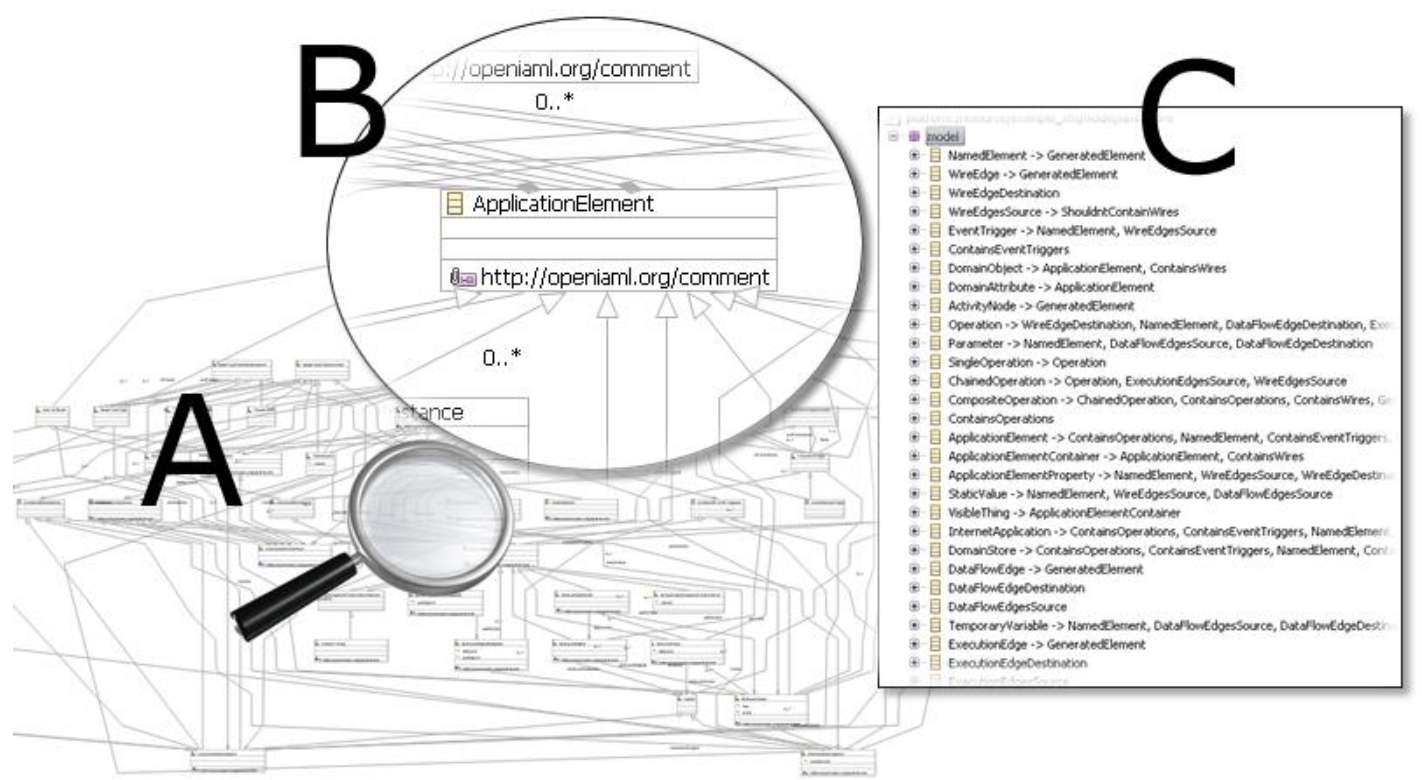

Figura 2.8 - Diagrama Ecore da iaml (A) com destaque para um de seus pontos (B) e sua representação hierárquica $(\mathrm{C})$

Os três pontos em destaque na Figura 2.8 indicam: A - diagrama Ecore das classes do metamodelo da linguagem em tamanho reduzido pela complexidade da mesma; B ampliação de um ponto importante da linguagem, a classe "ApplicationElement", que representa um elemento da aplicação e percebe-se que existem muitas relações de agregação e generalização (sendo uma classe ascendente, pois é a classe "mãe" de outras) e C - as mesmas classes do diagrama relacionadas em estrutura de árvore.

\footnotetext{
${ }^{11}$ http://openiaml.org/
} 


\subsection{Design Rationale}

Design Rationale (DR) pode ser definido como a referência ao raciocínio de um projeto incluindo os detalhamentos que justificam determinadas escolhas (GRUBBER e RUSSEL, 1991; MORAN e CARROLL, 1996).

Adicionalmente, MacLean et al. (1989) e Lee (1997) consideram que o DR não inclui apenas a descrição do artefato em potencial, mas também as justificativas das decisões, as experiências, alternativas e argumentações que levaram à sua criação e possíveis alterações ao longo do tempo, provendo assim a formação de uma base histórica dos artefatos.

O uso do DR auxilia no aprendizado do projeto como um todo e pode representar uma solução para guiar os projetistas na identificação de questões que devem ser consideradas no projeto, que de outra maneira poderiam passar despercebidas, colaborando também para identificação de premissas inadequadas e diminuição da tendência dos projetistas em não perceber alternativas possíveis em decisões importantes (HORNER e ATWOOD, 2006).

A explicitação do DR permite prover um vocabulário comum, produzir artefatos mais completos em menor tempo, com menor esforço e, possibilita a formação de um repositório de fatos que facilita a manutenção e evolução de um produto. Porém existem limitações que dificultam sua utilização na prática, conforme apresentam Regli et al. (2000): as dificuldades em recuperar informações capturadas, a diferença entre informações que os projetistas gostariam de registrar e as que o sistema permite, a generalidade das ferramentas e a não contribuição para a progressão natural das atividades de projeto.

O DR é empregado, segundo Dutoit et al. (2006), também para promover a colaboração entre membros de equipe, melhorar a qualidade dos artefatos e transferir conhecimentos. Lara (2005), adicionalmente apresenta que o DR pode:

- Auxiliar na redução da arbitrariedade, tornando o processo de tomada de decisões mais bem embasado, visto que as justificativas e os argumentos são arquivados e poderão ser recuperados;

- Contribuir para a compreensão do desenvolvimento, diminuindo a complexidade de manutenção e ajudando nas avaliações das consequências que podem surgir devido a alterações do sistema; 
- Melhorar a comunicação entre os membros da equipe do projeto, incluindo o apoio no diálogo de novos integrantes do grupo, projetistas e usuários; e

- Auxiliar no acompanhamento e descobertas de erros durante o desenvolvimento do projeto, possibilitando que razões, discussões e decisões de um projeto sirvam de base para o desenvolvimento de outros projetos.

Por meio do uso de sistemas de DR são definidos praticamente todos os aspectos de um desenvolvimento, como aqueles que representam as razões para cada problemática. Tal cenário é retratado na Figura 2.9, em que os serviços comuns são classificados em quatro grandes grupos de acordo com o perfil de usuários beneficiados: melhor suporte de desenvolvimento (desenvolvedores), melhor manutenção (mantenedores do sistema), aprendizado (novos funcionários e estudantes), e documentação (futuros desenvolvedores e mantenedores).

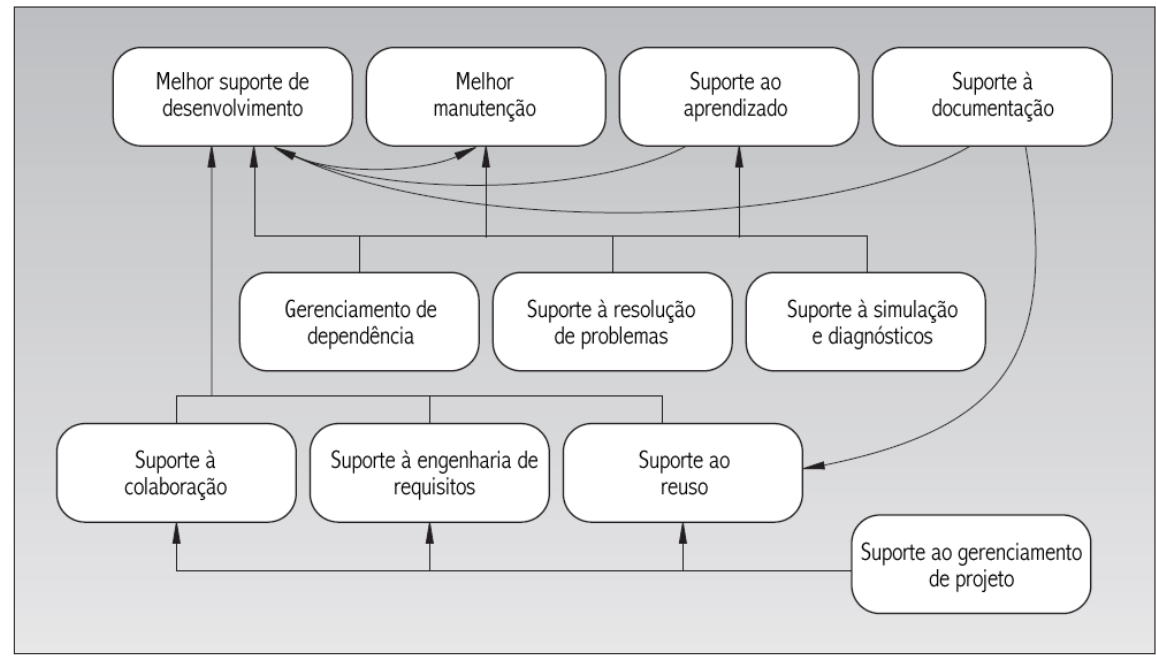

Figura 2.9 - Serviços providos por sistemas de DR, adaptado de Lee (1997)

Como apresentado na Figura 2.9, o serviço no final da seta (cauda) suporta o serviço do início. Por exemplo, usar razões de desenvolvimento para suporte ao gerenciamento do projeto auxilia na colaboração entre a equipe, engenharia de requisitos e reuso.

De acordo com Lee (1997), com a utilização de sistemas de DR, mecanismos são propostos a fim de tornar captura de decisões mais eficiente. Desse modo, há subsídios para uma melhora no gerenciamento de dependências, colaboração, reutilização, manutenção, aprendizagem e documentação. 
No entanto, armazenar registros de DR pode requerer um tempo significativo e ser custoso ao projeto, visto que vários sistemas que apoiam o seu gerenciamento podem falhar em considerar aspectos práticos, como seu custo efetivo e dificuldade de integração (LEE, 1997). Uma das alternativas que podem ser aplicadas para solucionar essa questão é a automatização do processo de captura e sua associação com o objeto de trabalho, inserindo esse processo como integrante do desenvolvimento em si.

Assim, o uso de DR encoraja o aprendizado em um projeto como um todo e pode representar uma solução para ajudar designers a identificar questões que poderiam passar despercebidas (GRUBBER e RUSSEL, 1991).

Falessi et al. (2006) mostram a necessidade de melhoria na colaboração entre as tomadas de decisão do projeto, refinando a rastreabilidade de requisitos e otimizando a utilização de novas tecnologias. Assim, é desenvolvida uma técnica de documentação específica para impulsionar os objetivos de decisão e projetos alternativos disponíveis.

De acordo com Lara (2005), o DR é importante para auxiliar no registro de conhecimento e é apresentada uma ferramenta que pode ser utilizada nesse registro. Apesar da relevância desses estudos apresentados, eles não mostram um uso específico de DR relacionado à acessibilidade.

\subsubsection{Colaboração}

Falessi et al. (2006) ressaltam a necessidade de uma colaboração eficiente entre membros de uma equipe para tomadas de decisão em um projeto de desenvolvimento de software. Nesse ponto o DR pode ser útil, favorecendo a rastreabilidade de requisitos com embasamento histórico e registro de pontos de vistas de cada membro.

Nesse contexto, Dutoit et al. (2006) relatam que o DR é importante para promover e apoiar a participação e colaboração em um projeto, de tal forma que os usuários possam compreender o raciocínio dos projetistas, as questões que estão sendo tratadas pelos desenvolvedores e as alternativas que estão sendo consideradas.

Whitehead (2007) relata que projetos de engenharia de software são inerentemente cooperativos, exigindo frequentemente muitos desenvolvedores que devem coordenar esforços colaborativos para a produção de artefatos. Esse autor aponta diferentes conceitos 
importantes para colaboração em desenvolvimento de software e o DR é um deles, permitindo o registro de escolhas de projeto como resultado de um processo de tomada de decisão racional, em que são verificadas variáveis e demais informações de interesse, devendo haver uma colaboração fundamentada.

\subsubsection{Manutenção e reuso}

A atividade de manutenção de determinado produto envolve o conhecimento intrínseco sobre seu funcionamento, de modo a mantê-lo em condições de atendimento em relação ao provimento efetivo de suas funcionalidades ao usuário. Tal atividade ainda requer que a equipe saiba o efeito das possíveis mudanças efetuadas e que possa acompanhar os resultados dessas.

Assim, o DR é significativamente útil na manutenção por evidenciar e explicitar o registro do conhecimento a partir das razões que implicaram em cada ação que compôs um desenvolvimento. Em relação ao reuso, o conhecimento de projeto é analogamente importante para que a equipe saiba o que determinado software faz para que ele possa ser reaproveitado de maneira eficaz. Para tanto, é importante que a equipe conheça o raciocínio e motivações dos desenvolvedores do projeto para sua reutilização em um novo contexto com acoplamento coerente (DUTOIT et al., 2006).

\subsubsection{Transferência de conhecimento}

O conhecimento de um projeto envolve união de todas as concepções de cada integrante da equipe para um determinado fato que ocorre no desenvolvimento ao longo do tempo. Ou seja, há um caminho seguido em contextos determinados que resultam na formação histórica do conhecimento.

Nessa linha, o DR pode ser útil para auxiliar na reutilização do conhecimento, incluindo o registro de fatos para projetos bem sucedidos, ou para aqueles que não tiveram um resultado satisfatório. Além disso, Wang e Burge (2010) mostram que o DR pode ser usado para capturar e gerenciar conhecimento arquitetônico, que são importantes em projetos de software, uma vez que incluem informações do ambiente e as razões para o processo de concepção e de negociação, definindo o resultado como produto final. 
A questão da transferência de conhecimento é frequentemente complexa, envolvendo fatores organizacionais e pessoais. É comum haver a centralização de conhecimento em determinadas pessoas que veem nisso uma forma de valorização pessoal. No entanto, o gerenciamento de um projeto deve levar em consideração o registro do conhecimento para que esse seja acessível a todos os responsáveis da equipe, permitindo uma descentralização do conhecimento. Tal registro precisa ser organizado, facilitando a compreensão de fatos por outros membros da equipe, permitindo inclusive que novos colaboradores se integrem mais facilmente às ações e desenvolvimentos de um projeto.

Para a construção de uma base de conhecimento é preciso documentar experiências, sendo isso importante inclusive para o desenvolvimento de projetos futuros. A documentação permite o registro de lições aprendidas e pode evitar o retrabalho (DUTOIT et al., 2006).

\subsection{Considerações finais}

Neste capítulo foram apresentados os conceitos que estão envolvidos na fundamentação teórica dos estudos desenvolvidos nesta tese.

O conhecimento tem demonstrado ser um fator decisivo para desenvolver aplicações Web acessíveis, tornando-se o foco das organizações para um melhor gerenciamento de todo o processo de desenvolvimento, envolvendo a tomada de decisões de forma constante.

O uso da Engenharia Web, MDD e DR foram utilizados como apoio completar ao desenvolvimento da abordagem de apoio a boas práticas para desenvolvimento de aplicações Web acessíveis, a qual é o objetivo final desta tese. Em específico, o conceito de DR foi selecionado, para auxiliar no uso e registro de decisões e técnicas em relação à acessibilidade na Web, uma vez que se pretende formar uma base útil para a gestão do conhecimento de projeto e reutilização de artefatos por equipes de desenvolvimento.

No próximo capítulo são apresentados os trabalhos relacionados de modo a identificar o que já tem sido feito na área e quais são as lacunas existentes. 


\section{Trabalhos relacionados}

\subsection{Considerações iniciais}

Nesta seção são apresentados, resumidamente e em ordem cronológica, os trabalhos relacionados referentes a estratégias que podem ser utilizadas para o desenvolvimento Web com acessibilidade, tais como abordagens, métodos e frameworks. Também são apontadas as diferenças conceituais desses trabalhos com a abordagem proposta nesta tese.

O critério para inclusão de trabalhos nesse capítulo foi selecionar aqueles que, de alguma forma, sugerem a incorporação de boas práticas para desenvolvimento Web que propiciem melhoria do quadro de acessibilidade, as quais podem envolver questões de treinamento, melhoria no ferramental e modelos de desenvolvimento.

Este capítulo é organizado da seguinte forma. Nas Seções de 3.2 a 3.8 são apresentados os trabalhos relacionados de forma sequencial. Na Seção 3.9 são ressaltadas as considerações finais, referentes a observações relevantes que foram utilizadas para o desenvolvimento da abordagem. Este estudo, sobre os trabalhos relacionados, foi necessário 
para que a tese, aqui apresentada, fosse desenvolvida baseada em contribuições originais e pertinentes, advindas de pesquisas já validadas.

\subsection{Uma abordagem para anotação semântica de elementos presentes em páginas da Web}

Plessers et al. (2005) ressaltam que a maioria dos sites não são acessíveis para usuários com deficiência visual por conta da falta de descrição para os elementos não textuais. Apesar de que o cenário possa ter mudado durante os últimos anos (2005-2012), esse trabalho ainda é relevante para esta tese devido às considerações sobre acessibilidade para desenvolvimento de uma abordagem para automatizar a geração de anotação semântica para usuários com deficiência visual.

Assim, os autores apresentam uma abordagem baseada na Engenharia Web para apoio à acessibilidade Web, em que as anotações necessárias para ajudar os usuários com deficiência visual são geradas no momento de desenvolvimento.

Para tanto, os elementos presentes em páginas são analisados durante a criação Web, sendo apoiada e automatizada essa boa prática de geração de anotações para auxiliar usuários com deficiência visual. Para viabilizar e facilitar essas anotações, o conhecimento semântico adquirido é explorado e descrições de elementos são geradas como um subproduto do processo de desenvolvimento, evitando haver esforço extra do desenvolvedor.

A abordagem proposta resolve as desvantagens das anotações manuais, visto que a geração de anotações é apoiada sistematicamente, não havendo custos adicionais. Além disso, o problema de manutenção é resolvido, haja vista que as alterações em um site são realizadas por meio de uma nova iteração do processo de Engenharia Web, que resulta na geração de elementos que incluem as anotações. Finalmente, problemas típicos com anotações manuais para páginas dinâmicas são eliminados, uma vez que a abordagem não faz uma distinção entre sites estáticos ou dinâmicos. 


\subsection{Um framework de aplicação das diretrizes WCAG no mundo real}

Kelly et al. (2005) propõem um framework para auxílio ao uso de diretrizes de acessibilidade, o qual tem como base a utilização de experiências exaustivas de desenvolvedores, objetivando acomodar a diversidade de usuários.

Um ponto interessante relatado é que a acessibilidade não pode ser tratada de forma isolada em relação a outros fatores, incluindo usabilidade e fatores locais, sendo que isso contribui significativamente para o sucesso da concepção de aplicações Web.

Durante o desenvolvimento desse estudo em 2005, as diretrizes WCAG ainda estavam na versão 1.0 e, apesar dos autores reconhecerem a importância dessas diretrizes, eles apresentam um resumo das principais discussões e problemas em relação ao seu uso:

- A natureza teórica das diretrizes, sendo distantes das práticas do mundo real e havendo pouco destaque para tecnologias não W3C;

- Dependência a outras diretrizes da WAI;

- Ambiguidade e complexidade das diretrizes;

- Natureza fechada das diretrizes, requerendo o uso de formatos W3C. As diretrizes também falham no conhecimento dos benefícios providos pelo ambiente do sistema operacional; e

- Um nível mínimo de entendimento de acessibilidade é requerido.

Os autores relatam ainda que é essencial uma avaliação manual de acessibilidade nos sites, sendo essa ação crucial para uma boa verificação do que foi desenvolvido.

A organização desse framework é baseada no oferecimento de recomendações de mais alto nível, denominadas camadas (layers), as quais são apresentadas a seguir:

- Contexto: deve ser verificado qual o contexto de utilização da aplicação Web, não existindo uma única solução que atenda a todos os projetos, chamada pelos autores de "one size-fits all";

- Políticas: deve abranger áreas como normas técnicas, usabilidade, acessibilidade e as finanças do gerenciamento de projetos; 
- Seleção: deve haver uma metodologia clara para se escolher padrões e as melhores práticas aplicáveis ao contexto particular do projeto;

- Conformidade: deve ser garantido que os padrões selecionados sejam bons e que as melhores práticas estejam sendo implementadas corretamente; e

- Fatores externos: é necessário considerar uma variedade de fatores externos que influenciam no desenvolvimento. Regras organizacionais e legislação vigente são exemplos comuns de fatores externos que devem ser considerados.

\subsection{Um modelo de processo para Design Inclusivo de Sistemas de Informação na Web}

Melo e Baranauskas (2006) apresentam um modelo de processo para Design Inclusivo de Sistemas de Informação na Web, focando na participação do usuário em espaços colaborativos de desenvolvimento para a concepção, proposição e avaliação de sistemas e suas interfaces.

Esse modelo de processo utiliza como referência o metamodelo de processo sugerido em OMG (2005), composto por atividades, em que considerações de acessibilidade são inseridas.

Melo e Baranauskas (2006) discorrem que é fundamental haver o diálogo entre designers e os diferentes usuários do produto em desenvolvimento, ocorrendo no modelo de processo a articulação de conceitos e práticas de disciplinas distintas como Semiótica Organizacional, Interação Humano-Computador e Engenharia de Software. O modelo de processo proposto foi baseado nos seguintes compromissos:

- Promoção da qualidade no uso de sistemas de informação na Web a partir de um entendimento da inclusão e das diferenças dos usuários;

- Entendimento dos sistemas de informação de forma abrangente;

- Consideração da diversidade de contextos e situações de uso da tecnologia;

- Reconhecimento e valorização das diferenças entre os usuários em suas capacidades perceptuais, cognitivas e motoras;

- Apoio no desenvolvimento sistemático e iterativo de sistemas de informação acessíveis na Web, com a utilização de métodos e técnicas adequados; 
- Participação dos usuários em espaços colaborativos de desenvolvimento: na concepção, na proposição e na avaliação de sistemas Web inclusivos;

- Promoção da participação das partes interessadas com base na igualdade de direitos e respeito mútuos; e

- Consideração de recomendações do W3C no desenvolvimento Web.

Em relação à organização de suas atividades, o modelo de processo apresenta uma divisão das atividades em nove disciplinas:

i) Clarificação do Problema;

ii) Requisitos de Sistema de Informação;

iii) Design de Interface do Usuário;

iv) Design de Sistema de Software;

v) Implementação;

vi) Verificação e Validação;

vii) Avaliação de Interface de Usuário;

viii) Implantação; e

ix) Gerência de Projeto.

\subsection{Um modelo de desenvolvimento focado na avaliação contínua de acessibilidade}

Abou-zahra (2008) apresenta um modelo de desenvolvimento focado na avaliação de acessibilidade em diferentes fases do processo de desenvolvimento Web, em que correções são feitas por etapas a partir de verificações nos desenvolvimentos.

De forma detalhada, as avaliações não devem se limitar à fase de produção, pois há geração de conteúdo Web após o produto ter sido liberado, contribuindo com a aplicação em geral, mas podendo incorporar contraposições às diretrizes de acessibilidade estabelecidas durante o desenvolvimento.

Desse modo, as avaliações devem percorrer todo o período de existência das aplicações, a fim de garantir procedência nos requisitos. Por exemplo, há muitos sites que possibilitam que usuários insiram ou modifiquem o conteúdo, como Wikis, blogs, fóruns e 
demais aplicações interativas. $\mathrm{O}$ gerenciamento de informações pelos usuários aumenta o desafio em se garantir acessibilidade, por depender de uma avaliação contínua ou restrição regrada na inserção e alteração desse conteúdo.

Para essas avaliações o autor sugere ainda que haja a combinação de diferentes técnicas de inspeções e testes de acessibilidade Web, para que se tenham resultados mais efetivos no apontamento de barreiras para o acesso de pessoas com deficiência. Essas técnicas são detalhadas nas subseções a seguir.

\subsubsection{Avaliação com ferramentas automatizadas}

A avaliação de acessibilidade com a utilização de ferramentas automatizadas é expressivamente importante pelo seu poder de atuação sistemático e apoiado em algoritmos computacionais, permitindo avaliações relativamente rápidas, com execução do processo de análise de conteúdo Web, processamento e resposta avaliativa.

Nesse tipo de avaliação alguns aspectos devem ser especialmente considerados, como:

- A estrutura organizacional, incluindo o processo de desenvolvimento adotado pela organização em que se deseja realizar a avaliação (para integração nas atividades de desenvolvimento); e

- A complexidade e o tamanho do site a ser avaliado.

A escolha das ferramentas depende diretamente das características do ambiente de desenvolvimento, já que algumas funcionam como extensões ou plug-ins em ferramentas de autoria ou navegadores.

Outra questão que deve ser observada para a seleção de ferramentas é a exportação dos dados, devendo ser considerado o formato da saída dos dados da avaliação, com possibilidade de exportação desses dados em diferentes formatos, seja em documentos gerenciais (com tratamento dos dados e exibição de informações estatísticas) ou em formatos para uso computacional, como em XML, para uma possível inserção das informações em bases de dados. 


\subsubsection{Inspeção manual realizada por especialistas em acessibilidade Web}

Embora os testes feitos por ferramentas automatizadas sejam de grande valia para identificar falhas rapidamente, estes devem servir apenas como suporte na avaliação. A análise humana é essencial para validar os resultados apresentados e aprimorar a avaliação em relação à acessibilidade, visto que em expressivos casos as ferramentas automatizadas não são capazes de discernir entre a conformidade ou não de critérios ergonômicos.

Abou-zahra (2008), então, discorre sobre a importância dos especialistas de acessibilidade Web para inspeção nos artefatos desenvolvidos, visto que esses são indivíduos com bom conhecimento para identificar as inúmeras questões de acessibilidade que devem ser interpretadas para checagens de existência (ou não) de barreiras de acessibilidade. Eles também devem atuar para auxiliar na correção e verificação dos artefatos em que os problemas foram constatados e, assim, adotar um ciclo de análise e ajuste que auxilie no processo de desenvolvimento.

\subsubsection{Teste com usuários}

Os testes feitos com usuários, se bem realizados, melhoram as avaliações e servem como complemento às duas técnicas já apresentadas nas subseções anteriores. Usuários representantes das diversas categorias de gênero, idade ou deficiências devem participar do teste para que possam haver resultados realmente abrangentes, com relação a verificação de problemas de acessibilidade nas aplicações Web.

Alguns métodos para testes com usuários podem ser considerados, como por exemplo o uso de medidas de desempenho, registro de ações do usuário, aplicação de questionários e observação direta do comportamento do usuário.

Em qualquer teste que envolva usuários finais, é preciso classificar os perfis de cada um, a fim de evitar conclusões infundadas e precipitadas diante de dificuldades apresentadas por eles na utilização de uma aplicação Web. 


\subsection{Um processo para o desenvolvimento de aplicações Web acessíveis}

Maia (2010) apresenta um processo para o desenvolvimento de aplicações Web acessíveis, o qual é composto por uma coleção de tarefas de acessibilidade inseridas nos subprocessos da Norma ISO/IEC 12.207 (IEEE/EIA 12.207.0-1996, 1998), intitulado como Modelo de Tarefas de Acessibilidade (MTA).

A Norma ISO/IEC 12.207 oferece um padrão para desenvolvimento de software, que contém um conjunto de processos categorizados em fundamentais, de apoio, organizacionais e de adaptação. Nesse âmbito, o foco do MTA é inserir considerações de acessibilidade nos processos da categoria fundamentais dessa norma, dentro dos subprocessos de desenvolvimento.

Para apoio ao MTA foram realizadas significativas modificações no "Pantaneiro", que é um framework para a geração de aplicações Web no domínio de E-Gov (cujo projeto teve início em 2005) (SANDIM, 2009). A motivação para essas modificações envolveu o fato de que as páginas geradas pelo Pantaneiro apresentavam problemas de acessibilidade, tais como: menu inacessível pelo teclado, imagens sem descrição textual e código HTML fora dos padrões estabelecidos pelo W3C.

O MTA engloba tarefas que vão desde a elicitação de requisitos até o teste do sistema. Essa concepção é válida e oportuna, pois existem considerações de acessibilidade em todas essas etapas do desenvolvimento de aplicações Web. Adicionalmente, são especificadas também, nas tarefas desse modelo, associações com as diretrizes WCAG 2.0 (nível A), propiciando um relacionamento interessante e promissor.

Como exemplificação do que é tratado no MTA, são definidas duas importantes tarefas consecutivas. A primeira é o projeto de interfaces acessíveis, sendo subdividida em três subtarefas: i) definir os elementos que irão compor a interface; ii) estabelecer a disposição dos elementos na interface; e iii) definir as cores dos elementos. A segunda tarefa é o projeto navegacional acessível, que tem como objetivo fazer com que os elementos que compõem a interface possam ser localizados, navegados e compreendidos corretamente. 


\subsection{Uma abordagem colaborativa para testes e melhorias de acessibilidade em sites governamentais}

Nietzio et al. (2010) apresentam uma abordagem colaborativa para projetos Web de governo eletrônico, chamada eGovMon, que visa realizar aferição de alto nível com testes e melhorias de acessibilidade, que são implementadas como correções em um site. De forma resumida, essa abordagem conta com os seguintes pilares:

- Um verificador on-line, chamado eAccessibility Checker, que fornece avaliações detalhadas de acessibilidade de páginas Web;

- Um fórum, chamado eGovMon Forum, para mantenedores de sites de municípios, especialistas em acessibilidade Web e desenvolvedores; e

- A publicação de relatórios de benchmarking de sites governamentais, que permitem a avaliação dos progressos (ou regressos) ao longo do tempo.

O fórum de discussão está organizado em estreita colaboração com o governo norueguês no sentido de fortalecer recursos e incentivar o projeto, permitindo a importante participação de especialistas em acessibilidade, a fim de enriquecer as discussões sobre medidas e análises sobre os relatórios disponibilizados. Permitindo, assim, um melhor aproveitamento dos resultados de pesquisa por outros municípios noruegueses. Como evolução para esse fórum, os autores sugerem que no futuro possa ser formada uma verdadeira comunidade on-line, com incremento de recursos.

Além da disponibilização de um fórum de discussão, há outros elementos na abordagem no sentido de melhorar a formação em acessibilidade dos envolvidos no projeto Web. Dentre esses elementos é importante relatar o oferecimento de seminários de formação para treinamento em tecnologias relacionadas à linguagem HTML, incluindo a sensibilização para os malefícios causados pela presença de barreiras de acessibilidade e a apresentação de técnicas para melhorar a acessibilidade.

Outra ação importante, descrita nessa abordagem, é a análise de modelos de geração de páginas dos gerenciadores de conteúdo utilizados pelos autores dos sites. Para tanto, esses modelos, para diferentes sistemas, são analisados por especialistas de acessibilidade Web, 
que identificam problemas de acessibilidade em potencial e descrevem uma possível correção.

\subsection{AWA, um suporte metodológico flexível para desenvolvimento de aplicações Web acessíveis}

López (2010) ressalta que, para tratar acessibilidade, não basta apenas seguir estritamente as diretrizes WCAG, em relação a aspectos técnicos de implementação. É necessário considerar a arquitetura das aplicações e integrar usabilidade e acessibilidade no desenvolvimento de software Web.

Para tanto, é proposto um framework chamado Acessibility for Web Application (AWA), o qual oferece um suporte metodológico flexível para desenvolvimento de aplicações Web acessíveis. Suas regras prezam pela incorporação do design centrado no usuário e design inclusivo em todo o ciclo de vida do desenvolvimento da aplicação Web.

De acordo com a autora, a flexibilidade do AWA advém, principalmente, de sua característica de não integração a métodos tradicionais de desenvolvimento, como o descrito no modelo de processo de software padrão ISO/IEC 12.207, portanto, a proposta deste framework baseou-se em um processo genérico.

O AWA é estruturado em modelos e regras, com base nas diretrizes WCAG, sendo composto por mecanismos (chamados de $A W A \_$Mecanismos $W C A G$ ) e requisitos (chamados de $A W A \_$RequisitosWCAG). Estes são considerados como atuantes no desenvolvimento desde o início das atividades de análise e projeto, incluindo, intrinsecamente, requisitos na modelagem de aplicações Web acessíveis.

A atividade de análise começa com a extração de informações do domínio da aplicação desejada, a partir da identificação e registro de requisitos. Dessa extração é deveras importante se estabelecer uma classificação de requisitos específicos que impactam na acessibilidade da aplicação, tais como a forma, o conteúdo, os usuários e as facilidades de navegação que serão providos. 


\subsection{Considerações finais}

Neste capítulo foram apresentados os trabalhos relacionados com a concepção da abordagem desenvolvida nesta tese. Estes foram importantes para a verificação de pontos positivos e diferenciais a serem incluídos no escopo desta pesquisa.

Assim, os trabalhos relacionados, suas principais contribuições, diferenciações e os itens correspondentes aos considerados nesta tese são:

- Trabalho: Uma abordagem para anotação semântica de elementos presentes em páginas da Web (PLESSERS et al., 2005).

- Contribuições: demonstra a perspectiva de inclusão do apoio a uma boa prática para desenvolvimento Web integrada no processo de desenvolvimento, indicando benefícios nessa visão.

- Itens tratados nesta tese: reconhecimento de que é possível e importante a inclusão de recursos de provimento de acessibilidade em ferramentas diretamente no processo de desenvolvimento.

- Diferenciação com esta tese: não trata diretamente outros aspectos e problemas de acessibilidade (o trabalho foca apenas no provimento de alternativas textuais durante o desenvolvimento de artefatos Web), também não foca em treinamento da equipe envolvida, em relação ao uso de diretrizes de acessibilidade.

- Trabalho: Um framework para auxílio no uso de diretrizes de acessibilidade (KELLY et al., 2005).

- Contribuições: apresenta a percepção de que acessibilidade não pode ser tratada de forma isolada de outros fatores, incluindo usabilidade e fatores locais. Também valoriza a importância das avaliações manuais de acessibilidade para um bom resultado do software desenvolvido.

- Itens tratados nesta tese: a camada "Seleção" do framework se assemelha com a abordagem proposta nesta tese nas atividades de gerência de decisões, pois também há a preocupação em relação às determinadas escolhas que devem ser feitas durante as ações de apoio a práticas para desenvolvimento de aplicações Web, considerando requisitos de acessibilidade. Da mesma 
forma, é tratada a preocupação com o desenvolvimento e ferramentas na camada "Conformidade", pois são evidenciadas considerações acerca de como se realizar a implementação das práticas e padrões selecionados.

- Diferenciação com esta tese: a organização desse framework é diferente da abordagem proposta, não sendo apresentadas as atividades detalhadas.

- Trabalho: Um modelo de processo para Design Inclusivo de Sistemas de Informação na Web (MELO e BARANAUSKAS, 2006).

- Contribuições: apresenta as vantagens do design inclusivo para Web, focando na participação do usuário.

- Itens tratados nesta tese: o espaço colaborativo para agregação de conhecimento e as propostas relativas à avaliação de acessibilidade contínua, elicitação de requisitos de acessibilidade e gerência de projeto, incluindo o apoio à tomada de decisões.

- Diferenciação com esta tese: existe uma distinção conceitual entre esse modelo de processo e a abordagem proposta nesta tese, não havendo conflitos, mas sim um nível de detalhamento e escopo diferente, visto que a abordagem desta tese tem um foco complementar em ferramentas, desde a escolha de ambientes até o treinamento da equipe.

- Trabalho: Um modelo de desenvolvimento focado na avaliação contínua de acessibilidade (ABOU-ZAHRA, 2008).

- Contribuições: ressalta a importância da avaliação de acessibilidade em diferentes fases do processo de desenvolvimento Web, em que correções são feitas por etapas a partir de verificações nos desenvolvimentos.

- Itens tratados nesta tese: o reconhecimento do monitoramento de acessibilidade com diferentes modalidades de verificações para garantia de qualidade no provimento de artefatos acessíveis.

- Diferenciação com esta tese: tal modelo difere do foco da abordagem proposta, não contemplando, por exemplo, as atividades de treinamento da equipe. Também não é apresentando diretamente como devem ser tratados o reuso e o apoio ferramental, utilizados para facilitar o trabalho da equipe de desenvolvimento. 
- Trabalho: Um processo para o desenvolvimento de aplicações Web acessíveis (MAIA, 2010).

- Contribuições: apresenta uma rica coleção de tarefas de acessibilidade, que permitiram um bom embasamento para a proposta desta tese.

- Itens tratados nesta tese: as vantagens e necessidade de prover um suporte metodológico para o processo de desenvolvimento.

- Diferenciação com esta tese: está relacionada diretamente ao uso da Norma ISO/IEC 12.207 no MTA e a não utilização da ideia do compartilhamento de conhecimento e reuso de código.

- Trabalho: Uma abordagem colaborativa para projetos Web de governo eletrônico (NIETZIO et al., 2010).

- Contribuições: enfatiza a necessidade da participação de especialistas em acessibilidade em discussões sobre experiências e dúvidas da equipe de desenvolvimento.

- Itens tratados nesta tese: a ideia de provimento de espaços on-line, como o fórum citado no trabalho, é aproveitada nesta tese para o desenvolvimento de uma ferramenta de colaboração de experiências.

- Diferenciação com esta tese: o foco do trabalho é em E-Gov, sendo essa a principal diferença.

- Trabalho: AWA, um suporte metodológico flexível para desenvolvimento de aplicações Web acessíveis (LÓPEZ, 2010).

- Contribuições: considera o tratamento da arquitetura das aplicações como uma atividade importante, integrando usabilidade e acessibilidade no desenvolvimento de software Web.

- Itens tratados nesta tese: a consideração do uso de modelos como meio de apoio ferramental para adoção efetiva de diretrizes de acessibilidade, permitindo a definição de regras e restrições para auxílio no momento de desenvolvimento e geração de código.

- Diferenciação com esta tese: não são tratadas questões relacionadas ao reuso de componentes, gerência de decisões e a importância dada ao treinamento 
dos desenvolvedores e colaboração dos mesmos entre si, como é apresentado na abordagem desta tese.

Assim, com a verificação desses trabalhos relacionados, fica nítida a percepção de que há diferentes objetivos e focos em cada estratégia proposta para o desenvolvimento com acessibilidade, tratando as várias questões (frequentemente complexas) para melhoria do cenário atual.

Observa-se também que há uma evolução contínua nas propostas, sendo que em todas existem contribuições oportunas e promissoras, em diferentes escopos, sempre visando um melhor desenvolvimento Web, considerando questões de acessibilidade.

No próximo capítulo tem-se a apresentação do desenvolvimento e resultados da condução de estudos de caso, objetivando coletar dados para a criação da abordagem. 


\section{Estudos de caso}

\subsection{Considerações iniciais}

Como previamente apresentado, esta tese visa desenvolver uma abordagem que auxilie na adoção de boas práticas para o desenvolvimento de aplicações Web acessíveis. Para alcançar tal objetivo, neste capítulo são descritos estudos de caso que foram realizados para coleta de dados empíricos sobre como são consideradas as diretrizes de acessibilidade no processo de desenvolvimento de aplicações Web.

Os estudos de caso executados têm como base os fundamentos analisados neste trabalho, apresentados no capítulo anterior, e se referem a experimentações práticas para diagnóstico de cenários de adoção de boas práticas para desenvolvimento Web, incluindo a verificação da possibilidade de apoio ao desenvolvedor na consideração das diretrizes de acessibilidade no momento do desenvolvimento ou quando usa ferramentas de autoria. A partir de analisadas as considerações resultantes desses estudos de caso, pôde-se criar uma 
base sólida de viabilidade e estratégias práticas para o desenvolvimento da abordagem proposta.

Este capítulo está organizado da seguinte forma: na Seção 4.2 têm-se uma visão geral dos estudos de caso realizados e na Seção 4.3 é descrito o primeiro estudo de caso desenvolvido, o qual envolve a verificação da existência de barreiras de acessibilidade em sites de prefeituras municipais brasileiras. Na Seção 4.4 é apresentado um editor gráfico desenvolvido nesta tese, o qual permite o uso de modelos para aferição de validações em tempo de desenvolvimento e apresentação de alertas ao desenvolvedor sobre possíveis problemas em relação a artefatos com barreiras de acessibilidade. A forma de persistência dos modelos e a possibilidade de realização de transformações são mostradas na Subseção 4.4.2. Na Seção 4.5 é apresentado o terceiro estudo de caso desenvolvido, no qual foi utilizado MDD para estruturação gráfica de uma Wiki com geração de código acessível. Por fim, na Seção 4.6, são apresentadas as considerações finais em relação aos três estudos de caso realizados.

\subsection{Visão geral dos estudos de caso}

Para apresentação dos estudos de caso realizados, no Quadro 4.1 é exibida uma visão geral desses estudos que resume a descrição, o objetivo, os conceitos envolvidos, a relação com a abordagem proposta e as tecnologias de software utilizadas em cada um dos estudos de caso.

Quadro 4.1 - Visão geral dos estudos de caso

\begin{tabular}{|l||l|l|l|}
\hline & Estudo de caso 1 & Estudo de caso 2 & Estudo de caso 3 \\
\hline Descrição & $\begin{array}{l}\text { Diagnóstico de } \\
\text { acessibilidade em sites } \\
\text { das prefeituras } \\
\text { municipais brasileiras. }\end{array}$ & $\begin{array}{l}\text { Criação de um editor } \\
\text { gráfico, usando MDD, } \\
\text { como prova de conceito } \\
\text { para apoio em } \\
\text { acessibilidade. }\end{array}$ & $\begin{array}{l}\text { Uso de MDD na } \\
\text { estruturação de uma Wiki } \\
\text { com geração de código } \\
\text { acessível. }\end{array}$ \\
\hline Objetivo & $\begin{array}{l}\text { Investigar de forma } \\
\text { automática os sites das } \\
\text { prefeituras municipais } \\
\text { brasileiras em relação à } \\
\text { presença de barreiras de } \\
\text { acessibilidade. }\end{array}$ & $\begin{array}{l}\text { Verificar se é possível um } \\
\text { apoio a boas práticas de } \\
\text { desenvolvimento com } \\
\text { alertas e restrições a partir } \\
\text { de ambientes que realizam } \\
\text { verificações a modelos para } \\
\text { checagens de diretrizes de } \\
\text { acessibilidade. }\end{array}$ & $\begin{array}{l}\text { Verificar se modelos } \\
\text { gráficos, com o uso de } \\
\text { padrões Web, podem ser } \\
\text { úteis para apoio em } \\
\text { ferramentas de gerência } \\
\text { de conteúdo Web (como } \\
\text { Wikis), gerando conteúdo } \\
\text { acessível. }\end{array}$ \\
\hline
\end{tabular}




\begin{tabular}{|c|c|c|c|}
\hline $\begin{array}{l}\text { Conceitos } \\
\text { envolvidos }\end{array}$ & $\begin{array}{l}\text { Diretrizes de } \\
\text { acessibilidade para Web } \\
\text { e verificação } \\
\text { automática com uso de } \\
\text { métrica. }\end{array}$ & $\begin{array}{l}\text { Diretrizes de acessibilidade } \\
\text { para Web, MDD e } \\
\text { ambientes de autoria. }\end{array}$ & $\begin{array}{l}\text { Diretrizes de } \\
\text { acessibilidade para Web, } \\
\text { padrões Web, MDD e } \\
\text { ambientes de autoria. }\end{array}$ \\
\hline $\begin{array}{l}\text { Relação } \\
\text { com a } \\
\text { abordagem } \\
\text { proposta }\end{array}$ & $\begin{array}{l}\text { Permite a verificação de } \\
\text { cenário da abordagem, } \\
\text { justificando a } \\
\text { necessidade da } \\
\text { melhoria no apoio a } \\
\text { práticas de } \\
\text { desenvolvimento de } \\
\text { aplicações Web } \\
\text { acessíveis. } \\
\text { Pode-se ver casos reais } \\
\text { que a avaliação trata e o } \\
\text { estudo de métricas, } \\
\text { mostrando subsídios } \\
\text { para a criação da fase } \\
\text { de avaliação contínua } \\
\text { da abordagem proposta. }\end{array}$ & $\begin{array}{l}\text { Permite o contato com } \\
\text { tecnologias de MDD, como } \\
\text { metamodelagem e geração } \\
\text { de um rico editor gráfico } \\
\text { que possibilita checagens a } \\
\text { considerações de } \\
\text { acessibilidade. } \\
\text { Demonstra a possibilidade } \\
\text { de uso desses recursos } \\
\text { sendo adaptados para } \\
\text { organizações. } \\
\text { Revela também o que pode } \\
\text { ser feito em ferramentas de } \\
\text { autoria para auxílio ao } \\
\text { desenvolvedor. }\end{array}$ & $\begin{array}{l}\text { Permite a verificação da } \\
\text { possibilidade de se } \\
\text { integrar recursos de } \\
\text { MDD a softwares já } \\
\text { existentes, como } \\
\text { gerenciadores de } \\
\text { conteúdo Web, incluindo } \\
\text { o aproveitamento de } \\
\text { padrões Web. } \\
\text { Assim, exemplifica como } \\
\text { podem ser providas } \\
\text { facilidades ao usuário. } \\
\text { Sendo isso tratado na } \\
\text { abordagem proposta no } \\
\text { âmbito de suporte } \\
\text { ferramental. }\end{array}$ \\
\hline $\begin{array}{l}\text { Tecnologias } \\
\text { de software } \\
\text { utilizadas }\end{array}$ & $\begin{array}{l}\text { PHP, HTTrack, Hera } \\
\text { metrics e WAB. }\end{array}$ & $\begin{array}{l}\text { Eclipse GMF, Ecore, Java, } \\
\text { XMI e RCP. }\end{array}$ & $\begin{array}{l}\text { PHP, Dokuwiki, Eclipse } \\
\text { GMF, XMI e JET. }\end{array}$ \\
\hline
\end{tabular}

A descrição detalhada dos passos metodológicos, tecnologias e resultados obtidos nos três estudos de caso realizados é apresentada nas próximas seções.

\subsection{Estudo de caso 1 - Diagnóstico de acessibilidade em sites das prefeituras municipais brasileiras}

No Brasil, o Decreto Lei 5.296/2004 de dezembro de 2004 estabeleceu que, no período de um ano, todos os sites governamentais deveriam se adequar às normas estabelecidas para atender requisitos de acessibilidade. No entanto, pôde-se observar que, na prática, o cenário encontrado não é o esperado. Esta constatação foi a motivação para a proposta e execução de um estudo de caso para investigar os sites das prefeituras municipais brasileiras em relação à presença de barreiras de acessibilidade.

A realização deste primeiro estudo de caso contou com a utilização da ferramenta EGOVMeter, desenvolvida durante o mestrado do autor desta tese (BITTAR, 2006). Tal 
ferramenta é um robô de acesso automático a sites (crawler) que realiza estatísticas sobre os sites das prefeituras municipais do Brasil.

Assim, o procedimento utilizado para a realização deste estudo de caso iniciou (Etapa 1) com a obtenção da lista de todas as URLs dos sites das prefeituras encontrados pela execução da EGOVMeter.

A execução da EGOVMeter, em setembro de 2007, foi efetuada a partir de uma lista de 5.551 municípios cadastrados a partir de dados obtidos do IBGE de 2006. Desses municípios, 1.980 deles $(37,67 \%)$ possuíam um site na Web e foram então selecionados para compor a listagem inicial.

Na Etapa 2, realizou-se a avaliação das páginas em dois níveis da hierarquia da navegação, totalizando 26.250 páginas verificadas, que correspondem a uma média de 13,25 páginas por site. A ferramenta HTTrack $^{12}$ foi utilizada para acessar os links das páginas e realizar a cópia dos arquivos a serem avaliados. Em seguida, as avaliações foram feitas por meio do módulo Hera metrics de Freire (2008), sendo esse uma extensão da ferramenta Hera ${ }^{13}$ com inclusão de métricas feitas a partir de diferentes pontos de verificação.

Para execução das etapas consecutivas deste estudo de caso, foi desenvolvido um sistema, o qual atuou como uma ferramenta auxiliar para efetuar o cálculo de resultado a partir do acesso a cada URL de uma base de dados. Adicionalmente, foi computada a métrica Web Accessibility Barrier (WAB) (PARMANTO e ZENG, 2005), em que são contabilizadas as barreiras existentes relativas à acessibilidade de acordo com critérios da WCAG 1.0, com atribuição de pesos a essas, levando também em consideração o número de páginas de um site.

Após calculada a métrica WAB, foram analisados os resultados das médias de acessibilidade para cada uma das cinco regiões geográficas do Brasil. Pôde-se observar que, na média e levando em consideração apenas verificações com análise automática de código, os sites das prefeituras de municípios brasileiros tinham, em 2008, um nível alto de barreiras de acessibilidade, não havendo uma diferença significativa entre as médias das diferentes

\footnotetext{
${ }^{12}$ http://www.httrack.com

${ }^{13}$ http://www.sidar.org/hera/
} 
regiões, ou seja, em todas as regiões existiam de forma quase homogênea problemas de acessibilidade nos sites pesquisados.

Assim, uma constatação desse estudo de caso foi de que mesmo com a existência de diretrizes e da obrigatoriedade de cumprir a legislação, um apoio mais convincente precisava ser apresentado aos responsáveis por projetos Web. Nesse sentido, a abordagem proposta nesta tese considera como elemento essencial a colaboração, melhoria no ferramental e outros apoios a boas práticas de desenvolvimento de aplicações Web acessíveis.

\subsection{Estudo de caso 2 - Editor gráfico, usando MDD, como prova de conceito para apoio em acessibilidade}

Uma prova de conceito, frequentemente denominada na literatura pela sigla $\mathrm{PoC}$, do inglês Proof of Concept, pode ser definida como uma atividade prática com teste curto ou incompleto (sinopse) de um método ou ideia a fim de demonstrar sua viabilidade. Essa atividade tem como objetivo também verificar se algum conceito ou teoria é provavelmente explorável em uma forma útil (GOTTLIEB, 2007; MARTINS, 2007).

Usualmente, uma prova de conceito envolve o desenvolvimento de um protótipo minimalista para mostrar uma ideia ou dispositivo em que se irá trabalhar, verificando, de forma prática, sua viabilidade inicial e a possibilidade de extensão do protótipo para o desenvolvimento final mais abrangente e completo.

Neste segundo estudo de caso, foi desenvolvida uma PoC objetivando verificar se é possível um apoio com alertas e restrições na construção de elementos com acessibilidade a partir de ambientes que realizam verificações a modelos para checagens no desenvolvimento Web (provenientes de padrões e diretrizes) e geração de código acessível. Assim, tem-se como prova de conceito a execução inicial de um detalhamento resumido e desenvolvimento de um editor gráfico em dois níveis de abstração para o desenvolvimento Web, a saber:

- Document Object Model (DOM) Simplificado: modela elementos próximos aos itens de codificação que compõem as páginas (links, páginas, formulários e tabelas). Esses itens representam os detalhes de mais baixo nível, sendo próximo 
aos atributos e estruturas que devem ser vistos na programação manual do código fonte; e

- Padrões Web: modela detalhes de funcionalidades de soluções de sucesso para problemas recorrentes da Web, permitindo sua implementação de forma facilitada.

Assim, foram desenvolvidos exemplos de metamodelos hierárquicos relacionados aos itens expostos para a criação de um editor para modelagem de elementos da Web com a atuação de checagens de acessibilidade.

Essa prova de conceito foi realizada na plataforma Eclipse GMF, sendo que todas as metamodelagens foram desenvolvidas de forma simplificada (para viabilidade desta etapa da pesquisa). As hierarquias dessas metamodelagens são apresentadas na Figura 4.1.

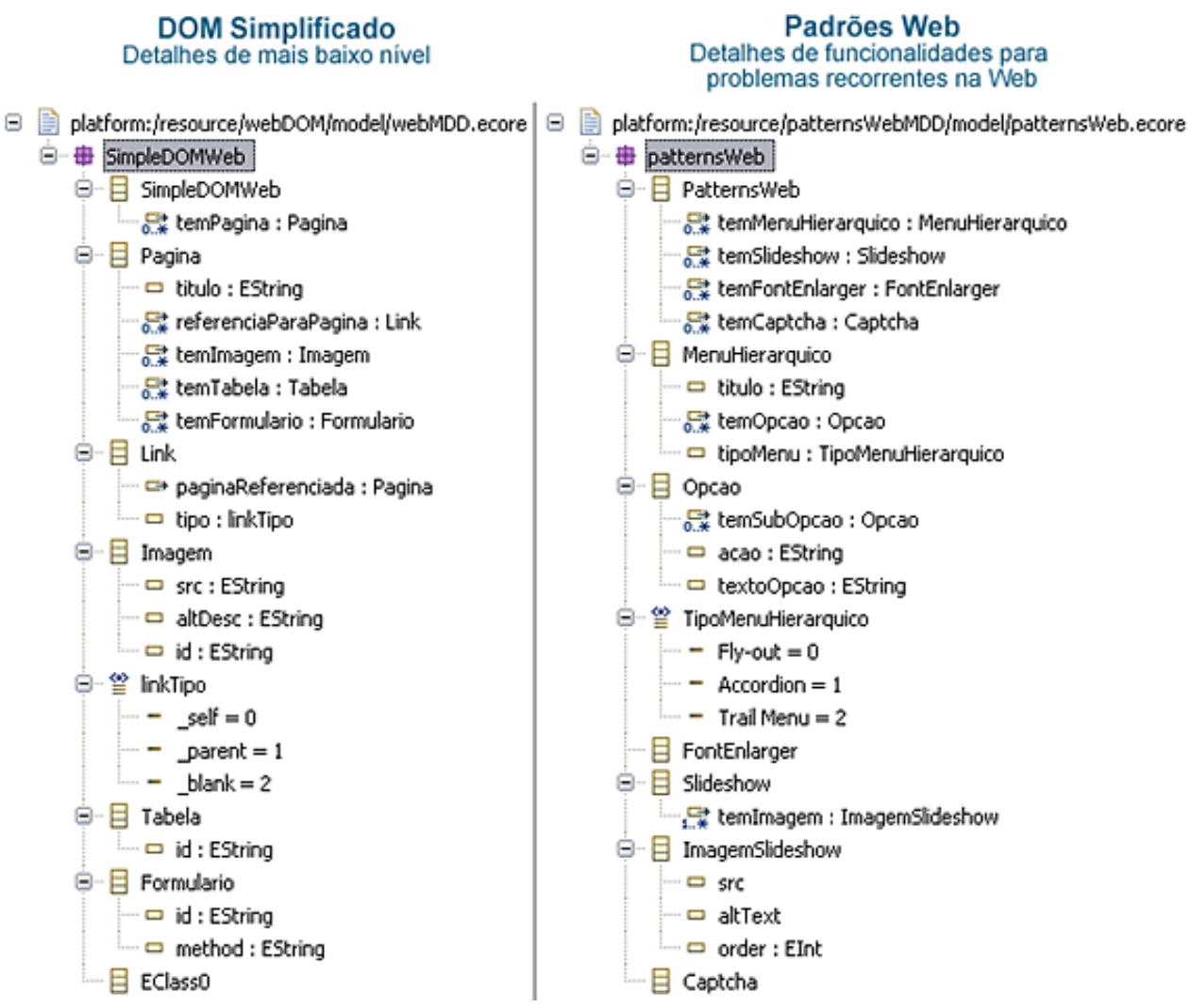

Figura 4.1 - Estruturas em árvore hierárquica de elementos em metamodelos Ecore

Cada metamodelo Ecore (conceito esse apresentado no Capítulo 2), além de poder ser visualizado de forma hierárquica, como mostrado na Figura 4.1, pode ainda ser visto e trabalhado em um diagrama gráfico. Essa diagramação para o DOM Simplificado pode ser vista na Figura 4.2. 


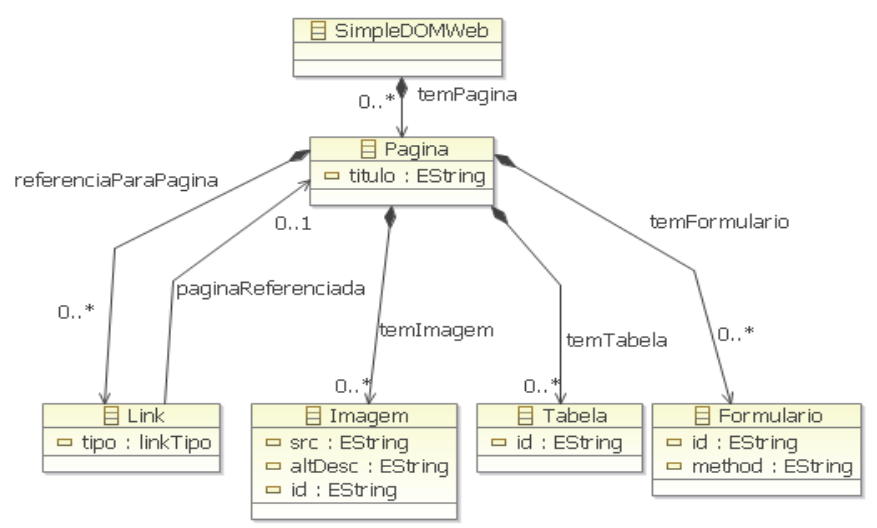

Figura 4.2 - Elementos dispostos em um subconjunto simples do DOM

Nesse diagrama da Figura 4.2 pode ser visto que, para o DOM Simplificado, é possível existir zero ou mais páginas, havendo links entre elas. Ainda é possível ver que uma página pode ter zero ou mais links (que são referências para outras páginas) e o modelo ainda possibilita que cada link tenha no máximo uma página referenciada. A ideia de possibilitar que um link não referencie outra página envolve sua posterior extensão para a utilização de links para disparar eventos (não necessariamente direcionando a navegação para outra página, importante no uso da tecnologia Ajax).

$\mathrm{Na}$ Figura 4.3, apresentada a seguir, visualiza-se a metamodelagem em relação ao nível de abstração composto por padrões Web. Foram modelados então alguns padrões de van Welie como "Slideshow" (exibição de fotos), "FontEnlarger" (gerenciamento do tamanho das fontes tipográficas - importante no campo da acessibilidade), "Captcha" (proteção contra acesso de robôs Web) e "MenuHierarquico" (lista de opções para o tipo de menu hierárquico: “Fly-out”, “Accordion” e "Trail Menu”). Tais padrões foram escolhidos pela sua utilização frequente em sites e também por haverem considerações relevantes de acessibilidade que influenciam na geração de seu código HTML. Um exemplo disso é a geração de menus em que o código deve permitir a escolha de opções com o uso do teclado, por meio da tecla " $t a b$ ". 


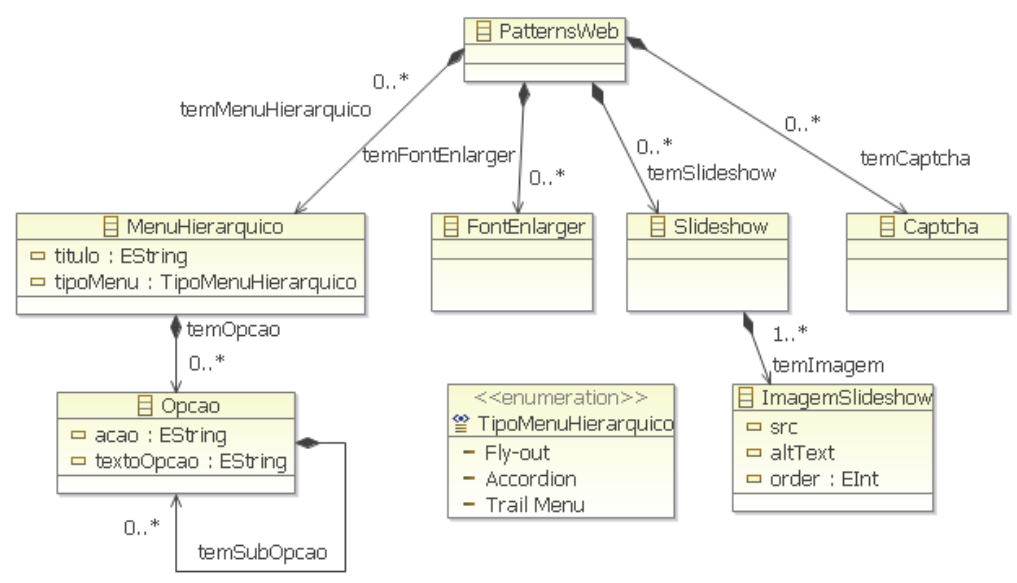

Figura 4.3 - Metamodelo de um conjunto de padrões para Web

Venkatesan (2006) apresenta um estudo de caso semelhante com modelagem gráfica de padrões, no entanto com foco no domínio de padrões de integração, incluindo inserção de regras de validação e especificação da comunicação entre elementos. Seus padrões são divididos em sete categorias: estilos de integração; canais para comunicação; construção de mensagens; roteamento de mensagens; transformações na comunicação; consumo de mensagens e comportamento final de clientes e sistemas de integração.

Outra perspectiva de análise pode ser considerada em relação à modelagem de features acoplando-se conceitos de MDD, como visto em Lucrédio (2009), com foco no reuso e gerenciamento de variabilidades em linhas de produto de software (do inglês Software Product Line - SPL).

\subsubsection{Editor gráfico para modelagem com recursos de validação}

Na Figura 4.4 visualiza-se o editor de diagramas desenvolvido a partir do modelo SimpleDOM. Este editor foi proposto visando verificar a possibilidade de estruturação de navegação em páginas e composição de artefatos Web, com checagens oportunas de acessibilidade em nível de modelo gráfico e posterior geração de código acessível. 


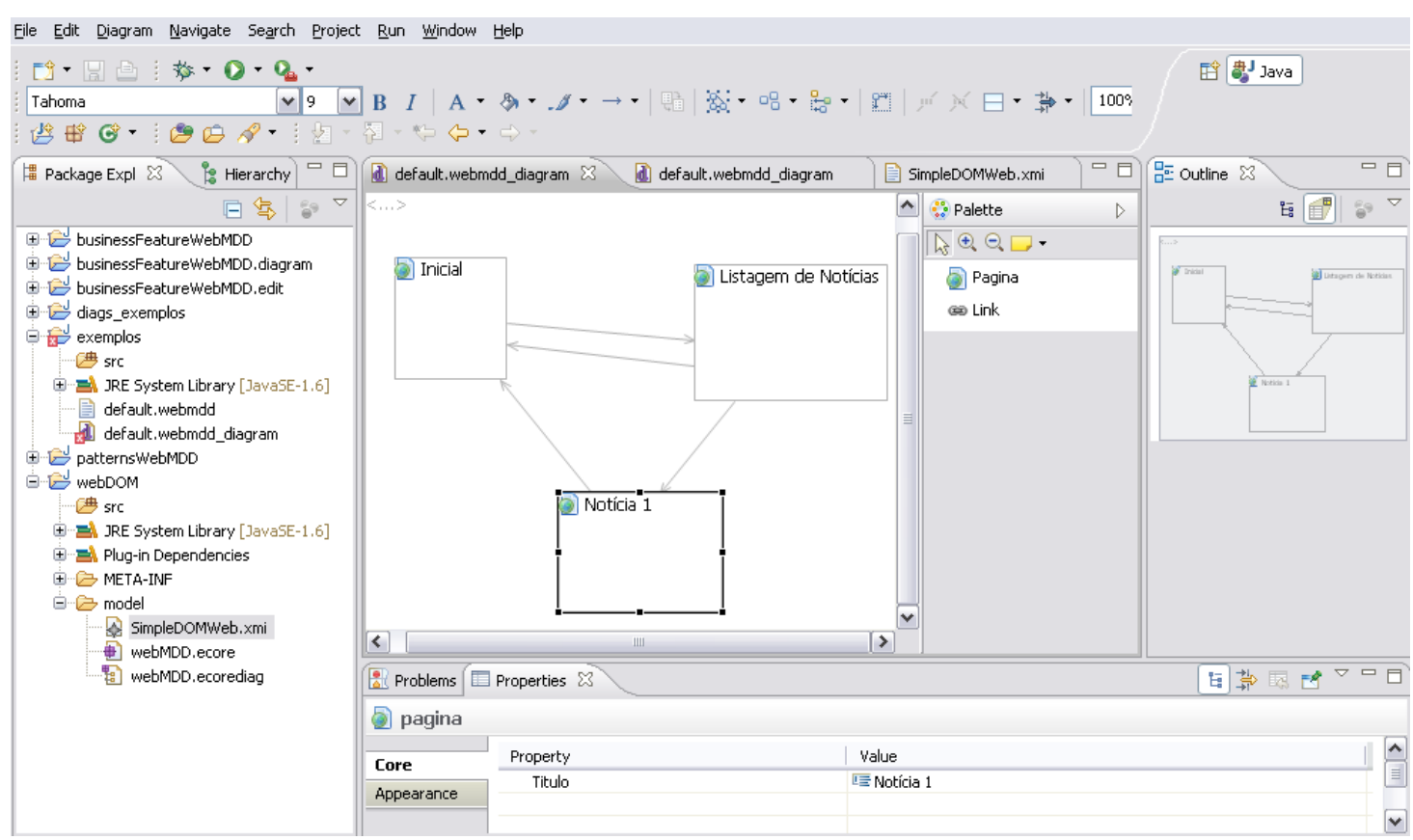

Figura 4.4 - Editor de diagramas para o modelo SimpleDOM, mostrando o primeiro nível de abstração com elementos de navegação

Na Figura 4.4 pode ser visto de modo simples o nível de navegação Web, sendo que ao selecionar um determinado elemento do modelo aparecem os seus atributos na barra de propriedades, localizada no espaço inferior da tela.

A utilização do conceito de subdiagramas em um mesmo modelo foi utilizada no exemplo mostrado na figura. Ao se interagir com duplo clique sobre o ícone de uma página Web, abre-se um novo modelo para inserção de elementos que podem compor tal página (que foi alvo do duplo clique), como formulários, imagens e tabelas.

Pode-se fazer uma analogia entre esse modelo de elementos e os modelos de composição da WebML (CERI et al., 2000) e de estrutura de navegação da UWE (KOCH et al., 2001; KROIß e KOCH, 2008). Mesmo com esse modelo, não é fácil abstrair todos os objetivos de navegação no modelo e transferi-los para o código, o qual contém detalhes complexos.

Na Figura 4.5, a seguir, é apresentado o modelo de elementos que podem compor uma página Web, funcionando como um subdiagrama. Adicionalmente, é apresentado como podem ser feitas checagens de regras de acessibilidade em um determinado modelo. 


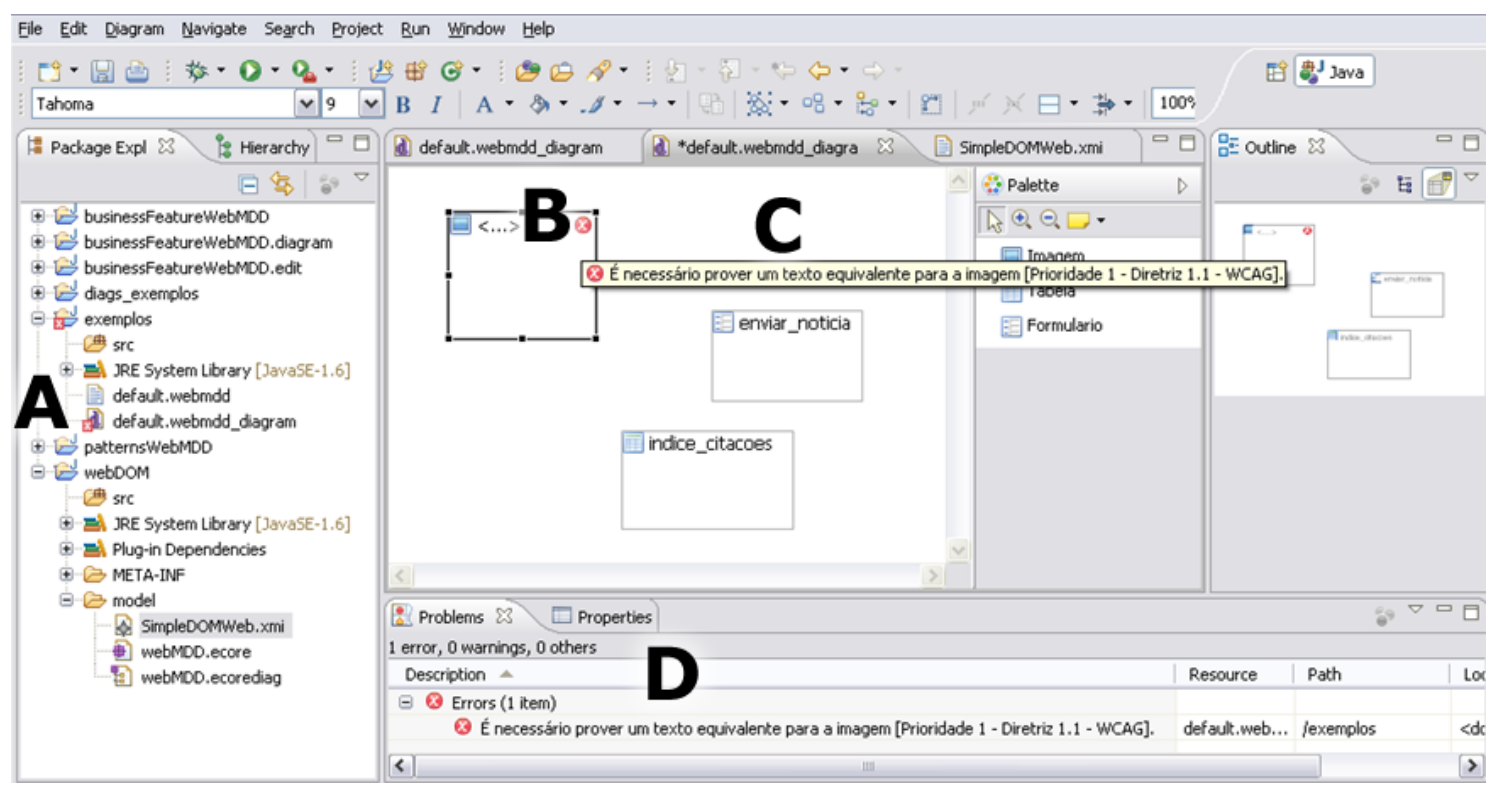

Figura 4.5 - Exemplo de validação do modelo para checagem de uma diretriz de acessibilidade

Com o exemplo da Figura 4.5, pode-se verificar que alertas, quanto à violação da regra de validação para o texto alternativo em imagens, aparecem em 4 pontos: A - na listagem de arquivos no compartimento Package Explorer (à esquerda) o ícone do arquivo fica diferenciado, indicando que tem pelo menos um problema de validação; B - com um ícone $(\mathrm{X})$ ao lado direito do elemento gráfico; $\mathbf{C}$ - ao posicionar o ponteiro do mouse alguns instantes em cima do elemento é exibida uma mensagem sobre a razão do problema e $\mathbf{D}$ - na aba "Problems" com a apresentação de uma listagem desse e de todos os outros problemas que podem ocorrer.

As regras de validação no GMF podem ser escritas em Object Constraint Language (OCL), Java ou Expressões regulares. Nesta prova de conceito utilizou-se Java para essa escrita pela maior experiência do autor desta tese nessa linguagem, tendo-se assim maior facilidade em se depurar possíveis validações escritas sintaticamente ou semanticamente erradas. Outro motivo para essa escolha é que usar uma linguagem de programação nesse contexto torna mais rica a validação, podendo ser feitas várias inferências quanto ao modelo em diferentes níveis de complexidade, inclusive com consulta a outros modelos e bases de dados. Assim, pode ser verificada desde a omissão de algum atributo obrigatório a até mesmo a presença de nomes de elementos iguais ou verificação de caminhos que nunca poderão ser acessados. 
Outro recurso interessante é que as regras de checagens (neste caso em relação ao atendimento a diretrizes de acessibilidade) podem ser declaradas para validação em tempo de desenvolvimento (live validation) para o editor criado. Assim, checagens são feitas imediatamente após cada execução de comandos, sendo que quando alguma violação de regra é detectada, sua execução é cancelada voltando ao estado anterior. Observa-se que a validação em tempo de desenvolvimento opera incrementalmente, com a possibilidade de regras se complementarem. Além da validação dos elementos em si, a cada relacionamento, regras de ligação são checadas como pré-condições para a execução dessa operação.

Na Figura 4.6 é apresentado um exemplo de janela de alerta que é exibida sempre quando uma regra de validação é infringida. Para cada alerta tem-se a razão pela qual houve a violação, no sentido de instruir o usuário a seguir a regra.

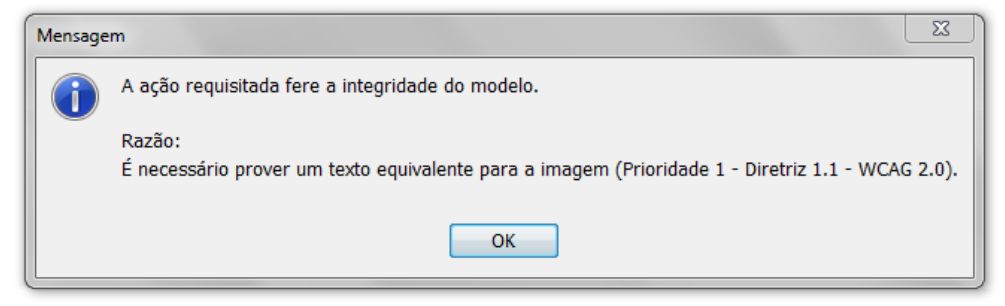

Figura 4.6 - Validação em tempo de desenvolvimento emitindo uma mensagem de violação da integridade de um modelo

No exemplo da Figura 4.6 vê-se uma mensagem de alerta para o descumprimento da regra relativa a elementos do tipo imagem, que sempre devem possuir um texto alternativo equivalente, de acordo com a diretriz 1.1 da WCAG 2.0. Ao pressionar OK o sistema volta automaticamente ao estado anterior ao da quebra de violação da regra, que nesse caso será o mesmo, pois nada foi inserido efetivamente no atributo de texto alternativo de uma imagem.

A vantagem no uso do recurso de validação em tempo de desenvolvimento é que o desenvolvedor não necessita acionar explicitamente o comando de validação e, desse modo, ele sempre será alertado de inconsistências quanto ao modelo.

\subsubsection{Persistência dos modelos}

Para desenvolvimento deste estudo, os modelos tiveram que ser armazenados de modo que possam ser recuperados para posterior leitura e realização de transformações para código acessível. Esse armazenamento foi feito em XMI, como pode ser visto na Figura 4.7. 
O XMI é um padrão do OMG para intercâmbio de informações baseado em XML. Seu uso comum é na troca facilitada de metadados entre ferramentas de modelagem e repositórios (OMG, 2007).

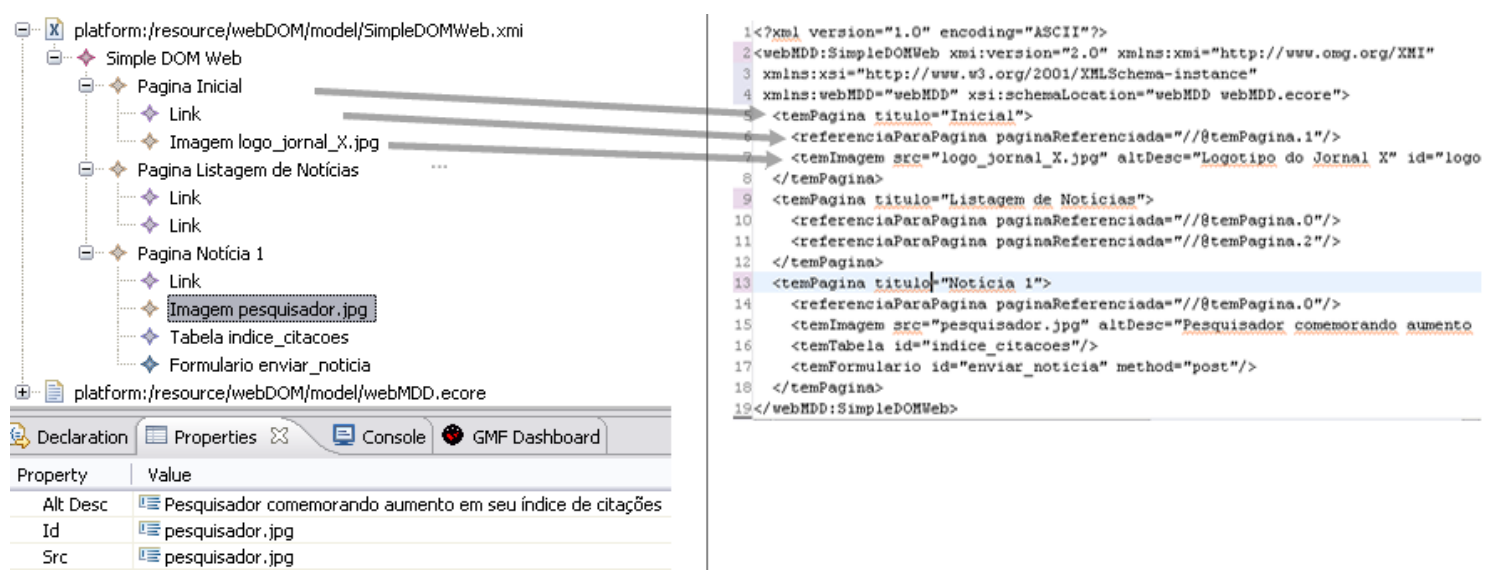

Figura 4.7 - Visualização gráfica do modelo persistido em XMI e seu mapeamento em código

No lado esquerdo da Figura 4.7 é apresentada a instância do modelo em forma gráfica hierárquica, provida pelo recurso do GMF chamado "Sample Reflective Ecore Model Editor". Tal recurso possibilita uma visualização melhor dos dados do arquivo XMI e teste mais fácil do metamodelo construído. As setas indicam como o mapeamento gráfico para o arquivo texto é feito, sendo que todos os elementos têm seu mapeamento para o código, porém, para melhor compreensibilidade da figura, somente foram indicadas no exemplo três relações.

Estando persistido um modelo, podem existir regras de transformação para a geração de código. No caso da persistência em XMI existem vários ganhos como a existência de leitores do tipo parsers que facilitam sua manipulação computacional.

\subsection{Estudo de caso 3 - Uso de MDD na estruturação de uma Wiki com geração de código acessível}

As Wikis têm representado um apoio ferramental importante para a disseminação de informações, permitindo que documentos sejam editados coletivamente, com uma linguagem simples, por meio de um navegador Web (WEST e WEST, 2008; HARRER et al., 2008). Isso pode facilitar a aplicação de diretrizes de acessibilidade, uma vez que o autor não está interagindo diretamente no código final HTML, sendo esse código final gerado pelo sistema da Wiki, que pode (e deve) fazer restrições e checagens em sua linguagem simples e em 
elementos de sua interface para que o autor não forneça elementos com problemas de acessibilidade (como, por exemplo, a inserção de uma imagem sem descrição textual alternativa).

Essa facilidade de edição se contrapõe aos métodos convencionais de criação Web que requerem, normalmente, um conhecimento mínimo de HTML e ferramentas de transferência de arquivos, como as que usam File Transfer Protocol (FTP).

O desenvolvimento convencional, além de ser geralmente mais complexo, é mais suscetível a erros, como a existência de links quebrados. Nas Wikis, por sua vez, um link para uma página inexistente não fica inacessível: é simplesmente uma nova página aguardando sua criação por algum usuário com permissão para tal.

Com o conteúdo inserido nas Wikis, há o provimento de vários recursos como controle de acesso por usuário (em operações de visualização, edição, entre outras), gerenciamento de versões, envio de diferentes tipos de mídia (PDF, DOC, entre outros), busca textual, inserção de complementos para extensão de suas funcionalidades (plugins) e disponibilização de feeds do tipo Really Simple Syndication (RSS).

O exemplo maior e mais conhecido de utilização de Wiki é a Wikipédia ${ }^{14}$, uma enciclopédia multilíngue livre e colaborativa. No entanto, em um estudo sobre essa enciclopédia, Buzzi e Leporini (2008) apontam várias barreiras de acessibilidade que prejudicam o acesso e autoria por indivíduos com deficiências visuais.

Assim, a utilização de Wiki neste terceiro estudo de caso foi proposta com vistas a verificar se o uso de modelos gráficos, com a inclusão de padrões de navegação (como o uso de menu e breadcrumbs), pode ser útil para o usuário e ainda permitir a geração de elementos acessíveis.

Neste sentido, foi desenvolvida uma extensão para uma Wiki existente para permitir a modelagem de sua estrutura, graficamente, por modelos. Para tanto foi selecionado um software livre chamado Dokuwiki ${ }^{15}$, devido a sua facilidade de uso e de estruturação via

\footnotetext{
14 http://www.wikipedia.org

15 http://www.dokuwiki.org/
} 
sistema de arquivos (ao contrário de outras que utilizam Sistemas Gerenciadores de Banco de Dados - SGBDs).

Para a modelagem estrutural da Wiki, utilizou-se o projeto de modelagem gráfica disponível no Eclipse (Graphical Modeling Project - GMP) ${ }^{16}$, e para a geração do código usou-se a tecnologia Java Emiter Templates (JET) ${ }^{17}$.

O passo inicial deste estudo de caso foi dedicado a analisar conceitualmente o design da informação, que verifica de que forma o conteúdo irá compor a arquitetura da informação. O segundo passo foi modelar essa arquitetura graficamente com elementos e suas propriedades e relações.

Para a geração automatizada de código da estrutura, inicialmente foi feita uma leitura computacional do modelo e, a partir de regras de transformação, foram criados arquivos estruturados de composição da Wiki.

Em seguida, para a geração de menus e elemento breadcrumbs utilizou-se um recurso de busca nos arquivos, retornando um vetor de itens. Isso garante uma estrutura de navegação atualizada, caso uma página seja excluída, seu link deixará de existir no menu e no elemento breadcrumbs.

\subsubsection{Estruturação em Wikis e a problemática envolvida}

A estruturação na Wiki refere-se à disposição dos seus elementos (páginas, links e demais conteúdos) de forma organizada, para formar uma "boa" arquitetura da informação, ou seja, que propicie adequada legibilidade ao usuário bem como facilite a procura das informações no conteúdo disponibilizado.

Nesse sentido, aspectos importantes que devem ser considerados na sinalização da estrutura de informações são: proporcionar fácil compreensão dos títulos, provimento adequado de feedback ao usuário durante a leitura e oferecimento de atalhos para os usuários experientes (NIELSEN, 2007).

\footnotetext{
${ }^{16}$ http://www.eclipse.org/modeling/gmp/

${ }^{17} \mathrm{http} / / / \mathrm{www}$. eclipse.org/modeling/m2t/?project=jet
} 
Assim, para essa sinalização, podem ser usados breadcrumbs que servem para mostrar a localização de uma página na hierarquia de um site. Nielsen (2007) aponta razões para utilizar breadcrumbs, como mostrar às pessoas sua localização corrente relativa e oferecer acesso facilitado para níveis mais elevados do site.

De acordo com Haake et al. (2005), a necessidade de se estruturar melhor as wikis é desafiadora e existem recursos para isso, no entanto, é relatado que usuários inexperientes têm dificuldades de criarem conteúdos estruturados. Essa falta de estruturação pode existir em várias situações, por exemplo, se o usuário não usar corretamente as tags hierárquicas de título ( $h 1, h 2, h 3$ e assim por diante). Outros problemas comuns, citados por Haake et al. (2005), estão relacionados a quando: i) o usuário coloca conteúdos semanticamente diferentes em uma página; e ii) o usuário não tem conhecimento ou não teve treinamento suficiente para saber dividir o conteúdo.

\subsubsection{Namespaces}

Os namespaces são usados para separar páginas e outros arquivos de mídia (documentos PDFs, músicas MP3, vídeos, dados em XMLs, entre outros). Assim, um namespace é a chave para acesso a recursos em diversos sites (WILDE, 2006). O conceito de estruturação envolvido na utilização de namespaces em Wikis é similar ao uso de diretórios, enquanto páginas são similares a arquivos (DOKUWIKI, 2011).

Normalmente, para se criar novos namespaces basta informar em um link o nome desejado seguido pelo caractere de dois pontos. O nome após o último dois pontos (:) será o nome da página propriamente dito, enquanto os outros nomes serão namespaces.

Neste sentido, namespaces são utilizados como meio para propiciar a organização e estruturação de conteúdos, importante para ter uma arquitetura organizada das páginas Web, auxiliando na navegação e localização da informação desejada pelo usuário.

\subsubsection{Implementação e resultados}

A partir de estudos de diferentes estruturações de navegação, foi desenvolvido um modelo de hierarquia de conteúdo e navegação usando MDD. 
Na Figura 4.8 é apresentado o metamodelo para organização conceitual e estrutural da Wiki.

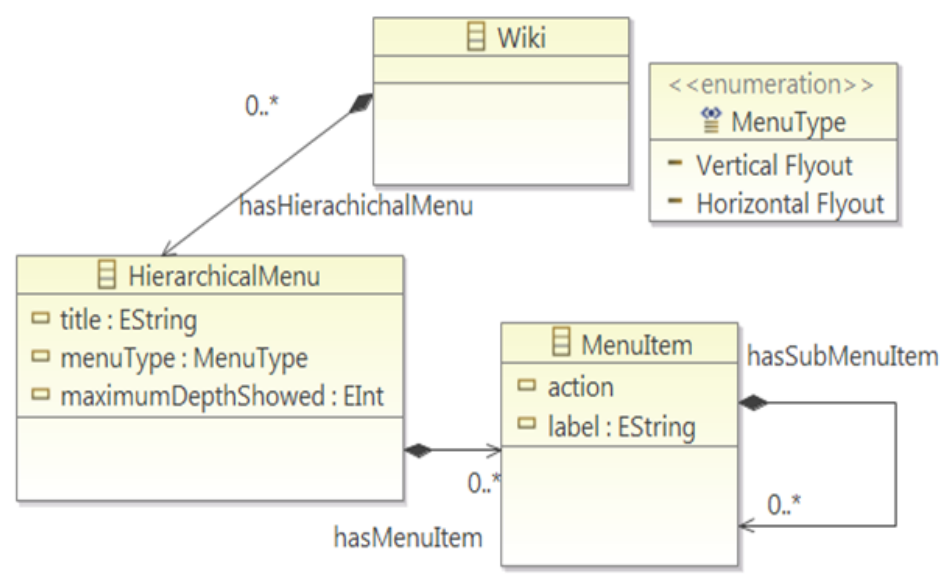

Figura 4.8 - Metamodelo de estruturação de menus feito na plataforma Eclipse GMF

De acordo com a Figura 4.8, uma Wiki pode ter zero ou mais menus hierárquicos, os quais possuem os atributos: título (importante também para a acessibilidade do elemento), tipo de menu e a máxima profundidade mostrada, para armazenar até que nível o usuário deseja exibir opções no menu. Além disso, cada item do menu pode ter recursivamente zero ou mais subitens (hasSubMenuItem).

A partir da definição desse metamodelo podem ser criados diferentes modelos para cada aplicação. Como exemplo, foi criado neste estudo de caso um menu hierárquico apresentado na Figura 4.9, que contempla 5 itens em seu nível inicial.

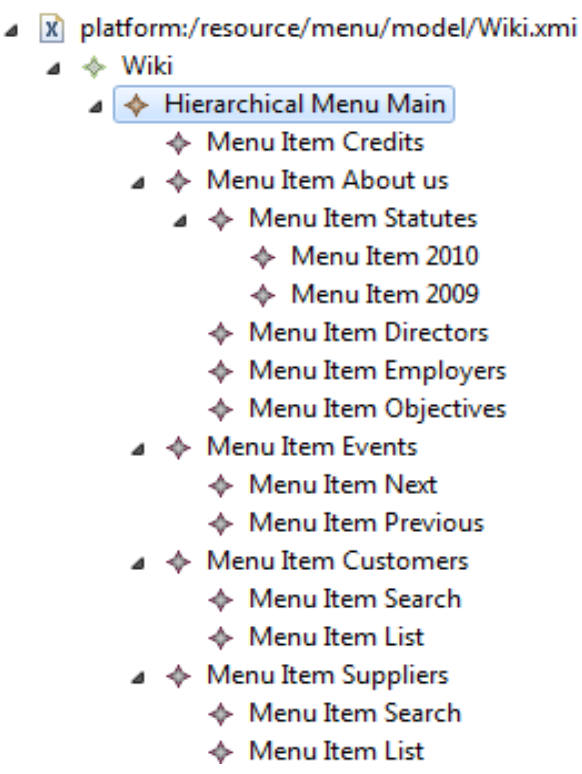

Figura 4.9 - Modelo com dados de um menu exemplo 
$\mathrm{O}$ armazenamento do modelo foi feito em sistema de arquivos no formato XMI, no arquivo "Wiki.xmi", que será lido (parsing) no momento da transformação para gerar a estrutura da Wiki desejada.

A vantagem dessa edição é que o autor da futura Wiki pode criar e remover nós facilmente em estruturas diferentes, visualizando como está ficando a organização desses elementos (podendo inclusive movimentar um nó para outro nó-pai). Vale ressaltar que o autor pode validá-la graficamente de forma ágil com outros interessados, inclusive com leigos em Wiki. Isso permite a realização de uma modelagem prévia, como forma de planejamento e, em caso de aprovação, o modelo pode ser computacionalmente lido e transformado nas páginas da Wiki bem estruturadas.

A cada novo item de menu criado no modelo, o usuário deve informar o conteúdo dos atributos, isso pode ser feito na aba "Properties", como pode ser visto na Figura 4.10.

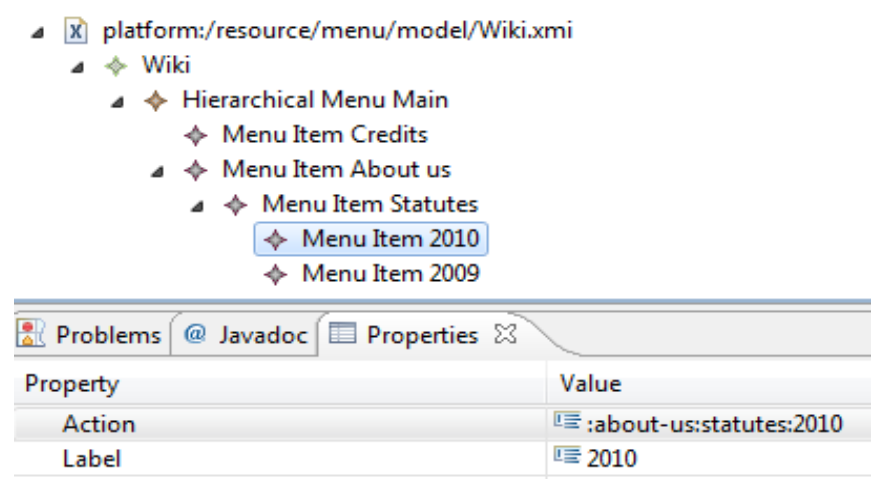

Figura 4.10 - Propriedades de um item do modelo

Por fim, com base no modelo conceitual da estrutura da Wiki armazenado como um modelo XMI, fez-se a transformação para geração de código HTML, que pode ser vista a seguir nas Figura 4.11 e Figura 4.12.

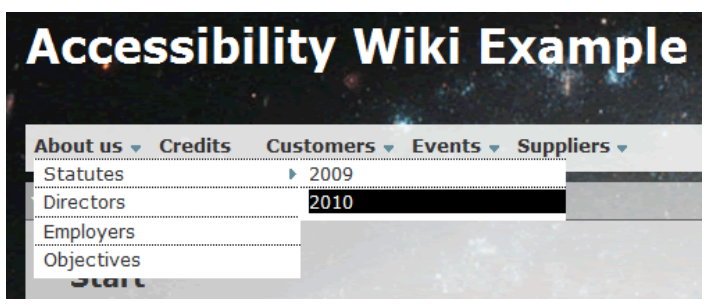

Figura 4.11 - Menu hierárquico gerado para a Wiki 


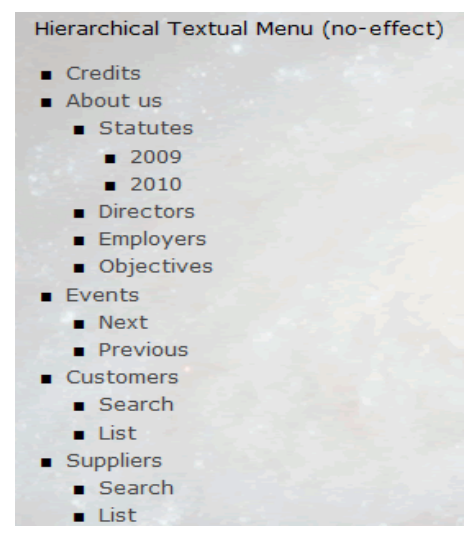

Figura 4.12 - Visão da Wiki gerada com links para a estrutura planejada no modelo

No exemplo mostrado na Figura 4.12, está ilustrado o potencial de um cenário escolhido como estudo, no qual o menu apresenta 17 opções modeladas para os subitens, em 3 níveis hierárquicos. Tal topologia de opções, que é relativamente simples se compararmos a casos reais, resulta em 6 pastas e 18 arquivos.

Dentre os resultados obtidos dessa modelagem, têm-se as possíveis vantagens: i) estímulo à colaboração por já apresentar as estruturas que serão alvo da inserção de conteúdo; ii) facilidade de criação de estruturas navegacionais eficientes de forma gráfica por pessoas não necessariamente especializadas em HTML; iii) menu organizado refletindo consistentemente o conteúdo disponibilizado; iv) melhor visualização de planejamento via interface gráfica, inclusive permitindo validação pelo cliente final; e v) facilidade de alteração de estilos de cores e tipografia pela tecnologia utilizada de definição de estilos em Cascading Style Sheets (CSS).

Seja com geração manual ou semiautomática, essa estrutura de arquivos precisa ser criada. Assim, pode-se usar uma ferramenta de geração semiautomática, de modo a possibilitar a criação correta e mais rápida dos arquivos. Outra observação relevante é que, depois de gerados os arquivos, o usuário pode testar a implementação, e se algum problema de arquitetura de informação for observado, as mudanças necessárias podem ser mais bem gerenciadas apenas alterando o modelo inicial e gerando novamente os arquivos.

O que se percebe na prática é que muitos desenvolvedores fazem uma estruturação de conteúdo de forma manual e conversam sobre ela com os interessados no projeto. Isso geralmente é feito em papel ou em editores de texto convencionais, sendo os documentos 
gerados nesse processo uma espécie de guia para a implementação, os quais nem sempre são fielmente seguidos.

Em relação ao usuário leigo, o uso de Wikis se mostra como um forte aliado, visto que o usuário poderá planejar graficamente a estrutura de sua informação e visualizar rapidamente sua Wiki funcionando de forma navegacional, sendo necessário apenas preencher as páginas geradas com o conteúdo desejado.

É importante ressaltar que a técnica aqui mencionada, de modelagem gráfica e geração de estrutura de Wikis, não prejudica a flexibilidade e liberdade dos usuários, sendo que eles podem criar normalmente novas páginas numa estruturação extensível. A ideia apresentada com este estudo é apoiá-lo na difícil tarefa de estruturar o conteúdo e usar elementos de navegação consistentes (por advirem de uma verificação no sistema de arquivos sobre a existência das páginas), efetivos (pelo sistema de Wiki se encarregar de prover os mecanismos corretos de efetivação da navegação com links corretos) e acessíveis (pelos elementos gerados, como menus, serem previamente avaliados em busca da não existência de barreiras com consideração de diretrizes de acessibilidade).

\subsection{Considerações finais}

Neste capítulo foram apresentados três estudos de caso que serviram de estudos técnicos e investigação exploratória para verificação de cenários práticos para a concepção da abordagem proposta nesta tese, de acordo com o referencial teórico abordado no capítulo anterior.

Nesses estudos de caso, embora tenham sido apresentados com nível de detalhamento reduzido, foram fundamentais para demonstrar que é possível e viável a proposição de apoio a boas práticas de desenvolvimento por meio de:

1) inserção de verificações computacionais em modelos de desenvolvimento e no uso de aplicações de gerenciamento de conteúdo Web, como em Wikis;

2) apresentação de alertas pertinentes ao desenvolvedor, auxiliando em casos de esquecimento ou, até mesmo, para ensino de boas práticas de forma integrada nos ambientes de desenvolvimento; e 
3) realização de uma geração de código com acessibilidade, por meio de transformações relativas a abordagem MDD.

No próximo capítulo é apresentada a ferramenta colaborativa desenvolvida nesta tese que objetiva promover o compartilhamento organizado de experiências e considerações sobre o desenvolvimento de artefatos Web com acessibilidade. 


\section{A ferramenta AccessibilityUtil}

\subsection{Considerações iniciais}

A partir da problemática contextualizada nos capítulos anteriores e do estudo de diretrizes de acessibilidade, neste capítulo são apresentados dados de desenvolvimento e utilização de uma ferramenta colaborativa na Web. Tal ferramenta tem por objetivo promover o compartilhamento organizado de experiências e considerações sobre o desenvolvimento de artefatos Web com acessibilidade.

Assim, o propósito deste capítulo é destacar como a colaboração pode ser útil no apoio ao uso de boas práticas durante o projeto e a implementação de aplicações Web acessíveis, a partir da utilização de uma ferramenta de apoio.

Este capítulo está organizado da seguinte forma: na Seção 5.2 têm-se a motivação para o trabalho desenvolvido bem como a concepção da ferramenta e conceitos envolvidos. 
Em seguida, na Seção 5.3 são apresentados os trabalhos relacionados a outras ferramentas para o domínio pesquisado. Na Seção 5.4 tem-se a metodologia que norteou o desenvolvimento da ferramenta. Já o desenvolvimento do trabalho é apresentado na Seção 5.5, incluindo a descrição de como é feita a moderação do conteúdo inserido na ferramenta e a gestão de decisões de acessibilidade em projetos. Na Seção 5.6 são apresentados os resultados de utilização da ferramenta, na Seção 5.7 se tem uma análise qualitativa das contribuições inseridas e, por fim, as conclusões são descritas na Seção 5.8.

\subsection{Motivação, concepção e conceitos envolvidos}

Como motivação para o desenvolvimento da ferramenta AccessibilityUtil, Sloan (2006) relata que uma das principais causas para o contínuo problema da inacessibilidade na Web é a falta de conhecimento sobre como realizar boas práticas de desenvolvimento visando acessibilidade, por parte dos envolvidos no desenvolvimento de aplicações Web e pela divulgação insuficiente de técnicas de implementação de tais práticas.

Adicionalmente, Bailey e Pearson $(2010 ; 2011)$ destacam que a falta de conhecimento dos desenvolvedores em relação à acessibilidade é um problema que se inicia na universidade. Como parte do currículo da graduação em Computação, os estudantes aprendem o desenvolvimento de aplicações Web, mas pouco se tem dado atenção para as questões de acessibilidade.

A partir da proposta e disponibilização da ferramenta, pretende-se alcançar um número expressivo de contribuições para a área de desenvolvimento com acessibilidade, de modo a possibilitar registros e consultas com a finalidade de disseminar informação para o desenvolvimento de aplicações Web acessíveis.

A ferramenta desenvolvida para discussão e apoio em acessibilidade, nomeada AccessibilityUtil $^{18}$, foi disponibilizada online desde o dia 01/05/2011. Na Figura 5.1 pode ser visualizado seu esquema conceitual.

\footnotetext{
${ }^{18}$ http://www.accessibilityutil.com
} 


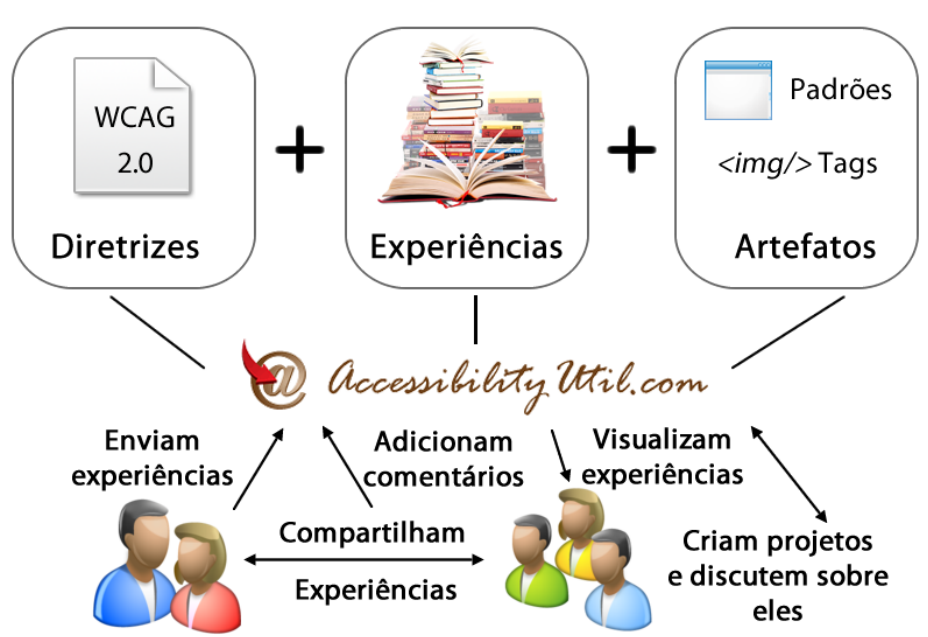

Figura 5.1 - Esquema conceitual da ferramenta

Como apresentado na Figura 5.1, o intuito geral da ferramenta é permitir uma junção organizada de experiências associadas com artefatos Web e diretrizes de acessibilidade. Tal junção auxilia na disseminação da informação e compartilhamento de experiências a partir do uso de mecanismos de colaboração, permitindo que um usuário participe apenas lendo o conteúdo disponibilizado ou que interaja com outros usuários por meio da adição de novas experiências, comentários ou tópicos em projetos.

A ferramenta foi desenvolvida para suportar os idiomas português e inglês, de modo a ampliar a possibilidade de contribuição e difusão de seu conteúdo. Assim, podem ser destacados três exemplos de cenários de uso da ferramenta:

1. Um desenvolvedor que deseja aprender boas práticas de desenvolvimento considerando acessibilidade dos artefatos finais Web, recomendadas de acordo com as diretrizes WCAG 2.0 e experiências de outros usuários;

2. Um desenvolvedor que usou uma dada técnica e quer apresentar comentários positivos ou negativos sobre ela, inserindo detalhes de sua experiência; e

3. Um desenvolvedor que deseja usar um certo padrão de interface ou interação e quer ponderar sobre as técnicas existentes e saber o que outros desenvolvedores e especialistas discutem sobre elas antes de usá-las. 


\subsection{Outras ferramentas}

De modo a contextualizar e identificar avanços em termos de meios computacionais que oferecem suporte ao desenvolvimento com acessibilidade, foi realizada uma pesquisa sobre ferramentas para o domínio de acessibilidade na Web e suas possíveis categorizações de acordo com as funcionalidades e resultados esperados da utilização de cada ferramenta. Dentre os estudos analisados pode-se destacar, em termos de categorização, que:

- Thatcher et al. (2006) apresentam uma divisão para o domínio em i) ferramentas de autoria, ii) ferramentas de avaliação e iii) tecnologias assistivas;

- López (2010) define uma categorização mais ampla em i) validadores de acessibilidade, ii) barras de desenvolvimento, iii) validadores de padrão, iv) validadores de aspectos de interface, v) leitores de tela, vi) ampliadores de tela, vii) navegadores acessíveis, viii) navegadores alternativos, ix) simuladores de incapacidade visual, $\mathrm{x}$ ) simuladores de pessoas com incapacidade cognitiva, xi) ferramentas para auxílio a epiléticos, xii) avaliadores de texto, xiii) avaliadores de cor, xiv) ferramentas para crianças com incapacidades motoras e xv) variadas; e

- a iniciativa WAI do W3C, em seus sites sobre ferramentas para acessibilidade, apresenta uma lista de ferramentas de avaliação de $\operatorname{sites}^{19}$ (com última atualização em 2006) e ferramentas de autoria ${ }^{20}$ (com última atualização em 2002) com subdivisão em: i) editores de marcação, ii) ferramentas com apoio de bases de dados, iii) editores de estilos, iv) ferramentas com opção de salvar para Web, v) editores multimídia e vi) ferramentas de conversão.

Verificou-se, portanto, que a AccessibilityUtil se encaixa em uma categoria nova e ainda pouco explorada que é a de ferramentas para a colaboração de experiências e aprendizado para interessados no desenvolvimento Web com acessibilidade.

Essa atuação no apoio à colaboração de experiências com a difusão de conhecimento é uma motivação para o desenvolvimento desse tipo de ferramenta, ressaltada a possibilidade de auxílio efetivo no aprendizado dos interessados nas fases de análise e desenvolvimento de aplicações Web. Isso, objetivando que se chegue ao momento de avaliação de acessibilidade

\footnotetext{
${ }^{19}$ http://www.w3.org/WAI/RC/tools/complete

${ }^{20}$ http://www.w3.org/WAI/ER/tools/
} 
de artefatos com o menor número possível de barreiras à acessibilidade, considerando que o custo de modificações após um desenvolvimento efetuado é expressivamente maior do que se a correção dos problemas ou o bom desenvolvimento forem empregados em etapas anteriores (MARTÍN et al., 2011).

Mesmo fazendo parte de uma categoria nova de aplicações, foram encontradas outras ferramentas que se aproximam, de alguma forma, com a AccessibilityUtil, sendo essas discutidas a seguir.

Bailey e Pearson (2010; 2011) descrevem o desenvolvimento de uma ferramenta Web de gerenciamento de conhecimento sobre acessibilidade, chamada Accessibility Evaluation Assistant $^{21}$ (AEA), focada em auxiliar na avaliação de acessibilidade para avaliadores não experientes, fornecendo uma base de práticas de treinamento para as checagens e um repositório de resultados de avaliação. De acordo com tais autores as ferramentas de avaliação ainda não são facilmente compreendidas por esses usuários, uma das causas verificadas é o difícil entendimento das diretrizes WCAG 2.0.

Para amenizar essa dificuldade de entendimento, os criadores da AEA apresentam critérios práticos para avaliação de forma distinta ao apresentado nas diretrizes WCAG 2.0, com indicação direta do que deve ser checado em cada página, com uma descrição sucinta e em passos, seguida por uma planilha interativa para marcação. Tal indicação do que deve ser checado é composta de três seções:

- "Porque isso é importante": descrevendo o problema e importância de solucionar a questão;

- "Como checar essa questão": apresentando os passos e modo de realizar a checagem da questão; e

- "Mostre-me como fazer isso": disponibilizando um vídeo de como realizar a avaliação da questão.

As questões para verificação de sites são organizadas na AEA com a separação em 10 tipos de deficiência: dislexia, deficiência de aprendizagem, baixa visão, deficiência visual

\footnotetext{
${ }^{21}$ http://arc.tees.ac.uk/aea/
} 
com usuários usando leitores de tela, deficiência motora, dificuldade de entendimento de textos na língua inglesa, deficiências gerais pela idade avançada (adultos de meia idade e idosos), deficiências visuais na percepção de cores, deficiências auditivas e crises de convulsão.

O motivo dessa organização é auxiliar os avaliadores a reconhecerem usuários reais e encorajá-los a encontrar princípios de acessibilidade comuns que auxiliem no processo de verificação de acessibilidade. A ferramenta AEA foi testada em um grupo de 38 alunos de graduação que realizaram a avaliação de sites com seu suporte.

Já o site AccessibilityTips ${ }^{22}$ oferece uma coleção de dicas, guias e sugestões práticas para o desenvolvimento de sites acessíveis. Seu formato difere da AccessibilityUtil, pois é estruturado em forma de Blog, não sendo possível a colaboração entre usuários, uma vez que a opção de comentários está desabilitada. Assim, todas as postagens são inseridas por responsáveis pelo site. Outra característica que os distinguem é que não há relação das sugestões apresentadas com as diretrizes oficiais do W3C. Além disso, um ponto que deve ser ressaltado é que a última postagem do site é referente ao ano de 2009 , indicando desatualização e uma possível descontinuidade.

Wald et al. (2011), por sua vez, apresentam a ferramenta web2Access ${ }^{23}$ que permite aos usuários avaliarem um site em relação ao documento WCAG 2.0 e outras diretrizes. A diferença com a ferramenta AccessibilityUtil é que seu propósito é a avaliação de um site já desenvolvido e suas funcionalidades e não de questões para desenvolvimento de artefatos que compõem um site. Uma questão a se considerar na avaliação de sites é o fator temporal, pois um site pode mudar frequentemente e, com isso, as características de acessibilidade podem ser alteradas e os dados postados na ferramenta ficarem desatualizados. Nesse sentido, web2Access apresenta oportunamente a data de avaliação do site.

Outra ferramenta que se assemelha com a AccessibilityUtil, em termos de suas ideias gerais de difusão de boas práticas para desenvolvimento de aplicações Web acessíveis, é a WARAU - Websites Atendendo a Requisitos de Acessibilidade e Usabilidade (Beta) ${ }^{24}$. Tal

\footnotetext{
${ }^{22}$ http://www.accessibilitytips.com/

23 http://www.web2access.org.uk/

${ }^{24}$ http://warau.nied.unicamp.br/
} 
ferramenta é nacional e tem como objetivo auxiliar equipes de desenvolvimento a adequarem seus sites a requisitos de acessibilidade e usabilidade por meio da disponibilização de um referencial teórico e um canal de comunicação entre seus usuários (ALMEIDA et al., 2008).

Seu conteúdo é disponibilizado objetivando apoio no desenvolvimento acessível, de forma análoga à AccessibilityUtil, no entanto podem ser apresentadas as seguintes distinções conceituais, verificadas mediante inspeção realizada nas duas ferramentas em agosto de 2012:

- Integração com referenciais de diretrizes: na AccessibilityUtil existe uma ligação obrigatória de cada conteúdo inserido com um critério de sucesso da WCAG 2.0 e um artefato. Já na WARAU não há essa ligação obrigatória, mas em alguns conteúdos existem citações para documentos do W3C WAI e e-MAG; e

- Organização do conteúdo: as duas apresentam divisões claras, porém distintas. $\mathrm{Na}$ AccessibilityUtil existe a estruturação de artefatos em categorias (Tags, Padrões e Outros), já na WARAU têm-se a divisão em cinco temas (HTML, CSS, Javascript, Acessibilidade e Usabilidade), sendo que um determinado tópico pode ser categorizado em mais de um tema.

Por meio do estudo realizado nas ferramentas aqui relacionadas é possível apresentar o Quadro 5.1, que sumariza importantes características, permitindo uma diferenciação conceitual delas.

Quadro 5.1 - Diferenciações das ferramentas apresentadas

\begin{tabular}{|l|c|c|c|}
\hline Ferramenta & $\begin{array}{c}\text { Associação com } \\
\text { diretrizes oficiais }\end{array}$ & $\begin{array}{c}\text { Colaboração } \\
\text { entre usuários }\end{array}$ & $\begin{array}{c}\text { Apoio na fase de } \\
\text { desenvolvimento }\end{array}$ \\
\hline \hline AccessibilityUtil & Sim & Sim & Sim \\
\hline AccessibilityTips & Não & Não & Sim \\
\hline AEA & Parcial & Não & Não \\
\hline$W A R A U$ & Parcial & Sim & Sim \\
\hline web2Access & Sim & Não & Sim \\
\hline
\end{tabular}

Para a marcação do Quadro 5.1, em relação às ferramentas WARAU e AEA, o critério "associação com diretrizes oficiais" foi marcado como tendo atendimento "parcial" por não ser obrigatória essa associação nos conteúdos. É importante deixar claro que a 
comparação de características de cada ferramenta é feita no sentido de evidenciar as capacidades e foco de cada uma. No entanto, apesar das semelhanças encontradas, em termos gerais de auxílio em acessibilidade, elas apresentam propósitos distintos, devendo ser considerados o contexto e finalidade de uso de cada ferramenta.

Verifica-se, assim, que o trabalho desenvolvido para a proposta da ferramenta AccessibilityUtil apresenta um modelo conceitual original, com envolvimento de diretrizes existentes realizando a associação dessas com artefatos próximos ao cotidiano de profissionais e demais interessados da área de desenvolvimento Web.

\subsection{Metodologia de trabalho}

A metodologia de pesquisa exploratória foi utilizada como meio para verificar conceitos sobre acessibilidade, resultados dos estudos desenvolvidos para embasar a proposta deste trabalho e executar o planejamento e desenvolvimento da ferramenta AccessibilityUtil. Para esse projeto, foi adotado o processo de desenvolvimento de software denominado "beta perpétuo", em que o produto é disponibilizado com evoluções constantes em termos de disponibilização de novas funcionalidades e melhorias nas existentes.

Assim, para planejamento e desenvolvimento da ferramenta, inicialmente foram utilizados os conceitos da Engenharia de Requisitos (ER), e assim foram obtidas as necessidades dos elementos que deveriam ser desenvolvidos na ferramenta (SOMMERVILLE e SAWYER, 1997). Em seguida, foram realizadas as etapas de análise, para compreender e fazer inferências sobre os dados, e projeto, que constitui a concepção de como devem ser desenvolvidos os requisitos analisados, propondo tanto uma arquitetura das funcionalidades, como um modelo conceitual dos dados para se chegar ao processo e ao produto final.

O primeiro passo realizado foi, então, o de verificar quais os objetivos e necessidades para o desenvolvimento da ferramenta, avaliando o cenário existente por meio de uma pesquisa sobre a área de ferramental de apoio à utilização de diretrizes de acessibilidade em projetos Web. Assim, foi elaborado um documento de planejamento, em que requisitos foram elicitados e uma lista de casos de uso foi criada (presente no Apêndice A). 
Para o desenvolvimento da ferramenta, uma equipe de seis pessoas foi formada. Além do autor desta tese, colaboraram um aluno de mestrado e uma pesquisadora experiente em acessibilidade na Web, orientadora desta tese. Dois alunos de iniciação científica e um pesquisador externo também auxiliaram de forma secundária com a realização de testes e enviando sugestões e críticas.

A partir da formação da equipe, foram coletados dados sobre a experiência de cada integrante e atribuídas tarefas específicas para cada um, visando o desenvolvimento com divisão adequada de responsabilidades. Então foi realizada uma pesquisa-ação aplicada de modo a identificar práticas de desenvolvimento com acessibilidade que são relacionadas às diretrizes existentes. Essa identificação inicial subsidiou a verificação de quais campos devem existir no modelo de dados da ferramenta.

Para orientar as noções que regulamentam a diversidade de problemas e soluções de acessibilidade, as quais devem ser discutidas nas interações com a ferramenta AccessibilityUtil, foi definida a adoção das diretrizes WCAG 2.0, por ser um conjunto de diretrizes oficiais do $\mathrm{W} 3 \mathrm{C}$, sendo um dos documentos mais difundidos da área.

Adicionalmente, foram definidos perfis de usuários e as permissões estabelecidas em termos de funcionalidades da ferramenta. Essa definição vai de encontro com outro ponto importante que foi observado no planejamento, de que a colaboração necessita de moderação, para que seja evitada a duplicação de informações e para que dados inválidos não sejam mantidos na ferramenta. A definição de uma política de moderação foi projetada e está descrita na Subseção 5.5.1 deste capítulo.

Um requisito não funcional relevante para o trabalho está relacionado à necessidade da ferramenta ser acessível, o que permeou todo o seu projeto e implementação, com a realização de verificações e ajustes periódicos sobre sua acessibilidade. Para tanto, foi utilizada com sucesso a ferramenta $A C h e c k e r^{25}$ e avaliações manuais por inspeções.

Com a primeira versão da AccessibilityUtil pronta, foi definido um planejamento de como realizar a sua divulgação, uma vez que esse ponto se apresenta como aspecto importante para o sucesso e efetividade do projeto. A princípio, foram convidados

\footnotetext{
${ }^{25}$ http://achecker.ca
} 
desenvolvedores e demais interessados em criação Web, por e-mail e utilizando redes sociais, a participarem do projeto, seja como apenas visualizadores de experiências ou como colaboradores ativos de conteúdo.

A lista de casos de uso, mencionada anteriormente, desde então, tem sido constantemente atualizada, sendo isso importante para a percepção de quais funcionalidades a ferramenta tem oferecido suporte e de que forma essas estão organizadas.

\subsection{Projeto da ferramenta}

A ferramenta AccessibilityUtil foi desenvolvida em $\mathrm{PHP}^{26}$, como linguagem de programação do código para a aplicação no lado do servidor, com auxílio do framework Javascript JQuery ${ }^{27}$, para manipulação de eventos na interface e MySQL ${ }^{28}$ como Sistema Gerenciador de Banco de Dados (SGBD).

Tal desenvolvimento demandou esforço inicial de cerca de quatro meses para criação de sua primeira versão e, após esse período, a ferramenta continua evoluindo estando em fase de refinamentos para correções de eventuais problemas e inclusão de novas funcionalidades.

Como base para utilização a ferramenta então possibilita o cadastro de usuários para que possam:

i) cadastrar artefatos;

ii) visualizar os artefatos já presentes e as experiências a eles associadas; e

iii) realizar avaliações de artefatos com inserção de experiências.

As avaliações são realizadas por meio da inserção de experiências e decisões de projeto dos usuários cadastrados, que contribuem com relatos de uso de técnicas para o atendimento a critérios de acessibilidade para cada artefato. Esses relatos são então disponibilizados aos demais usuários, e de forma colaborativa, recebem comentários.

A base de dados modelada possibilitou a inserção das diretrizes WCAG 2.0, refletindo sua estrutura e conteúdo para que fosse possível a sua vinculação com artefatos. Nessa base

\footnotetext{
${ }^{26}$ http://www.php.net/

${ }^{27}$ http://jquery.com

${ }^{28} \mathrm{http}: / /$ www.mysql.com/
} 
estão inseridos todos os princípios, com suas respectivas descrições e códigos e as diretrizes, com nome, código e descrição, além dos critérios de sucesso, com nome e código.

Quanto aos tipos de informação, que são conteúdo alvo das discussões na AccessibilityUtil, optou-se pelo cadastro de artefatos Web para tornar o sistema flexível, ao invés de suportar apenas padrões Web, por exemplo. São considerados artefatos, nesse contexto, quaisquer elementos presentes na construção de aplicações Web, para os quais haja alguma consideração sobre acessibilidade. A base de dados deve comportar, também, as seguintes informações:

- os tipos de artefatos, com nome e descrição; e

- as avaliações, com seus respectivos dados, como a data de seu registro, os comentários, o nível de entendimento e de dificuldade de desenvolvimento acessível para cada experiência relatada e recomendações que o usuário achar pertinentes.

Ao administrador cabe o gerenciamento dos tipos de artefatos aceitos pela ferramenta, a visualização de relatórios de utilização e realização da moderação dos conteúdos enviados.

Para acesso aos recursos administrativos da ferramenta e visualização dos conteúdos, existem links para busca de artefatos e um formulário de acesso (login) na página inicial da ferramenta, apresentada na Figura 5.2. 


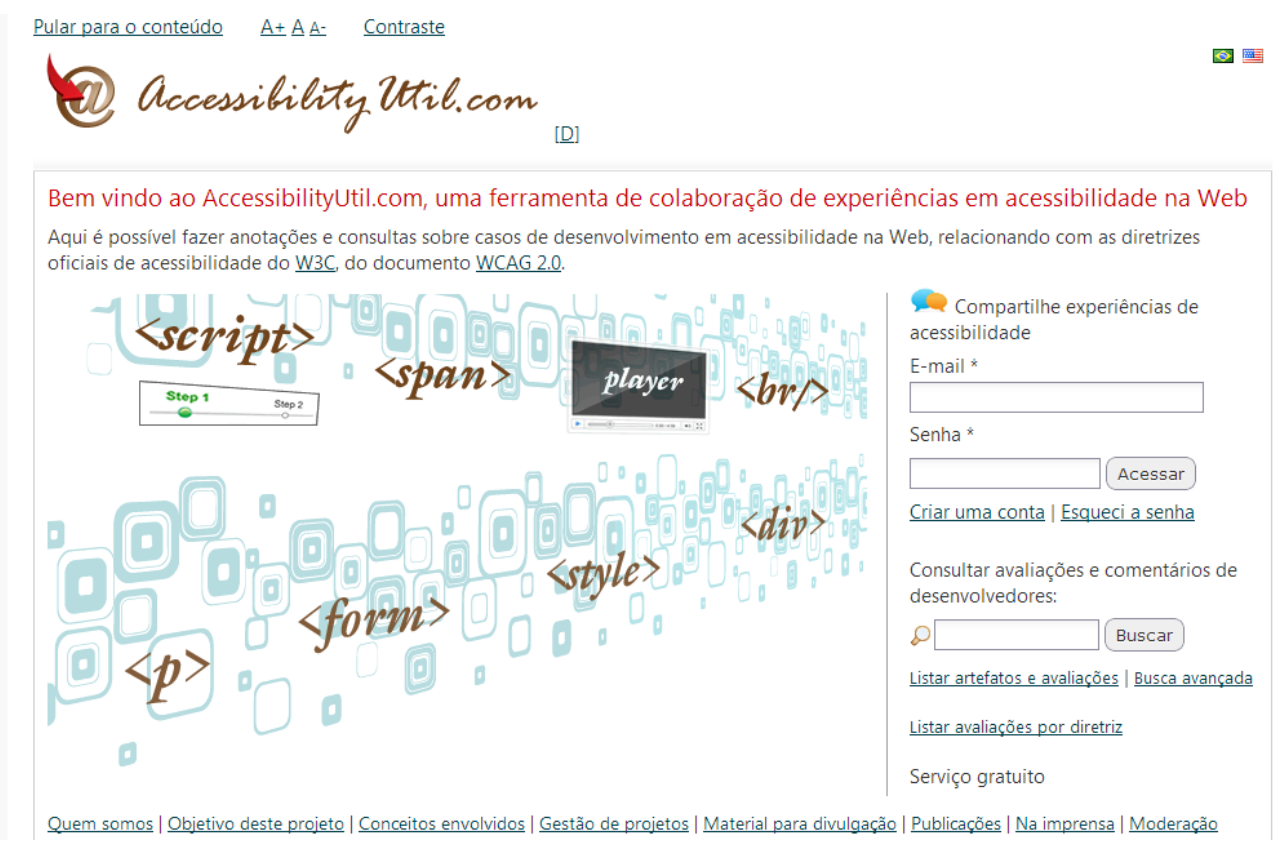

Figura 5.2 - Página inicial da ferramenta AccessibilityUtil

A criação de tipos de artefatos auxilia para melhorar a organização dos mesmos, categorizando-os. As categorias iniciais inseridas foram as seguintes: "Padrões", "Tags" e "Outros".

A intenção de se ter a categoria genérica "Outros" é permitir flexibilidade na categorização inicial, sendo que, caso essa categoria venha a conter um número elevado de artefatos, os mesmos serão analisados e uma nova categoria pode ser criada para os acomodar.

Assim, o modelo relacional da base de dados foi definido por meio da criação de 18 tabelas com relacionamentos entre si, como pode ser visto na Figura 5.3, gerada com apoio da ferramenta MySQL Workbench ${ }^{29}$.

\footnotetext{
${ }^{29}$ http://www.mysql.com/products/workbench/
} 


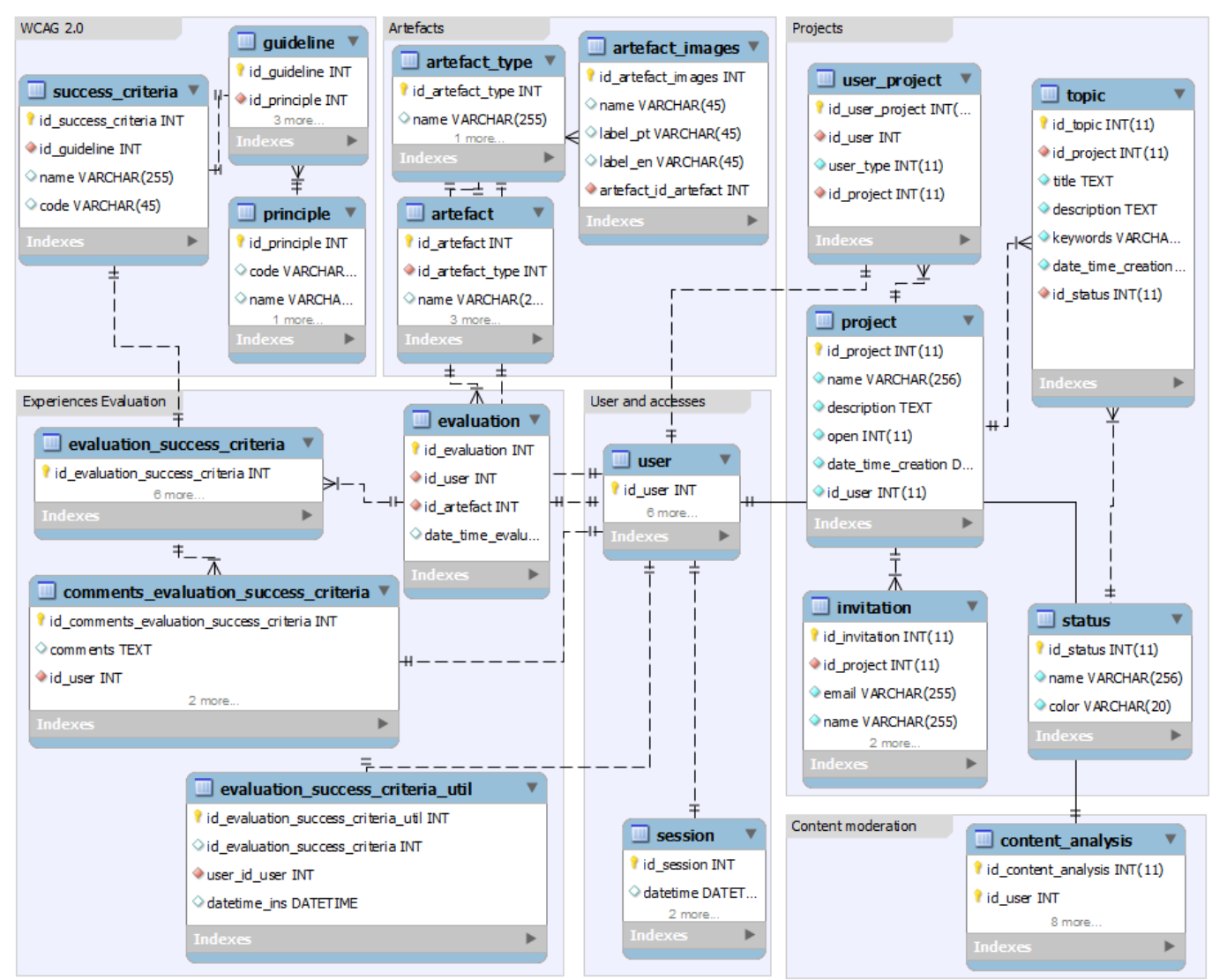

Figura 5.3 - Modelo de dados relacional da ferramenta

Na Figura 5.3 são apresentados os seis pacotes definidos para organização lógica das tabelas no diagrama relacional. Esses pacotes, que representam os conceitos mais abrangentes dos dados da ferramenta, são: "User and accesses", "Experiences evaluation", "Artifacts", "WCAG 2.0", "Projects" e "Content moderation".

Vale ressaltar que na tabela "evaluation_success_criteria" são armazenadas as informações que representam as contribuições dos usuários que colaborativamente elaboram o conteúdo da ferramenta. Assim, nela são registradas as avaliações contendo comentários gerais, recomendações de acessibilidade, referências para a literatura e qual o grau de dificuldade de desenvolvimento com acessibilidade relacionando com um critério de sucesso das diretrizes WCAG 2.0.

Além do conteúdo referente às diretrizes, essa base de dados ainda comporta o cadastro de usuários, seus dados pessoais, nível de expertise e perfil, se administrador ou 
participante. O dicionário de dados de tal modelo com a descrição de todos os seus campos (vistos na Figura 5.3) pode ser encontrado no Apêndice A.

Quanto ao projeto das interações da ferramenta, para fornecer o suporte adequado às suas funcionalidades, foram desenvolvidos formulários, que foram criteriosamente elaborados seguindo orientações de acessibilidade. $\mathrm{O}$ formulário de cadastro de artefato pode ser visualizado na Figura 5.4, no qual são requeridas informações como o tipo do artefato previamente cadastrado pelo administrador, seu nome, descrição, imagens associadas e referências literárias. Além da versão em português, é possível atribuir as traduções para o idioma inglês nos campos, a fim de que esses possam ser disponibilizados para participantes internacionais.

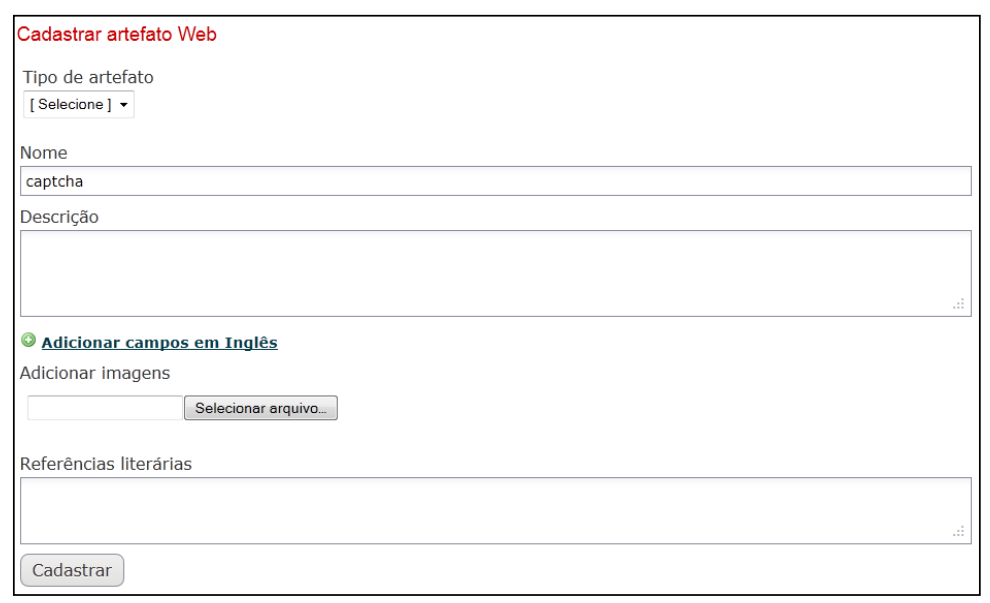

Figura 5.4 - Cadastro de artefato

Além de inserir artefatos, o participante pode realizar avaliações inserindo suas experiências em relação aos artefatos existentes. Na Figura 5.5 é apresentada a visualização de um artefato com uma imagem associada e o formulário para avaliação. 


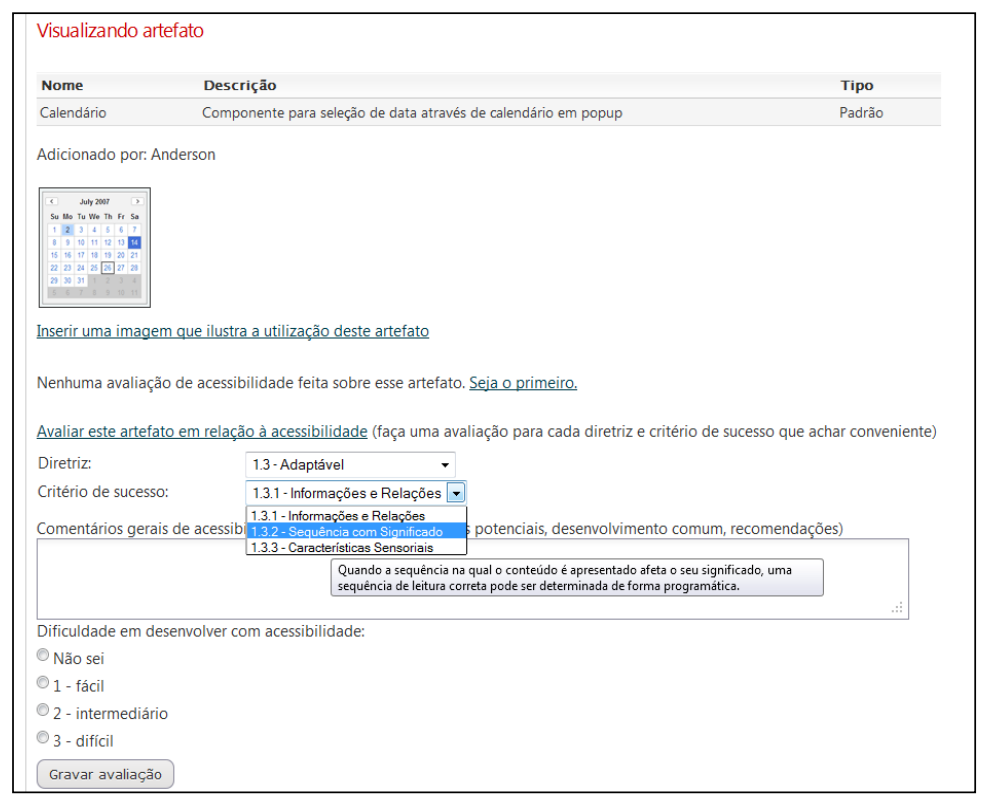

Figura 5.5 - Visualização de artefato

Uma característica do projeto da ferramenta AccessibilityUtil foi o estudo e projeto de interação buscando auxiliar para que os usuários tenham uma boa experiência de uso durante as interações com a interface da mesma. Desse modo, o cadastro de artefatos, por exemplo, é feito de maneira a dificultar duplicações de registros. Quando o participante insere o nome do artefato é realizada uma busca para mostrar possíveis candidatos que descrevam o artefato a ser inserido pelo participante. Caso esse nome do artefato já exista na ferramenta, o participante pode complementar a descrição do mesmo e fazer avaliações sem precisar cadastrá-lo novamente.

Para a funcionalidade de avaliação do artefato, a ferramenta proporciona uma associação com as diretrizes WCAG 2.0. Assim, o usuário deve selecionar a diretriz de acessibilidade e posteriormente escolher os critérios de sucesso habilitados a partir da seleção da diretriz. Os outros dois campos a serem preenchidos são os comentários gerais de acessibilidade e a pontuação da dificuldade em se desenvolver com acessibilidade.

É importante destacar que a interface foi planejada para apoiar aqueles que não têm conhecimento em profundidade sobre o conjunto de diretrizes presente, mostrando o texto relacionado a uma determinada diretriz quando o usuário permanece com o foco ou o ponteiro do mouse alguns instantes em cada opção, via atributo "title". Caso fosse um 
requisito conhecer as diretrizes para fazer a avaliação, isso poderia ser uma barreira para os usuários, e portanto, da forma proposta na ferramenta, ajuda na disseminação das mesmas.

Entre as características técnicas implementadas, as que merecem destaque por auxiliar na acessibilidade e usabilidade da ferramenta são:

i) uso de URLs amigáveis na visualização dos artefatos;

ii) adição de controles para aumentar o contraste e tamanho de caracteres; e

iii) uso de títulos específicos mais adequados para as páginas.

Os itens i) e iii) auxiliam também na indexação dos conteúdos por mecanismos de busca como o Google.

Outra possibilidade de colaboração incluída na ferramenta é a existência de um botão em cada experiência relatada em um artefato para usuários registrados se manifestarem, marcando se aquele conteúdo lhe foi útil. Cada usuário pode, então, fazer essa manifestação uma única vez para cada conteúdo de um comentário. Um exemplo dessa marcação é apresentado na Figura $5.6^{30}$.

Feita em: 30/05/2011 por - Critério de sucesso: 1.1.1 - Conteúdo Não Textual

Avaliação: Exemplo <img src="imagens/d91f57a71fd9057fcf6b103b7bd2a420.jpeg" alt="Imagem sem descrição" />

Na imagem acima deveria ser colocada uma descrição melhor da imagem no atributo 'alt' o que facilitaria a acessibilidade no caso de pessoas que necessitam de um programa para ler estas páginas.

$\square$ Comente Reportar spam, erro ou abuso $\quad 2$ usuários acharam útil. Você marcou isso como útil. (Desfazer)

Comentário feito por esse é um caso clássico de uso ruim da Tag. Sintaticamente está certo, porém, semanticamente está errado. Preencher a tag alt com "imagem sem descrição" fará com que os avaliadores automáticos tratem como correta a sua implementação, porém está inacessível. Ou seja, os criadores de conteúdo devem estar conscientes.

Figura 5.6 - Marcação de um conteúdo inserido como útil

Assim, é possível observar quantos usuários consideram útil determinadas avaliações, de acordo com marcações voluntárias, fazendo com que haja uma diferenciação entre as colaborações inseridas, isso em termos de um julgamento colaborativo da comunidade que utiliza a ferramenta.

\footnotetext{
${ }^{30}$ Todos os dados pessoais dos usuários, incluindo suas fotografias de perfil, foram desfocados propositalmente nas figuras apresentadas. Uma das motivações para isso é que a intenção deste trabalho é detalhar exemplos das colaborações realizadas e dos mecanismos de interação presentes na ferramenta AccessibilityUtil, e não o usuário.
} 


\subsubsection{Moderação do conteúdo}

A atividade de moderação do conteúdo consiste em uma ação reguladora para a organização, gestão e acompanhamento das atividades de colaboração. Com a realização de moderação, é possível se ter um controle sobre a inserção de conteúdos inapropriados aos objetivos de uma aplicação, filtrando informações, que podem ser tendenciosas, erradas ou com anúncios (CHEN et al., 2011).

A moderação pode ser colaborativa ou centralizada unicamente por líderes. $\mathrm{Na}$ moderação colaborativa, os usuários podem notificar aos líderes da colaboração sobre os conteúdos que consideram impróprios, para que haja a condução de uma avaliação das informações postadas. Esse tipo de moderação segue a premissa de que se muitas pessoas podem analisar informações e reportar erros em um conteúdo, eles serão corrigidos de forma mais barata e rápida. Já na moderação realizada por líderes, esses ficam como responsáveis por analisar os conteúdos inseridos e habilitar sua visualização ou não pelos demais usuários.

Por ser incentivada a colaboração ampla e de modo informal, a moderação colaborativa contribui para que, nas discussões feitas, possa se aprender com os erros e reportar experiências, diferente de ser um repositório de diretrizes corretas ou um guia. Desse modo, uma discussão para mostrar possíveis demonstrações equivocadas, com exemplos, partindo-se de experiências e seus resultados, se apresenta como uma base importante para compor um discurso que contribua de maneira a possibilitar a difusão de diretrizes, que se constituem como os preceitos corretos que devem ser seguidos.

No contexto dessa moderação, a ideia proposta por trás da ferramenta AccessibilityUtil não é armazenar conteúdo irrefutável sobre um assunto, mas sim prezar pela discussão contínua e evolutiva. Entende-se que o objetivo da ferramenta não é concorrer com repositórios formalmente constituídos e normatizados, que são referência para os assuntos em questão. Mas sim, dentro de limites da informalidade e liberdade de expressão, pretende-se, com a devida moderação, que o conteúdo inserido na ferramenta seja correto e compreensível a todos os interessados, em especial ganhando adeptos novatos que fiquem estimulados para aprender com as experiências dos demais. Assim, é necessária a moderação 
realizada por líderes, que corrijam e esclareçam, colaborando com a construção do conhecimento, corrigindo o raciocínio, bem como a participação de especialistas no assunto.

Em contrapartida, deve-se ter cuidado durante a definição das políticas de moderação, para que seu exercício se apresente de forma equilibrada, visando não inibir a colaboração e participação dos usuários interessados.

Dessa maneira, o tipo de moderação da ferramenta AccessibilityUtil é estritamente colaborativo, no qual busca-se por discussões que agregam diferentes pontos de vistas em um meio comum, construindo um enredo dinâmico de conhecimento, privilegiando a construção de conhecimento coletivo e decisões de um grupo informado para um determinado contexto.

Na Figura 5.7 é apresentada parte de uma tela da ferramenta AccessibilityUtil, na qual é possível visualizar os links que permitem o envio de indicação de conteúdo pelo usuário.

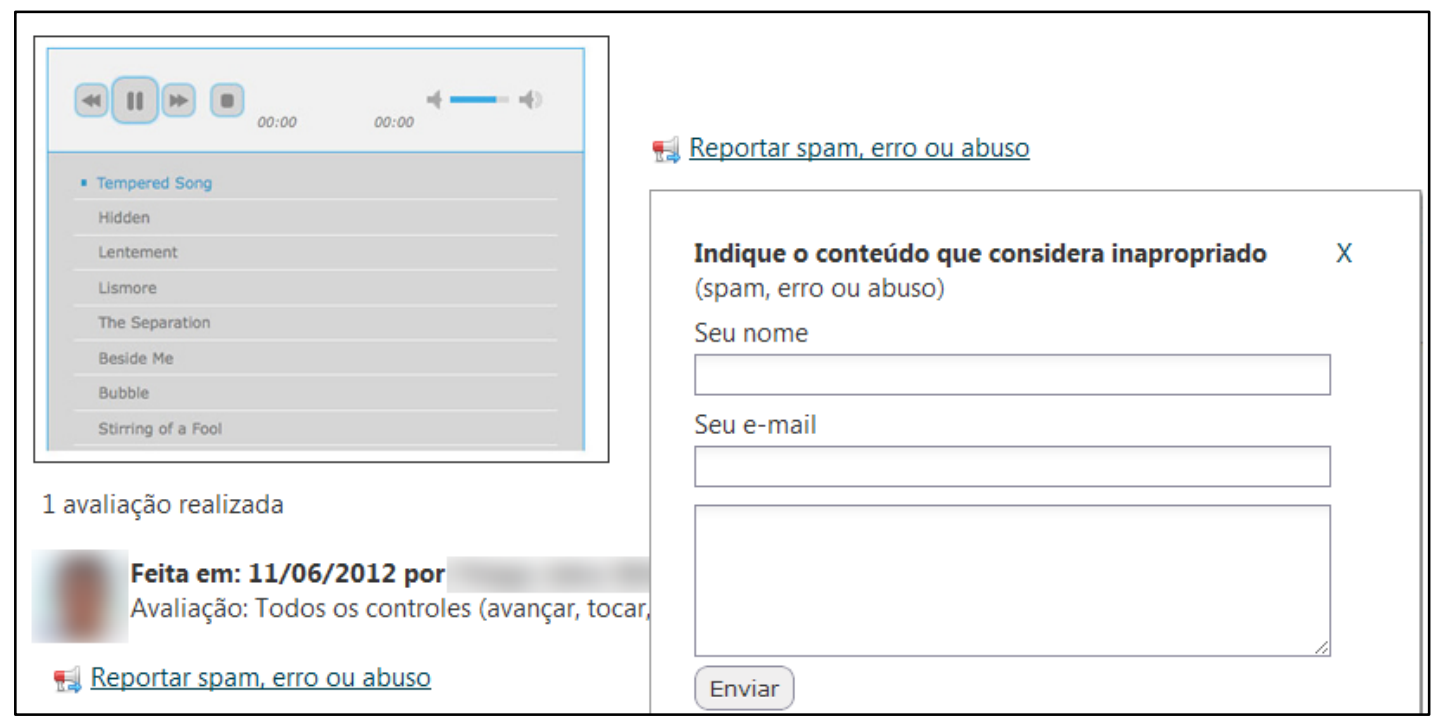

Figura 5.7 - Links e formulário para indicação de conteúdo a analisado por um administrador

Na Figura 5.7 é possível ver que estão sendo requisitados o nome e e-mail do informante, permitindo que usuários não registrados possam enviar indicação de conteúdo inadequado, ampliando a participação na moderação. No caso do usuário ser registrado e estar autenticado, ele não precisa informar seu nome e e-mail, pois tais dados são resgatados de seu cadastro. Após o envio dos dados, os administradores são notificados para analisar cada indicação enviada, referente a possíveis ocorrências de conteúdo inapropriado.

Outra característica da moderação implementada é que houve uma definição de regras claras e públicas, em que todos os usuários têm os mesmos direitos em uma comunidade, 
seguindo uma política igualitária. Para tanto, na página inicial da ferramenta encontra-se um link para uma página que informa tais regras. Dentre os conteúdos indesejados, têm-se aqueles como spam, pornografia, violação de direito autoral e propagandas.

\subsubsection{Gestão de decisões de acessibilidade em projetos}

Um módulo adicionado posteriormente à primeira versão da AccessibilityUtil foi o que permite a gestão de decisões de acessibilidade em projetos específicos, por meio de discussão de tópicos inseridos por colaboradores incluindo a sugestão de uso de diretrizes.

Os projetos podem ter um ou mais usuários colaborando entre si. Inicialmente, um usuário, criador do projeto, convida outros para participarem de seu projeto inserindo questões para discussão. Os usuários podem, desse modo, iniciar discussões de Design Rationale $(D R)$, as quais são identificadas por comentários centralizados por um tópico contendo um status, descrição e nome do criador.

A cada tópico de discussão criado, os demais usuários podem contribuir fazendo comentários, sendo que inicialmente o tópico fica sob o status de "em discussão”. Após a inserção de comentários, os usuários podem marcar o tópico com o status de "concluído", mas não há impedimento que estando, então, finalizado, um usuário possa reabrir o tópico para discussão, voltando o status para "em discussão”.

A visualização de um tópico com sua discussão é apresentada na ferramenta, como mostrado na Figura 5.8. 


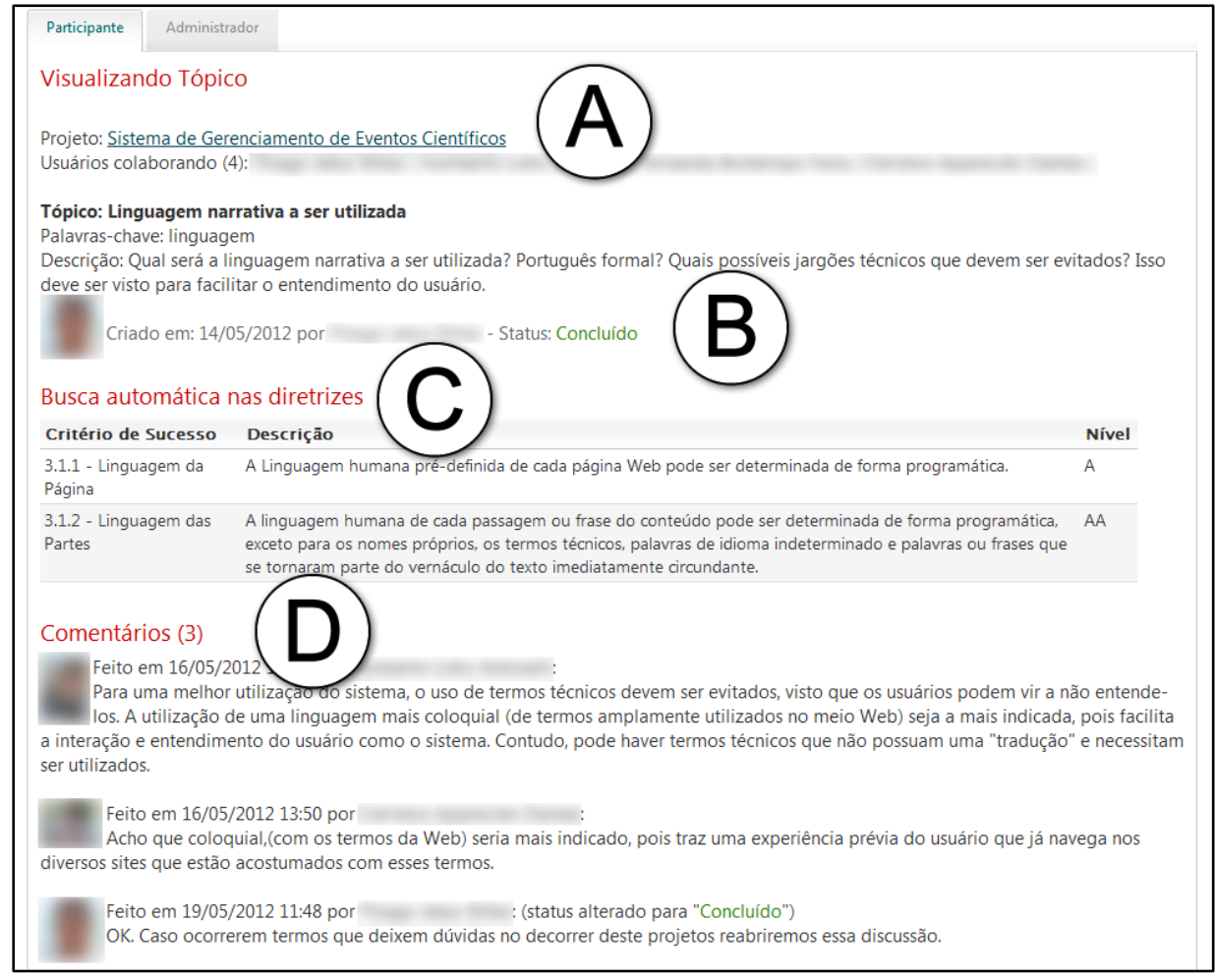

Figura 5.8 - Visualização de um tópico de um projeto e a discussão realizada

Como pode ser visto na Figura 5.8, a discussão de um tópico de um projeto é dividida em quatro partes principais:

A) detalhes do projeto em questão e listagem de quais usuários estão colaborando;

B) detalhes do tópico com seu título, descrição, palavras-chave, dados de sua criação e seu status;

C) resultado da busca automática nas diretrizes pelas palavras-chave para auxiliar na discussão; e

D) comentários feitos no tópico com data e autor do mesmo.

\subsection{Resultados de utilização parcial}

A ferramenta AccessibilityUtil foi disponibilizada para o público em maio de 2011 e seus resultados de uso têm sido analisados para subsidiar a pesquisa da abordagem proposta nesta tese. Além do desenvolvimento da ferramenta, que consumiu tempo e esforços significativos, como resultado pode-se ressaltar os dados coletados com a aplicação da ferramenta a partir do uso de seus mecanismos de interação e colaboração. 
Desde o seu lançamento até agosto de 2012, foram computados 819 acessos de usuários registrados na ferramenta, 151 usuários e 89 artefatos distribuídos em três tipos, conforme detalhados na Tabela 5.1.

Tabela 5.1 - Distribuição inicial dos artefatos

\begin{tabular}{|l|r|}
\hline Tipos de artefato & Quantidade \\
\hline \hline Padrões & 45 \\
\hline Tags & 22 \\
\hline Outros & 22 \\
\hline Total & 89 \\
\hline
\end{tabular}

Em relação às colaborações inseridas têm-se nesse mesmo período: 602 avaliações, 71 imagens e 203 comentários adicionados em avaliações, como mostrado na Tabela 5.2.

Tabela 5.2 - Colaborações na ferramenta

\begin{tabular}{|l|r|}
\hline Tipos de colaboração & Quantidade \\
\hline \hline Experiências & 602 \\
\hline Imagens & 71 \\
\hline Comentários & 203 \\
\hline Total & 876 \\
\hline
\end{tabular}

Na Tabela 5.3 são apresentados os números em relação ao módulo de projetos, criado em maio de 2012.

Tabela 5.3 - Números do módulo de projetos

\begin{tabular}{|l|r|}
\hline Tipos de colaboração & Quantidade \\
\hline \hline Projetos & 13 \\
\hline Tópicos & 58 \\
\hline Comentários & 165 \\
\hline Total & 236 \\
\hline
\end{tabular}

Em relação ao número de usuários distintos colaborando em algum projeto tem-se um total de 25, que produziram os 165 comentários em 58 diferentes tópicos.

A ferramenta AccessibilityUtil se mostrou, portanto, como uma aplicação bem sucedida, inclusive com o feedback positivo de usuários, e com um modelo de dados 
proposto que desempenhou papel importante no sentido de proporcionar colaboração no domínio de acessibilidade na Web, que necessita de esforços de todos para melhorar o quadro de inadequação de muitos artefatos em relação às diretrizes existentes.

O Google Analytics ${ }^{31}$ tem sido utilizado para acompanhamento detalhado dos acessos e para mensurar a utilização da ferramenta. Dentre as várias informações disponibilizadas a partir desse acompanhamento, na Tabela 5.4 é apresentado o resumo do relatório medido desde seu lançamento, durante 14 meses.

Tabela 5.4 - Resultados de diferentes métricas de utilização da ferramenta AccessibilityUtil

\begin{tabular}{|l|r|}
\hline Métrica & \multicolumn{2}{|c|}{ Resultado } \\
\hline Visitas & 2.876 \\
\hline Visitantes únicos & 1.901 \\
\hline Visualizações de página (pageviews) & 20.520 \\
\hline Páginas por visita & 7,13 \\
\hline Média de tempo de uma visita & 07 minutos e 13 segundos \\
\hline Porcentagem de novos visitantes & $65,51 \%$ \\
\hline
\end{tabular}

A Tabela 5.4 mostra que o conteúdo da AccessibilityUtil teve uma quantidade significativa de acessos, com mais de 20 mil páginas acessadas em 2.876 visitas. O tempo médio de permanência do usuário é algo expressivo, demonstrando um interesse de leitura e interação com o ferramental e conteúdos disponibilizados.

Em relação às organizações as quais os usuários são pertencentes fez-se um levantamento manual para se conhecer a origem e a abrangência da ferramenta: dos 151 usuários, 132 marcaram suas organizações, sendo 37 distintas, com os dados classificados conforme apresentados na Tabela 5.5. A listagem completa com o nome de cada organização pode ser vista no Apêndice A.

\footnotetext{
${ }^{31} \mathrm{http} / / / w w w . g o o g l e . c o m / a n a l y t i c s /$
} 
Tabela 5.5 - Número de usuários por tipo de organização

\begin{tabular}{|l|c|c|}
\hline Tipo de organização & Número de organizações & Número de usuários \\
\hline \hline Instituição de ensino superior & 19 & 113 \\
\hline Empresa de desenvolvimento de software & 4 & 5 \\
\hline Órgão público & 5 & 5 \\
\hline Instituição de ensino médio ou tecnológico & 4 & 4 \\
\hline Órgão privado & 3 & 3 \\
\hline Instituição de ensino superior internacional & 2 & 2 \\
\hline
\end{tabular}

A partir dos dados apresentados na Tabela 5.5, observa-se que a maioria dos usuários são vinculados a organizações de ensino superior, resultado esse provavelmente ocorrido pela maior divulgação da ferramenta no meio acadêmico. A utilização nesse tipo de organização é importante para auxiliar na educação tecnológica, visando o ensino de boas práticas para desenvolvimento Web considerando acessibilidade. Verifica-se também a participação de usuários ligados a órgãos públicos e empresas de desenvolvimento de software, o que demonstra um princípio de interesse e utilização da ferramenta no meio não acadêmico.

Outro ponto de destaque foram algumas definições no projeto da ferramenta, como, por exemplo, a escolha do domínio e nome da aplicação: para que o projeto tenha maior abrangência, inclusive internacional, foi escolhido o seu acesso por meio de um domínio “.com”. Essa característica permite ao projeto não ficar associado a um domínio de uma única instituição, já que o mesmo envolve diferentes instituições e outras poderão se associar como parceiras.

Além disso, uma característica interessante de resultados é em relação aos diferentes relatórios que podem ser gerados a partir da base de dados da ferramenta, envolvendo diferentes visões. Um exemplo dessa característica pode ser visto na Figura 5.9, em que é mostrada uma parte do relatório que informa quantas avaliações cada critério de sucesso possui. 


\begin{tabular}{|ll|}
\hline Nome & Avaliaçōes \\
\hline Princípio: 1 - Perceptivel & \\
\hline 1.1 - Alternativas em Texto & $\underline{79}$ \\
\hline 1.1 .1 - Conteúdo Não Textual & \\
\hline 1.2 - Mídias com base no tempo & $\underline{0}$ \\
\hline 1.2 .1 - Apenas Áudio e apenas Vídeo (Pré-gravado) & $\underline{0}$ \\
\hline 1.2 .2 - Legendas (Pré-gravadas) & $\underline{0}$ \\
\hline 1.2 .3 - Audiodescrição ou Mídia alternativa (Pré-gravada) & $\underline{0}$ \\
\hline 1.2 .4 - Legendas (Ao Vivo) & $\underline{2}$ \\
\hline 1.2 .5 - Audiodescrição (Pré-gravada) & $\underline{0}$ \\
\hline 1.2 .6 - Linguagem de sinais (Pré-gravada) & $\underline{2}$ \\
\hline 1.2 .7 - Audiodescrição Extendida (Pré-gravada) & $\underline{1}$ \\
\hline 1.2 .8 - Mídia Alternativa (Pré-gravada) & $\underline{13}$ \\
\hline 1.2 .9 - Apenas áudio (Ao vivo) & $\underline{\underline{4}}$ \\
\hline 1.3 - Adaptável & $\underline{17}$ \\
\hline 1.3 .1 - Informações e Relações & $\underline{27}$ \\
\hline 1.3 .2 - Sequência com Significado & \\
\hline 1.3 .3 - Características Sensoriais & \\
\hline 1.4 - Discernivel & \\
\hline 1.4 .1 - Utilização da Cor & \\
\hline 1.4 .2 - Controle de Áudio & \\
\hline
\end{tabular}

Figura 5.9 - Número de avaliações por critério de sucesso

De acordo com a listagem presente na Figura 5.9, é possível perceber que um critério com muitas avaliações é o "1.1.1 - Conteúdo Não Textual”, em que houveram 79 comentários nos artefatos cadastrados.

\subsection{Análise qualitativa das colaborações}

Até agosto de 2012, por meio das colaborações realizadas na AccessibilityUtil, pôdese identificar dados qualitativos e efetuar uma análise que é apresentada nesta seção. Conforme visto anteriormente, o número de colaborações é extenso, sendo inviável e fora do objetivo desta tese apresentar todas as experiências presentes na ferramenta. Então são apresentados nas subseções a seguir: uma seleção de trechos de contribuições e considerações sobre esses, uma análise e verificação de concordância nas discussões e, por fim, considerações gerais sobre a base de dados total formada.

\subsubsection{Seleção de trechos de contribuições e considerações}

Alguns exemplos de contribuições de usuários e considerações do autor desta tese são apresentados a seguir. Tal seleção foi feita de forma a selecionar critérios de sucesso dos 3 
princípios das diretrizes WCAG 2.0, apresentando o conteúdo presente na ferramenta sucintamente e de forma ampla em relação à cobertura desses princípios.

- Critério de sucesso: 3.1.1 - Linguagem da Página.

- Artefato: $\langle\mathrm{p}>($ tag).

- Experiência reportada nessa avaliação: "O parágrafo atrai a atenção do usuário. Isso ajuda fazendo com que ele olhe para o início do texto e comece a leitura até o seu fim. Um texto sem parágrafo é cansativo, não fica organizado e interessante”.

- Considerações do autor desta tese: essa contribuição é pertinente por incentivar o uso correto da tag de parágrafo, deixando o texto mais bem organizado. Isso vem de encontro a um possível e comum erro encontrado em sites referente à composição de textos erroneamente com quebras de linha (usando a tag $\langle$ br $>$ ) ao invés do uso do artefato em questão.

- Critério de sucesso: 2.1.1 - Teclado.

- Artefato: <select> (tag).

- Considerações do autor desta tese: "O select ou combo-box torna o preenchimento de formulários mais fácil. Ele ajuda não só as pessoas com dificuldade, mas todo mundo poupando-os a escrever algo que já está definido. Em vez de digitar uma opção, basta selecionar a opção e ela está pronta".

- Experiência reportada nessa avaliação: há o relato sobre o uso de uma caixa de seleção e seu possível auxílio no preenchimento de formulários, em termos de usabilidade. É fato que realmente altera o modo de preenchimento de um determinado campo, possibilitando que seja escolhida uma ou mais opções (no caso de uma caixa de seleção múltipla) de uma listagem, podendo realmente facilitar ao usuário. No entanto, esse é um elemento que deve ser utilizando apenas em um determinado contexto de uso, em que existem possíveis respostas para um campo.

- Critério de sucesso: 1.3.1 - Informações e Relações.

- Artefato: Menu Accordion (padrão). 
- Experiência reportada nessa avaliação: “Acordeões são uma boa maneira de organizar um site. É necessário que ele possa ser lido por leitores de tela. Os acordeões tornam mais rápida a localização dos objetos em um site, porque tudo fica dividido em tópicos, assim a navegação se torna mais fácil".

- Considerações do autor desta tese: nesse trecho apresentado é possível ver uma justificativa para utilização desse menu para se ter um boa organização no auxílio à navegação e localização de conteúdo de um site, permitindo a separação de informação em tópicos. A preocupação com a acessibilidade pode ser vista de maneira mais geral, sendo relatado que o menu precisa ser desenvolvido de forma a ser lido por leitores de tela, porém não é explicado detalhadamente como isso deve ser feito.

Nos pontos a seguir são apresentadas considerações sobre as contribuições acerca de artefatos, sendo que a escolha dos exemplos foi feita dentre aqueles que têm um bom número de contribuições (mais de 8 avaliações cada um) na ferramenta AccessibilityUtil:

- “Banner de propaganda" (da categoria "padrão" com 15 avaliações): tais elementos devem ter descrição textual incluindo textos alternativos e legendas (em caso de animações e vídeos). Eles também podem dificultar a leitura do conteúdo principal de uma página, porém foi levada em consideração a questão comercial da presença deles, para a viabilidade da existência dos sites. Nesse sentido, como uma possível solução, é importante que se tenha uma boa formatação e alinhamento dos banners e suas descrições textuais. Outra preocupação apontada pelos usuários é a questão de banners que aparecerem abruptamente na tela, frequentemente atrapalhando o usuário;

- "Menu de ícones" (da categoria "padrão" com 8 avaliações): cada figura desse menu deve ter sua descrição textual clara e objetiva. Outra questão verificada é que esse menu, se formado por ícones representativos, facilita o acesso a determinadas seções de um site por usuários analfabetos funcionais, que nesse tipo de elemento usam a análise visual para agregar significado à descrição textual presente; e

- "Reprodutor de vídeo" (da categoria "padrão" com 12 avaliações): os colaboradores discorrem sobre a necessidade de se haver um aviso textual e metadados sobre o que o vídeo irá mostrar, devendo esse texto claro ao usuário. Além 
disso, deve existir em cada vídeo uma descrição textual, que é a informação do que está acontecendo em cada instante do vídeo, mais do que uma simples transcrição de falas.

\subsubsection{Verificação de concordância nas discussões}

Um ponto característico da ferramenta AccessibilityUtil é promover discussões sobre a aplicação de diretrizes em que vários usuários podem inserir seus diferentes pontos de vista. Tais discussões envolvem: i) concordância total, em que os usuários confirmam o que foi discorrido anteriormente por outro usuário, podendo inserir ou não mais detalhes; ii) concordância parcial, em que algum ponto de uma contribuição é aceito por outro usuário e outro ponto não é aceito e, iii) discordância total do que foi informado em relação à contribuição de outro usuário.

Um caso em que ocorre concordância total pode ser visto nas contribuições para o artefato "autocompletar", que é um recurso utilizado em formulários para o usuário receber sugestões a partir de parte do texto digitada. Essa concordância é relativa à importância desse recurso para facilitar a inserção de informações pelo usuário, porém as contribuições na AccessibilityUtil deixam claro que esse recurso deve ser provido de forma a não atrapalhar a interação do usuário, não prejudicando o seu foco ou deixando a digitação lenta. Outra questão apontada nas contribuições é como fazer esse auxílio também ser adequado quando o site estiver sendo usado por ferramentas de leitura de tela.

Já a concordância parcial é encontrada frequentemente nas discussões feitas na ferramenta AccessibilityUtil, sendo uma maneira de discussão em que há algum conflito de ideias, porém apresentado de forma mais amena. Um exemplo de concordância parcial pode ser encontrado na discussão sobre a utilização do artefato "site em Flash", em que há a incorporação no HTML de um objeto desenvolvido na tecnologia Adobe Flash. A discussão foi acerca da necessidade de utilização de recursos para uma interação mais rica pelo usuário, que nas primeiras versões do HTML e CSS só era possível ser feita por meio de tal tecnologia.

Tal discussão contemplou a avaliação feita por um usuário que ressalta a dificuldade de acesso frequentemente encontrada por deficientes visuais no acesso com uso de leitores de 
tela a conteúdos de sites que utilizam a tecnologia Adobe Flash. Nesse caso, a ocorrência da concordância parcial se deu no seguinte comentário de um usuário: "de fato concordo com a avaliação e também com os comentários, mas, olhando na questão de interatividade, uso de recursos de som em animações e vídeos, o site sem alguns desses recursos fica ruim. Para pessoas sem necessidades especiais fica muito melhor um site assim..." (grifo do autor desta tese para evidenciar a concordância parcial). Tal comentário demonstra que os desenvolvedores não querem deixar de usar recursos de melhoria da interação para tornar o site acessível, sendo que eles estão preocupados com o bom uso pelas "pessoas sem deficiências".

Verifica-se, assim, que a possibilidade de colaboração propiciada enriqueceu a avaliação feita, trazendo à tona diferentes pontos de vista, incluindo esse comentário destacado anteriormente que reconhece a necessidade de melhoria da interação com uso de recursos nem sempre acessíveis.

Sobre a discordância total, de acordo com as verificações feitas, essa situação foi a que menos ocorreu, porém, nos casos onde houve tal ocorrência, são evidenciadas de forma clara as diferentes posições dos usuários. Um exemplo dessa situação é no artefato "exclusão de conta", em que os comentários envolveram o quão deve ser fácil de ser encontrada essa opção e como deve ser feita sua apresentação visual. Nos comentários sobre esse artefato, um usuário não concorda que a opção de excluir a conta precisa ser de fácil acesso, visto que é usada poucas vezes e pode ser acionada por alguma confusão do usuário (se estiver em grande evidência). Outro usuário, logo em seguida, insere sua opinião contrária e a justifica com argumentos, enriquecendo a contribuição inicial reportando que não haverá confusão do usuário se tal funcionalidade for bem desenvolvida, devendo contemplar uma verificação de senha de usuário como requisito para permitir a exclusão.

Existe outra situação encontrada nas inserções que é a ausência de discussão entre os usuários, que ocorre quando em um determinado artefato apenas uma pessoa insere informações. Acredita-se que existem as seguintes motivações para essa situação: colaboração de difícil entendimento pelos usuários; conteúdo que não desperta interesse de outros usuários e uma colaboração fora do escopo de acessibilidade da ferramenta. 
Existem outros casos em que há a participação de mais de uma pessoa, porém sem haver discussões significativas. Um exemplo disso pode ser visto nos registros sobre o artefato "Blockquote" (bloco de citação), em que existem cinco narrações de experiências e somente uma avaliação apresenta um comentário de outro usuário.

\subsubsection{Considerações gerais}

Após a leitura das contribuições presentes na ferramenta podem ser feitas inferências gerais sobre o conteúdo disponibilizado e sobre como os recursos de colaboração influenciaram no delineamento de discussões em relação aos artefatos presentes. Essas inferências são apresentadas nas seguintes considerações:

- Informalidade: os termos utilizados nas colaborações foram informais, de acordo com a proposta da ferramenta, sendo algo que já era esperado. Isso pode facilitar a leitura e compreensão do conteúdo, porém tem como desvantagem a característica de não haver um rigor textual, podendo gerar um entendimento confuso;

- Construções textuais simples: os parágrafos foram constituídos por construções simples que também facilitam a leitura pelo usuário, que vê cada experiência reportada como um tópico geralmente curto e simples;

- Dificuldade na associação com as diretrizes: percebe-se que alguns relacionamentos de contribuições com as diretrizes se distanciam do contexto apresentado na WCAG 2.0. Apesar de ser apresentado um texto explicativo sobre cada critério de sucesso das diretrizes, entende-se que o usuário pode ter dificuldade nessa associação. Pode ocorrer também que uma determinada contribuição envolve mais de um critério de sucesso, sendo que a ferramenta não suporta essa associação múltipla, devendo ser inseridas as experiências de forma separada para cada critério de sucesso associado;

- Exemplificação: os usuários procuraram associar cada implementação a exemplos práticos incluindo, em alguns casos, a inserção de links. A possibilidade do envio de imagens do uso dos artefatos também contribuiu para essa característica, auxiliando no entendimento do texto; e 
- Correlação ao tema acessibilidade: nas discussões são mencionados fatos e argumentos de outros temas correlacionados com a preocupação com acessibilidade. Isso demonstra que a acessibilidade não deve ser vista de maneira isolada, existindo todo um contexto que reflete nas ações e desenvolvimentos em prol de se ter artefatos Web acessíveis. Como exemplificação disso, podem ser mencionados: fatores temporais (prazo curto), razões comerciais (propagandas), usabilidade (uso de senhas e facilidade de navegação) e regras de negócios que exigem determinada implementação (necessidade de autenticação e seletor de idiomas).

\subsection{Considerações finais}

Neste capítulo foram apresentadas as decisões de projeto, planejamento, desenvolvimento e resultados de uma ferramenta de colaboração para avaliação de artefatos associando com as diretrizes de acessibilidade WCAG 2.0.

Como lição aprendida deste estudo e desenvolvimento, pode-se destacar que não basta apenas coletar informações e decisões de projetos para acessibilidade, existe a necessidade de organizar essas informações de acordo com as diretrizes estabelecidas. A organização feita com base no modelo de dados apresentado se mostrou importante para a obtenção de bons resultados a partir da disponibilização da ferramenta.

Assim, pelos acessos à ferramenta e comentários das avaliações, há condições de se avaliar o que é considerado pela equipe de desenvolvimento da ferramenta o seu ponto forte: a colaboração para ajudar os desenvolvedores a decidirem que técnicas usar. Almeja-se que isso possa contribuir para aproximar experiências de casos reais de desenvolvimento (na forma de artefatos) às diretrizes e possibilitar a colaboração com comentários entre desenvolvedores e stakeholders.

As principais contribuições deste trabalho em termos de funcionalidades e base de dados podem ser resumidas conforme apresentadas a seguir:

i) contato dos participantes com as diretrizes de acessibilidade e visualização de diferentes pontos de vista sobre a mesma avaliação; 
ii) colaboração dos participantes para a inserção de experiências que envolvem a consideração de diretrizes de acessibilidade para o desenvolvimento de um determinado artefato;

iii) montagem, evolução e difusão de uma base de dados de experiências práticas sobre desenvolvimentos com usabilidade relacionando com artefatos e diretrizes oficiais; e

iv) consulta por artefatos já avaliados e atendentes às diretrizes, provendo maior aprendizado e identificação de premissas inadequadas.

A ferramenta está sendo divulgada na comunidade entre as diferentes expertises para avaliação de inúmeros artefatos que são criados pelos próprios participantes. Nessa linha, como resultados indiretos, é possível mencionar a divulgação do tema acessibilidade na mídia a partir do desenvolvimento e disponibilização da ferramenta. Tais divulgações ocorreram na mídia em forma de vídeos e matérias escritas em meios como: i) TV Globo Catalão-GO - Anhanguera; ii) TVE São Carlos-SP; iii) Revistas; e iv) site da USP e da UFG, dentre outros. Um detalhamento da veiculação feita pode ser encontrado no site da ferramenta na seção "Na imprensa"32.

Como limitações, observou-se a dificuldade em obter experiências para o tema de acessibilidade na Web, sendo que é um desafio a motivação de usuários para participarem com contribuições.

Como trabalho futuro, novos conjuntos de diretrizes poderão ser adicionados à ferramenta, com o propósito de avançar nos requisitos de acessibilidade e tornar os artefatos cada vez mais acessíveis. Outra possibilidade ainda é integrar os comentários sobre os artefatos em ambientes de desenvolvimento, facilitando a tarefa do desenvolvedor, que poderá visualizar recomendações e experiências práticas em modo de desenvolvimento, por exemplo, por meio de "arrastar e soltar" um elemento e aparecerem textos de recomendações e diretrizes auxiliando-o.

No próximo capítulo é apresentada a abordagem desenvolvida nesta tese, desde sua concepção até a descrição de cada atividade contemplada.

\footnotetext{
${ }^{32} \mathrm{http} / / / \mathrm{www}$.accessibilityutil.com/press-clipping
} 


\section{Uma abordagem de apoio a boas práticas para desenvolvimento de aplicações Web acessíveis}

\subsection{Considerações iniciais}

Como mencionado nos capítulos anteriores, uma questão crítica no desenvolvimento Web está relacionada à utilização das diretrizes de acessibilidade durante a implementação dos artefatos de software. Neste sentido, em um projeto Web, é importante identificar quais, como e quando diretrizes de acessibilidade devem ser consideradas.

De modo a resolver os problemas ocasionados pela falta de consideração sobre acessibilidade na Web, são apresentados neste capítulo os conceitos e trabalhos relacionados 
envolvidos na concepção da abordagem desta tese, que objetiva o apoio efetivo na consideração e aplicação de diretrizes de acessibilidade durante o desenvolvimento Web.

Este capítulo é organizado da seguinte forma: nas Seções de 6.2 a 6.6 são descritos detalhes da abordagem criada, seus 3 eixos, as atividades, entradas e saídas pertinentes. $\mathrm{Na}$ Seção 6.7, por sua vez, tem-se uma integração da abordagem com o modelo de processo da norma ISO/IEC. Já, na Seção 6.8, são elencadas considerações gerais, incluindo ameaças e dificuldades para sua aplicação e exemplos de domínios que estão fora do escopo deste trabalho. Por fim, na Seção 6.9, são apresentadas as considerações finais referentes ao desenvolvimento da abordagem.

\subsection{Concepção da abordagem}

A concepção da abordagem envolveu a investigação da problemática, fundamentação de princípios teóricos (conceitos envolvidos) e ações práticas (estudos realizados). Assim, a abordagem foi baseada em ideias coletadas por meio de estudos sobre acessibilidade, Engenharia Web, modelos e DR disponíveis na literatura (Capítulo 2), por meio dos resultados identificados a partir de uma análise automatizada em sites de prefeitura municipais brasileiras, de modo a verificar o grau de acessibilidade, bem como de resultados observados por meio de uma prova de conceito, com verificação de facilidades que podem ser utilizadas em editores Web e gerenciadores de conteúdo, como em Wikis (Capítulo 3). A abordagem foi desenvolvida seguindo uma metodologia top-down, sendo criada de forma abstrata e refinada evolutivamente, a partir dos resultados coletados por meio de revisões bibliográficas, de pesquisas empíricas e do feedback recebido na apresentação de trabalhos em conferências.

A abordagem foi desenvolvida para ser utilizada de forma sistemática, iterativa e interativa em níveis de análise e projeto de artefatos Web. Ela é sistemática, haja vista que segue uma sequência de atividades que devem ser executadas, tendo entradas que devem ser consideradas e apresentando um conjunto de artefatos que devem ser produzidos como saída. É iterativa porque o processo deve ser contínuo durante o desenvolvimento do projeto, na forma de atividades que devem ser executadas, de modo a separar e fundamentar práticas de desenvolvimento com acessibilidade para se ter um bom resultado no projeto. É interativa 
desde que as saídas de uma atividade podem ser utilizadas para prover as entradas das atividades subsequentes, ou seja, as atividades não são isoladas umas das outras.

Com o uso da abordagem, é possível realizar planejamentos e execução de ações para corrigir possíveis problemas de artefatos desenvolvidos com barreiras de acessibilidade. A abordagem apresenta atividades sobre o que deve ser considerado durante o desenvolvimento Web, incluindo ações de treinamento contínuo, gerência de decisões e auxílio no desenvolvimento, de modo a apoiar a implementação, tendo a acessibilidade como requisito.

Como exemplo, pode-se citar um possível cenário de uso da abordagem relacionado às organizações que desejam adotar ou melhorar a adoção de boas práticas para desenvolvimento de aplicações Web acessíveis. Detalhando esse cenário, verifica-se que são requeridos esforços operacionais no que tange à necessidade da equipe, como:

- Conscientizar a equipe de desenvolvimento e possibilitar o aprendizado relacionado a como executar boas práticas de desenvolvimento;

- Prover treinamentos, visando a disseminação de informação sobre acessibilidade entre os membros da equipe;

- Gerenciar decisões para um desenvolvimento com acessibilidade, reutilizando soluções de sucesso a partir da formação e consulta a bases históricas;

- Elicitar requisitos de acessibilidade e documentar o que está sendo desenvolvido, de acordo com os perfis de usuários e necessidades de negócio;

- Escolher ferramentas de desenvolvimento adequadas e utilizar seus recursos eficazmente, visando tornar a adoção de boas práticas mais fácil e rápida; e

- Utilizar e reusar componentes de software Web com acessibilidade verificada.

Assim, para orientar tais esforços e suprir os requisitos necessários para prover acessibilidade (como apresentado nos capítulos anteriores), a abordagem desenvolvida é apresentada tendo como base a utilização de atividades específicas. Tais atividades são organizadas em eixos, de modo a nortear o trabalho da equipe durante a análise e implementação de artefatos Web acessíveis.

O conceito de reuso de código e conhecimento que permeia, de forma importante, a abordagem apresentada nesta tese, é inspirado na abordagem relatada por Lucrédio (2009), 
que apresenta uma base teórica sobre a reutilização de software de forma sistemática, considerando uma família de sistemas similares em um determinado domínio. Há também o conceito de se elevar a importância dos modelos de desenvolvimento, fazendo com que esses sirvam como entrada para geração efetiva de códigos de uma aplicação.

Além de considerar e sugerir o reuso, a abordagem apresentada aqui ainda tem como característica ser flexível e extensível para apoio ao desenvolvimento Web, sendo que, durante os ciclos de projeto, ela tem por objetivo promover o apoio a boas práticas para desenvolvimento, reportando o resultado de validações com consulta a diretrizes e padrões para apoio ao projeto de aplicações Web acessíveis.

Uma vez que as atividades práticas para desenvolvimento de artefatos com acessibilidade são pouco difundidas nos projetos de desenvolvimento Web, como já demostrado nos capítulos anteriores, viu-se a necessidade de desenvolver uma abordagem simples e clara em sua estrutura e atividades. Isso foi definido para facilitar sua adoção, diminuindo a resistência em relação à sua aplicação, por parte dos desenvolvedores, de forma que a mesma não seja considerada como mais uma dificuldade a ser enfrentada durante o desenvolvimento Web e sim como um auxílio que complementa os passos já seguidos pela equipe envolvida.

Nesse contexto, se a abordagem apresentar um extenso e difícil conjunto de atividades, poderá se tornar custosa à organização e dificilmente resolverá a falha em relação às considerações que devem ser seguidas para aplicar as diretrizes de acessibilidade durante o desenvolvimento.

Um embasamento fundamental da abordagem está relacionado com a sugestão do uso de forma prática e eficaz de diretrizes oficiais do W3C - WCAG 2.0 e ATAG 1.0 e ATAG 2.0 (que ainda está em desenvolvimento, apresentada em modo de rascunho - "draft").

Assim, pode-se destacar a relevância de uma evolução contínua que ocorreu durante o desenvolvimento da abordagem (como pôde ser visto na linha do tempo dos trabalhos efetuados, presente no Capítulo 1), uma vez que a mesma foi melhorada à medida que novos achados foram identificados e refinamentos realizados. 
Isso não garante que a abordagem ainda não deva ser evoluída, mas permite ter uma base sólida em relação à construção da mesma sobre os aspectos da acessibilidade, visto que foi desenvolvida sobre resultados de estudos que tinham esse tema como foco principal.

\subsection{A abordagem}

O foco principal da abordagem é apoiar boas práticas que aproximem diretrizes de acessibilidade ao cotidiano de trabalho de uma equipe de desenvolvimento Web. Especificamente, ela consiste de um conjunto de instruções utilizadas de modo a conscientizar os desenvolvedores e demais envolvidos na criação de projetos Web sobre a necessidade de tais diretrizes, guiando-os e fornecendo meios de aplicá-las durante o desenvolvimento.

A abordagem é composta por três eixos, os quais são definidos para agrupar atividades semelhantes, a fim de formar um conjunto de ações que devem ser seguidas para apoio a boas práticas de desenvolvimento, considerando acessibilidade em aplicações Web. Tais eixos são:

- 1 - TA. Treinamento em Acessibilidade;

- 2 - GD. Gerência de Decisões; e

- 3 - DF. Desenvolvimento e Ferramental.

O Eixo 1 - TA foi definido pela necessidade de conscientização e treinamento dos envolvidos no desenvolvimento de projetos Web acerca da problemática sobre acessibilidade, incluindo a apresentação de soluções. Tal eixo foi motivado baseado no trabalho apresentado em Freire et al. (2008), onde se verifica que uma considerável parcela dos envolvidos em projeto de software não conhece as diretrizes de acessibilidade e, consequentemente, não as consideram.

Já a definição do Eixo 2 - GD é justificada devido à relevância em se ter decisões coerentes relacionadas ao processo de apoio a boas práticas para desenvolvimento Web. Observa-se que existem diferentes métodos e estratégias para apoio e adoção de tais práticas, entretanto, durante a tomada de decisões, escolhas erradas podem comprometer o andamento do projeto. Assim, espera-se que, com este eixo, critérios e controle de qualidade sejam 
considerados em relação às decisões necessárias sobre as avaliações discutidas pelos usuários, relacionadas às questões de acessibilidade.

Finalmente, o Eixo 3 - DF foi definido visto que é necessário, além de conscientizar e verificar decisões, definir as ações a serem implementadas e colocá-las em prática durante o desenvolvimento. Desse modo, deve-se considerar o apoio ferramental com importantes recursos que auxiliem e viabilizem o desenvolvimento de forma ágil e com reuso.

Os eixos são compostos por atividades, as quais, se corretamente executadas, produzirão saídas resultantes da aplicação de considerações de acessibilidade durante o desenvolvimento dos artefatos. Na Figura 6.1 é apresentada uma visão geral da abordagem, com seus eixos e atividades.

\section{EIXOS DA ABORDAGEM E SUAS ATIVIDADES}

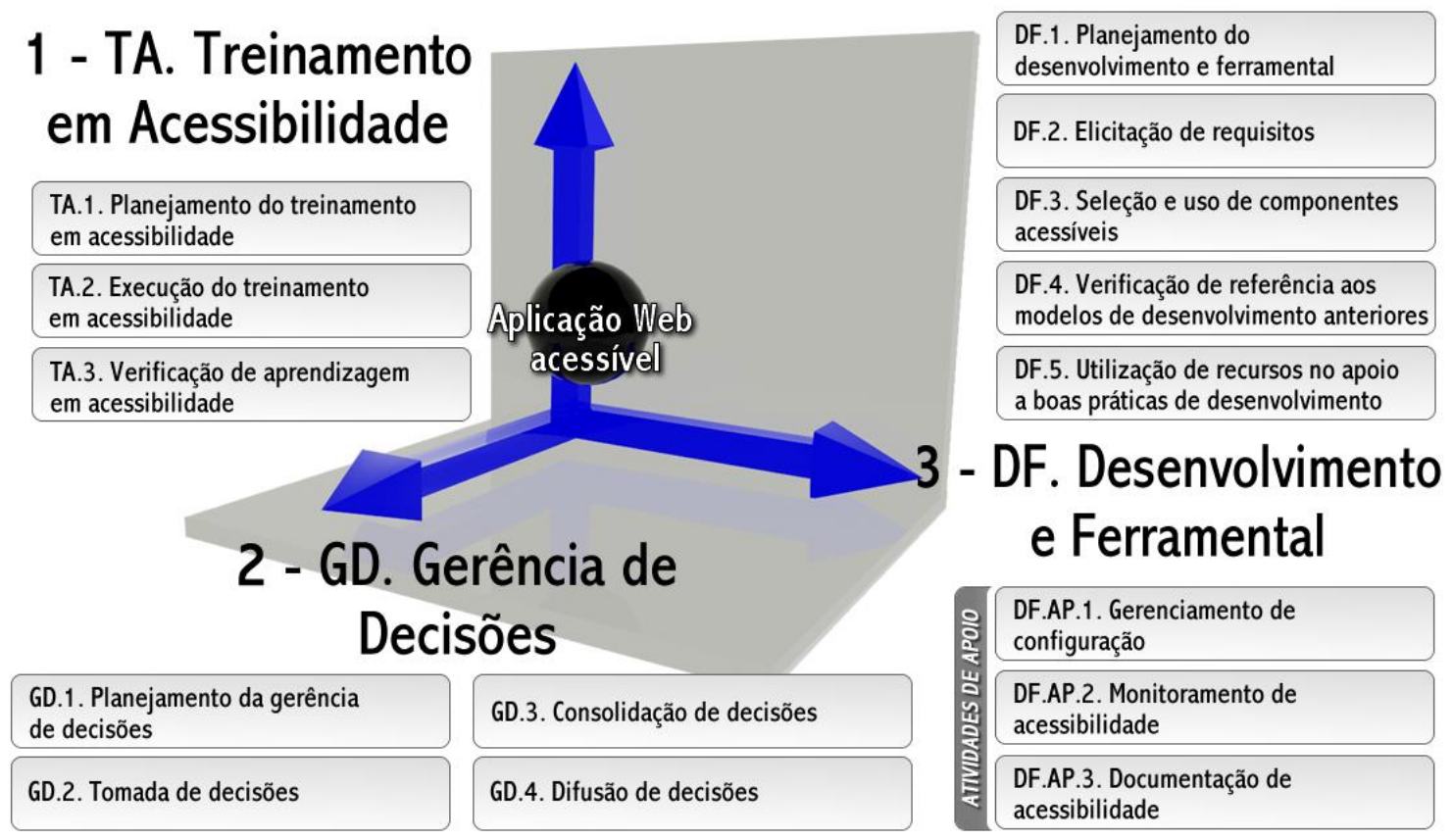

Figura 6.1 - Abordagem desenvolvida

Conforme apresentado na Figura 6.1 essa divisão por eixos deu-se devido à necessidade de uma separação lógica de preocupações que se complementam para atingir um desenvolvimento Web acessível. Um exemplo dessa característica de complementação é o princípio de que não adianta haver recursos para prover um bom desenvolvimento, com boas ferramentas de autoria, se os desenvolvedores e demais stakeholders não estiverem 
conscientizados e treinados sobre a problemática envolvida (NIETZIO et al., 2010; MELO e BARANAUSKAS, 2006).

Por outro lado, mesmo que haja conscientização e treinamento, relacionados à acessibilidade, e se tenha acesso às diretrizes, resultados satisfatórios com acessibilidade nos artefatos dificilmente serão providos, se não houver planos, recursos e técnicas eficientes para o bom desenvolvimento e tomada adequada de decisões.

De modo a confirmar ainda mais a decisão pelos eixos estabelecidos, pode-se citar Sloan et al. (2006), em que é relatada a importância das ferramentas para suportar a autoria de avaliação de artefatos, as quais podem amenizar a dificuldade adicional e a complexidade no bom desenvolvimento. Os mesmos autores discorrem que é importante conscientizar as pessoas envolvidas sobre a relevância de um bom desenvolvimento com acessibilidade.

A abordagem é apresentada em detalhes nas próximas seções, onde são mostrados os possíveis papéis que atuam no desenvolvimento e ressaltadas as vantagens de sua utilização, bem como os desafios que devem ser alcançados para torná-la, cada vez mais, próxima a atender diferentes tipos de cenários em projetos Web.

Uma definição de expressões foi feita de forma a padronizar a utilização de uma terminologia técnica e conceitual na abordagem, sendo essa definição apresentada no Quadro 6.1:

Quadro 6.1 - Definição do padrão de expressões para a abordagem

\begin{tabular}{|l|l|}
\hline Expressão & Significado \\
\hline \hline Ambiente & $\begin{array}{l}\text { Conjunto de recursos e circunstâncias que propiciam a execução de algum } \\
\text { evento ou ação. Pode ser um determinado lugar físico ou um conjunto de } \\
\text { softwares executando em ambiente local ou on-line. }\end{array}$ \\
\hline Artefato & $\begin{array}{l}\text { Qualquer objeto desenvolvido ou que serviu de entrada para um } \\
\text { desenvolvimento. No caso de artefatos Web, são designações para } \\
\text { elementos que compõem sites, como menus, links, títulos, etc... }\end{array}$ \\
\hline Atividade & $\begin{array}{l}\text { Realização de uma ação específica que terá resultado em um determinado } \\
\text { recurso. }\end{array}$ \\
\hline $\begin{array}{l}\text { Componente de } \\
\text { software }\end{array}$ & $\begin{array}{l}\text { Elemento de software que encapsula funcionalidades para um determinado } \\
\text { contexto, provendo interfaces bem definidas para interação com outros } \\
\text { elementos. }\end{array}$ \\
\hline $\begin{array}{l}\text { Equipe de } \\
\text { desenvolvimento }\end{array}$ & $\begin{array}{l}\text { Grupo de pessoas formado para desenvolvimento Web, incluindo todos } \\
\text { aqueles que, de alguma forma, contribuem para o resultado final, que é o }\end{array}$ \\
\hline
\end{tabular}




\begin{tabular}{|l|l|}
\hline Web & software Web produzido. \\
\hline Ferramenta & Conjunto de instrumentos empregados para apoio a um desenvolvimento. \\
\hline Gerência & $\begin{array}{l}\text { Conjunto de atividades de delegação e acompanhamento de tarefas com } \\
\text { relação a controle da equipe, suas funções e sobre os recursos envolvidos. }\end{array}$ \\
\hline Papel & $\begin{array}{l}\text { Função a ser desempenhada por uma pessoa em uma equipe para designar } \\
\text { responsabilidades a esse indivíduo. }\end{array}$ \\
\hline Projeto & Delineamento claro e objetivo do que deve ser desenvolvido. \\
\hline Recurso & Elemento que serve para alcançar um determinado fim. \\
\hline Treinamento & Conjunto de atividades para ensinar determinada ação ou prática. \\
\hline
\end{tabular}

\subsubsection{Descrição de papéis e suas responsabilidades}

Chisholm e Henry (2005) relatam que a responsabilidade pela garantia de acessibilidade envolve diferentes responsabilidades humanas, também consideradas como componentes do processo.

Nesse sentido, na abordagem são organizadas as reponsabilidades para cada atividade em papéis adequados às diferentes preocupações. Os seguintes papéis são necessários para o bom funcionamento da abordagem:

- Cliente: contratante do serviço, geralmente é uma instituição que necessita de uma aplicação Web para atender seu público alvo, que são os usuários finais;

- Desenvolvedor: implementa os requisitos do usuário, gerando o código final dos artefatos. Se pouco instruído sobre boas práticas de desenvolvimento, esse pode falhar durante a criação dos artefatos de software;

- Especialista em acessibilidade: responsável por garantir que a acessibilidade está sendo considerada durante o desenvolvimento, devendo possuir proficiência nas questões relativas às barreiras e possíveis soluções de acessibilidade, incluindo principalmente a boa aplicação das diretrizes desenvolvidas pelos órgãos competentes;

- Gerente de projeto: verifica o andamento geral do projeto e aloca os stakeholders de acordo com as atividades que devem ser executadas, considerando a especialidade e competência de cada um, bem como os recursos disponíveis. Quanto à acessibilidade, o gerente de projeto também estabelece um conjunto de práticas que garantam a integridade e a qualidade dos artefatos do projeto; 
- Stakeholder: influencia no projeto sendo as partes interessadas ou atuantes, podendo ser uma pessoa, um grupo ou uma entidade. No caso de uma organização, podem ser citados como stakeholders: funcionários, gestores, proprietários, fornecedores e clientes;

- Testador: valida e verifica se as funcionalidades foram bem implementadas e se a acessibilidade foi considerada durante o desenvolvimento. Assim, são realizadas as atividades centrais do esforço de teste, as quais envolvem a produção de casos de teste, suas execuções e o registro de resultados; e

- Usuário final: responsável por utilizar o sistema desenvolvido no ambiente real. Para atender a diversidade de necessidades dos usuários finais, deve-se identificar quem são esses usuários (público alvo) e verificar se a acessibilidade foi aplicada corretamente.

A quantidade de pessoas atuando em cada papel é flexível e depende do tamanho da organização, devendo ser analisada pelos gerentes de projeto. Em organizações pequenas, uma pessoa pode desempenhar mais de um papel, como, por exemplo, o gerente de projeto também atuar como especialista em acessibilidade, porém essa não é uma situação ideal.

\subsection{Eixo 1 - TA. Treinamento em Acessibilidade}

No Eixo 1 - TA. Treinamento em Acessibilidade são apresentadas atividades relacionadas ao que deve ser feito para prover instrução acerca de acessibilidade aos desenvolvedores e demais membros da equipe de desenvolvimento. É ressaltada a importância do treinamento contínuo que se inicia antes mesmo dos desenvolvimentos, incluindo aspectos sobre a relevância, conceitos e práticas utilizadas para prover acessibilidade. Esse treinamento é justificado, uma vez que se deve fornecer aos desenvolvedores conhecimento e prover manutenção de um ambiente onde discussões e demais práticas de treinamento serão conduzidas.

Adicionalmente, neste eixo, é útil a existência e utilização de ferramentas Web que auxiliem e organizem o processo de treinamento dos envolvidos nos projetos. Assim, podem 
ser utilizadas ferramentas de e-learning para inserção e gerenciamento de material instrucional de acessibilidade.

A AccessibilityUtil, apresentada no Capítulo 5, é um exemplo de ferramenta de apoio ao ensino e aprendizagem sobre acessibilidade, uma vez que a mesma propicia a formação de uma base de conhecimento sobre acessibilidade na Web.

No Quadro 6.2 é apresentada uma listagem das atividades do Eixo 1, seguida pelos papéis dos stakeholders, que devem estar envolvidos para executá-las, bem como as entradas necessárias para aplicação da atividade e saídas resultantes de sua execução.

Quadro 6.2 - Atividades do Eixo 1 - TA. Treinamento em Acessibilidade

\begin{tabular}{|c|c|c|c|}
\hline Atividades & Papéis & Entradas & Saídas \\
\hline $\begin{array}{l}\text { TA.1. Planejamento do } \\
\text { treinamento em } \\
\text { acessibilidade } \\
\text { TA.1.1. Escolha de } \\
\text { materiais instrucionais de } \\
\text { acessibilidade } \\
\text { TA.1.2. Escolha de } \\
\text { ambientes } \\
\text { TA.1.3. Verificação de } \\
\text { conhecimento prévio da } \\
\text { equipe }\end{array}$ & $\begin{array}{l}\text { - Especialista em } \\
\text { acessibilidade } \\
\text { - Gerente de } \\
\text { projeto }\end{array}$ & $\begin{array}{l}\text { - Lista de materiais } \\
\text { instrucionais de } \\
\text { acessibilidade } \\
\text { - Lista de ambientes de } \\
\text { aprendizagem } \\
\text { - Instrumento para coleta } \\
\text { de informações sobre o } \\
\text { conhecimento prévio da } \\
\text { equipe }\end{array}$ & $\begin{array}{l}\text { - Materiais escolhidos } \\
\text { - Ambientes } \\
\text { escolhidos } \\
\text { - Diagnóstico dos } \\
\text { conhecimentos } \\
\text { prévios da equipe }\end{array}$ \\
\hline $\begin{array}{l}\text { TA.2. Execução do } \\
\text { treinamento em } \\
\text { acessibilidade } \\
\text { TA.2.1. Disponibilização } \\
\text { de materiais } \\
\text { TA.2.2. Disponibilização } \\
\text { de ambientes } \\
\text { TA.2.3. Promoção de } \\
\text { discussões mediadas } \\
\text { TA.2.4. Treinamento } \\
\text { com exemplos }\end{array}$ & $\begin{array}{l}\text { - Especialista em } \\
\text { acessibilidade } \\
\text { - Gerente de } \\
\text { projeto } \\
\text { - Stakeholder }\end{array}$ & $\begin{array}{l}\text { - Infraestrutura para } \\
\text { ambiente de treinamento } \\
\text { - Recursos para } \\
\text { investimentos de aquisição } \\
\text { de materiais }\end{array}$ & $\begin{array}{l}\text { - Ambiente para } \\
\text { treinamento (on-line) } \\
\text { - Ambiente para } \\
\text { treinamento (físico) } \\
\text { - Materiais } \\
\text { instrucionais } \\
\text { - Relatórios de } \\
\text { discussões }\end{array}$ \\
\hline $\begin{array}{l}\text { TA.3. Verificação de } \\
\text { aprendizagem em } \\
\text { acessibilidade }\end{array}$ & $\begin{array}{l}\text { - Especialista em } \\
\text { acessibilidade } \\
\text { - Gerente de } \\
\text { projeto } \\
\text { - Stakeholder }\end{array}$ & - Instrumento avaliativo & $\begin{array}{l}\text { - Resultado da } \\
\text { avaliação } \\
\text { - Tabulação de } \\
\text { deficiências }\end{array}$ \\
\hline
\end{tabular}

Para visão de fluxo e melhor entendimento de como podem ocorrer as atividades, foram desenvolvidos diagramas com símbolos, de acordo com a legenda da Figura 6.2. 


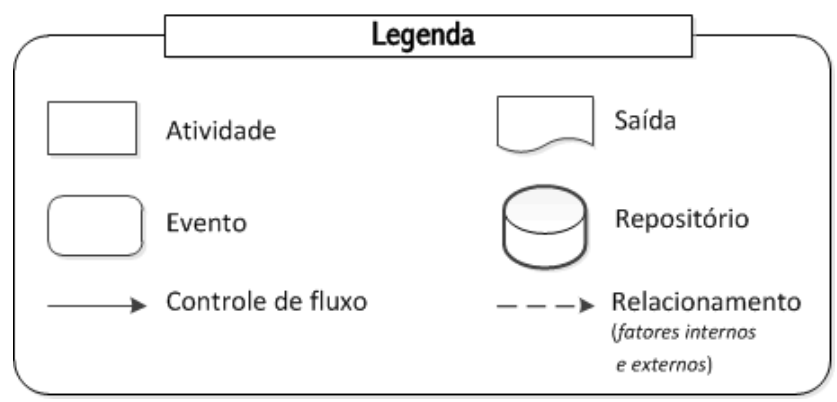

Figura 6.2 - Legenda para os digramas de fluxo de atividades

O fluxo simplificado de atividades sugerido para este eixo é apresentado na Figura 6.3.

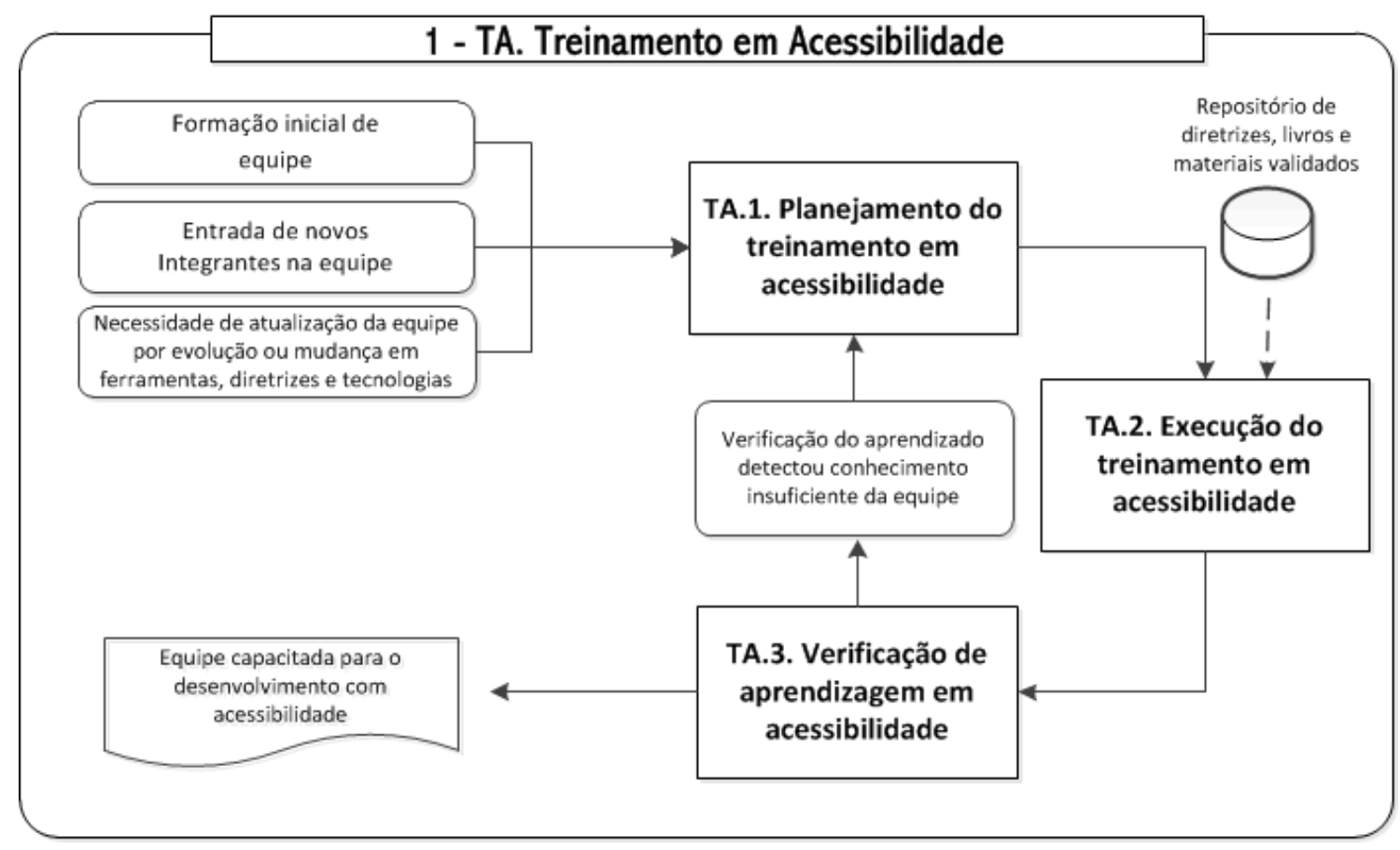

Figura 6.3 - Fluxo simplificado de atividades sugerido para o Eixo 1 - TA

Na parte esquerda superior da Figura 6.3, são apresentadas condições que levam ao início do fluxo de atividades do Eixo 1: "Formação inicial de equipe", "Entrada de novos integrantes na equipe" e "Necessidade de atualização da equipe por evolução ou mudança em ferramentas, diretrizes e tecnologias". Essa última condição deixa claro que as atividades do eixo ocorrem em vários momentos do desenvolvimento, ressaltando a necessidade de atualização da equipe. Por exemplo, se uma ferramenta de apoio em acessibilidade tem nova 
versão disponibilizada, é preciso verificar quais evoluções ela oferece e instruir todos os seus usuários quanto a isso, para melhor aproveitamento dos recursos disponibilizados.

As atividades para treinamento em acessibilidade, listadas no Quadro 6.2, incluindo a conscientização dos stakeholders, são detalhadas a seguir.

\subsubsection{Atividade TA.1. Planejamento do treinamento em acessibilidade}

Papéis: Especialista em acessibilidade e Gerente de projeto.

Entradas: Lista de materiais instrucionais de acessibilidade; Lista de ambientes de aprendizagem; Instrumento para coleta de informações sobre o conhecimento prévio da equipe.

Saídas: Materiais escolhidos; Ambientes escolhidos; Diagnóstico dos conhecimentos prévios da equipe.

O planejamento é essencial para execução de qualquer ação e, quando relacionado às atividades de treinamento, esse deve ser um ponto chave, uma vez que, se mal definido, pode comprometer todo o projeto. Não planejar adequadamente tais atividades, pode significar o não aproveitamento do treinamento e conscientização dos stakeholders envolvidos sobre quais características são essenciais sobre acessibilidade. Desse modo, no contexto de acessibilidade, é necessário que escolhas adequadas sejam feitas sobre quais materiais instrucionais serão utilizados como base ao aprendizado, bem como quais ambientes serão utilizados para prover o treinamento.

De modo a facilitar a execução e aplicação de tal atividade, definiu-se algumas subatividades que devem ser executadas. Essas são essenciais para um planejamento satisfatório, para obtenção de resultados relevantes relacionados à conscientização dos envolvidos no projeto sobre a importância da acessibilidade e, consequentemente, para o aprendizado sobre as diretrizes que devem ser consideradas.

\section{Subatividade TA.1.1. Escolha de materiais instrucionais de acessibilidade}

Para o treinamento é preciso fornecer acesso a materiais de consulta, como guias e recomendações de acessibilidade. Como o material presente na Web é extenso e não uniforme, existe a necessidade de uma seleção prévia e discussão de quais materiais serão 
utilizados. Isso não deve excluir a busca livre por material de apoio por parte de cada desenvolvedor, porém, nessas buscas, é preciso verificar a confiabilidade e a aderência de cada material ao modo de desenvolvimento da organização, sendo priorizados os materiais que já tenham sido validados.

Além do uso de materiais disponíveis na Web, é importante a consulta a livros e a outros tipos de documentação, de modo a enriquecer o treinamento feito na organização. Mais do que o acesso, a organização deve prover treinamentos em grupo, disponibilizando tempo hábil para que o estudo seja feito e, ainda, disponibilizar recursos para que haja uma aquisição eficiente dos conceitos.

\section{Subatividade TA.1.2. Escolha de ambientes}

Em geral, existem vários ambientes, como on-line e físico, que contemplam recursos para auxílio ao treinamento. Para a escolha do ambiente, devem ser consideradas questões de custo, sua utilização no mercado (com verificação de históricos de sucesso), receptividade com os usuários e compatibilidade do ambiente na organização em que ele será utilizado.

Deve-se também haver uma avaliação sobre quais recursos são oferecidos pelos ambientes e se é possível realmente utilizá-los na prática. Para ambientes on-line, alguns recursos interessantes que podem ser destacados são: mural de mensagens, fórum, salas de bate-papo, repositório de arquivos, Wiki e suporte de tutoria. Esses, se bem utilizados, podem resultar em treinamentos eficientes e produtivos.

Sobre o ambiente físico, deve ser disponibilizado um espaço para o treinamento em acessibilidade, com mobiliário adequado, boa iluminação e recursos de apresentação multimídia. Em organizações pequenas, isso pode ser um entrave e devem ser feitas adaptações para possibilitar o treinamento em acessibilidade.

\section{Subatividade TA.1.3. Verificação de conhecimento prévio da equipe}

A meta desta subatividade é obter um diagnóstico de conhecimento prévio da equipe, no sentido de realizar um melhor direcionamento do treinamento.

Caso algum participante da equipe tenha um bom conhecimento prévio sobre questões envolvendo a acessibilidade, isso deve ser aproveitado com a participação ativa desse, 
atuando como multiplicador de conhecimento e fornecendo apoio a aqueles que apresentem maior dificuldade durante o treinamento.

Para verificar o nível de conhecimento dos participantes, de modo a nivelar os grupos, pode-se utilizar as metodologias de entrevista com a equipe e aplicação de uma avaliação, que deve conter questionamentos em diferentes níveis de dificuldade, englobando situações práticas de desenvolvimento e a possibilidade de uso das diretrizes de acessibilidade.

\subsubsection{Atividade TA.2. Execução do treinamento em acessibilidade}

Nesta atividade são definidas e aplicadas ações para a realização do treinamento em acessibilidade, que correspondem a fornecer os materiais para apoio a aprendizagem, disponibilizar os ambientes e solicitar aos participantes a utilização dos recursos alocados de forma eficiente.

Papéis: Especialista em acessibilidade; Gerente de projeto e Stakeholder.

Entradas: Infraestrutura para ambiente de treinamento e recursos para investimentos de aquisição de materiais.

Saídas: Ambiente para treinamento (on-line); Ambiente para treinamento (físico); materiais instrucionais e relatórios de discussões.

\section{Subatividade TA.2.1. Disponibilização de materiais}

Esta subatividade contempla o oferecimento de acesso aos materiais, de forma fácil e efetiva, porém com gerenciamento, que pode ser feito a partir do registro de acesso a cada artefato de ensino.

\section{Subatividade TA.2.2. Disponibilização de ambientes}

Após a escolha dos ambientes, nesta subatividade tem-se o preparo para disponibilização de tais ambientes. Para tanto, é necessário que seja feita a devida instalação e configuração dos mesmos.

Tal disponibilização deve ser feita de modo a prezar pela facilidade de acesso a todos os participantes, sendo que, além do provimento dos recursos do ambiente, é necessário informar a todos sobre os mecanismos e dados para acesso ao ambiente. 


\section{Subatividade TA.2.3. Promoção de discussões mediadas}

Deve-se promover a realização de discussões mediadas entre os interessados, sempre após a apresentação de algum material instrucional. Uma discussão pode promover uma rica interação entre a equipe e permite a fixação dos conceitos vistos, sendo que são verificados onde e como podem ser aplicadas determinadas práticas no ambiente de desenvolvimento.

\section{Subatividade TA.2.4. Treinamento com exemplos}

Devem ser apresentados exemplos de desenvolvimento Web com acessibilidade aos participantes. Tais exemplos devem ser claros e coerentes, mostrando problemas comuns de acessibilidade e suas consequências na prática, em relação a vantagens e desvantagens para o projeto.

Para a busca desses exemplos, o especialista em acessibilidade pode buscar nos próprios códigos fontes que foram desenvolvidos pela equipe em projetos realizados. Assim, podem ser apresentados os problemas que existem nesses exemplos e possíveis soluções de forma mais próxima aos artefatos da organização.

\subsubsection{Atividade TA.3. Verificação de aprendizagem em acessibilidade}

Papéis: Especialista em acessibilidade; Gerente de projeto e Stakeholder.

Entradas: Instrumento avaliativo.

Saídas: Resultado da avaliação e tabulação de deficiências.

Nesta subatividade é verificado o nível de aprendizagem adquirida pelos participantes após a aplicação do treinamento. Para essa verificação, podem ser feitas entrevistas e aplicadas avaliações, contendo questionamentos em diferentes níveis de dificuldade, abordando com a equipe de desenvolvimento, situações práticas de desenvolvimento e a necessidade de consideração de diretrizes de acessibilidade.

\subsection{Eixo 2 - GD. Gerência de Decisões}

O Eixo 2 - GD. Gerência de Decisões foi definido objetivando garantir que as tomadas de decisões, por parte dos stakeholders do projeto, sejam feitas da maneira mais 
consciente e segura. Este eixo é necessário, uma vez que é observado que existem deficiências em relação às metodologias que frequentemente são utilizadas para orientar o processo de decisão em projetos de software, ocorre também em muitos casos que não são utilizadas metodologias formais para apoiar esse processo (CUNHA et al., 2008).

Assim, a gerência de decisões envolve as atividades relacionadas à identificação e gerenciamento de problemas que podem ocorrer no projeto, incluindo a existência de conflitos entre diferentes posicionamentos de indivíduos. Tais problemas, se não mitigados, podem levar a ocorrência de riscos, os quais comprometem o desenvolvimento do projeto e, em vezes, pode até levá-los ao fracasso (LOBATO, 2012).

Desse modo, em tal gerência, são verificadas quais ações demandam alguma verificação de opções que influenciam no desenvolvimento e, consequentemente, podem afetar a aplicação da acessibilidade.

Um dos principais desafios nesta área é realizar boas decisões com o embasamento adequado sobre quais resultados podem ser gerados com a execução de ações específicas, tal embasamento pode ser obtido por meio da consulta a fatores históricos e metodológicos. Em relação à verificação histórica, é oportuno o reuso de soluções que tiveram sucesso no passado, conseguidas por meio das lições aprendidas do projeto, sendo esse um fator que ajuda a prever consequências e aproveitar um trabalho de sucesso já executado.

A formação e manutenção de uma base histórica é algo que já foi definido em clássicos modelos de qualidade, como o Capability Maturity Model (CMM), que é um modelo para aferição da maturidade de uma organização no que diz respeito ao seu processo de desenvolvimento de software. A ideia presente na abordagem descrita aqui é utilizar uma base histórica que inclua considerações sobre acessibilidade nos artefatos, aproveitando os benefícios que podem ser conseguidos.

No Quadro 6.3 é apresentada uma listagem das atividades do Eixo 2, seguidas pelos papéis envolvidos, as entradas necessárias e as saídas resultantes da execução da atividade. 
Quadro 6.3 - Atividades do Eixo 2 - GD. Gerência de Decisões

\begin{tabular}{|c|c|c|c|}
\hline Atividades & Papéis & Entradas & Saídas \\
\hline $\begin{array}{l}\text { GD.1. Planejamento da gerência } \\
\text { de decisões } \\
\text { GD.1.1. Escolha de métodos } \\
\text { GD.1.2. Escolha de ambientes } \\
\text { GD.1.3. Confirmação de papéis e } \\
\text { responsabilidades }\end{array}$ & $\begin{array}{l}\text { - Especialista em } \\
\text { acessibilidade } \\
\text { - Gerente de projeto }\end{array}$ & $\begin{array}{l}\text { - Lista de } \\
\text { métodos de } \\
\text { gerência de } \\
\text { decisões } \\
\text { - Lista de } \\
\text { ambientes para } \\
\text { gerência de } \\
\text { decisões } \\
\text { - Lista de } \\
\text { pessoas e } \\
\text { papéis a } \\
\text { definir }\end{array}$ & $\begin{array}{l}\text { - Métodos } \\
\text { escolhidos } \\
\text { - Ambientes } \\
\text { escolhidos } \\
\text { - Associação de } \\
\text { papéis às } \\
\text { pessoas }\end{array}$ \\
\hline $\begin{array}{l}\text { GD.2. Tomada de decisões } \\
\text { GD.2.1. Realizar associação com } \\
\text { diretrizes }\end{array}$ & $\begin{array}{l}\text { - Gerente } \\
\text { - Stakeholder }\end{array}$ & $\begin{array}{l}\text { - Candidatos a } \\
\text { decisões: } \\
\text { problemas, } \\
\text { dúvidas e } \\
\text { incertezas } \\
\text { - Base de } \\
\text { diretrizes }\end{array}$ & $\begin{array}{l}\text { - Decisões } \\
\text { tomadas e seus } \\
\text { embasamentos }\end{array}$ \\
\hline GD.3. Consolidação de decisões & $\begin{array}{l}\text { - Especialista em } \\
\text { acessibilidade } \\
\text { - Gerente de projeto }\end{array}$ & $\begin{array}{l}\text { - Decisões } \\
\text { tomadas e seus } \\
\text { embasamentos }\end{array}$ & $\begin{array}{l}\text { - Consolidação } \\
\text { das decisões }\end{array}$ \\
\hline GD.4. Difusão de decisões & $\begin{array}{l}\text { - Especialista em } \\
\text { acessibilidade } \\
\text { - Gerente de projeto }\end{array}$ & $\begin{array}{l}\text { - Decisões } \\
\text { tomadas e seus } \\
\text { embasamentos } \\
\text { - Lista de } \\
\text { meios para } \\
\text { difusão }\end{array}$ & $\begin{array}{l}\text { - Documentos } \\
\text { de difusão das } \\
\text { diretrizes }\end{array}$ \\
\hline
\end{tabular}

As atividades descritas no Eixo 2, listadas no Quadro 6.3, são propostas para facilitar a tomada de decisões durante a execução do projeto. O fluxo simplificado de atividades sugerido para este eixo é apresentado na Figura 6.4. 


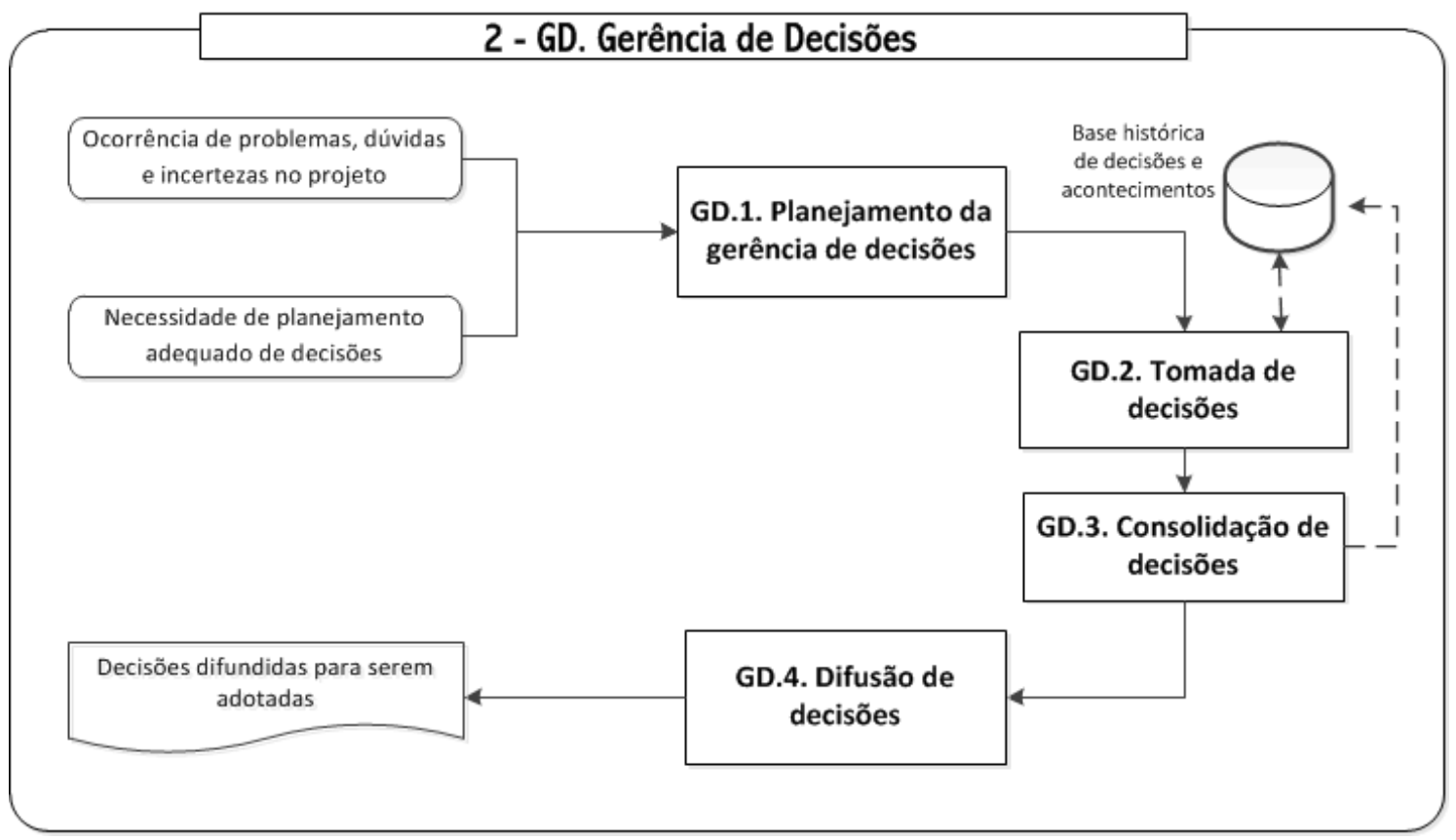

Figura 6.4 - Fluxo simplificado de atividades sugerido para o Eixo 2 - GD

Conforme pode ser visualizado na Figura 6.4, as condições de início das atividades deste eixo estão relacionadas a: "Ocorrência de problemas, dúvidas e incertezas no projeto" e "Necessidade de planejamento adequado de decisões". Pode ser observado também o fluxo de informação que ocorre nas atividades de tomada e consolidação de decisões, havendo uma interação contínua e em duplo sentido para criação, uso e atualização de uma base histórica de decisões e acontecimentos.

Após a apresentação desse fluxo de atividades, têm-se um detalhamento de atividades nas próximas subseções.

\subsubsection{Atividade GD.1. Planejamento da gerência de decisões}

Papéis: Especialista em acessibilidade; Gerente de projeto.

Entradas: Lista de métodos de gerência de decisões; Lista de ambientes para gerência de decisões; Lista de pessoas e papéis a definir.

Saídas: Métodos escolhidos; Ambientes escolhidos; Associação de papéis às pessoas.

Nesta atividade é feito o planejamento de como será o processo de gerência de decisões na organização, em relação a possíveis questionamentos e dúvidas sobre a consideração e execução de boas práticas de desenvolvimento. 
Neste sentido, devem ser considerados os vários aspectos relacionados às decisões de projeto, que vão desde a escolha de uma entre várias opções de decisões, por um stakeholder ou pela equipe, até a comunicação de decisões e suas execuções. Para tanto, são listadas as seguintes subatividades, com seus devidos detalhamentos.

\section{Subatividade GD.1.1. Escolha de métodos}

Nesta subatividade é feita a escolha dos métodos de gerência de decisões, que devem permitir o registro de decisões a serem tomadas, a interação dos atores que podem argumentar e a marcação da decisão tomada.

É importante que esse método seja de fácil utilização e compreensão por todos, sendo esse aspecto importante para o sucesso da aplicação do método em uma organização.

\section{Subatividade GD.1.2. Escolha de ambientes}

A escolha do ambiente de gerência de decisões é outro fator importante para a efetividade desse eixo. Os ambientes escolhidos devem ter total compatibilidade com o método de gerência de decisões adotado e devem estar acessíveis por todos os envolvidos no projeto que devam ter acesso.

\section{Subatividade GD.1.3. Confirmação de papéis e responsabilidades}

Devem ser confirmados os papéis e responsabilidades com cada ator que será envolvido no trabalho de gerência de decisões. Tal confirmação é importante para deixar claro as responsabilidades de cada um no projeto e verificar a aceitação do stakeholder em relação ao papel e, consequente, atividades que este deverá executar. É importante que pessoas confortáveis aos papéis sejam destinadas a eles, isso viabiliza e melhora a qualidade na execução das atividades.

\subsubsection{Atividade GD.2. Tomada de decisões}

Papéis: Gerente e stakeholder.

Entradas: Candidatos a decisões: problemas, dúvidas e incertezas; Base de diretrizes.

Saídas: Decisões tomadas e seus embasamentos. 
Nesta atividade tem-se a execução, propriamente dita, da gerência de decisões, em que há um mecanismo de recebimento e tratamento de candidatos a decisões, que podem ser, por exemplo, relatos, problemas, dúvidas e incertezas.

É preciso haver um embasamento e prover argumentos válidos para se tratar cada decisão a ser tomada. Para tanto, deve-se verificar fatos históricos em uma base própria e também fornecer uma referência com as diretrizes de acessibilidade e outros elementos da literatura referentes ao assunto em questão.

As subatividades que estão associadas a esta atividade são descritas a seguir.

\section{Subatividade GD.2.1. Realizar associação com diretrizes}

Deve-se fazer associação com diretrizes para embasar a tomada de decisões, pois essas são validadas e oficiais. Nesse caso, diretrizes oficiais e acessibilidade na Web são fontes interessantes e pertinentes de informação.

Existem vários conjuntos de diretrizes para acessibilidade, nesse sentido, Sloan et al. (2006) relata que a WAI tem uma grande relevância, porém apresenta deficiências e não deve ser a única a ser considerada. Outros conjuntos que podem ser citados são o Section 508, utilizada pelo governo norte-americano, e o conjunto e-MAG - Modelo de Acessibilidade de Governo Eletrônico, definido pelo governo brasileiro.

Outra questão pertinente é que alguns conjuntos de diretrizes têm como base a aplicação das diretrizes WCAG para uso em ambientes particulares, como por exemplo, a IMS Guidelines para treinamento à distância acessível.

\subsubsection{Atividade GD.3. Consolidação das decisões}

Papéis: Especialista em acessibilidade e Gerente de projeto.

Entradas: Decisões tomadas e seus embasamentos.

Saídas: Consolidação das decisões.

A partir de uma tomada de decisões, é preciso realizar a consolidação dessas, relacionado à execução das práticas envolvidas, que irão fornecer o suporte para que a equipe realize o que foi decidido de forma efetiva. 
É possível que a consolidação da decisão não seja feita por vários motivos, que vão desde problemas no ambiente ou insuficiência de recursos. Assim, deve-se haver um relatório sobre a não consolidação e a decisão deve ser reanalisada para ser refeita ou mesmo aguardar algum fator externo para que essa seja devidamente consolidada.

\subsubsection{Atividade GD.4. Difusão das decisões}

Papéis: Especialista em acessibilidade e Gerente de projeto.

Entradas: Decisões tomadas e seus embasamentos; Lista de meios para difusão.

Saídas: Documentos de difusão das diretrizes.

Nesta atividade estão inclusas as ações de difusão em diferentes meios das decisões tomadas, para que todos os envolvidos no projeto tenham conhecimento dos procedimentos a serem adotados. Isso é fundamental para se garantir a total disseminação do que foi decidido, evitando que componentes da equipe aleguem desconhecimento de uma determinada decisão.

Como meios de difusão, podem ser citados: intranets e sites da organização, envio de e-mails, publicação em murais físicos no ambiente de trabalho e divulgação oral em reuniões presenciais.

\subsection{Eixo 3-DF. Desenvolvimento e Ferramental}

O Eixo 3 - DF. Desenvolvimento e Ferramental contempla atividades relacionadas ao modo de desenvolvimento do projeto, considerando a acessibilidade como requisito mandatório, e o apoio ferramental que devem ser utilizados para promover e apoiar boas práticas para desenvolvimento de aplicações Web acessíveis.

É importante utilizar um ambiente eficiente para desenvolvimento para viabilizar o andamento adequado do projeto e prover facilidades aos stakeholders. Para tanto, é sugerido o uso de Ambientes Integrados de Desenvolvimento (Integrated Development Environment IDE), que reúnem características e ferramentas de apoio ao desenvolvimento de software com o objetivo de agilizar este processo. 
Trewin et al. (2010) apresentam uma survey aplicada para 49 desenvolvedores Web, em que foi constatado que é esperado que haja facilidades em ferramentas para o desenvolvimento acessível. Tais desenvolvedores esperam que exista, de forma integrada, um checklist de problemas detectados e uma explicação de cada problema.

A relevância na utilização de ferramentas para apoio à acessibilidade é justificada pelo fato de que as ferramentas de criação podem estimular e auxiliar os desenvolvedores na criação de conteúdos acessíveis, por meio de avisos, alertas, arquivos de ajuda, análise automatizada dentre outras facilidades. As diretrizes ATAG 1.0 (2000) confirmam tal afirmação, mostrando que as ferramentas de autoria devem ser acessíveis e seguir os propósitos básicos de: i) auxiliar usuários a produzir conteúdo acessível e ii) apoiar a criação de interfaces de autoria acessíveis.

Apesar dessa recomendação oficial pelo uso de ferramentas para apoio a acessibilidade, pouco se tem visto na literatura sobre sua aplicação. Power e Petrie (2007) examinaram a acessibilidade de uma coleção de ferramentas de autoria Web não profissionais, as quais são voltadas ao público sem conhecimento técnico aprofundado em linguagens computacionais para esse domínio. Como resultados, verificaram que existem várias oportunidades ainda não aproveitadas para prover conteúdo acessível, sobretudo em sites pessoais (blogs, sites de compartilhamento de fotos e vídeos, agendas, entre outros). A pesquisa também demonstrou que muitos desses problemas de acessibilidade podem ser abordados com relativamente pouco esforço, inclusive em relação às ferramentas de autoria no contexto da Web 2.0. Nos dias de hoje, tal cenário é ainda encontrado, uma vez que as ferramentas não são bem exploradas e a prática da acessibilidade durante o desenvolvimento Web não é bem difundida (BITTAR et al., 2012).

Schulz e Pieper (2006) reportam que é importante resolver questões de acessibilidade continuamente para diferentes tipos de usuários. Nesse estudo, é apresentada uma proposta para determinar se, utilizando um CMS (Content Management System) correto, é possível fornecer uma tecnologia que permite a atualização de sites sem conhecimento específico de acessibilidade. Ou seja, pretende-se verificar se apenas com um clique em um botão integrado no CMS, é possível fornecer a verificação de acessibilidade de acordo com diretrizes. 
Neste sentido, um recurso que merece destaque é o WYSIWYG (What You See Is What You Get), que tem por objetivo permitir que um documento, enquanto manipulado na tela, tenha a mesma aparência de sua utilização, usualmente sendo considerada final. Isso facilita para o desenvolvedor, que pode trabalhar visualizando a aparência do documento sem precisar salvar em vários momentos e abrir em um software separado de visualização (THATCHER et al., 2006).

Apesar dos benefícios desse recurso de edição de páginas, Spiesser e Kitchen (2004) ressaltam que o código gerado automaticamente, geralmente contém marcações repetitivas e desnecessárias. Então deve-se ter um cuidado adicional com o uso de ambientes de desenvolvimento com melhor geração de código e realizar verificações manuais nas marcações feitas a partir do uso de editores WYSIWYG. Sendo que, para essas verificações, várias ferramentas permitem a divisão da tela de desenvolvimento em duas partes dinamicamente atualizadas: código HTML e visualização final.

Por outro lado, Power e Petrie (2007) justificam que a acessibilidade pode ser facilitada através da evolução da Web. Assim, a Web 2.0 é uma nova oportunidade para inclusão de características de apoio à acessibilidade em ferramentas de autoria, para que usuários não especialistas possam contribuir cada vez mais com conteúdo acessível. No entanto, os mesmos autores confirmaram o cenário já descrito, em que o apoio ao desenvolvedor relacionado à acessibilidade está longe de ser o ideal, isso foi verificado por meio da investigação de duas ferramentas, a Apple iWeb (ferramenta desktop) e a Google Page Creator (ferramenta Web).

Assim, neste eixo são definidas e detalhadas as atividades que permeiam questões de desenvolvimento e como pode haver uma atuação plena do planejamento e execução de ações de adoção de diretrizes de forma efetiva para o domínio. No Quadro 6.4 tem-se uma listagem de tais atividades com papéis das pessoas envolvidas, entradas e saídas. Neste eixo também existe um tipo especial de atividade, as de apoio, que devem ser executadas em todo o processo de desenvolvimento para auxílio nas outras atividades, essas são apresentadas no Quadro 6.5. 
Quadro 6.4 - Atividades do Eixo 3 - DF. Desenvolvimento e Ferramental

\begin{tabular}{|c|c|c|c|}
\hline Atividades & Papéis & Entradas & Saídas \\
\hline $\begin{array}{l}\text { DF.1. Planejamento do } \\
\text { desenvolvimento e ferramental } \\
\text { DF.1.1. Escolha de ferramentas } \\
\text { DF.1.2. Preparação da base de } \\
\text { componentes } \\
\text { DF.1.3. Levantamento de perfis } \\
\text { de utilização }\end{array}$ & $\begin{array}{l}\text { - Especialista em } \\
\text { acessibilidade } \\
\text { - Gerente de projeto }\end{array}$ & $\begin{array}{l}\text { - Critérios para } \\
\text { escolha de } \\
\text { ferramentas } \\
\text { - Critérios para } \\
\text { escolha da base } \\
\text { de componentes } \\
\text { - Definição de } \\
\text { propósitos da } \\
\text { aplicação }\end{array}$ & $\begin{array}{l}\text { - Lista de } \\
\text { ferramentas } \\
\text { escolhidas } \\
\text { - Base de } \\
\text { componentes } \\
\text { - Documentação } \\
\text { sobre perfis de } \\
\text { utilização }\end{array}$ \\
\hline DF.2. Elicitação de requisitos & $\begin{array}{l}\text { - Especialista em } \\
\text { acessibilidade } \\
\text { - Gerente de projeto } \\
\text { - Cliente } \\
\text { - Usuário final }\end{array}$ & $\begin{array}{l}\text { - Entrevistas } \\
\text { - Questionários } \\
\text { - Verificação de } \\
\text { funcionalidades }\end{array}$ & $\begin{array}{l}\text { - Listagem de } \\
\text { requisitos }\end{array}$ \\
\hline $\begin{array}{l}\text { DF.3. Seleção e uso de } \\
\text { componentes acessíveis }\end{array}$ & $\begin{array}{l}\text { - Especialista em } \\
\text { acessibilidade } \\
\text { - Gerente de projeto } \\
\text { - Desenvolvedor }\end{array}$ & $\begin{array}{l}\text { - Repositório de } \\
\text { componentes } \\
\text { acessíveis }\end{array}$ & $\begin{array}{l}\text { - Refinamento de } \\
\text { componentes } \\
\text { - Componentes } \\
\text { aplicados }\end{array}$ \\
\hline $\begin{array}{l}\text { DF.4. Verificação de referência } \\
\text { aos modelos de } \\
\text { desenvolvimento anteriores }\end{array}$ & $\begin{array}{l}\text { - Especialista em } \\
\text { acessibilidade } \\
\text { - Gerente de projeto } \\
\text { - Desenvolvedor }\end{array}$ & $\begin{array}{l}\text { - Modelos de } \\
\text { desenvolvimento } \\
\text { anteriores }\end{array}$ & $\begin{array}{l}\text { - Relatório de } \\
\text { aderência aos } \\
\text { desenvolvimentos } \\
\text { anteriores }\end{array}$ \\
\hline $\begin{array}{l}\text { DF.5. Utilização de recursos no } \\
\text { apoio a boas práticas de } \\
\text { desenvolvimento } \\
\text { DF.5.1. Usar validação em tempo } \\
\text { de desenvolvimento } \\
\text { DF.5.2. Usar Scaffolding como } \\
\text { forma de auxílio ao } \\
\text { desenvolvimento }\end{array}$ & $\begin{array}{l}\text { - Especialista em } \\
\text { acessibilidade } \\
\text { - Gerente de projeto } \\
\text { - Desenvolvedor }\end{array}$ & $\begin{array}{l}\text { - Código sendo } \\
\text { construído }\end{array}$ & $\begin{array}{l}\text { - Alertas de } \\
\text { acessibilidade em } \\
\text { relação ao código } \\
\text { - Auxílios para } \\
\text { construção de } \\
\text { código }\end{array}$ \\
\hline
\end{tabular}

Quadro 6.5 - Atividades de apoio do Eixo 3 - DF. Desenvolvimento e Ferramental

\begin{tabular}{|c|c|c|c|}
\hline Atividades & Papéis & Entradas & Saídas \\
\hline $\begin{array}{l}\text { DF.AP.1. Gerenciamento de } \\
\text { configuração }\end{array}$ & $\begin{array}{l}\text { - Especialista em } \\
\text { acessibilidade } \\
\text { - Gerente de projeto } \\
\text { - Desenvolvedor }\end{array}$ & $\begin{array}{l}\text { - Gerenciador de } \\
\text { configuração }\end{array}$ & $\begin{array}{l}\text { - Artefatos com } \\
\text { controle de } \\
\text { configuração }\end{array}$ \\
\hline $\begin{array}{l}\text { DF.AP2. Monitoramento de } \\
\text { acessibilidade } \\
\text { DF.AP.2.1. Teste } \\
\text { DF.AP.2.2. Inspeção } \\
\text { DF.AP.2.3. Possibilitar e } \\
\end{array}$ & $\begin{array}{l}\text { - Gerente de projeto } \\
\text { - Testador } \\
\text { - Desenvolvedor } \\
\text { (para correções) }\end{array}$ & $\begin{array}{l}\text { - Artefatos ainda } \\
\text { não verificados } \\
\text { - Feedback de } \\
\text { usuários }\end{array}$ & $\begin{array}{l}\text { - Artefatos com } \\
\text { apontamentos de } \\
\text { acessibilidade }\end{array}$ \\
\hline
\end{tabular}




\begin{tabular}{|l|l|l|l|}
\hline $\begin{array}{l}\text { considerar o feedback de } \\
\text { usuários }\end{array}$ & - Usuário final & & \\
\hline $\begin{array}{l}\text { DF.AP.3. Documentação de } \\
\text { acessibilidade }\end{array}$ & Toda a equipe & $\begin{array}{l}\text { - Fatos a serem } \\
\text { documentados }\end{array}$ & $\begin{array}{l}\text { - Documentação } \\
\text { organizada dos } \\
\text { fatos }\end{array}$ \\
\hline
\end{tabular}

O fluxo simplificado de atividades sugerido para este eixo é apresentado na Figura 6.5 .

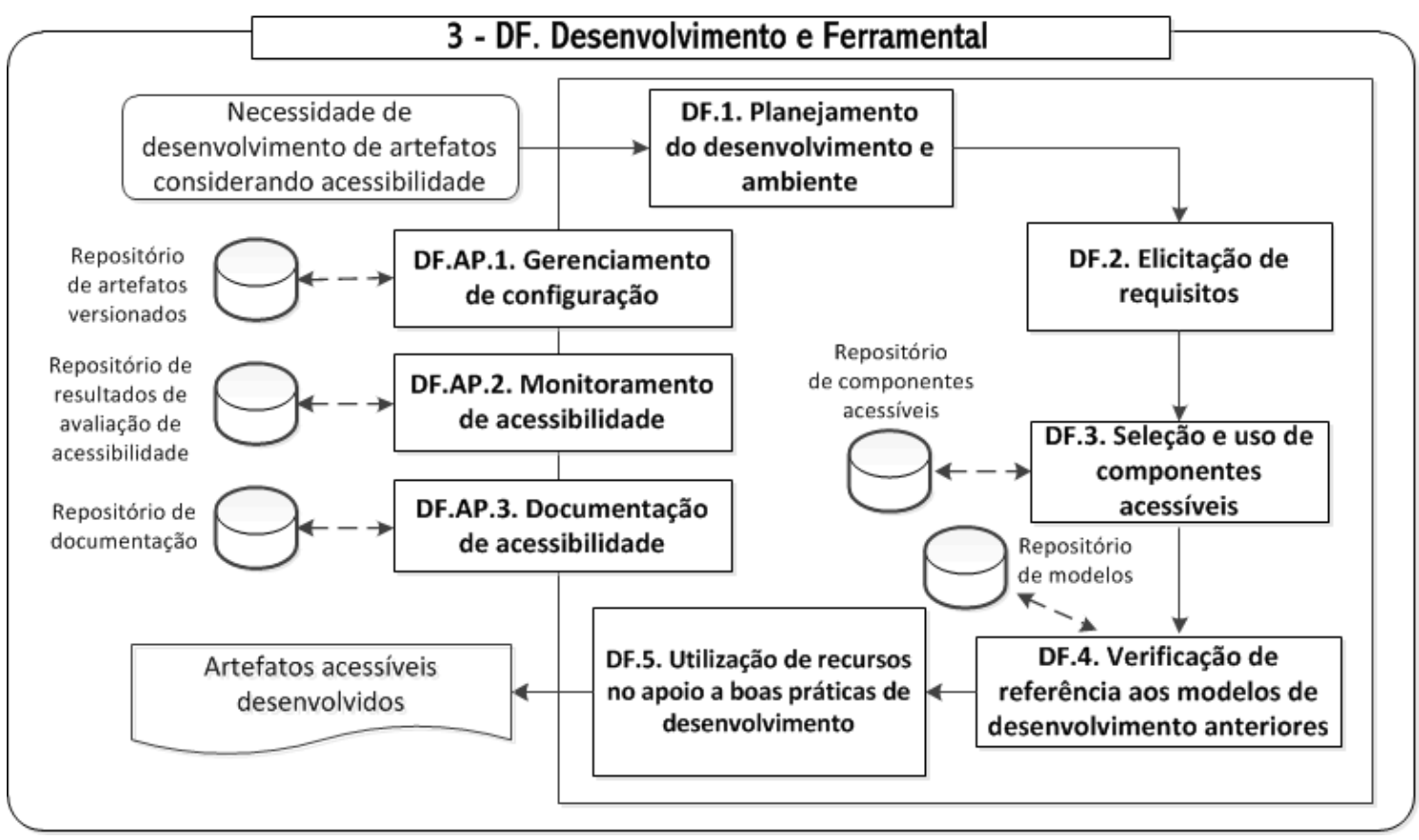

Figura 6.5 - Fluxo simplificado de atividades sugerido para o Eixo 3 - DF

Conforme pode ser visualizado na Figura 6.5, a condição de início das atividades deste eixo é relacionada a "Necessidade de desenvolvimento de artefatos considerando acessibilidade". Pode ser observado também o fluxo de informação que ocorre com a utilização de vários repositórios para auxílio na busca e utilização de componentes e informações existentes para este eixo. Os repositórios que são utilizados são: "Repositório de artefatos versionados", "Repositório de resultados de avaliação de acessibilidade", "Repositório de documentação" e "Repositório de modelos".

O uso de facilitadores no ambiente de desenvolvimento com preocupação em acessibilidade é importante para que desenvolvedores conscientes possam usar recursos de forma efetiva em ferramentas de autoria e avaliação. Tais facilitadores podem ser, por 
exemplo, validadores, alertas em tempo de desenvolvimento, padrões de desenvolvimento e uso de componentes.

De acordo com Thatcher (2006) grande parte do foco em acessibilidade está na responsabilidade dos desenvolvedores, mas essa visão falha em não dar o devido valor na interdependência dos demais elementos que estão presentes neste contexto, como navegadores, tecnologias assistivas e ferramentas de autoria.

As atividades definidas no Eixo 3, bem como suas subatividades, são detalhadas a seguir.

\subsubsection{Atividade DF.1. Planejamento do desenvolvimento e ferramental}

Papéis: Especialista em acessibilidade e Gerente de projeto.

Entradas: Critérios para escolha de ferramentas; Critérios para escolha da base de componentes; Definição de propósitos da aplicação.

Saídas: Lista de ferramentas escolhidas; Base de componentes; Documentação sobre perfis de utilização.

A seguir são descritas as subatividades que compõem a atividade Planejamento.

\section{Subatividade DF.1.1. Escolha de ferramentas}

De acordo com o conjunto ATAG 1.0, que versa sobre as diretrizes para ferramentas de autoria em relação à acessibilidade, deve haver um apoio para o desenvolvimento de conteúdo acessível. No entanto, as ferramentas de autoria atualmente ainda não proveem amplos recursos para essa questão (BITTAR et al., 2012; MARTÍN et al., 2011; POWER e PETRIE, 2007).

Desse modo, é importante saber como reconhecer boas ferramentas para esse domínio. Para isso, Bittar et al. (2012) discorrem que esse reconhecimento não é trivial, sendo difícil verificar todas as diretrizes disponibilizadas, especialmente para organizações pequenas, geralmente com poucos recursos. Como uma possível solução foi apresentado por esses autores um conjunto reduzido e prático composto por 14 critérios. Eles, então, avaliaram 5 ferramentas de autoria Web do tipo desktop por meio desses critérios, que foram 
definidos a partir do entendimento de que é possível ser feito um auxílio automatizado das ferramentas com base na WCAG 2.0 e ATAG 1.0.

Esses critérios indicados pelos autores podem ser vistos no Quadro 6.6. Os códigos iniciados por $\mathbf{H}$ representam técnicas para HTML e XHTML e, aqueles iniciados por $\mathbf{G}$, representam técnicas gerais. A descrição desses critérios e técnicas está presente no Apêndice C.

Quadro 6.6 - Critérios sugeridos para inspeção de ferramentas de autoria Web

\begin{tabular}{|c|c|c|}
\hline Critério estabelecido & $\begin{array}{l}\text { Relacionamento } \\
\text { com a ATAG 1.0 }\end{array}$ & $\begin{array}{l}\text { Relacionamento com a } \\
\text { WCAG 2.0 }\end{array}$ \\
\hline $\begin{array}{l}1 \text { - Auxilia no desenvolvimento de tabelas } \\
\text { acessíveis }\end{array}$ & 1.3 e 1.1 & $1.3 .1(\mathrm{H} 73, \mathrm{H} 39$ e H51) \\
\hline $\begin{array}{l}2 \text { - Emite um alerta e auxilia na inserção de } \\
\text { imagens sem texto alternativo }\end{array}$ & 3.1 e 1.1 & 1.1.1 (H37 e H67) \\
\hline 3 - Cria formulários com rótulos apropriados & 1.3 e 1.1 & $\begin{array}{c}\text { 1.1.1, 1.3.1, } \\
3.3 .2 \text { e } 4.1 .2(\mathrm{H} 44)\end{array}$ \\
\hline 4 - Critica o uso incorreto de abreviações & 1.3 e 1.1 & $3.1 .4(\mathrm{H} 28)$ \\
\hline 5 - Insere vídeos com texto alternativo & 3.1 & 1.2 \\
\hline $\begin{array}{l}6 \text { - Verifica a validade das tags (fechamento de } \\
\operatorname{tag} s, \text { atributos corretos, ...) }\end{array}$ & 1.3 e 1.1 & 4.1.1 (H75 e G134) \\
\hline $\begin{array}{l}7 \text { - Emite um alerta se tags de título não forem } \\
\text { inseridas no texto }(\mathrm{h} 1, \mathrm{~h} 2, \ldots)\end{array}$ & 1.3 e 1.1 & $\begin{array}{l}1.3 .1 \text { e } 2.4 .10(\mathrm{G} 141 \mathrm{e} \\
\mathrm{H} 52)\end{array}$ \\
\hline 8 - Auxilia a fazer títulos no texto $(\mathrm{h} 1, \mathrm{~h} 2, \ldots)$ & 1.3 e 1.1 & $\begin{array}{l}1.3 .1 \text { e } 2.4 .10(\mathrm{G} 141 \mathrm{e} \\
\mathrm{H} 42)\end{array}$ \\
\hline $\begin{array}{l}9 \text { - Apresenta relatório sobre atendimento a } \\
\text { diretrizes }\end{array}$ & 4.1 e 4.4 & - \\
\hline 10 - Auxilia para inserção de conteúdo ao vivo & 1.3 e 1.1 & 1.2 \\
\hline $\begin{array}{l}11 \text { - Alerta quando elementos sem contraste } \\
\text { adequado são inseridos }\end{array}$ & 1.3 e 1.1 & 1.4 .3 \\
\hline 12 - Exige um título de página & 1.3 e 1.1 & 2.4 .2 \\
\hline 13 - Verifica links quebrados & 1.3 e 1.1 & 3.2 .3 \\
\hline $\begin{array}{l}14 \text { - Apresenta documentação de acessibilidade } \\
\text { integrada }\end{array}$ & 6.2 & - \\
\hline
\end{tabular}

Outra questão que deve ser considerada é que a própria ferramenta deve ser acessível, sendo que algumas não são, dificultando o entendimento e utilização por parte dos usuários que têm deficiências. Desenvolvedores de ferramentas geralmente assumem que pessoas com deficiência não são capazes ou não desejam criar conteúdo Web, porém, deve-se ter em 
mente que muitos artistas gráficos continuam a trabalhar mesmo depois de sua visão diminuir com o envelhecimento (CHISHOLM e HENRY, 2005).

O ambiente de desenvolvimento formado por tais ferramentas deve permitir a colaboração entre desenvolvedores apoiando o trabalho em equipe de forma adequada. Com isso, são evitados retrabalhos e conflitos relacionados a diferentes atuações no código.

\section{Subatividade DF.1.2. Preparação da base de componentes}

Uma base de componentes é um repositório onde os desenvolvedores buscam e selecionam artefatos para reutilizá-los em um determinado projeto. Sendo assim, essa subatividade consiste de preparação dessa base que irá receber os componentes.

Deve haver mecanismos para disponibilização dessa base a todos os desenvolvedores e é interessante que ela seja integrada ao ambiente de desenvolvimento e gerenciamento de versões. No entanto, caso não seja possível essa integração, ou o uso de soluções sofisticadas para a base, é indicado o uso de soluções mais simples, como prover uma pasta compartilhada para cada componente no sistema operacional.

É importante também que, para cada componente disponibilizado, seja incluída uma descrição de utilidade do mesmo, quais suas interfaces de integração e sua compatibilidade, bem como todas as informações técnicas que forem úteis à equipe de desenvolvimento.

\section{Subatividade DF.1.3. Levantamento de perfis de utilização}

Alguns autores questionam o fato de que é difícil desenvolver um site Web universalmente acessível a todos os tipos de deficiências. Observa-se que tem aumentado o uso de soluções, recursos de áudio para texto e versões alternativas de estilos, provendo formatações alternativas em alguns sites. Logo, percebe-se que a realização de um projeto seguindo as diretrizes WCAG, gerando um site para todos e a obrigação de usuários adotarem somente navegadores que sigam as diretrizes UAAG não é uma aproximação realista com a atualidade.

O perfil de utilização está intrinsecamente relacionado ao contexto de uso, que contempla as seguintes variáveis:

- Características do usuário: as habilidades (e deficiências) do grupo alvo, incluindo qualidades perceptivas, cognitivas, motores e linguísticas; 
- Domínio: as tarefas que devem ser suportadas, questões sociais e culturais, padrões de comunicação, fatores de ambiente;

- Tecnologia: disponibilidade de software e hardware, incluindo plug-ins; e

- Requisitos de desempenho: são verificados, por exemplo, taxa de sucesso, tempo para completar tarefas, taxa de satisfação e qualidade da saída resultante da execução de tarefa.

Kelly et al. (2005) argumentam também, nesse sentido, que diretrizes de acessibilidade devem ser aplicadas verificando:

- Quais são as tarefas típicas dos grupos de usuários e o que eles esperam;

- A audiência almejada; e

- O ambiente de uso (quais os navegadores Web e tecnologias assistivas que a audiência poderá usar).

Um dos meios para se fazer isso é utilizando o desenvolvimento centrado no usuário para a construção de aplicações Web. Nessa metodologia de desenvolvimento as necessidades, desejos e limitações do usuário são levados em conta durante as fases de concepção e desenvolvimento do projeto. (CONSTANTINE e LOCKWOOD, 2002; BEVAN, 1999).

\subsubsection{Atividade DF.2. Elicitação de requisitos}

Papéis: Especialista em acessibilidade, Gerente de projeto, Cliente e Usuário final.

Entradas: Entrevistas; Questionários; Verificação de funcionalidades.

Saídas: Listagem de requisitos.

Para se realizar tarefas relacionadas ao gerenciamento de requisitos, pode-se utilizar entrevistas e aplicação de questionários - a partir do resultado desses levantamentos de dados, devem ser feitas documentações e descritos cenários de uso. A diferença é que há requisitos não funcionais a serem adicionados, que são relacionados às diretrizes de acessibilidade. 
Apesar da importância da documentação relacionada aos requisitos, frequentemente ela não é mantida atualizada com o passar do tempo em um projeto (LUCRÉDIO, 2009).

\subsubsection{Atividade DF.3. Seleção e uso de componentes acessíveis}

Papéis: Especialista em acessibilidade; Gerente de projeto e Desenvolvedor.

Entradas: Base de componentes acessíveis.

Saídas: Refinamento de componentes; Componentes aplicados.

Podem ser utilizados como componentes implementações de padrões já desenvolvidos pela empresa ou por terceiros, desde que se tenha uma garantia de acessibilidade aos mesmos, que pode ser vista pelo teste de cada componente.

O uso de componentes permite uma evolução do software em etapas, com modificações e características acopladas de forma mais genérica e para diversas plataformas.

A inclusão de informações de boas práticas nos modelos e transformadores permite a geração de um código com essas soluções aplicadas de forma eficiente e automática. De modo a exemplificar a formação de um componente acessível, com o apoio de modelos, apresenta-se a Figura 6.6.

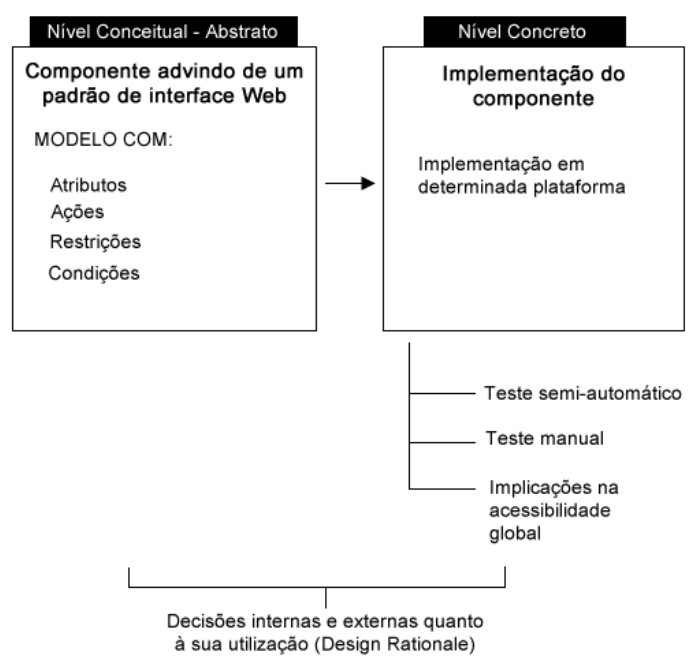

Figura 6.6 - Nível conceitual e concreto para formação de um componente acessível

Na Figura 6.6 é apresentado um nível conceitual - abstrato, que é independente da implementação do componente, e um nível concreto, em que já são considerados detalhes de 
implementação com a definição de elementos próximos do ambiente tecnológico a ser utilizado.

O projetista especifica, então, classes e suas relações (graficamente ou textualmente em alguma linguagem) sendo que esse modelo deve servir para a construção de transformadores para a geração de código da aplicação. Nesse caso, é possível gerar artefatos reusáveis de aplicações Web acessíveis que fiquem dispostos como componentes em um repositório.

Um possível fluxo de busca no repositório, com reuso ou construção de componentes, em um desenvolvimento de aplicações acessíveis, pode ser visto na Figura 6.7.

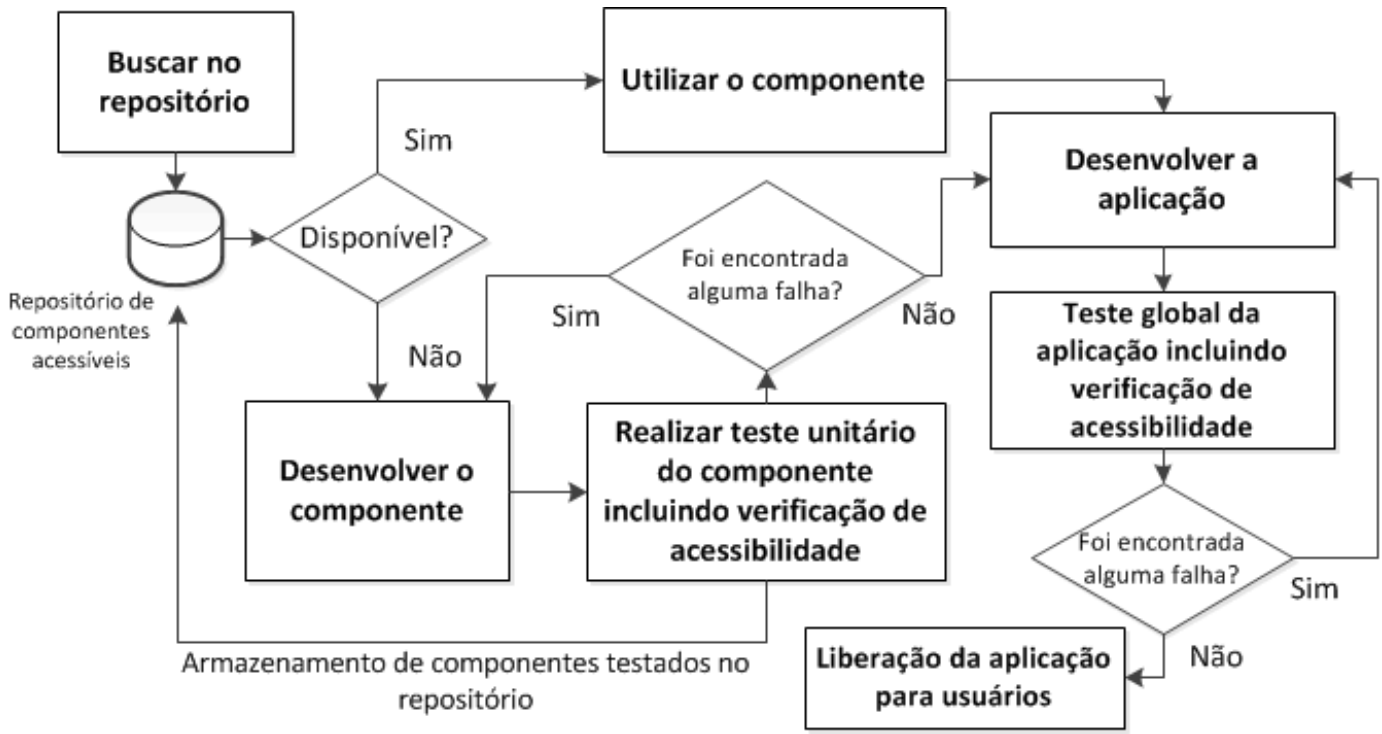

Figura 6.7 - Possível fluxo de seleção, uso, construção e testes de componentes

Como pode ser visualizado na Figura 6.7, existe uma busca de componentes no repositório, de acordo com os requisitos da aplicação. No caso de existir o componente no repositório, fica a cargo do desenvolvedor utilizá-lo para construção da aplicação, sendo importante a realização de teste do resultado final do desenvolvimento com verificação de acessibilidade. Já no caso de não existir o componente no repositório, deve ser feito o seu desenvolvimento e teste unitário, incluindo a verificação de acessibilidade para sua posterior inclusão no repositório de componentes e uso na aplicação. 


\subsubsection{Atividade DF.4. Verificação de referência aos modelos de desenvolvimento anteriores}

Papéis: Especialista em acessibilidade; Gerente de projeto; Desenvolvedores.

Entradas: Modelos de desenvolvimento anteriores.

Saídas: Relatório de aderência aos desenvolvimentos anteriores.

Outra preocupação que deve ser considerada é se existem meios efetivos de referenciar modelos de desenvolvimento anteriores, como documentação de requisitos, por exemplo. Isso faz com que haja uma ligação entre as fases e se saiba o porquê e a origem de cada funcionalidade desenvolvida, favorecendo a rastreabilidade.

\subsubsection{Atividade DF.5. Utilização de recursos no apoio a boas práticas de desenvolvimento}

Papéis: Especialista em acessibilidade; Gerente de projeto e Desenvolvedor.

Entradas: Código sendo construído.

Saídas: Alertas de acessibilidade em relação ao código; Auxílios para construção de código.

Esta atividade engloba a preocupação em se ter recursos de desenvolvimento nas ferramentas e no modo de trabalho que facilitem a adoção de boas práticas com funcionalidades que alertem e validem o que está sendo feito.

Cada recurso de desenvolvimento deve ser testado e reportada sua funcionalidade a todos os desenvolvedores, fazendo que haja uma sintonia e esclarecimento desses para o bom uso.

A seguir são listadas e detalhadas as subatividades pertinentes nesse contexto.

\section{Subatividade DF.5.1. Usar validação em tempo de desenvolvimento}

Um recurso interessante no desenvolvimento é o uso de regras de validação que atuam em tempo de desenvolvimento, também conhecidas pelo termo em inglês live validation. Assim, checagens são feitas imediatamente após cada escrita de código, sendo que quando alguma violação de regra é detectada, é apresentada uma mensagem na tela. 
Observa-se que a validação em tempo de desenvolvimento opera incrementalmente com a possibilidade das regras se complementarem. Além da validação dos elementos em si, a cada relacionamento, regras de ligação são checadas como pré-condições para a execução de outras validações dentro de um contexto de desenvolvimento.

Uma vantagem especialmente importante no uso do recurso de validação, em tempo de desenvolvimento, é que o desenvolvedor não necessita acionar explicitamente o comando de validação e, desse modo, ele sempre será alertado de inconsistências quanto ao modelo e quanto às boas práticas definidas no metamodelo.

Com esse recurso atuando, é possível, ainda, fazer consultas automáticas a um determinado modelo de desenvolvimento, obtendo restrições, alertas e dicas de implementação.

Alguns elementos como textos, tem avaliação subjetiva, então, para alguns elementos a serem usados na aplicação, é necessário um alerta, do tipo: "verifique se o texto é claro para seu perfil de usuário".

Subatividade DF.5.2. Usar Scaffolding como forma de auxílio ao desenvolvimento

Scaffolding é um termo em inglês que originalmente denota o uso de andaimes e outras estruturas para suportar temporariamente trabalhadores de maquinário, enquanto a construção definitiva não está pronta. Esse mesmo termo é usado em desenvolvimento de software para indicar auxílios para a criação de códigos, como a geração de esqueletos de códigos usados para tornar a aplicação funcional.

Assim, com o uso de scaffolding, guias podem ser utilizados pelo desenvolvedor de modo a auxiliá-lo durante o desenvolvimento. Tais guias, além de ajudar no desenvolvimento, também podem contribuir para o aprendizado (CEZAR et al., 2006).

O scaffolding é geralmente usado para gerar códigos de uma aplicação para a realização de operações básicas com o banco de dados. As quatro operações, em conjunto, são chamadas de CRUD (Create, Read, Update e Delete). Porém, o scaffolding vai além da construção de tais operações, podendo ser aplicado em outros cenários, como na geração de 
estruturas para testes e na construção de interfaces Web acessíveis, com a ajuda de frameworks adequados para essa funcionalidade.

Um uso bastante conhecido do scaffolding, para desenvolvimento Web, é relacionado ao framework Ruby on Rails ${ }^{33}$ (RoR), em que o scaffolding se posiciona como um modo rápido para gerar partes principais de uma aplicação, incluindo as operações CRUD, com base na arquitetura Model View Controller (MVC) (ROR, 2012).

A técnica permite uma aceleração na construção de processos considerados triviais, a partir do uso de soluções validadas que permitam a sua automação, apoiando a construção de artefatos de maneira eficaz, podendo ser um recurso adequado para auxílio a desenvolvedores novatos de forma prática (QUINTANA et al., 2002; DORN e GUZDIAL, 2010).

Assim, por indicar um caminho a seguir de fácil entendimento, que é bem documentado, a técnica introduz o desenvolvedor no modelo de desenvolvimento que o framework acredita ser o ideal. Então, esta atividade contempla o conceito de uso desse recurso no sentido de apoio ao desenvolvedor a aplicar boas práticas de desenvolvimento Web, para se ter uma aplicação acessível.

Porém o desenvolvedor deve tomar cuidado e aprender os detalhes de como a estrutura do scaffolding funciona, para isso, é essencial a leitura da documentação do modo de desenvolvimento ou framework que estiver sendo utilizado.

\subsubsection{Atividade de apoio DF.AP.1. Gerenciamento de configuração}

Papéis: Especialista em acessibilidade, Gerente de projeto e Desenvolvedores.

Entradas: Gerenciador de configuração.

Saídas: Artefatos com controle de configuração.

O gerenciamento de configuração de software é a atividade de controle de diferentes versões de artefatos que compõem o sistema, geralmente composto por arquivos. Tal controle é feito desde o registro de código fonte, nome de desenvolvedor, até detalhes de data, horário e motivo da alteração ou criação de cada artefato.

\footnotetext{
${ }^{33}$ http://rubyonrails.org/
} 
A criação de um modelo para a realização de controle de versão flexível e refinado pode proporcionar um controle de versão mais detalhado (JUNQUEIRA et al., 2008). A ideia é que se possa incluir nesses detalhes características de alterações em requisitos de acessibilidade realizados nos artefatos Web, podendo haver um gerenciamento eficiente das mudanças que estão sendo realizadas efetivamente em relação ao desenvolvimento sem barreiras de acessibilidade.

\subsubsection{Atividade de apoio DF.AP.2. Monitoramento de acessibilidade}

Papéis: Gerente de projeto; Testador; Desenvolvedor e Usuário final.

Entradas: Artefatos ainda não verificados; Feedback de usuários.

Saídas: Artefatos com apontamentos de acessibilidade.

É importante um acompanhamento contínuo sobre questões de acessibilidade durante o desenvolvimento dos projetos, para tanto são necessários testes constantes nos novos componentes desenvolvidos, bem como nas atualizações de conteúdo efetuadas nos sites (SCHULZ e PIEPER, 2006).

A avaliação de acessibilidade, que é uma ação presente no monitoramento em questão, é um campo amplo que combina diferentes disciplinas e habilidades. Ela envolve a verificação de aspectos técnicos, como conformidades em relação a diretrizes, e também a aspectos não técnicos, como o envolvimento de usuários finais durante o processo de avaliação (ABOU-ZAHRA, 2008).

De acordo com Abou-Zahra (2008), a acessibilidade na Web deve ser verificada de forma qualitativa e experimental, não sendo apenas medida como uma propriedade quantitativa e concreta. Assim, deve haver técnicas e estratégias robustas, confiáveis e efetivas para medi-la.

\section{Subatividade DF.AP.2.1. Teste}

Um teste é uma atividade dinâmica para determinação do cumprimento (ou não) de requisitos da especificação, que requer que os artefatos de software sejam executados. Para 
essa validação, são definidos e executados casos de teste, que são compostos por conjunto de dados de entrada e a correspondente saída esperada.

Os resultados da execução dos testes são então examinados para analisar se o software operou de acordo com o esperado. O teste de software é, assim, elemento crítico para a qualidade do produto, pois representa a análise final da execução dos artefatos, executados de acordo com a especificação que guia o desenvolvimento.

A percepção de que ocorreu um comportamento de execução diferente do esperado, a partir da realização de um caso de teste, é chamada de falha, que deve ser reportada como resultado do teste, à equipe de desenvolvimento, para a correção dos artefatos (SOMMERVILLE, 2007).

Em relação à acessibilidade, existem diversas ferramentas que permitem o teste automático de uma aplicação Web, relativo ao atendimento de diretrizes por meio do acesso a sua URL e análise do conteúdo recuperado. No entanto, apenas testes automáticos não são suficientes para garantir a acessibilidade de artefatos Web, são ainda necessários testes manuais com a participação de usuários finais.

Em geral, a atividade de teste não é fácil e apresenta custo elevado, sendo importante a realização de testes com usuários finais, incluindo aqueles com deficiências.

\section{Subatividade DF.AP.2.2. Inspeção}

A inspeção é um processo estático de revisão formal em artefatos do processo de desenvolvimento de software, sendo uma importante atividade da área de Garantia de Qualidade de Software (GQS). O principal objetivo dessa atividade é a descoberta antecipada de falhas (SOMMERVILLE, 2007).

Em relação à inspeção de acessibilidade em artefatos Web, é possível relatar o procedimento de análise do código fonte HTML das páginas que compõem um site. Essa análise resulta em importantes verificações, sem precisar testar com um usuário com deficiências ou simular esse uso, facilitando o trabalho.

Sobre os problemas numa inspeção podem ser citadas a dependência da experiência do inspetor e a dificuldade em fazer uma inspeção formal que assegure uma prova concisa de qualidade. 


\section{Subatividade DF.AP.2.3 - Possibilitar e considerar o feedback de usuários}

De acordo com Takagi et al. (2009), o usuário final deve ter um meio fácil para solicitar melhorias aos desenvolvedores e até mesmo propor a inclusão de textos alternativos e, apontamentos de títulos em páginas.

Um mecanismo relativamente simples de ser implementado para prover esse recurso é a disponibilização de um endereço de e-mail, para que os usuários entrem em contato. Porém, para maior efetividade, pela facilidade de utilização por parte do usuário, pode ser disponibilizado, no site, um formulário, para que o usuário descreva seu contato e situação enfrentada.

\subsubsection{Atividade de apoio DF.AP.3. Documentação de acessibilidade}

Papéis: Toda a equipe.

Entradas: Fatos a serem documentados.

Saídas: Documentação organizada dos fatos.

A documentação é uma atividade que permeia toda a abordagem, sendo contínua em todo o processo de desenvolvimento. Essa atividade deve promover não só o registro do que está sendo feito e dos resultados, mas também as decisões e justificativas para elas em cada momento, provendo assim, a transparência na tomada de decisões.

Nesse sentido, Sloan et al. (2006) destacam a importância da documentação e a associam com atividades de avaliação do que está sendo produzido e de identificação de contexto, como análise de características de usuário e de requisitos tecnológicos, de desempenho e do domínio.

\subsection{Integração com o modelo de processo da norma ISO/IEC 12.207}

A abordagem descrita aqui é flexível e adaptativa, não sendo vinculada à necessidade da organização seguir um modelo de processo formal de desenvolvimento de software. Caso houvesse essa vinculação, uma restrição seria imposta a várias organizações de 
desenvolvimento que ainda não utilizam um modelo de processo formal de desenvolvimento, e essas, por sua vez, frequentemente, são de pequeno e médio porte, e constituem uma parcela considerável do rol de organizações.

Outra restrição que também merece ser citada é o caso de uma organização já adotar um determinado modelo de processo e, a abordagem ser integrada e requisitar sua aplicação em outro modelo. Isso ocasionaria a necessidade dessas organizações mudarem seu modelo de processo, o que é improvável e comumente inviável na prática.

No entanto, a sua característica de adaptabilidade com atividades separadas, permite que a solução proposta neste trabalho possa ser integrada a modelos de processo formais. Com base nisso, é feito, nesta seção, um exercício de integração com o modelo de processo de desenvolvimento de software especificado na norma ISO/IEC 12.207, mostrando, de forma sucinta, qual seria uma possível arquitetura de atividades nessa integração.

A norma ISO/IEC 12.207 descreve um padrão para o desenvolvimento de software contendo um conjunto de processos organizados como: i) fundamentais; ii) de apoio; iii) organizacionais e iv) de adaptação. Cada uma dessas divisões conta com várias atividades para guiar o ciclo de vida do desenvolvimento de software.

Essa possível integração é apresentada na Figura 6.8, em que as atividades da abordagem apresentada foram sobrepostas nas atividades na norma ISO/IEC 12.207. 


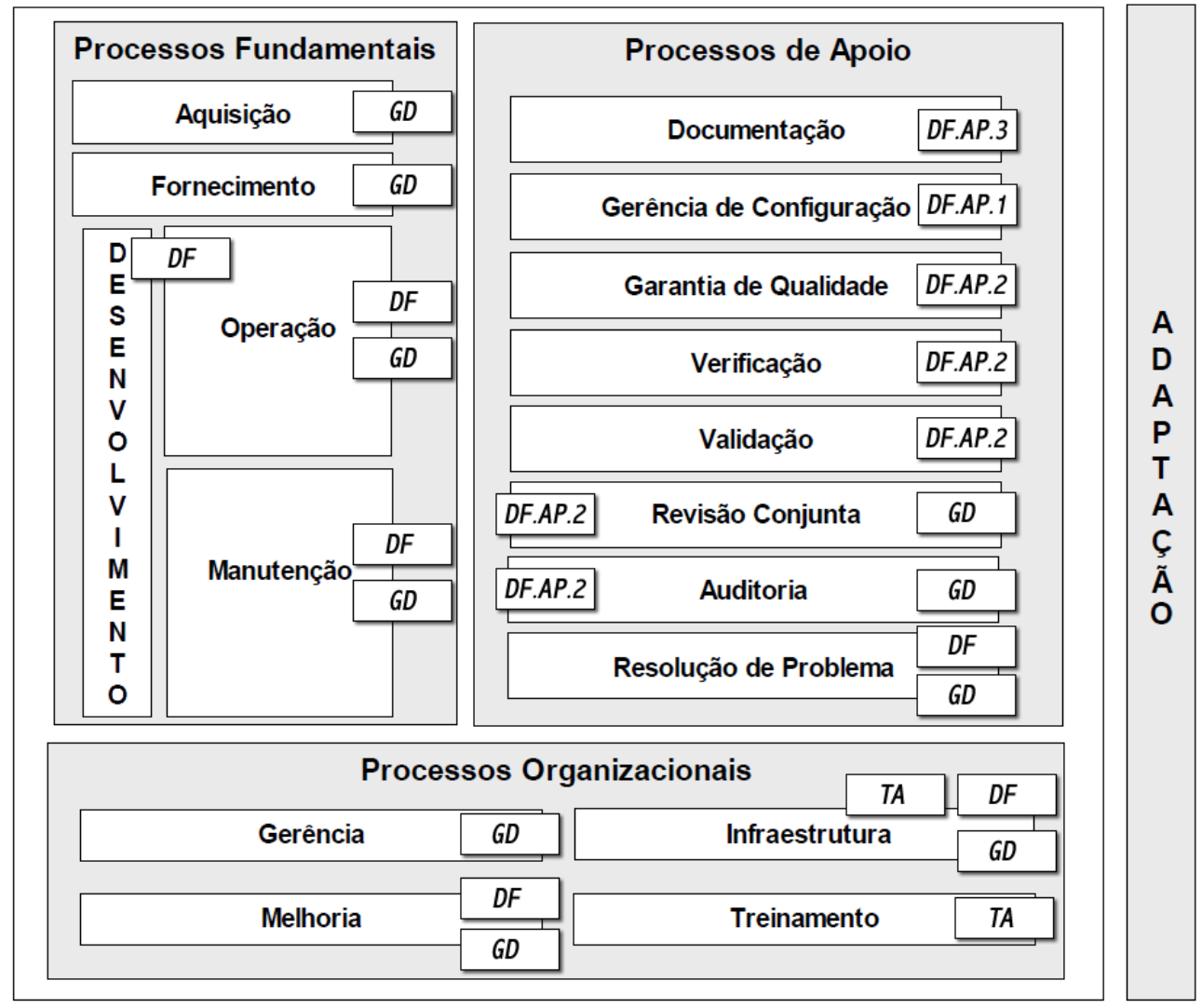

Figura 6.8 - Possível integração da abordagem apresentada com o modelo de processo da norma ISO/IEC 12.207

A descrição das atividades e da associação realizada é apresentada a seguir nas subseções, de acordo com a organização da norma ISO/IEC 12.207. Sobre a seção de adaptação de tal norma, não existem atividades específicas da abordagem proposta que auxiliem a realizar a adequação à organização descrita na norma.

\subsubsection{Processos fundamentais}

- Aquisição: inclui a definição da necessidade de adquirir um software (sendo esse um produto ou serviço), incluindo desde a realização do pedido de proposta até a seleção do fornecedor, a gerência da aquisição e a aceitação do software. Em relação à abordagem desta tese, deve haver a verificação de acessibilidade em cada momento de compra de componentes Web e outros softwares de terceiros, que venham a ser utilizados no processo de desenvolvimento, sendo que isso deve ser incluso na proposta de compra. O processo de aquisição deve ser apoiado pelo eixo Gerência de Decisões (GD) da abordagem para ver se 
realmente a aquisição é necessária e decidir questões técnicas sobre características da aquisição.

- Fornecimento: engloba as atividades que o fornecedor de software realiza. Inclui a preparação de uma proposta, assinatura de contrato, determinação de recursos necessários, planos de projeto e entrega do software. No escopo desta tese, deve ser assegurado que o software fornecido seja acessível. Diferentes questões que abrangem esse fornecimento devem ser tratadas no eixo GD.

- Desenvolvimento: reúne as atividades do desenvolvedor de software, incluindo análise de requisitos, projeto, codificação, integração, testes, instalação e aceitação do software. Nesse ponto, há uma relação direta com o eixo DF da abordagem, que orienta a utilização de boas práticas para o desenvolvimento de aplicações Web acessíveis.

- Operação: contempla a operação do software e suporte operacional aos usuários. A operação é associada ao eixo DF e GD para uso do ferramental de forma eficiente, com tratamento adequado de decisões.

- Manutenção: reúne as atividades feitas quando o software é submetido a modificações após a entrega, devido à detecção de falhas e verificação de necessidades de melhoria e adaptação. A manutenção aproveita todos os benefícios dos eixos DF e GD, para utilizar recursos para o desenvolvimento e se ter uma base histórica de consulta de razões que motivaram definições de projeto.

\subsubsection{Processos de apoio}

- Documentação: envolve o propósito de prover e manter um registro de informações de software. Está associada a DF.AP.3, Documentação de acessibilidade, pois inclui o registro de que funcionalidades e verificações foram consideradas em relação à acessibilidade dos artefatos Web desenvolvidos.

- Gerência de Configuração: controla a identificação dos itens do software e suas mudanças, incluindo: controle de armazenamento, manipulação, distribuição e modificação de cada um dos itens que compõem o software. Esta seção da norma está diretamente associada à atividade DF.AP.1, Gerenciamento de configuração da abordagem. 
- Garantia de Qualidade: engloba ações que permitem a seleção e utilização de recursos para certificar que produtos e processos estão em conformidade com os requisitos pré-definidos. Está associada ao DF.AP.2, Monitoramento de acessibilidade, pois ao se realizar o monitoramento sobre o número de barreiras presentes, que, se forem altas, indicam que a qualidade, em termos de acessibilidade, não está adequada.

- Verificação: determina se os produtos de software de uma atividade atendem completamente as condições para as quais foram produzidos. Também está associada ao DF.AP.2, Monitoramento de acessibilidade.

- Validação: determina se os requisitos e o produto final de software atendem ao uso específico proposto. Também está associada ao DF.AP.2, Monitoramento de acessibilidade.

- Revisão Conjunta: define atividades para avaliar a situação e produtos de uma atividade de um projeto, se apropriado. Nesse sentido, as atividades do eixo GD auxiliam para que seja avaliado como estão inseridas as decisões sobre o que foi realizado, para cada produto do desenvolvimento de aplicações Web acessíveis.

- Auditoria: determina de forma independente a conformidade dos produtos e processos com os requisitos definidos. Está associada à Gerência de Decisões e Monitoramento de acessibilidade, no sentido de possibilitar a autoria sobre como estão sendo tomadas as decisões que envolvem outras atividades.

- Resolução de Problema: analisa situações de problemas e estabelece ações para resolução dos problemas de qualquer natureza ou fonte, que advém da execução do desenvolvimento, operação, manutenção ou outros processos. Para apoio nessa resolução (ferramental e sobre decisões a serem tomadas), é indicada a associação aos eixos GD e DF da abordagem.

\subsubsection{Processos Organizacionais}

- Gerência: organiza, monitora e controla a iniciação e o desempenho dos processos. Para apoio nesse controle, existe a associação ao eixo GD. 
- Melhoria: reúne atividades para avaliar, medir, controlar e melhorar um processo de ciclo de vida de software. Para o apoio a tais atividades é indicada a associação aos eixos DF e GD da abordagem.

- Infraestrutura: estabelece e mantém a infraestrutura para outros processos. Tal infraestrutura inclui a disponibilização de hardware, software, ferramentas, técnicas, padrões e recursos utilizados no desenvolvimento, operação e manutenção do software. Verifica-se uma associação desse ponto com os 3 eixos da abordagem, pois existe uma necessidade de provimento de diferentes recursos em relação ao treinamento, gerência de decisões e recursos de desenvolvimento, objetivando-se o tratamento de questões de acessibilidade.

- Treinamento: contempla atividades para manter a equipe treinada em relação aos conhecimentos desejáveis para a condução dos demais processos e sobre a estrutura governamental. Está associado ao eixo TA, que objetiva qualificar a equipe em um treinamento sobre questões de acessibilidade.

\subsection{Considerações gerais}

A abordagem aqui apresentada foi proposta e desenvolvida atentando para as seguintes considerações gerais:

- Comunicação: deve haver comunicação contínua entre os desenvolvedores e outros interessados no projeto Web. Um possível registro organizado dessa comunicação é viabilizado pela formação da base de conhecimento na gerência de decisões e, na documentação do que está sendo desenvolvido;

- Aplicabilidade: a abordagem não é restrita a projetos usando determinados processos ou métodos, assim, ela pode ser utilizada em variadas organizações de desenvolvimento Web. Porém, é necessário verificar a existência de tempo hábil e recursos para que ela possa ser utilizada, sendo que, nesse sentido, a abordagem foi desenvolvida para exigir o mínimo de recursos possível, para não inviabilizar sua aplicação em organizações pequenas, com restrição de recursos;

- Contínua: a aplicação da abordagem é contínua, desde o aprendizado dos desenvolvedores e outros interessados, até a manutenção e monitoramento de 
acessibilidade nos desenvolvimentos, isso para que se possa haver ganhos concretos e a acessibilidade mantida de forma constante;

- Flexível: a natureza de aplicabilidade da abordagem e suas atividades foram concebidas para a mesma ser utilizada nos mais variados processos e equipes de desenvolvimento Web, sempre com acompanhamento dessas atividades e verificação de resultados;

- Consistente: tem base em testes e em resultados históricos considerados adequados. Suas atividades são claras e práticas, visando resultados satisfatórios e concisos de adoção de boas práticas, que podem ser mensuradas a partir de avaliações de acessibilidade;

- Padrão: a abordagem segue um padrão sistemático de atividades e considerações, prezando pela aderência a diretrizes de acessibilidade;

- Custo: o custo não pode inviabilizar sua aplicação, portanto são propostas atividades que utilizam recursos da própria organização, de forma adaptável e escalável. A ideia é minimizar o "overhead" de utilização da abordagem durante o desenvolvimento, em termos de tempo, recursos e de pessoal envolvido;

- Replicável: as atividades que compõem a abordagem são descritas para serem replicáveis em diversas situações e projetos de desenvolvimento Web. Suas atividades têm foco em situações que frequentemente ocorrem e são indicadas possíveis ações a serem conduzidas; e

- Rastreabilidade: a falta de acessibilidade pode ocorrer em diferentes momentos de um projeto e em diversos artefatos. Com o uso de históricos, componentes e DR, é possível saber sobre problemas, onde existem falhas e quais correções foram ou devem ser feitas.

\subsubsection{Ameaças e dificuldades para aplicação da abordagem}

Nesta seção são descritas ameaças e dificuldades para aplicação da abordagem proposta, que devem ser conhecidas para que possam ser tratadas adequadamente.

A primeira e maior dificuldade vislumbrada é em relação ao treinamento em acessibilidade, pois treinar a equipe é uma tarefa complexa que envolve questões de ambiente 
e experiência. Nesse ponto, pode ocorrer uma resistência de desenvolvedores e até mesmo das organizações para realizar as atividades de treinamento, visto que nem sempre os envolvidos consideram tais práticas atrativas.

Somada a essa resistência, existe a possibilidade de um conhecimento prévio insuficiente ou errôneo de determinada técnica interferir em todo um desenvolvimento, resultando em problemas de acessibilidade. Por exemplo, um desenvolvedor pode achar que algo está certo e escrever isso numa base histórica de experiências, influenciando negativamente os próximos desenvolvimentos.

Outra dificuldade é em relação à utilização de componentes e reuso. Por mais que os benefícios dessa utilização sejam claros, é possível haver uma dificuldade para que todos se acostumem com esse modo de desenvolvimento. Ocorre que vários desenvolvedores podem criar novamente um determinado artefato, por considerar difícil buscar e reusar um componente pronto.

Sobre o uso de ferramentas com mais recursos de acessibilidade, existem dois entraves que merecem destaque: o custo de um determinado ferramental (várias são proprietárias e não gratuitas) e a resistência no uso de algumas delas por parte da equipe de desenvolvimento. Pode ser que os integrantes de tal equipe estejam acostumados com determinado ambiente de desenvolvimento e é complexo determinar uma obrigatoriedade em fazer a mudança das ferramentas que compõem esse ambiente.

\subsubsection{Fora do escopo}

O escopo da abordagem não está relacionado a como devem ser implementados os artefatos, uma vez que isso já é definido nas diretrizes de acessibilidade, mas sim é referente a em como apoiar o trabalho de projeto Web, adotando ações e definições de tais diretrizes durante o desenvolvimento.

Outro ponto de escopo é o objetivo de apoio à construção de interfaces e interação, não incluindo, por exemplo, aspectos internos de regras de negócio e banco de dados. 


\subsection{Considerações finais}

Neste capítulo foi apresentada a abordagem idealizada, com seus objetivos, estrutura e detalhamentos. A ideia é que tal abordagem possa ser um instrumento para apoio no sentido de que diretrizes de acessibilidade possam ser utilizadas efetivamente no desenvolvimento Web.

Uma característica marcante do conteúdo apresentado aqui é o fato da abordagem ser resultado de intenso trabalho de investigação da literatura e de acompanhamento de casos reais de desenvolvimento. Procurou-se não desenvolver novas diretrizes nem estendê-las, mas sim, prover um norteamento para aplicação das diretrizes existentes, por meio de atividades organizadas em três eixos.

No próximo capítulo é feita uma validação da abordagem apresentada com importantes considerações para sua aplicação. Houve, assim, a utilização da abordagem por estudantes, neste caso, representados por alunos de Ciência da Computação, os quais analisaram a mesma, a partir da perspectiva de integrantes de uma equipe de desenvolvimento Web. 



\section{Experimento para validação da abordagem proposta}

\subsection{Considerações iniciais}

Neste capítulo são apresentados detalhes do planejamento e execução de um experimento controlado com o objetivo de verificar os benefícios e as desvantagens do uso da abordagem desenvolvida (apresentada no capítulo anterior). $\mathrm{O}$ experimento contou com a participação de alunos de graduação do curso de Ciência da Computação da Universidade Federal de Goiás (UFG). Após um treinamento inicial, houve a divisão em grupos e condução do desenvolvimento de uma aplicação Web de agendamento de bancas. Assim, pôde-se realizar uma validação qualitativa da abordagem, bem como analisar considerações sobre sua utilização pelas equipes que participaram do desenvolvimento. 
O restante deste capítulo é organizado como segue: na Seção 7.2 é mostrada a metodologia aplicada para desenvolvimento do experimento. Na Seção 7.3 é apresentada a definição do experimento, incluindo os objetivos, as questões que este estudo deve responder e as métricas utilizadas para verificar tais questões. O planejamento do experimento é detalhado na Seção 7.4 e sua operação na Seção 7.5. Na Seção 7.6 são apresentados os resultados identificados com o experimento. Já na Seção 7.7 tem-se a apresentação da aplicação de questionários e uma entrevista, bem como a síntese e análise das respostas. E, por fim, na Seção 7.8, têm-se as conclusões do experimento.

\subsection{Metodologia}

A metodologia utilizada consiste no planejamento e condução de etapas de planejamento, execução e análise de resultados de um experimento controlado. Tal tipo de estudo é empregado quando se deseja investigar e compreender em profundidade fenômenos por meio de abordagens empíricas e holísticas de problemas contemporâneos. Além disso, este tipo de estudo é especialmente pertinente quando as perguntas de pesquisa buscam a compreensão de como se desenvolvem determinados processos, suas causas e motivações (YIN, 2005; WOHLIN et al., 2000; LAZAR et al., 2010).

Uma vez que intervenções externas estão envolvidas com a aplicação de experimentos no cenário de utilização real, como em empresas, concorda-se que um experimento rigoroso exige tempo e, às vezes, investimentos adicionais. Além disso, é difícil encontrar empresas dispostas a utilizar durante seus processos propostas acadêmicas sem serem efetivamente testadas. Nesse sentido, Höst et al. (2000), discorrem que, em certas condições, estudantes podem ser utilizados em experimentos controlados, sem necessariamente resultar em uma ameaça à validade do experimento. Assim, justifica-se relevante o desenvolvimento deste experimento no contexto acadêmico, em que estudantes utilizaram a abordagem proposta.

Em contrapartida, entende-se que o cenário acadêmico pode não permitir a generalização dos resultados encontrados para uma diversidade maior de casos, não sendo possível inferir que os mesmos dados encontrados poderiam ser novamente verificados se o experimento fosse replicado em um contexto diferente. Mas como o objetivo é verificar a 
abordagem proposta, o estudo pode sim servir para estabelecer valores de referência para futuros estudos e possibilitar a coleta de dados relevantes aos objetivos definidos.

A fim de executar um experimento sistemático, foram também seguidas as recomendações definidas por Wohlin et al. (2000), que descrevem como deve ser feito o plano ou protocolo, utilizado para a realização do experimento e também a forma de analisar os resultados.

Outro estudo relevante que indicou ações a serem seguidas foi o apresentado por Kampenes et al. (2009), que conduziram uma revisão sistemática sobre causas e efeitos de diferentes eventos e sua relação com a validade e possíveis ameaças em experimentos de Engenharia de Software. Tal revisão sistemática envolveu a análise de artigos publicados em periódicos e conferências da área, sendo assim, essa foi uma importante base metodológica de tratamentos para o experimento apresentado neste capítulo.

\subsection{Definição do experimento}

O experimento foi conduzido e desenvolvido por três pesquisadores: i) uma Ph.D. expert em Engenharia de Software Empírica, a qual ajudou a definir o processo a ser seguido durante o desenvolvimento e execução do experimento, sendo experiente na execução de experimentos para desenvolvimento de software (orientadora desta tese); ii) um estudante de Ph.D., o qual tem trabalhado com acessibilidade na Web por 5 anos (autor desta tese); e iii) um estudante de mestrado, o qual ajudou na análise dos resultados.

A fase de definição do experimento consiste da descrição dos objetivos e práticas do estudo, sendo que nessa fase aplicou-se o método Objetivo-Questão-Métrica (Goal-QuestionMetric - GQM), utilizado para definição e avaliação da pesquisa desenvolvida.

Como apresentado por Basili (1992), o GQM é usado para coletar e analisar métricas que são utilizadas para definir os objetivos da pesquisa, sendo constituído por três níveis:

- Objetivo (ou nível conceitual): é descrito o objeto em estudo, relacionado às razões envolvidas as quais justificam o desenvolvimento da pesquisa com base em vários pontos de vista, em relação a um determinado ambiente; 
- Questão (ou nível operacional): são definidos os caminhos que devem ser seguidos, de modo a definir a avaliação que será executada; e

- Métrica (ou nível quantitativo): ocorre o refinamento das questões definidas para conduzir o experimento em métricas ou meios quantitativos para analisar os resultados coletados com o experimento. São verificadas duas classes de resultados, relacionadas à i) análises objetivas - quando depende do objeto sob análise; e ii) análises subjetivas - quando depende do objeto sob análise e do ponto de vista em que o mesmo foi analisado.

\subsubsection{Objetivo}

O objetivo é definido com base no problema a ser resolvido. Nesse sentido, para uma boa definição do objetivo foi verificado o que discorrem Wohlin et al. (2000), que propuseram um framework, sendo esse foi seguido para facilitar a definição dos objetivos de forma clara, como segue:

- Objeto de estudo (o que é estudado?): o objeto de estudo neste experimento está calcado na avaliação da abordagem, de modo a verificar a viabilidade de sua aplicação durante o desenvolvimento de aplicações acessíveis, avaliando assim as atividades definidas na abordagem, bem como a qualidade dos artefatos produzidos como resultados e sua aplicabilidade de uso;

- Propósito (qual é a intenção?): é verificada a aplicabilidade da abordagem no cenário de estudo definido - neste caso no contexto acadêmico para desenvolvimento da aplicação de gerenciamento de bancas científicas que considere a acessibilidade como um requisito;

- Foco da Qualidade (qual efeito é estudado?): verifica e explora os benefícios alcançados com o uso da abordagem proposta e as principais dificuldades enfrentadas pelos participantes do experimento durante o entendimento e uso da abordagem proposta;

- Perspectiva (qual é a visão?): há duas perspectivas que devem ser consideradas: i) uma é baseada no ponto de vista do pesquisador, que aplica o experimento para avaliar a viabilidade de utilização da abordagem, e outra ii) a partir do expert em 
acessibilidade, que usa a abordagem para verificar se o uso da acessibilidade tem sido considerado durante o desenvolvimento da aplicação proposta; e

- Contexto (onde o estudo conduzido?): o experimento foi realizado no Departamento de Ciência da Computação da UFG. Os participantes são alunos que têm desenvolvido pesquisas e trabalhos relacionados ao desenvolvimento de software para Web.

Assim, o objetivo deste estudo foi verificar a abordagem proposta com relação ao seu uso em um experimento controlado, verificando o ponto de vista dos participantes envolvidos e avaliando seus desenvolvimentos.

\subsubsection{Questões}

As seguintes perguntas foram definidas para atingir o objetivo do experimento:

- Q1. A quantidade de conformidades em relação a um conjunto definido de diretrizes de acessibilidade do documento WCAG 2.0 aumentou quando a abordagem foi seguida?

- $\mathbf{Q 2}$. O requisito de se ter elementos de interface ricos, interativos e acessíveis foi mais bem cumprido quando a abordagem foi utilizada?

\subsubsection{Métricas}

As seguintes métricas foram utilizadas para que fosse possível analisar qualitativamente as questões definidas:

- M1. Número de conformidades (NC): esta métrica refere-se a Q1; e

- M2. Número de atendimentos em relação ao requisito solicitado (NA): esta métrica refere-se a $Q 2$.

\subsection{Planejamento do experimento}

Após a fase de definição do experimento, deve-se considerar a fase de planejamento em que é descrito como o experimento será aplicado (WOHLIN et al., 2000). Nesta fase é detalhado o plano, ou protocolo, que é usado para executar o experimento e também para 
analisar os resultados identificados. A fase de planejamento consiste de sete passos, como apresentado na Figura 7.1.

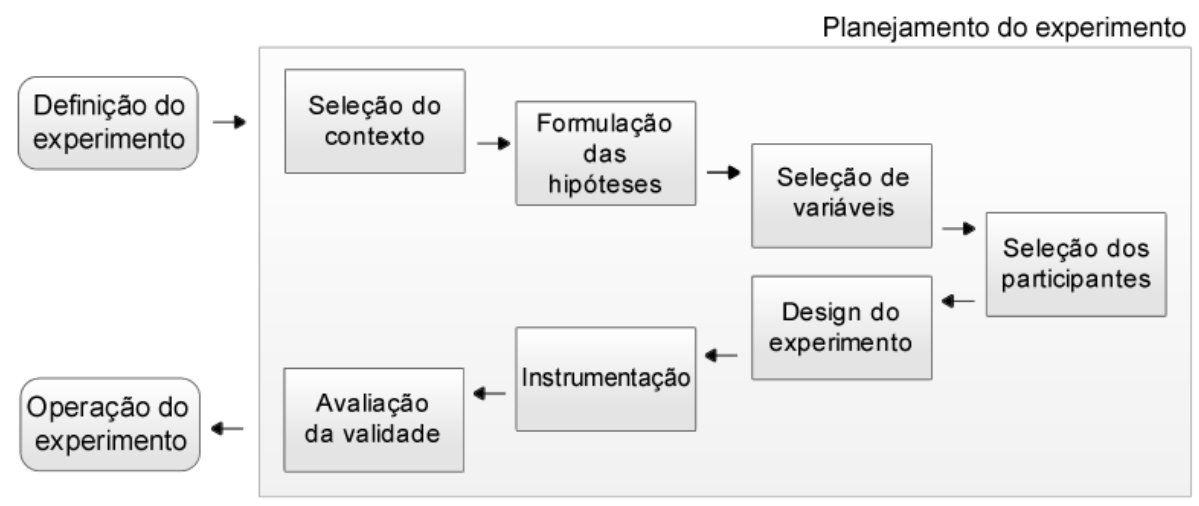

Figura 7.1 - Visão geral da fase de planejamento do experimento (WOHLIN et al., 2000)

\subsubsection{Seleção do contexto}

Wohlin et al. (2000) descrevem que para se ter resultados que possam ser replicados em estudos mais amplos, é recomendado que os experimentos sejam desenvolvidos em projetos reais, com a participação de profissionais. No entanto, nem sempre tal cenário pode ser conseguido, visto que envolve o interesse das empresas pelo estudo, sendo necessário um maior tempo dedicado à aplicação do experimento nas empresas e mais recursos financeiros para conduzi-los. Nesse sentido, este estudo foi desenvolvido de modo a retratar um cenário específico, uma vez que a abordagem foi aplicada no contexto acadêmico, mas existiram tratamentos para a validade do experimento, conforme indicados por Höst et al. (2000) e Kampenes et al. (2009).

\subsubsection{Formulação das hipóteses}

Juzgado e Moreno (2001) ressaltam que é necessário definir claramente o que será avaliado e Wohlin et al. (2000) destacam que as hipóteses podem ser utilizadas para isso. Dois tipos de hipóteses podem ser considerados para a definição do experimento: i) Hipótese Nula $\left(\mathrm{H}_{0}\right)$, que afirma que não existem tendências reais ou padrões no experimento e ii) Hipótese Alternativa $\left(\mathrm{H}_{1}\right)$, relacionada ao benefício alcançado com o experimento e, se atingida, torna a hipótese nula rejeitada. As hipóteses definidas neste experimento são apresentadas na Seção 7.5. 


\subsubsection{Seleção de variáveis}

Hipóteses bem definidas definem as variáveis dependentes e independentes do estudo (LAZAR et al., 2010). Variáveis independentes referem-se a fatores que os pesquisadores estão interessados em estudar, sendo independentes do comportamento do participante. As variáveis independentes são aquelas que podem ser controladas e alteradas no experimento, como: i) quais problemas de acessibilidade serão verificados; ii) como os componentes acessíveis serão obtidos e verificados; e iii) número de conformidades conseguidas com o uso da abordagem. As variáveis dependentes referem-se aos resultados ou efeitos que o pesquisador está interessado. Em sua maioria, não são diretamente mensuráveis e devem ser cuidadosamente validadas, uma vez que afetam o resultado do estudo. Tem-se como exemplo de variáveis dependentes: i) eficácia, ii) eficiência da abordagem desenvolvida e iii) facilidade de aprendizado.

\subsubsection{Seleção dos participantes}

Os participantes foram selecionados utilizando a amostragem por conveniência, o que significa que as pessoas mais próximas e mais convenientes foram selecionadas (WOHLIN et al., 2000).

Assim, foram selecionados 24 alunos de graduação do curso de Ciência da Computação. Tal amostra foi escolhida uma vez que os alunos tem alguma experiência com desenvolvimento de software, bem como facilidades com o uso de ferramentas de autoria para Web.

\subsubsection{Design do experimento}

Após o problema do estudo ter sido declarado, as variáveis do experimento definidas, os participantes escolhidos e os detalhes para conduzir o experimento acordados, tornou-se possível definir o design do experimento. Neste caso, dois cenários foram estipulados, um em que os participantes contam com o apoio da abordagem para desenvolvimento da aplicação Web e outro em que não há tal apoio. Assim, o design do experimento, nesse caso, tem um fator com dois tratamentos possibilitando comparação entre eles. 


\subsubsection{Instrumentação}

A fim de garantir que o experimento foi bem calibrado, dois projetos pilotos foram conduzidos com a mesma estrutura definida no planejamento. O primeiro piloto teve como objetivo detectar possíveis problemas no experimento e calibrá-lo antes de sua execução real. Alguns problemas foram verificados, como aqueles relacionados ao primeiro enunciado de apresentação do experimento aos participantes e sobre como aplicar as diretrizes para o desenvolvimento de aplicações Web acessíveis. Isso depende da percepção dos desenvolvedores e do contexto do projeto ao qual a abordagem foi aplicada (sendo bem explicado esse contexto aos participantes).

O segundo piloto foi realizado por um único participante, o qual tem experiência no desenvolvimento de experimentos na área de Engenharia de Software, e que dispõe de conhecimento sobre acessibilidade, desenvolvimento Web e estudos empíricos. Nesse piloto foram detectados problemas relacionados com os artefatos desenvolvidos como suporte para esse experimento, e, portanto, modificações foram feitas para solucioná-los. Além disso, problemas com os questionários (usados para coletar dados dos participantes) foram também identificados. Assim, definições para avaliar a abordagem foram identificadas e considerações foram removidas ou modificadas.

\subsubsection{Avaliação da validade}

Uma questão fundamental sobre os resultados de um experimento é a forma como eles são válidos. De acordo com Wohlin et al. (2000), durante a fase de planeamento é importante considerar a validade de estudos já desenvolvidos anteriormente, de modo a antecipar possíveis ameaças que estão envolvidas no domínio em que a pesquisa é conduzida.

Para tratar ameaças à validade utilizou-se as considerações organizadas por Kampenes et al. (2009). De modo sucinto essas considerações compreenderam ações como a divisão dos participantes em grupos, de acordo com o nível de experiência e conhecimento de cada um, de modo a possibilitar que os grupos estejam balanceados tecnicamente. Assim, o protocolo do experimento contemplou a identificação e análise de background com dados coletados por meio das respostas dos participantes, incluindo o reconhecimento de suas experiências, e a divisão desses em grupos de acordo com a análise prévia de especialidades de cada um. 
Outra ação metodológica que foi realizada, de acordo com a literatura verificada, foi solicitar que participantes de grupos distintos não conversassem sobre o experimento. Isso auxilia para que seja amenizada a interferência de uma possível ajuda de indivíduos de grupos que utilizam a abordagem com informações sobre as atividades realizadas.

Neste sentido, após o planejamento ter sido definido, pôde-se executar o experimento de modo a coletar dados para verificar a viabilidade da abordagem proposta nesta tese, como apresentado nas próximas seções.

\subsection{Operação do experimento}

Em relação às hipóteses definidas neste experimento, buscou-se verificar se, com o uso da abordagem proposta, as diretrizes de acessibilidade têm sido mais bem aplicadas durante o desenvolvimento das aplicações Web. Assim, para definição das hipóteses nulas e das hipóteses alternativas utilizou-se, como suporte, as questões de pesquisa apresentadas na fase de definição do experimento. As hipóteses definidas são:

- Hipóteses Nulas $\left(\mathbf{H}_{0}\right): \mathbf{H}_{01}$. A quantidade de conformidades em relação às diretrizes de acessibilidade selecionadas da WCAG 2.0 não aumenta se a abordagem é seguida. $\mathbf{H}_{\mathbf{0 2}}$. Não são aplicados elementos de interface ricos, interativos e acessíveis com a utilização da abordagem durante o desenvolvimento da aplicação Web; e

- Hipóteses Alternativas $\left(\mathbf{H}_{1}\right)$ : $\mathbf{H}_{11}$. A quantidade de conformidades em relação às diretrizes de acessibilidade selecionadas da WCAG 2.0 aumenta se a abordagem é seguida. $\mathbf{H}_{12}$. São aplicados elementos de interface ricos e interativos com a utilização da abordagem durante o desenvolvimento da aplicação Web.

As hipóteses nulas devem ser refutadas, de modo a negar que a utilização da abordagem não interfere no desenvolvimento Web em relação às considerações de acessibilidade. No mesmo sentido, as hipóteses alternativas devem ser confirmadas, de modo a comprovar que a utilização da abordagem contribui positivamente para a facilidade no uso de componentes acessíveis durante o desenvolvimento Web. 
Na Figura 7.2 é apresentado o esquema seguido de etapas do experimento, sendo mostradas as atividades para definição da experiência dos participantes e a caracterização dos grupos, bem como outras atividades relacionadas ao desenvolvimento do experimento em si e avaliação dos resultados identificados.

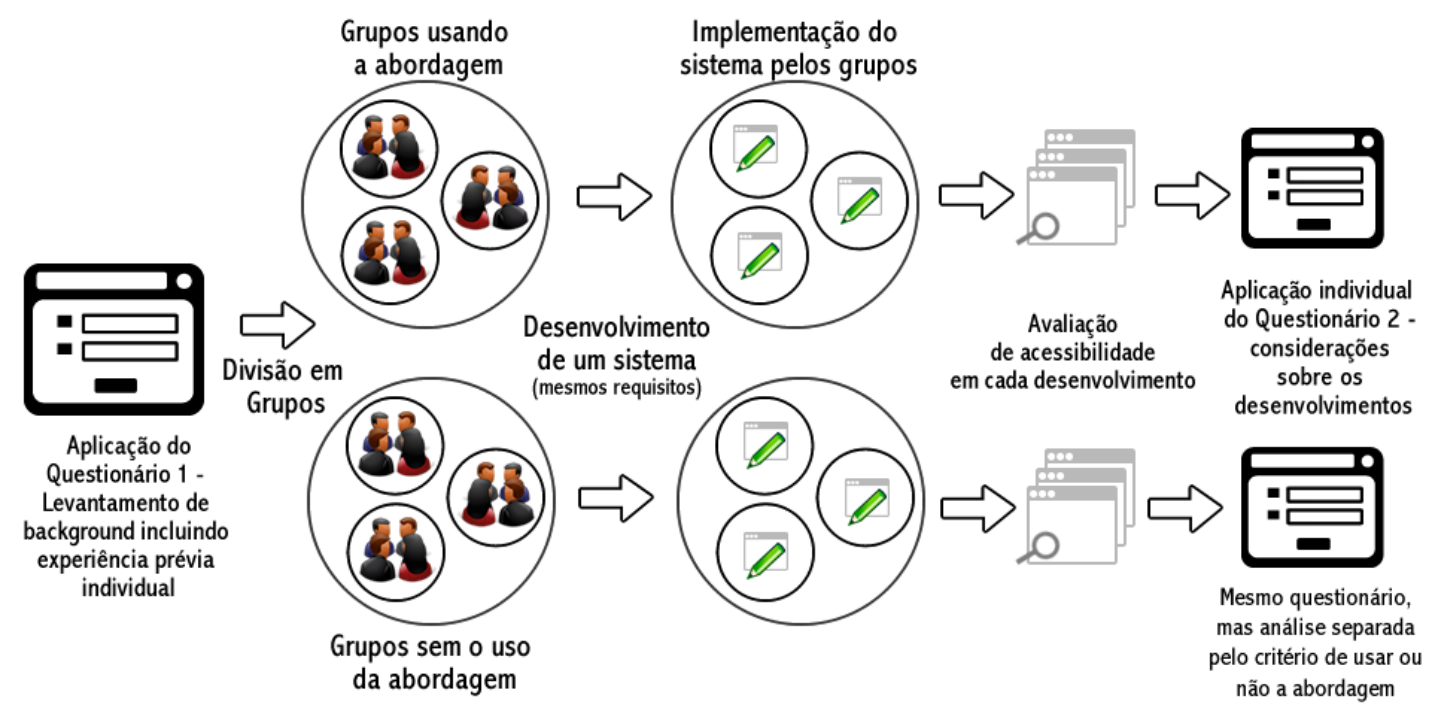

Figura 7.2 - Esquema ilustrado do experimento conduzido

Conforme pode ser visto na Figura 7.2, após a divisão em 2 tipos de grupos foi requerido o desenvolvimento de um sistema por cada grupo, com base nos mesmos requisitos. Esse cenário foi necessário uma vez que se pretende identificar e pontuar os diferentes resultados atingidos pelos grupos que utilizaram a abordagem proposta nesta tese e os grupos que não tiveram essa mesma base de apoio para o desenvolvimento do experimento.

Assim, para a realização do experimento, contou-se com a participação de 24 pessoas organizadas em 6 grupos de 4 indivíduos, sendo que cada grupo contou com pelo menos um membro com significativa experiência em desenvolvimento Web. Isso foi necessário de modo a balancear os grupos, mantendo-os em um nível aproximado de conhecimento técnico. A lista com os detalhes das experiências reportadas pelos participantes pode ser vista no Apêndice B, sendo que a experiência considerada e analisada para a divisão dos grupos foi a relatada pelos participantes nas questões 3 e 4 . 
De forma resumida, a experiência dos participantes foi medida por meio das respostas relacionadas a já terem desenvolvido aplicações Web em empresas privadas ou em trabalhos produzidos em disciplinas oferecidas na universidade.

Em seguida, para efeito de comparação, foram definidos grupos para usarem a abordagem e outros sem esse uso. Para essa separação foi realizado um sorteio entre os grupos, os quais teriam auxílio da abordagem como ferramental de apoio, sendo sorteados os de número 2,3 e 5.

O treinamento inicial ocorreu em quatro períodos de 4hs (totalizando 16hs) envolvendo apresentação do termo de consentimento livre e esclarecido, enunciado do experimento e de uma revisão de conceitos de HTML, bem como foi feita uma leitura dirigida em artigos sobre desenvolvimento Web. Após cada apresentação, feita pelo coordenador do experimento ou realizada por integrantes dos grupos sob a forma de seminários, foram feitas discussões por todos ressaltando detalhes interessantes sobre as leituras realizadas incluindo a importância de conceitos, enfatizando a necessidade da acessibilidade para o desenvolvimento Web.

Em seguida foi apresentada a proposta da aplicação Web que deveria ser desenvolvida pelos grupos, a qual está relacionada à implementação de um sistema Web para agendamento de bancas de projetos finais de curso. Tal sistema deve contemplar as seguintes entidades principais:

- Bancas: compostas por um presidente e por mais membros (em geral 2), data com horário inicial e final, sala, um apresentador e um trabalho a ser apresentado;

- Salas: sendo que cada sala possui um nome, código e localização;

- Pessoas: com nome, e-mail, telefone, instituição e senha.

Uma sugestão de modelo de base de dados para uso dos grupos foi apresentada (presente no Apêndice B), a qual é composta por 7 tabelas com relacionamentos entre si. Tais tabelas são: "sala", onde é realizada uma apresentação de trabalho; "pessoa", que pode ser o apresentador, participante ou administrador, papéis esses definidos pelo relacionamento das tabelas "perfil" e "pessoa_perfil"; "banca": que consiste do horário inicial e final da 
apresentação, do resultado, da nota final e dos membros da mesma, caracterizados pelo relacionamento das tabelas "banca_pessoa" e "função_banca".

Algumas regras de negócio também foram incluídas como requisitos para o desenvolvimento, como segue:

- Não é permitido duas bancas no mesmo horário e local;

- Não é permitido uma pessoa ser presidente e membro da banca ao mesmo tempo; e

- O horário inicial da banca deve ser menor que o horário final.

Um suposto cliente foi determinado, o qual é representado pelo coordenador do experimento, autor desta tese, cujo papel é solicitar aos desenvolvedores que a aplicação seja interativa e usável, com menus drop-down, calendário para auxiliar na escolha da data, dentre outras características que se enquadram em requisitos funcionais e não funcionais.

Todos os grupos foram instruídos a realizar a captura de DR, registrando decisões e informações importantes do desenvolvimento e postando-as na ferramenta AccessibilityUtil ou numa Wiki seguindo o formato: i) tópico; ii) data de criação e nome do criador; iii) qual ponderação para a criação do tópico; iv) comentários de cada elemento da equipe; e v) a decisão final do grupo.

Adicionalmente, foi estabelecido um prazo de duas semanas para a entrega dos artefatos desenvolvidos. Esse período é considerado curto e foi definido assim para simular o ambiente geralmente encontrado em empresas de desenvolvimento de software, em que os desenvolvedores se deparam com a pressão de cronograma e prazo de entrega - time-tomarket.

Um conjunto de critérios foi definido para pontuar os artefatos produzidos, o que foi utilizado para possibilitar a avaliação do desenvolvimento final de cada grupo. Esses critérios correspondem à verificação de adequação a um subconjunto das diretrizes WCAG 2.0, como pode ser visto no Quadro 7.1.

Os códigos entre parênteses apontam relacionamentos com a seção de técnicas específicas para se cumprir um determinado critério de sucesso. Os códigos iniciados por $\mathbf{H}$ 
representam técnicas para HTML e XHTML e aqueles iniciados por G representam técnicas gerais.

A descrição desses critérios e técnicas selecionados está presente no Apêndice $\mathbf{C}$ desta tese.

Quadro 7.1 - Critérios estabelecidos para verificação de acessibilidade

\begin{tabular}{|l|c|}
\hline Critério estabelecido & Relacionamento com a WCAG 2.0 \\
\hline \hline 1 - Uso de tabelas acessíveis & $1.3 .1(\mathrm{H} 73, \mathrm{H} 39$ e H51) \\
\hline 2 - Uso de imagens com texto alternativo & $1.1 .1(\mathrm{H} 37$ e H67) \\
\hline 3 - Formulários com uso apropriado de labels & $1.1 .1,1.3 .1,3.3 .2$ e $4.1 .2(\mathrm{H} 44)$ \\
\hline 4 - Uso correto de tags de cabeçalho $(\mathrm{h} 1, \mathrm{~h} 2, \ldots)$ & 1.3 .1 e $2.4 .10(\mathrm{G} 141$ e H42) \\
\hline 5 - Elementos com contraste adequado & 1.4 .3 \\
\hline 6 - Uso apropriado de título nas páginas & 2.4 .2 \\
\hline 7 - Não existem links quebrados & 3.2 .3 \\
\hline
\end{tabular}

Um conjunto menor de diretrizes WCAG 2.0 foi escolhido para a avaliação, conforme visualizado no Quadro 7.1. Isso foi feito com intuito de viabilizar a execução da pesquisa e teve origem na verificação de que várias diretrizes não se aplicavam ao domínio de desenvolvimento solicitado aos participantes. Assim, não se fez necessário a utilização de todas as diretrizes, visto que essas poderiam dificultar o entendimento da análise final. Por exemplo, diretrizes que envolvem a exibição de vídeos não se aplicam ao domínio escolhido.

Para a verificação de cada critério foi realizada uma inspeção nos artefatos produzidos por cada grupo, sendo que, para a verificação do atendimento aos critérios 1, 2, 3, 4 e 7 (descritos no Quadro 7.1), se fez necessário a verificação do código fonte HTML produzido. Para a verificação de contraste (critério 5) foi utilizada a extensão "WCAG Contrast Checker ${ }^{34}$ do navegador Web Firefox ${ }^{35}$.

\footnotetext{
${ }^{34}$ https://addons.mozilla.org/pt-BR/firefox/addon/wcag-contrast-checker/

${ }^{35} \mathrm{http} / / /$ www.mozilla.org/pt-BR/firefox/new/
} 


\subsection{Análise e interpretação}

O experimento foi realizado em uma disciplina de graduação de 64hs, em janeiro e fevereiro de 2012, na qual foram apresentados os conceitos de acessibilidade e suas diretrizes, para que então fosse desenvolvido o projeto na prática.

Todos os grupos estabelecidos conseguiram desenvolver a aplicação proposta, mas em diferentes níveis de completude dos requisitos e com distintos problemas de acessibilidade, que são resumidamente apresentados, de forma qualitativa, nas próximas subseções.

\subsubsection{Grupo 1}

Sobre o trabalho desenvolvido pelo Grupo 1, erros foram encontrados nos artefatos desenvolvidos, como a grafia de português incorreta, o uso de imagens sem textos alternativos e formulários com problemas de acessibilidade. Na Figura 7.3 é mostrado um exemplo do desenvolvimento deste grupo.

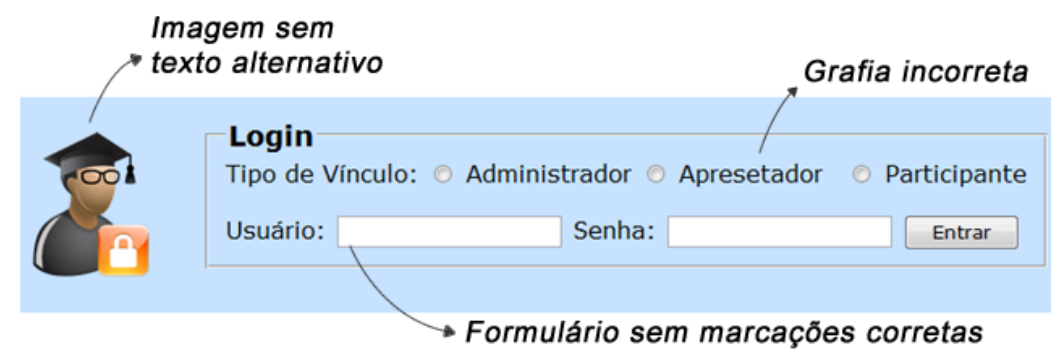

Figura 7.3 - Design do Grupo 1 com apontamento de problemas

Adicionalmente, em relação aos problemas no desenvolvimento dos formulários, não foi utilizada a tag label corretamente para os rótulos. Visualmente o formulário parece estar correto, porém quando utilizado por um usuário usando leitor de tela, esse pode se confundir para saber a que um determinado campo se refere. $O$ uso de tabelas como forma de organização de layout também foi considerada como uma técnica errada que foi utilizada pelo grupo, prejudicando na leitura e compreensão dos dados por pessoas com deficiência.

\subsubsection{Grupo 2}

Desde que o Grupo 2 foi selecionado para utilizar as orientações apresentadas pela abordagem desenvolvida nesta tese, espera-se que resultados satisfatórios sejam encontrados 
nos artefatos desse grupo. Isso foi confirmado pela utilização correta de tags para título H1 e H2, como mostrado na Figura 7.4.

Existem outros pontos positivos que podem ser destacados, como: a inclusão de artefatos interessantes como menu drop-down acessível via teclado, o uso de elementos para aumentar o texto e contraste, a utilização correta de labels e o uso de texto alternativo nas imagens.

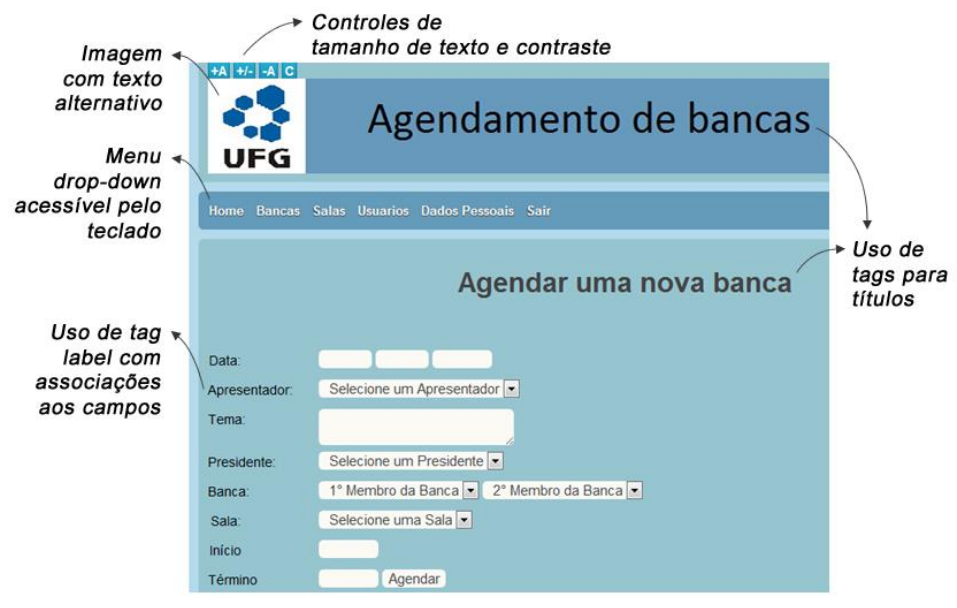

Figura 7.4 - Design do Grupo 2

Os resultados identificados nos desenvolvimentos do Grupo 2 confirmaram a suposição de que com o uso de diretrizes e de práticas pré-estabelecidas a acessibilidade é inserida durante o desenvolvimento de aplicações Web. Percebe-se assim, que tendo a abordagem como apoio ferramental, boas práticas para desenvolvimento considerando acessibilidade foram adotadas pelo grupo.

\subsubsection{Grupo 3}

No desenvolvimento apresentado pelo Grupo 3 foi feita a utilização da tag $\mathrm{H} 1$ para títulos, a qual foi corretamente aplicada, como mostrado na Figura 7.5. 

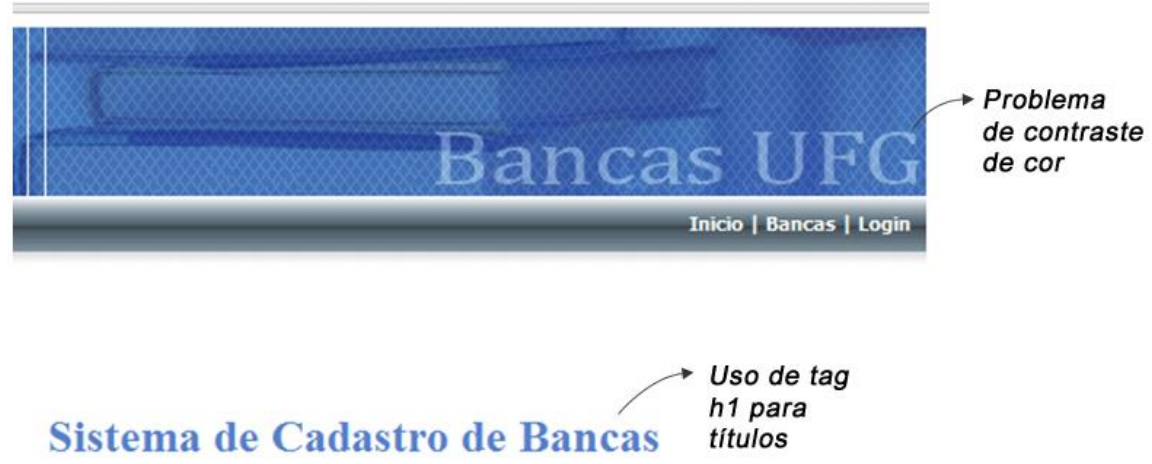

Sistema de Cadastramento de bancas da Universidade Federal de Goiảs

Figura 7.5 - H1 para título correto, porém há problema de contraste de cor no cabeçalho

No entanto, no cabeçalho do sistema há a aplicação de um título usando uma imagem e ainda com problema de contraste de cor. A relação de contraste de nível 02:04:01 foi encontrada, fato esse que deixa de cumprir as orientações das diretrizes WCAG 2.0 nos níveis AA e AAA (critério de sucesso 1.4.3). Mesmo se tratando de uma arte que faz parte do cabeçalho, um nível de contraste adequado é um requisito essencial para a leitura do texto, sendo uma forma do usuário reconhecer em que ponto da navegação ele está.

Outra questão a ser destacada como ponto negativo é a existência de tabelas com problemas de acessibilidade, onde não há marcação de cabeçalhos e resumo. Em contrapartida, um ponto positivo é que foram marcados os campos obrigatórios a serem preenchidos no formulário de acesso ao sistema (login).

O Grupo 3 não usou elementos que melhoram a interação e usabilidade do usuário, como o caso de menus drop-down e calendários para facilitar a escolha de datas. Isso impossibilitou a avaliação e observância de possíveis problemas de acessibilidade, uma vez que tais elementos não existem. No entanto, para essa aplicação esses artefatos são necessários, principalmente em termos de usabilidade, sendo isso solicitado como requisito pelo cliente.

Em termos de mercado, a não utilização de elementos mais complexos e com interação facilitada é um fator de desestímulo para utilização do sistema, podendo resultar na perda de usuários para concorrentes. 


\subsubsection{Grupo 4}

No desenvolvimento apresentado pelo Grupo 4, as tabelas foram produzidas corretamente, utilizando o atributo de resumo textual ("summary") e marcação de cabeçalho (“header"), como apresentado na Figura 7.6.

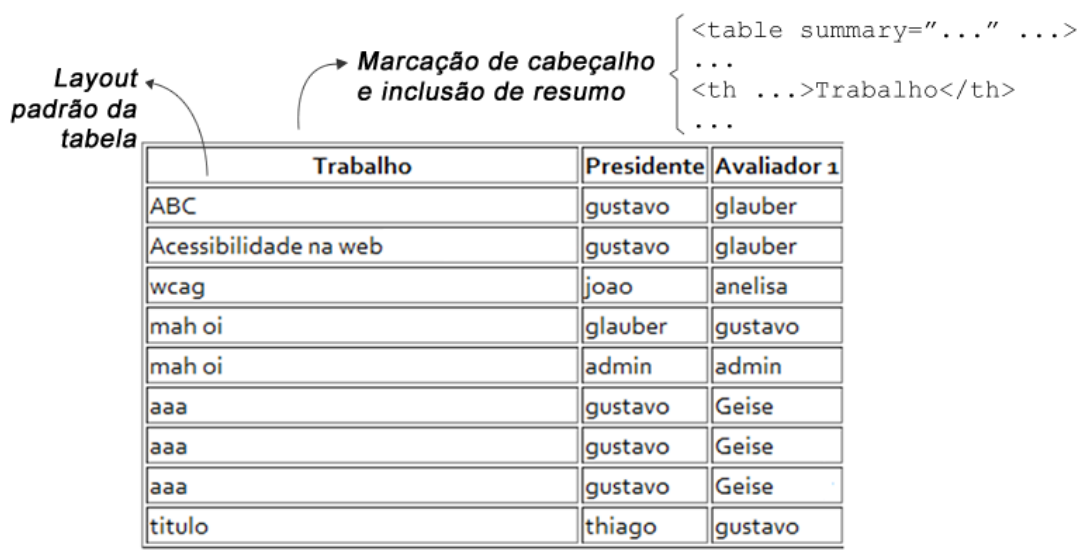

Figura 7.6 - Uso de recomendações de acessibilidade para a tabela, mas com lay-out pobre

Como pode ser visto na Figura 7.6, o sistema possui interface simples não havendo controles de acessibilidade mais avançados, como exemplo não há o uso de um link objetivando avançar para um determinado conteúdo. Assim, torna-se mais difícil para o usuário ir diretamente ao ponto de navegação que ele deseja, especialmente por aqueles usando leitores de tela.

Outro ponto que demonstra falta de consideração com o desenvolvimento de uma boa interface é a ausência de definições de estilo para as tabelas. Assim os desenvolvedores utilizaram apenas o visual padrão (estilo de borda, espaçamento e cores) do artefato tabela em HTML.

Já os formulários desenvolvidos pelo Grupo 4 foram feitos corretamente, mediante a utilização de labels, e foi realizada ainda a validação de campos, como pode ser visto na Figura 7.7. 


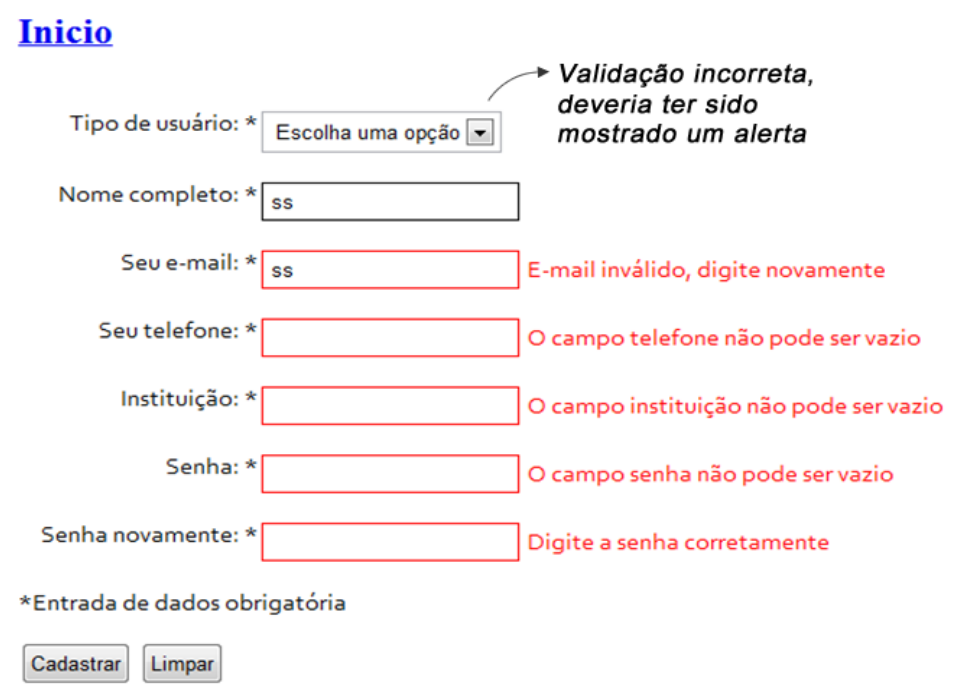

Figura 7.7 - Validação de campos de entrada de texto

Estes recursos de validação são pertinentes, uma vez que permitem a exibição de alertas para o usuário sobre possíveis erros de preenchimento. No entanto, na validação feita dos campos, há um erro de verificação do primeiro campo, “Tipo de usuário", em que, como mostrado na Figura 7.7, não foi realizada a escolha de uma opção e o sistema não apresentou uma indicação de alerta ao usuário. Isso evidencia que não houve um teste eficiente do formulário desenvolvido.

\subsubsection{Grupo 5}

No desenvolvimento do Grupo 5 existe um menu drop-down que é acessível via teclado, por meio da tecla Tab, e as tabelas foram criadas corretamente, como mostrado na Figura 7.8.

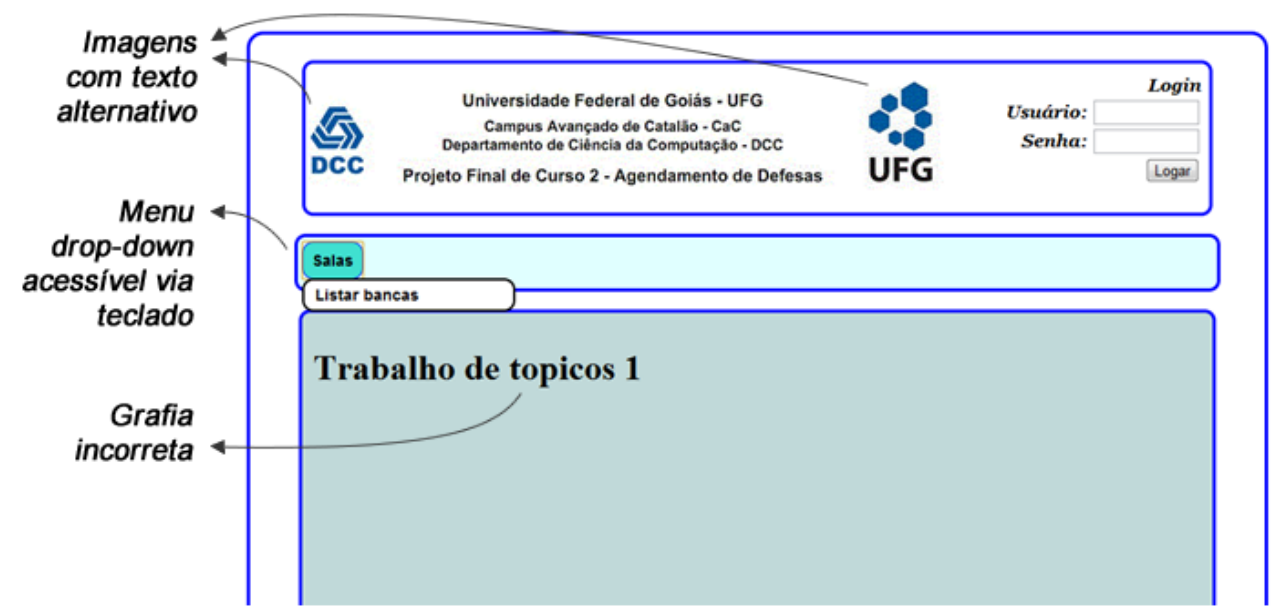

Figura 7.8 - Menu acessível e uso correto do elemento H1 
Quanto aos aspectos negativos, alguns erros de português e layout pobre podem ser mencionados. Isso pode ser justificado uma vez que alguns participantes podem não prestar atenção durante a escrita de textos e não ter preocupação em como fazer um layout mais bem elaborado e atrativo.

Entretanto, apesar desses aspectos negativos, este é o grupo que apresentou a melhor avaliação de acordo com os critérios verificados. Acredita-se que a abordagem tenha contribuído para o sucesso da qualidade do desenvolvimento do Grupo 5, tendo a acessibilidade sido considerada.

\subsubsection{Grupo 6}

Nos artefatos produzidos pelo Grupo 6 foi possível verificar o uso correto de H1, como pode-se ver na Figura 7.9. Porém a listagem dos dados foi apresentada com tamanho pequeno de caractere e as tabelas não são acessíveis. Ainda, os elementos de rótulo em formulário foram feitos corretamente, mas algumas imagens não possuem texto alternativo.

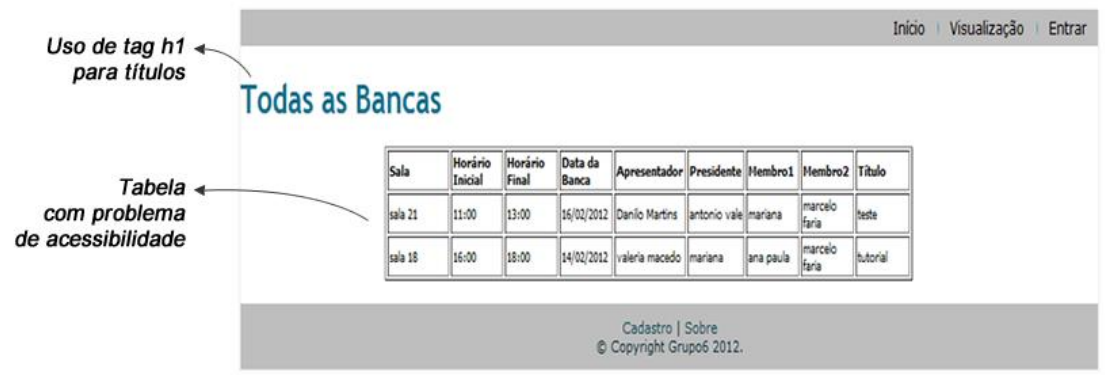

Figura 7.9 - Uso correto do elemento H1, mas a tabela apresenta problemas de acessibilidade

O Grupo 6 fez alterações expressivas na base de dados sugerida, de modo a simplificá-la em apenas 4 tabelas, a saber: "bancas", "pessoa", "sala” e "sala_ocupada". A motivação para essas alterações foi reportada no DR: "Fizemos mudanças no banco de dados a fim de facilitar nossa vida, onde agrupamos algumas tabelas e criamos outras. Essa medida foi feita para agilizar na construção do sistema, já que tínhamos pouco tempo".

Esse relato é importante para que outros desenvolvedores, que por ventura tenham acesso ao sistema e desejam modificá-lo, consigam compreender o que foi feito anteriormente, podendo inclusive reaproveitar bons desenvolvimentos. Ou seja, pode auxiliar no reuso e na agilidade do desenvolvimento de novos recursos e na manutenção do sistema. 


\subsubsection{Resultados consolidados}

De acordo com as considerações apontadas nas subseções anteriores e como resultado da avaliação de acessibilidade realizada, tem-se apresentação de Tabela 7.1. Para a marcação da mesma houve a verificação de atendimento (usando o símbolo $\checkmark$ ) ou não (usando o símbolo X) de critérios para cada desenvolvimento.

Tabela 7.1 - Resultado da avaliação de acessibilidade nos desenvolvimentos efetuados

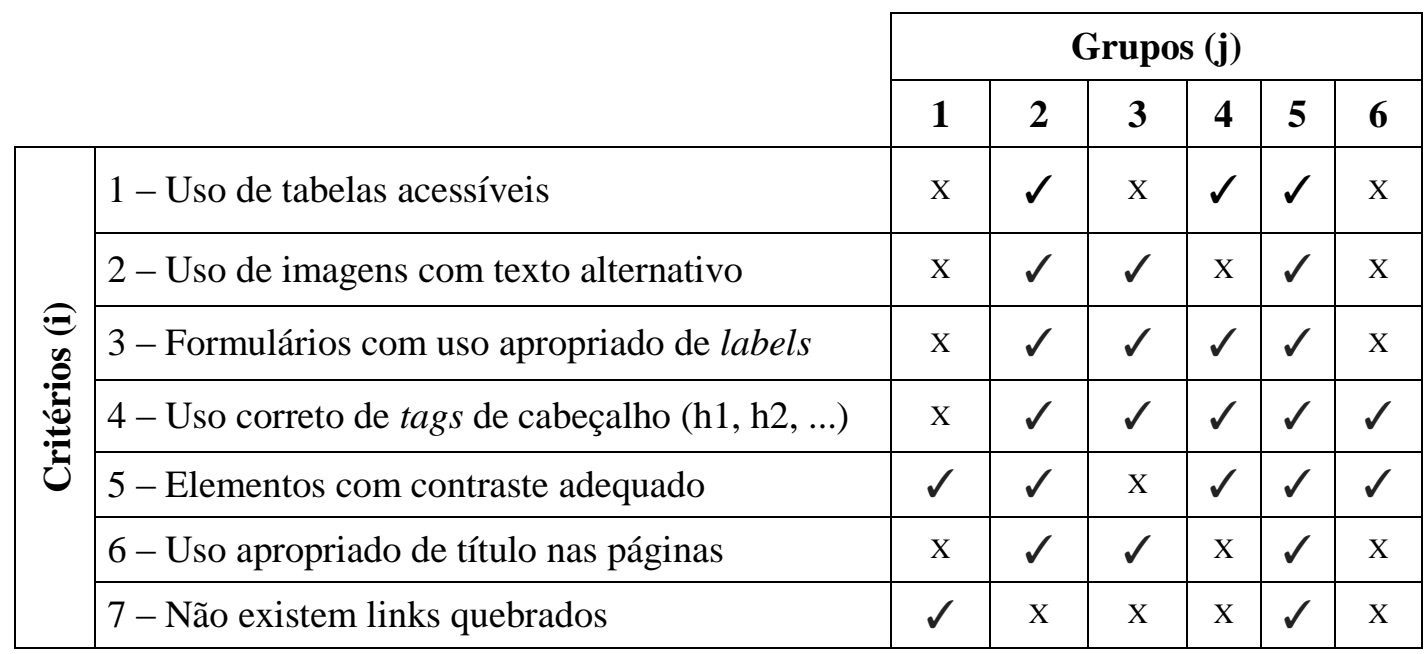

A partir da marcação da Tabela 7.1, realizou-se uma avaliação quantitativa para verificação da qualidade final do trabalho de cada grupo, de acordo com os critérios definidos. Foram associados os valores 1 para cada adequação a um critério e $\mathbf{0}$ para o desenvolvimento não adequado. Então, para se obter a pontuação de cada grupo j (chamada de SGj), fez-se o cálculo da métrica desses valores associados a partir da somatória expressa pela Equação 7.1.

$$
\mathrm{SG} j=\sum_{i=1}^{7} \mathrm{X}_{i j}
$$

Onde $\mathbf{X} \boldsymbol{i j}$ é o valor a ser somado iterativamente, sendo $\boldsymbol{i}$ o índice que indica o critério (nas linhas) e $\boldsymbol{j}$ indicando o grupo (nas colunas). Ressalta-se que, para se obter uma determinada pontuação de um grupo, o índice $j$ fica fixo, e são somados os valores associados a cada critério, começando de $i=1$ até $i=7$. O resultado de todas as somatórias por grupo pode ser visto na Figura 7.10, apresentada a seguir. 


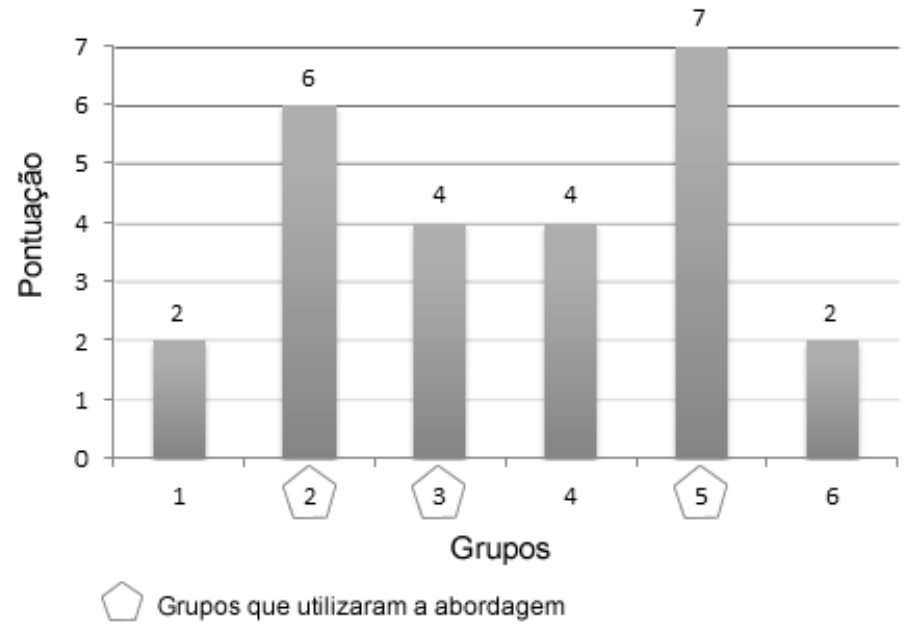

Figura 7.10 - Gráfico de barras com a pontuação total de cada grupo

Como principal resultado visto na Figura 7.10 tem-se que os grupos que utilizaram a abordagem apresentaram pontuação mais alta ou igual quando comparados àqueles que não a utilizaram. A igualdade pode ser apontada em relação aos Grupos 3 e 4, sendo que o primeiro usou a abordagem e o segundo não. Isso pode ser justificado pelo fato da abordagem ser apenas uma ajuda, não uma garantia de que as diretrizes de acessibilidade sejam consideradas.

Outra visualização pertinente, com os mesmos dados da verificação de pontuação dos desenvolvimentos, pode ser vista em gráficos do tipo box-plot, que mostram bem a distribuição dos valores. Se for analisado o conjunto de dados de todos os grupos tem-se a Figura 7.11.

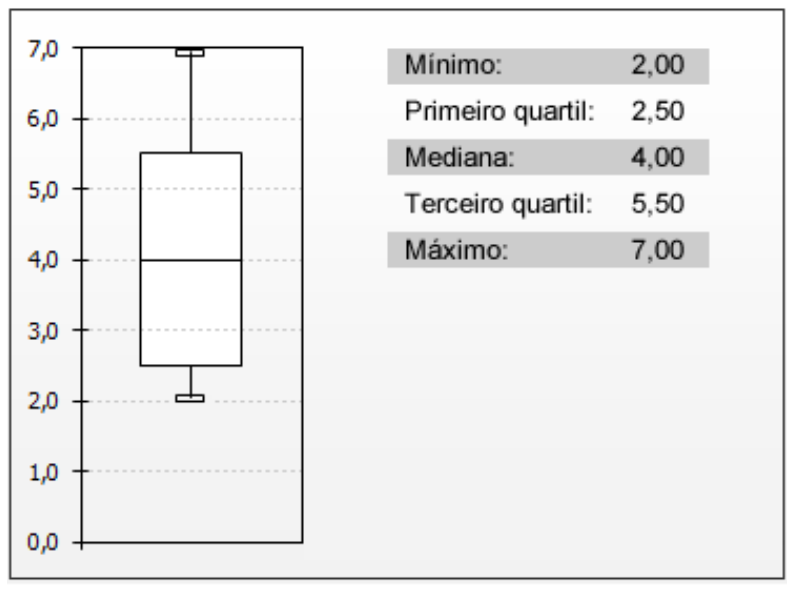

Figura 7.11 - Distribuição de dados de todos os grupos em um gráfico box-plot 
Com a Figura 7.11 é possível visualizar a distribuição da pontuação dos grupos, sendo que nenhum alcançou a pontuação zero, indicando a importância do treinamento inicial da equipe, independente do uso da abordagem.

Já se for feita uma separação pelo uso ou não da abordagem tem-se o seguinte gráfico apresentado na Figura 7.12.

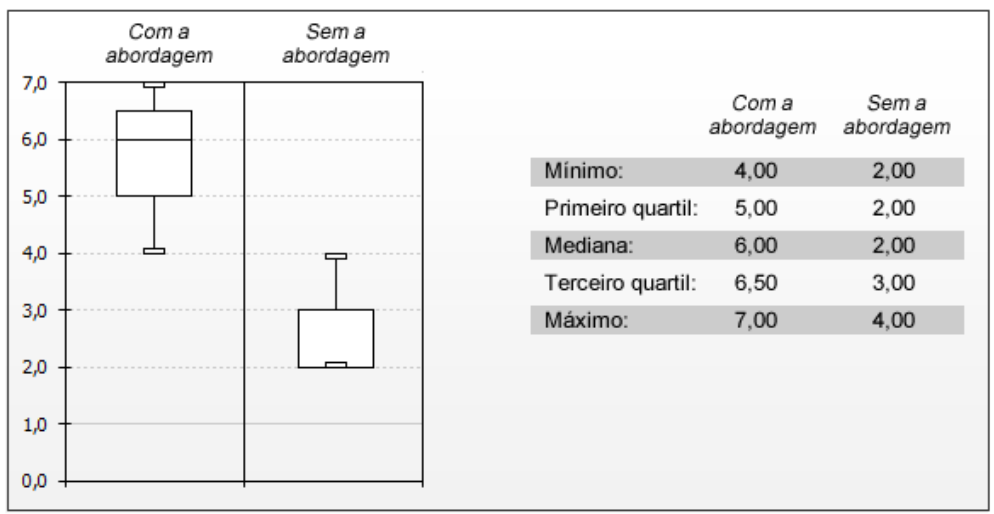

Figura 7.12 - Distribuição dos dados separados por grupos usando ou não a abordagem

Nessa análise comparativa fica evidente a diferença de distribuição dos valores de pontuação entre os grupos que usaram ou não a abordagem. $\mathrm{O}$ valor mínimo de pontuação foi obtido por um grupo que não usou a abordagem e, consequentemente, o valor máximo foi alcançado pelo grupo que a utilizou. Assim, o valor mínimo dos grupos que utilizaram a abordagem foi o valor máximo apresentado por aqueles que não a utilizaram, o que é um bom indício de que a utilização da mesma contribuiu para o desenvolvimento de artefatos com acessibilidade. No entanto, é importante ressaltar que o número de pontuações (6) é pequeno para uma inferência estatística densa, sendo esses gráficos apresentados apenas para clarificar o cenário encontrado, resultado do experimento, não sendo suficiente para generalizar previsões para novos casos.

Uma vez que este estudo foi realizado utilizando o DR como suporte, na Tabela 7.2 são apresentados os números de DRs capturados de cada grupo. 
Tabela 7.2 - Número de DRs capturados por grupos

\begin{tabular}{|l|c|c|}
\hline Grupo & Número de DRs & Usou a abordagem \\
\hline \hline Grupo 1 & 21 & Não \\
\hline Grupo 2 & 11 & Sim \\
\hline Grupo 3 & 10 & Sim \\
\hline Grupo 4 & 18 & Não \\
\hline Grupo 5 & 15 & Sim \\
\hline Grupo 6 & 13 & Não \\
\hline
\end{tabular}

De acordo com os dados da Tabela 7.2 e pelo próprio conceito de DR é possível perceber que não há uma relação direta entre o número de registros capturados e a qualidade final do produto. No entanto, esse registro é interessante para futuros projetos e auxílio na comunicação da equipe e manutenção desse sistema.

O fato de usar ou não a abordagem também não teve uma relação direta com a quantidade de DRs registrados, visto que o Grupo 1 teve uma pontuação final baixa na verificação de acessibilidade, sem uso da abordagem, mas teve o maior número de DRs registrados (21).

De forma resumida, os DRs envolveram discussões sobre tecnologia a ser utilizada, estruturação de arquivos, ambiente de desenvolvimento, questões para o desenvolvimento de artefatos em HTML, criação de interfaces (cores, formas, etc.) e busca de componentes prontos (calendário, captcha, etc.).

\subsection{Levantamento de dados sobre o desenvolvimento efetuado}

Nesta seção são apresentados os detalhes sobre o desenvolvimento e aplicação de questionários, para identificação de experiência e feedback dos participantes, e uma entrevista final. Ainda, são descritos em detalhes os resultados coletados com esse levantamento de dados, sendo identificadas as contribuições da utilização da abordagem durante o desenvolvimento. 
Assim, tem-se como intenção levantar dados junto aos participantes para reconhecer suas impressões sobre o desenvolvimento efetuado, incluindo a verificação da problemática relacionada à acessibilidade e possíveis vantagens no uso da abordagem.

As etapas que permearam a execução do levantamento de dados referente ao feedback dos participantes, sobre o uso da abordagem, podem ser divididas em: i) definição dos assuntos e problemática a serem indagados, ii) planejamento da pesquisa e dos instrumentos de coleta de dados, iii) aplicação de tais instrumentos e iv) tabulação e análise dos dados.

Os instrumentos de coleta, representados por questionários, foram compostos por questões para respostas abertas e fechadas. Em alguns casos foi utilizada uma escala do tipo likert, com possíveis valores para sua marcação variando de 1 a 5 .

Assim, foram definidos 2 questionários para ser aplicados aos participantes, os quais apresentam objetivos diferentes. O Questionário 1 foi utilizado para verificar a experiência prévia de cada participante, o qual foi aplicado no início do experimento para que os grupos pudessem ser definidos. Já o Questionário 2 foi utilizado para avaliar e pontuar detalhes sobre o desenvolvimento efetuado, o qual foi aplicado no final do experimento para os participantes de ambos os grupos.

Adicionalmente, uma entrevista foi aplicada para reconhecer de modo mais abrangente e flexível os benefícios e desvantagens do uso da abordagem durante o desenvolvimento da aplicação Web proposta, sendo necessária a seleção de um participante pertencente a um grupo que utilizou a abordagem.

As atividades de análise e tabulação de dados do questionário sobre o desenvolvimento efetuado foram feitas de forma separada em relação ao participante ser ou não de um grupo que usou a abordagem, sendo esse o critério utilizado como meio de estratificação. Como informado anteriormente, o foco da análise não é proceder a uma inferência estatística profunda e fazer generalizações para futuros projetos, mas sim apresentar os resultados do experimento realizado e discutir qualitativamente de forma descritiva as impressões dos participantes em relação ao que foi desenvolvido. 


\subsubsection{Análise de dados da experiência - Questionário 1}

$\mathrm{Na}$ aplicação do Questionário 1, para identificação do conhecimento dos participantes, os mesmos deveriam relatar sua experiência prévia em relação ao tema da pesquisa. A maioria $(54,2 \%)$ declara a opção 3 de 0 (para nenhuma) a 5 (para muita) em relação à experiência em desenvolvimento Web. Já sobre questões relacionadas à acessibilidade, a maioria relata que possui pouco conhecimento $(45,8 \%$, referente ao ponto 1 de uma escala de 0 a 5$)$ ou nenhum $(37,5 \%)$.

Esse cenário encontrado é semelhante ao reportado por Bailey e Pearson (2010), em que se verifica que a falta de conhecimento dos desenvolvedores em relação à acessibilidade inicia-se na universidade. Dessa forma, conclui-se que técnicas de desenvolvimento Web em geral são bem difundidas entre os participantes, porém conhecimentos sobre acessibilidade ainda estão obscuros para esses.

$\mathrm{Na}$ resposta para a questão aberta em que os participantes poderiam relatar suas observações sobre acessibilidade são encontrados vários relatos em que esse conceito é até conhecido, porém não em detalhes e sem conhecer ações para adoção de boas práticas nesse sentido. Algumas respostas interessantes podem ser citadas: "apesar de ter uma noção sobre o tema, não tenho experiência alguma" e "tecnicamente não sei como tornar um site acessível, nem analisar se um site é realmente acessível para certos tipos de deficiência".

Outro ponto interessante sobre a experiência dos participantes é que a maioria (58\%) relata que não conhece pessoas que têm dificuldade ou enfrentam barreiras em acessar algum site. Isso pode ser questionado, visto que é reportado na literatura que muitos usuários apresentam sérios problemas em relação à acessibilidade na Web. No entanto, esse não conhecimento, por parte dos participantes, pode ser justificado pela amostra pouco abrangente selecionada, uma vez que todos os participantes estão inseridos no domínio da computação com perfis parecidos.

\subsubsection{Análise de dados do desenvolvimento efetuado - Questionário 2}

Independente do uso ou não da abordagem, a maioria dos participantes relata que há uma significativa dificuldade adicional em desenvolver garantindo acessibilidade. Ou seja, 
ainda é um desafio amenizar essas dificuldades usando meios que apoiem boas práticas para desenvolvimento de aplicações Web acessíveis. Isso pode ser visualizado por meio dos resultados da Questão 1 do Questionário 2, apresentados na Figura 7.13.

Dificuldade adicional em desenvolver com preocupação em garantir acessibilidade

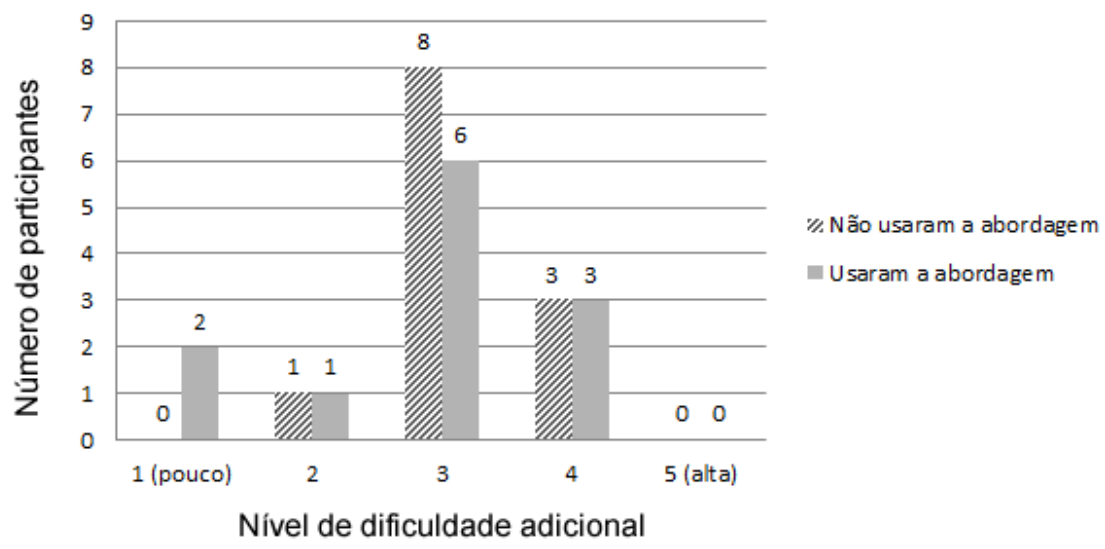

Figura 7.13 - Gráfico da Questão 1 sobre dificuldade adicional em desenvolver com preocupação em garantir acessibilidade

No entanto o uso da abordagem auxiliou se comparados os dois estratos de respostas e se forem analisadas as respostas em relação à questão aberta subsequente (Questão 2), que solicitava aos participantes que explicassem as dificuldades encontradas para 0 desenvolvimento acessível.

Sobre as respostas da Questão 2, em relação às dificuldades encontradas, essas resumidamente versam sobre: i) problemas no suporte das ferramentas de autoria, ii) desenvolvimento de algo usável e agora também estar sendo requisitado de ser acessível e iii) incremento de novos procedimentos e verificações no momento do desenvolvimento.

A pergunta subsequente (Questão 3) é relacionada ao uso de componentes acessíveis, sendo que a maioria dos participantes, independentemente do uso da abordagem, considera esse uso importante, como pode ser visto na Figura 7.14. 


\section{Componentes acessíveis podem melhorar os desenvolvimentos}

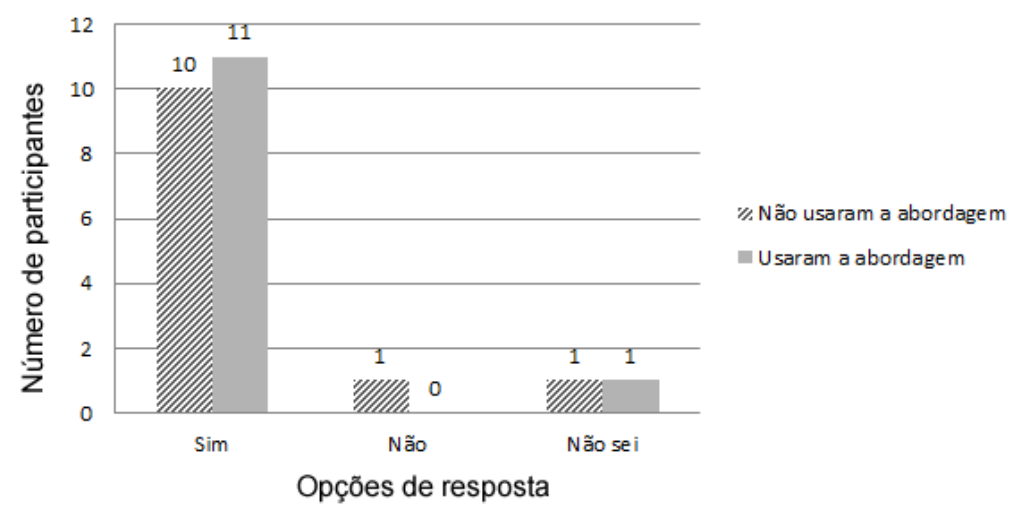

Figura 7.14 - Gráfico da Questão 3 sobre a percepção de cada participante sobre a importância de componentes acessíveis

Em relação ao uso da WCAG 2.0 (Questão 4) há uma divisão de opiniões entre os participantes. Para aqueles que usaram a abordagem, 33,3\% considera fácil e viável aplicálas. Já no caso daqueles que não a utilizaram, esse mesmo resultado é significativamente menor, sendo de apenas $25 \%$. Isso indica que o uso da abordagem auxiliou na aproximação de conceitos e utilização desse conjunto de diretrizes. No entanto, nenhuma das duas estratificações pesquisadas considerou fácil aplicar as diretrizes WCAG 2.0. A distribuição dos dados dessa questão pode ser vista na Figura 7.15.

\section{Consideração sobre ser fácil e viável aplicar as diretrizes WCAG 2.0}

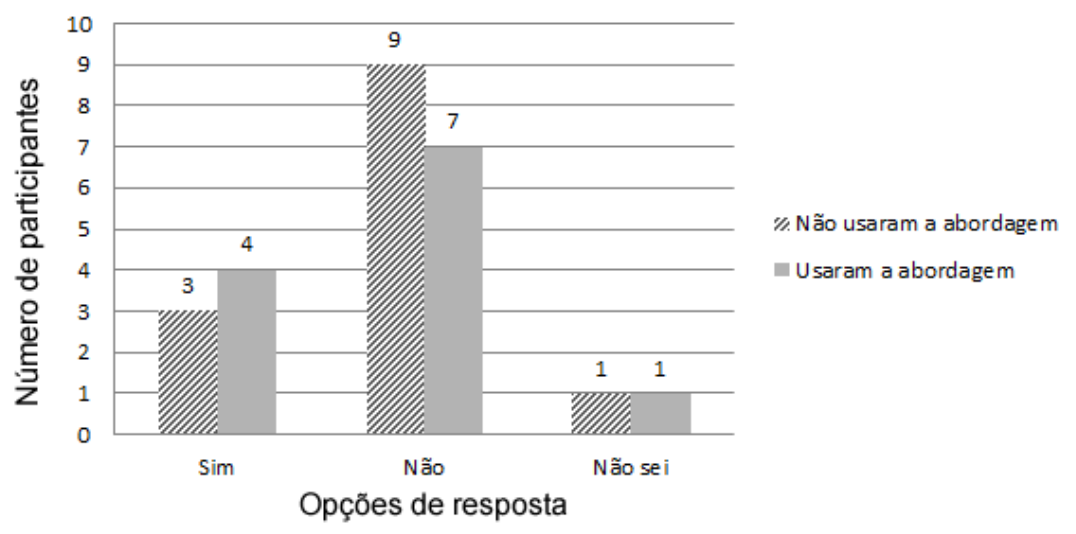

Figura 7.15 - Gráfico da Questão 4 sobre a consideração sobre ser fácil e viável aplicar as diretrizes

$$
\text { WCAG 2.0 }
$$


Para obtenção de mais detalhes sobre o uso da WCAG 2.0, na Questão 5 procurou-se obter uma explicação textual sobre a marcação dos dados da questão anterior. Em suas respostas, a maioria dos participantes consideraram algumas diretrizes difíceis de serem aplicadas na prática, sendo distantes do universo de desenvolvimento por eles já utilizado. Isso pode ser visto no seguinte comentário, que também evidencia outro ponto interessante de ser mencionado, que é a dificuldade de entendimento delas: "Algumas diretrizes são até possíveis e diretas, porém outras são muito difíceis de entender e de aplicar na prática. Definitivamente não dá pra seguir todas..."

No entanto, não foi explicitado por participante algum quais seriam essas diretrizes que não puderam ser aplicadas na prática. Para tanto, verifica-se que poderia haver nas diretrizes uma descrição de aplicabilidade para cada critério de sucesso em relação a determinados projetos. Por exemplo, não são todos os projetos que utilizam elementos com áudio e vídeo, sendo assim, várias diretrizes não precisam ser verificadas.

Em relação à importância do registro de decisões usando DR, na Questão 6, tem-se o seguinte gráfico de distribuição de respostas apresentado na Figura 7.16.

\section{O uso de Design Rationale foi importante}

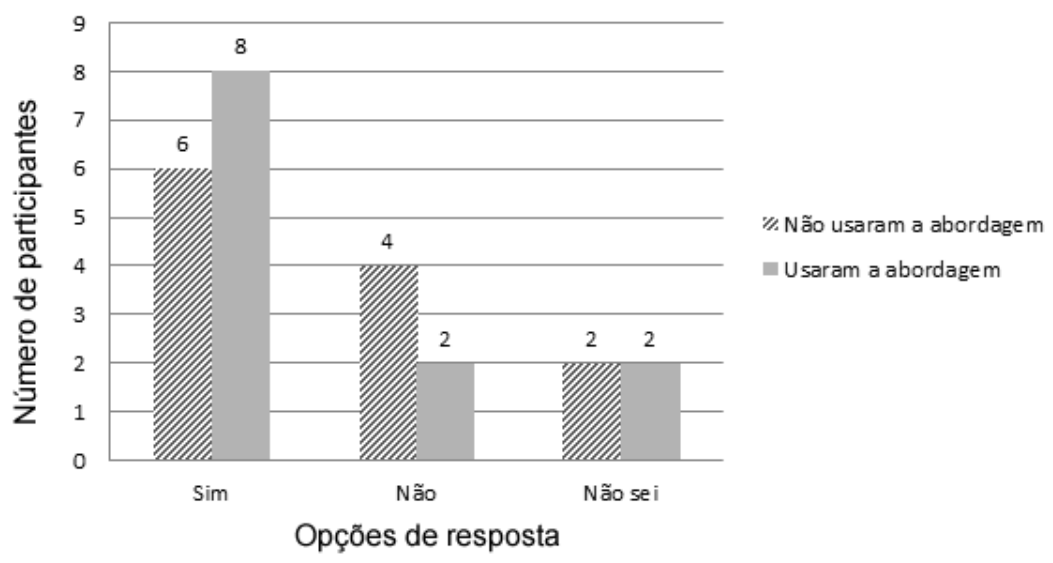

Figura 7.16 - Gráfico da Questão 6 sobre a importância do uso de DR para registro de decisões do projeto

É possível ver pela Figura 7.16 que os participantes que usaram a abordagem consideraram mais importante o uso de DR como meio de discussão e armazenamento de decisões, em comparação àqueles que não a usaram. Acredita-se que esse fato ocorre por 
conta da abordagem incentivar um registro de decisões de forma organizada e com referência às diretrizes.

Após o questionamento sobre a importância do DR, o foco passa a ser sobre o ferramental utilizado. Assim, na Questão 7, indagou-se quais ferramentas de desenvolvimento Web foram utilizadas por cada grupo. Percebe-se que os grupos que utilizaram a abordagem optaram por um ferramental com mais recursos, sendo que a mais escolhida por esse estrato foi a Adobe Dreamweaver, que tem interessantes recursos de acessibilidade, conforme visto em Bittar et al. (2012), e sendo essa a ferramenta escolhida para auxílio de programação para redesign acessível de um site de universidade apresentado por Lauke (2006).

Ainda sobre essa questão, algumas respostas do estrato que não usou a abordagem evidenciam que não houve um tratamento melhor na escolha do ferramental, sendo possível citar os seguintes trechos para essa análise: "Não usei nenhuma" e "Bloco de notas e Google". Ou seja, foram utilizados editores de texto comuns sem nenhum suporte à acessibilidade ou para auxílio na escrita de marcações HTML.

Finalmente, sobre o auxílio obtido com o uso de ferramentas de autoria, tem-se a distribuição das respostas da Questão 8, apresentada na Figura 7.17.

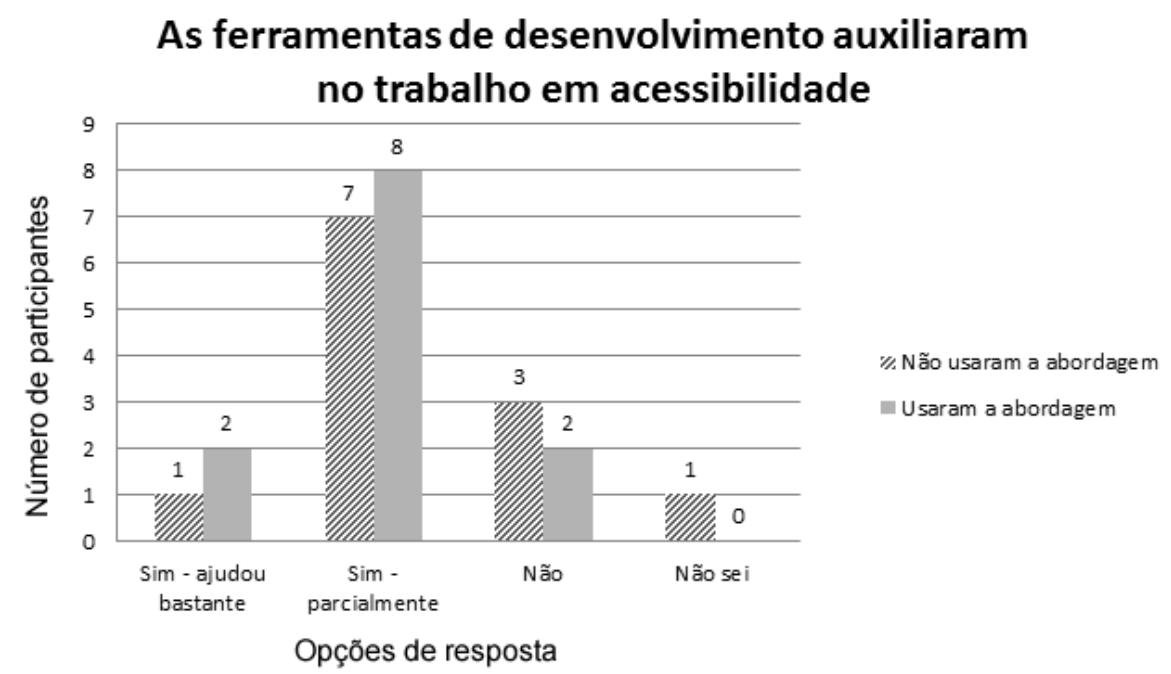

Figura 7.17 - Gráfico da Questão 8 sobre o auxílio das ferramentas de desenvolvimento no trabalho em acessibilidade 
É possível observar que as respostas foram muito próximas, independentemente da estratificação feita, sendo que a maioria dos desenvolvedores marcou que as ferramentas auxiliaram parcialmente no desenvolvimento com acessibilidade. Tal resultado faz sentido se forem analisados os resultados da Questão 9, apresentados na Figura 7.18, em que também há uma aproximação nas respostas, ficando claro que os desenvolvedores acreditam ser possível um maior apoio ferramental a boas práticas para desenvolvimento de aplicações Web acessíveis.

As ferramentas de desenvolvimento podem apoiar mais no desenvolvimento com acessibilidade

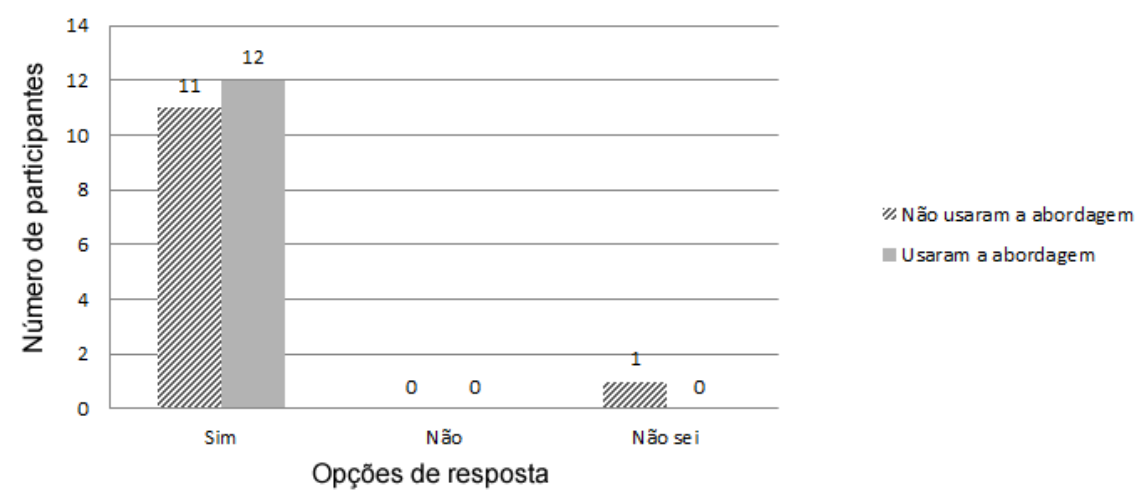

Figura 7.18 - Gráfico da Questão 9 sobre o fato das ferramentas de desenvolvimento poderem apoiar mais no desenvolvimento com acessibilidade

Assim, verifica-se que os participantes compreendem a importância do uso das ferramentas de desenvolvimento, porém acreditam ser possível um maior apoio dessas em relação ao desenvolvimento com acessibilidade. Um bom exemplo disso pode ser visto na resposta da Questão 10, em que o participante solicitou uma explicação sobre a marcação anterior: "Poderiam integrar demonstrações de algumas recomendações de acessibilidade, assim como a documentação das mesmas. Poderiam criticar mais, visto que alguns auxílios que essas ferramentas dão são somente recomendações, elas poderiam ser obrigatórias".

Na Questão 11, a última deste questionário, houve a indagação sobre quais utilidades os desenvolvedores acreditam serem importantes nas ferramentas de desenvolvimento para apoio em acessibilidade. A distribuição de respostas pode ser visualizada na Figura 7.19. 


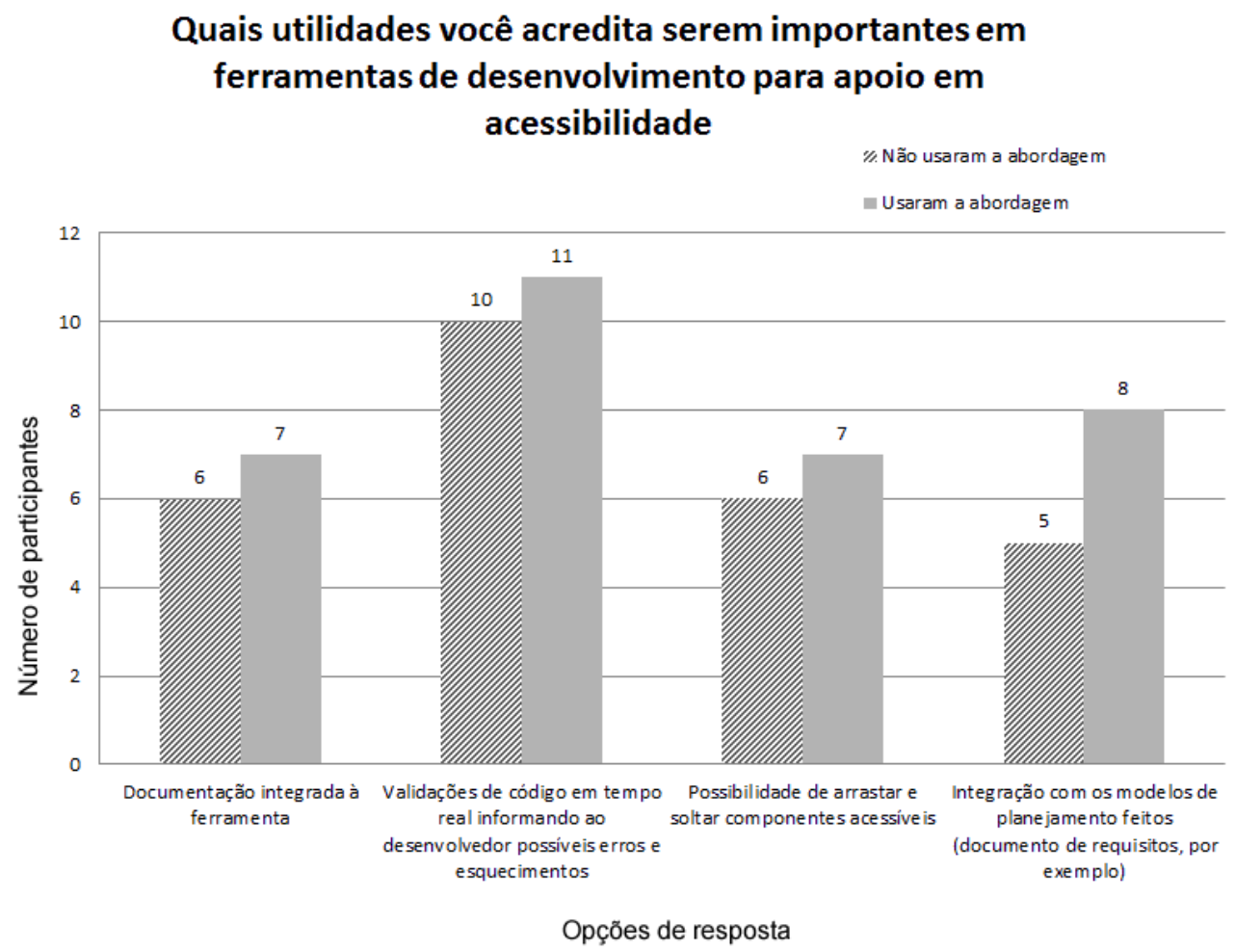

Figura 7.19 - Gráfico da Questão 11 sobre quais utilidades o desenvolvedor acredita serem importantes em ferramentas de desenvolvimento para apoio em acessibilidade

Em relação a Figura 7.19, pode-se observar que todas as utilidades para o desenvolvimento Web com acessibilidade, foram consideradas importantes, sendo que uma delas teve maior destaque: a validação de código em tempo real informando ao desenvolvedor possíveis erros e esquecimentos.

\subsubsection{Análise de dados do uso da abordagem - Entrevista}

Após o levantamento dos dados, por meio de aplicação dos dois questionários apresentados no Apêndice B, optou-se por conduzir uma entrevista com um membro de um grupo que utilizou a abordagem. Para tanto, decidiu-se pela condução de uma entrevista semiestruturada presencial de modo a se obter maior detalhamento e flexibilidade na coleta de dados, a qual também é apresentada no Apêndice B.

$\mathrm{Na}$ entrevista semiestruturada, o investigador tem uma lista de questões ou tópicos a serem cobertos (roteiro), porém a entrevista em si permite uma relativa flexibilidade. 
A entrevista é justificada uma vez que se fez necessário verificar detalhes das impressões sob a perspectiva de um integrante de uma equipe de desenvolvimento sobre os benefícios e desvantagens da utilização da abordagem. Assim, as perguntas definidas para o roteiro da entrevista tiveram como foco avaliar se os benefícios almejados foram alcançados e se as dificuldades sentidas foram empecilhos para o desenvolvimento da aplicação Web. Tal análise é descrita nos pontos a seguir:

- A abordagem norteou de forma adequada o trabalho de aplicação e aprendizado das diretrizes pelo membro entrevistado do grupo, o qual ficou ciente da necessidade de seguir as atividades descritas;

- Grande parte das atividades foi passível de aplicação, com entendimento pelos sujeitos. A inaplicabilidade de algumas atividades já era esperada por conta do tempo oferecido ao grupo;

- O "Eixo 1 - Treinamento em Acessibilidade" foi considerado importante pelo entrevistado. No entanto, o mesmo admite que isso pode atrasar o desenvolvimento de um projeto, sendo difícil ter tempo e recursos para realizar as atividades desse eixo na prática. Além disso, o entrevistado também relata que existe vasto conteúdo sobre o tema a ser aprendido, o que dificulta sua difusão e retenção. A existência de material em inglês dificulta o trabalho de educação, sendo isso um problema que deve ser levado em consideração no sentido de motivar a escrita e tradução de materiais em português;

- Sobre a experiência do entrevistado, o mesmo reconhece que faltaram ensinamentos prévios específicos em acessibilidade e que o Eixo 1 auxiliou para que ele pudesse conhecer mais do assunto;

- Em relação ao uso da ferramenta AccessibilityUtil fica evidenciado sua utilidade, mas é preciso haver melhorias no sentido de inserção de mais informações e de ajustes na classificação do material provido;

- Para o "Eixo 2 - Gerência de Decisões" é marcante que várias discussões sejam feitas pela equipe para o desenvolvimento Web, mesmo que de forma adHoc. Nesse sentido, a abordagem ajudou no sentido de organizar as discussões e abrir maior espaço para o gerenciamento das decisões. Os principais temas discutidos 
foram design de layout e detalhes de programação, incluindo referências às questões de acessibilidade;

- Em relação ao "Eixo 3 - Ferramentas e Desenvolvimento" o entrevistado apresenta uma boa percepção sobre a importância do uso de ferramentas que auxiliem na adoção de diretrizes de acessibilidade e em um desenvolvimento que leve em consideração tais diretrizes. Essa percepção é válida por serem várias verificações que devem ser feitas no momento da construção de artefatos Web. Adicionalmente, o entrevistado relata que é difícil lembrar tudo que deve ser feito durante o desenvolvimento com acessibilidade. Apesar de ter havido um plano para escolha de ferramentas, foi visto que se espera mais desse mercado em relação ao auxílio em acessibilidade; e

- Sobre o monitoramento contínuo em acessibilidade viu-se que esse não pôde ser bem avaliado e testado com o experimento executado, já que não houve uma fase de manutenção após a entrega do produto final. No entanto, o entrevistado relata que foram feitas avaliações após o desenvolvimento dos artefatos entregues, sendo corrigidas as falhas que foram detectadas.

Como conclusão da entrevista, pode-se afirmar que a falta de tempo e dificuldade em se registrar tudo o que é feito no desenvolvimento foi uma crítica pertinente, a qual foi apresentada pelo entrevistado, em relação às atividades de documentação e gerência de configuração. Ou seja, isso demonstra que, para a aplicação da abordagem proposta, é necessário que a organização se prepare e disponibilize tempo hábil e recursos de pessoal e ainda esteja apta à adoção da abordagem de maneira consciente e sem imposições obrigatórias, as quais podem causar maiores danos ao andamento do projeto.

\subsection{Considerações finais}

Existem muitos benefícios em implementar um apoio a boas práticas para desenvolvimento de aplicações Web acessíveis. Assim, o uso da abordagem se mostrou importante, visto que facilita aos desenvolvedores aplicar as práticas corretas sobre acessibilidade de uma maneira facilitada com a condução de atividades da abordagem. 
Adicionalmente, esta tese contribui de forma positiva para a área de pesquisa uma vez que é uma maneira de inserir o tema acessibilidade ao cotidiano dos desenvolvedores. Por meio da abordagem, torna-se possível o registro das decisões de projeto, relacionando-os com as diretrizes existentes para o domínio, de modo a separar as informações por ordem de importância ou outros aspectos, o que facilita sua reutilização em outros projetos e torna o desenvolvimento mais ágil.

Assim, as ferramentas de apoio auxiliam para que os desenvolvedores saibam o que é necessário para gerir acessibilidade, pois nem sempre se tem total conhecimento das diretrizes de acessibilidade. Pode-se observar que os grupos que utilizaram a abordagem foram os que sugeriram as contribuições mais relevantes e desenvolveram os componentes requisitados pelo cliente, como o calendário e o menu drop-down. Isto pode ser justificado devido ao curto tempo para execução das tarefas e assim esse grupo levaram vantagens, uma vez que pode contar com o repositório de componentes já estabelecidos na abordagem proposta. O modelo de dados sugerido, a transcrição da entrevista feita e as respostas completas coletadas, com marcação de porcentagens, podem ser vistos no Apêndice B.

Uma questão que deve ser destacada é a dificuldade encontrada por todos os grupos para criar layouts atrativos. Esse problema ocorreu devido à falta de conhecimento sobre design de interface por parte dos participantes do experimento. Assim, os problemas que existiram e as dificuldades condizentes com o uso das diretrizes de acessibilidade foram maximizadas devido a falta de conhecimento dos desenvolvedores em relação às diretrizes, o que gerou uma significativa dificuldade para execução do experimento.

Apesar dos problemas apontados, todos os grupos conseguiram realizar as atividades definidas. No entanto, os que tiveram acesso à abordagem conseguiram cumprir mais metas em termos de atendimento aos requisitos em um menor tempo, com menor dificuldade em relação aos demais e qualidade no desenvolvimento. Isto nos fornece indícios de que a abordagem auxilia de forma eficaz no desenvolvimento de aplicações Web acessíveis. Neste sentido, as hipóteses nulas foram refutadas e as alternativas foram confirmadas.

Assim, em relação às questões definidas no planejamento do experimento $(\boldsymbol{Q} 1 . A$ quantidade de conformidades em relação a um conjunto definido de diretrizes de acessibilidade do documento WCAG 2.0 aumentou quando a abordagem foi seguida? e Q2. 
$O$ requisito do cliente de se ter elementos de interface ricos, interativos e acessíveis foi melhor cumprido quando a abordagem foi utilizada?) pode-se verificar que ambas tiveram respostas sim após a análise detalhada dos resultados reportados pelos grupos. 



\section{Conclusões}

\subsection{Considerações iniciais}

O objetivo deste trabalho foi o de investigar os estados da arte e da prática sobre o apoio na adoção de boas práticas para desenvolvimento de aplicações Web acessíveis. Para tanto, foram desenvolvidos inicialmente estudos teóricos e empíricos, de modo a verificar quais são essas boas práticas e como aplicá-las.

Neste sentido, esta tese foi proposta a fim de amenizar a lacuna existente em relação à investigação e aplicação prática de diretrizes de acessibilidade durante o desenvolvimento Web. Os resultados identificados foram utilizados para subsidiar a criação de uma abordagem que viabilize o apoio a boas práticas para desenvolvimento de aplicações Web acessíveis.

A abordagem apresentada tem como objetivo fornecer uma maneira sistemática para aplicar as diretrizes de acessibilidade e gerenciar os resultados alcançados durante o 
desenvolvimento Web. Tal abordagem apresenta atividades, papéis, entradas e saídas que devem ser seguidas para que a acessibilidade seja considerada.

Um experimento controlado foi desenvolvido para verificar os benefícios da utilização da abordagem, sendo ressaltados os ganhos advindos do seu uso, bem como quais melhorias puderam ser incorporadas por meio dos resultados identificados. Para tanto, existiram grupos de participantes utilizando a abordagem e outros que não fizeram uso da mesma.

Como resultado principal do experimento, pôde-se verificar que os grupos que utilizaram a abordagem tiveram maior facilidade e apoio a boas práticas de desenvolvimento para a utilização de requisitos de acessibilidade. Tai indício ocasionou em contribuições positivas para o trabalho desenvolvido, visto que os participantes foram guiados em relação a detalhes de atividades que devem ser executadas para o desenvolvimento de aplicações acessíveis.

\subsection{Principais contribuições}

Nesta tese foram discutidas propostas e conceitos para resolver problemas relacionados ao apoio a boas práticas para o desenvolvimento de aplicações Web acessíveis. Para tanto, contribuições expressivas foram resultantes do trabalho realizado, as quais são apresentadas a seguir:

- Desenvolvimento da ferramenta AccessibilityUtil (Capítulo 5), a qual se mostrou como um importante ferramental para o compartilhamento organizado de experiências sobre acessibilidade na Web;

- Desenvolvimento da abordagem (Capítulo 6), que se mostrou importante para o norteamento de ações para a melhoria do cenário de consideração efetiva das diretrizes de acessibilidade disponibilizadas;

- Criação e desenvolvimento de um projeto na UFG para investigação de práticas de apoio a acessibilidade. Esse projeto é identificado pelo código 35418, tendo envolvido a participação de 4 alunos que pesquisaram temas de acessibilidade na Web para desenvolvimento com sucesso de trabalhos de conclusão de curso; e 
- Participação com desenvolvimento de ações que auxiliaram no âmbito do projeto FAPESP de código 2010/05626-7 - "Acessibilidade na Evolução de Aplicações Web Interativas: diretrizes e ferramentas".

O conjunto de contribuições pode ainda ter sua descrição ampliada pelas respostas às questões de pesquisa definidas nesta tese, conforme segue:

\section{É possível e importante um melhor apoio de ferramentas para o desenvolvimento}

\section{Web com acessibilidade?}

Os resultados da realização dos estudos de caso (Capítulo 4) e da execução do experimento controlado (Capítulo 7) demonstraram que é possível um melhor apoio de ferramentas para o desenvolvimento Web com acessibilidade, em que podem ser feitas ajudas em tempo de desenvolvimento e aproveitamento de códigos já validados por parte da equipe, que deve ser bem treinada.

O compartilhamento e reuso de experiências de desenvolvimento é importante e eficaz no apoio ao desenvolvimento Web com acessibilidade?

O desenvolvimento e disponibilização da ferramenta AccessibilityUtil (Capítulo 5), demonstrou que é importante e eficaz o compartilhamento e reuso de experiências de desenvolvimento para o auxílio em questões de acessibilidade na Web. Esse compartilhamento propicia que os integrantes de diferentes equipes de desenvolvimento possam trocar experiências de forma informal e rápida. No entanto, verificou-se que é importante a integração com as diretrizes existentes e moderação do conteúdo de experiências a serem compartilhadas, para evitar que premissas incoerentes sejam difundidas.

Reunir considerações para nortear o desenvolvimento Web, incluindo ações de treinamento de equipe, gerência de decisões e apoio ferramental, resulta na criação de artefatos com menos barreiras de acessibilidade?

A revisão bibliográfica efetuada, os estudos desenvolvidos, a ferramenta AccessibilityUtil, bem como a abordagem criada e os resultados da execução do experimento controlado, permitem a conclusão de que o norteamento é útil para que as equipes sejam melhores instruídas sobre o que deve ser feito em relação à execução das tarefas de desenvolvimento. Nesse sentido, as ações de treinamento de equipe, gerência de decisões e 
apoio ferramental se mostraram importantes preocupações no âmbito da acessibilidade na Web. Em relação ao número de barreiras dos artefatos construídos, observou-se, que com a execução do experimento, uma melhoria significativa e consequente redução dessas barreiras, de acordo com os critérios e métricas definidas para verificação. Esse é um indício positivo de que o norteamento descrito na abordagem, por meio de suas atividades, seja realmente útil e eficiente para outras equipes de desenvolvimento.

\subsection{Lições aprendidas e impressões pessoais}

Durante o desenvolvimento desta tese algumas considerações foram observadas, levando à adaptações para a definição final da proposta. A ampliação do acesso à tecnologia foi um dos fatores que evidenciou ainda mais a necessidade de acessibilidade nos recursos providos, especialmente na Web. Com a revisão bibliográfica observou-se que diferentes ferramentas de avaliação de acessibilidade têm sido propostas e, cada vez mais, um código padrão está sendo valorizado no âmbito da interpretação pelos navegadores. No entanto, apesar de tais verificações, há muito ainda a ser feito em relação ao treinamento dos desenvolvedores para que haja uma preocupação maior na produção de artefatos acessíveis.

Outra questão que tem merecido destaque é a utilização cada vez mais comum de vários dispositivos pelos usuários, com destaque para os móveis, como smartphones e tablets, os quais tornaram a utilização da Web mais próxima ao cotidiano dos usuários. A partir dessas evoluções, observou-se que o tema “desenvolvimento acessível” deve ser uma preocupação recorrente durante o desenvolvimento e que os desenvolvedores devem ter apoio a boas práticas durante as implementações de aplicações Web acessíveis. Isso deve ser feito objetivando reduzir as barreiras existentes enfrentadas por pessoas com algum tipo de deficiência durante o uso da Web.

Outra lição que veio a tona neste trabalho foi relacionada à importância da integração deste com outros trabalhos do grupo de pesquisa. Reuniões presenciais frequentes e discussões on-line auxiliaram no amadurecimento deste trabalho, uma vez que pesquisadores de diferentes níveis, da graduação ao pós-doutorado, apresentaram contribuições significativas ao trabalho, permitindo, assim, maximizar os resultados. 
Após cinco meses do exame de qualificação, o doutorando iniciou sua experiência como professor assistente na Universidade Federal de Goiás (UFG), Campus Catalão. Isso trouxe mais responsabilidades e situações ricas que contribuíram na formação do mesmo e influenciaram positivamente nesta pesquisa. Porém ocasionou também uma necessidade de desenvolvimento de tarefas de pesquisa de forma integrada com as atividades de docência, sendo um desafio a conciliação plena das atividades para obtenção de resultados satisfatórios em ambas.

Ainda, no contexto do ingresso como docente, houve a lição de que a orientação de alunos de graduação é uma atividade rica e útil, que possibilitou ao doutorando um exercício do ensino da metodologia científica e acompanhamento da evolução dos alunos e de seus trabalhos.

Por fim, a experiência em eventos científicos tem um valor inestimável e possibilitou alguns benefícios ao doutorando, a saber: i) conhecimento de outras pesquisas e tendências nas áreas de atuação; ii) feedback das pesquisas apresentadas a partir de sugestões e críticas construtivas e iii) expansão de contatos na comunidade acadêmica e industrial. Ainda no período do doutorado foram feitas 5 viagens internacionais para participação em eventos científicos, as quais propiciaram amadurecimento do doutorando como pesquisador e permitiu uma validação contínua das pesquisas.

\subsection{Premiação da ferramenta AccessibilityUtil}

Um resultado relevante para a equipe deste projeto foi a obtenção do segundo lugar na primeira edição do Todos@Web - Prêmio Nacional de Acessibilidade na Web ${ }^{36}$, promovido pelo W3C Escritório Brasil em 2012.

Por meio de inscrição voluntária, a ferramenta AccessibilityUtil foi inscrita na categoria "Tecnologias assistivas / Aplicativos" que premiaria os melhores aplicativos e tecnologias assistivas que permitam o acesso à Web de pessoas com deficiência.

\footnotetext{
${ }^{36}$ http://premio.w3c.br
} 
Como premiação para o projeto foi concedido o valor de $\mathrm{R} \$ 3.000,00$, um troféu e a exposição do trabalho em publicação do W3C.

O evento contou com a participação de mais de 300 pessoas, envolvendo importantes autoridades como secretários do Ministério do Planejamento, equipe do Governo do Estado de São Paulo e coordenadores da Associação de Assistência à Criança Deficiente (AACD).

A participação honrou a todos os membros da equipe que desenvolveu a ferramenta e proporcionou novos contatos e trocas de experiências com a sociedade e o público alvo das pesquisas realizadas.

A materialização desses contatos ficou mais evidente com a inclusão de todos os finalistas em um Grupo de Trabalho em Acessibilidade do NIC.br, Núcleo de Informação e Coordenação do Ponto BR, que mantém uma lista de discussão por e-mail, informando e aproximando interessados, especialistas de acessibilidade e integrantes de órgãos da área.

\subsection{Limitações e trabalhos futuros}

Baseado nos resultados identificados por meio dos estudos realizados nesta tese, pôde-se observar a necessidade de uma extensiva pesquisa sobre o uso de acessibilidade durante o desenvolvimento de aplicações Web. Isso é justificado visto que a maioria dos desenvolvedores desconhecem as diretrizes de acessibilidade que devem ser seguidas. Assim, futuros estudos empíricos devem ser executados, apresentando suficiente rigor para garantir a identificação de relevantes evidências sobre acessibilidade na Web. Neste sentido, alguns trabalhos futuros podem ser apontados:

- Mapeamento usando Cross Case: Cross Case é uma metodologia usada para mapeamento de resultados identificados em diferentes estudos de caso. Neste sentido, é sugerido que sejam verificados estudos de caso sobre a aplicação de acessibilidade na Web e sejam destacados os pontos positivos observados, bem como as falhas identificadas. Este estudo é relevante, uma vez que possibilita o mapeamento das ações executadas nos estudos em relação às diretrizes que devem ser atingidas para que a acessibilidade seja suficientemente utilizada pelos desenvolvedores, bem como a identificação de novas atividades para garantir o uso da acessibilidade; 
- Verificação de influências no uso das diretrizes de acessibilidade: além da análise de quais diretrizes de acessibilidade são utilizadas pelos desenvolvedores, também é importante verificar como efetivamente influências desse uso têm impactado nas estratégias de negócios e processos de tomada de decisão. Assim, uma estratégia possível é a aplicação de uma pesquisa com gerentes de projeto, a fim de descobrir como efetivamente as práticas para desenvolvimento com acessibilidade estão impactando nas organizações (positivamente e negativamente);

- Verificação de atividades específicas para manutenção de aplicações: podem ser detalhadas atividades específicas para a fase de manutenção de aplicações, incluindo aquelas que não foram desenvolvidas com preocupação inicial em questões de acessibilidade na Web; e

- Criação de um mecanismo para visualização gráfica: um mecanismo de visualização gráfica pode ser desenvolvido para apresentar quais ações podem ser aplicadas que resultarão nas diretrizes de acessibilidade já propostas na literatura. Isso visa facilitar a aplicação de tais diretrizes pelos desenvolvedores.

Este trabalho demonstrou que existem vários desafios relativos à aplicação de acessibilidade durante o desenvolvimento de aplicações Web. Assim, é necessário que os profissionais e pesquisadores apresentem mais estudos detalhados e resultados obtidos a partir de seus projetos, de modo que soluções inovadoras sejam propostas. A maioria das abordagens disponíveis, as quais contemplam o apoio na área de acessibilidade na Web, não satisfazem as suas necessidades específicas, dadas as suas limitações teóricas e a amplitude de questões existentes nessa área.

\subsection{Publicações resultantes}

Além dos resultados atingidos com o desenvolvimento desta tese, pode-se citar contribuições na forma de publicações científicas, as quais estão diretamente relacionadas à tese: 
1. BitTAR, T. J.; AMARAL, L. A., LOBATO, L. L. e FORTES, R. P. M. Applying an approach to support good practices during the development of accessible Web applications. Proceedings of $15^{\text {th }}$ International Conference on Human-Computer Interaction, Las Vegas, USA, 2013 (em publicação). (BITTAR et al., 2013).

2. BITTAR, T. J.; AMARAL, L. A.; FARIA, F. B. e FORTES, R. P. M. Supporting the Developer in an Accessible Edition of Web Communications: a Study of Five Desktop Tools In: Workshop of Information Systems and Design of Communication (ISDOC2012 - EuroSIGDOC), 2012, Lisboa. Proceedings of Workshop of Information Systems and Design of Communication (ISDOC2012 EuroSIGDOC). Nova York: ACM, 2012. v.1. p.3-9. (BITTAR et al., 2012a).

3. BITTAR, T. J.; ALMEIDA, A. K. e FORTES, R. P. M. Panorama of the accessibility add-ons use in Firefox. In: DSAI 2012 - Software Development for Enhancing Accessibility and Fighting Info-exclusion, 2012, Porto. Proceedings of DSAI 2012 - Software Development for Enhancing Accessibility and Fighting Info-exclusion, 2012 - Procedia Computer Science, Elsevier. Volume 14, p. 311318. (BITTAR et al., 2012b).

4. BITTAR, T. J.; AMARAL, L. A. e FORTES, R. P. M. Evolução da ferramenta AccessibilityUtil: apoio a projetos, moderação de conteúdos e verificações de uso. In: Conferência IADIS Ibero Americana WWW/INTERNET 2012, 2012, Madrid. Actas da Conferência IADIS Ibero Americana WWW/INTERNET 2012. Lisboa: IADIS, 2012. v. 01. p. 107-114. (BITTAR et al., 2012c).

5. AMARAL, L. A.; BITTAR, T. J. e FORTES, R. P. M. Um ambiente de análise para comparar resultados de avaliações de acessibilidade e usabilidade na Web. In: Conferência IADIS Ibero Americana WWW/INTERNET 2012, 2012, Madrid. Actas da Conferência IADIS Ibero Americana WWW/INTERNET 2012. Lisboa: IADIS, 2012. v. 01. p. 166-170. (AMARAL et al., 2012).

6. BITTAR, T. J., FARIA, F. B., AMARAL, L. A. e FORTES, R. P. M. Uma verificação de acessibilidade em formulários de contato de universidades brasileiras. In: 7a Conferencia Ibérica de Sistemas y Tecnologías de Información (CISTI), 2012, Madrid. Actas de la $7 a$ Conferencia Ibérica de Sistemas y 
Tecnologías de Información. Braga, Portugal: APPACDM, 2012. v. 01. p. 783 788. ISBN: 978-989-96247-6-4. (BITTAR et al., 2012d).

7. BITTAR, T. J.; AMARAL, L. A. e FORTES, R. P. M. AccessibilityUtil: a tool for sharing experiences about accessibility of Web artifacts. $29^{\text {th }}$ ACM international conference on Design of communication, 2011, Pisa. Proceedings of $29^{\text {th }}$ ACM international conference on Design of communication, 2011. v. 1. p. 17-24. (BITTAR et al., 2011a).

8. BITTAR, T. J.; LOBATO, L. L.; AMARAL, L. A. e FORTES, R. P. M. Desenvolvimento e Aplicação da Ferramenta AccessibilityUtil.com: colaboração e experiências em acessibilidade na Web. Conferência IADIS Ibero Americana WWW/INTERNET 2011, Rio de Janeiro. Actas da Conferência IADIS Ibero Americana WWW/INTERNET 2011, 2011. (BITTAR et al., 2011b).

9. BITTAR, T. J.; AMARAL, L. A.; LOBATO, L. L. e FORTES, R. P. M. AccessibilityUtil.com: uma ferramenta para colaboração de experiências de acessibilidade na Web. In: Simpósio Brasileiro de Sistemas Multimídia e Web Webmedia 2011, Workshop on Tools and Applications. 2011, Florianópolis. Anais do Simpósio Brasileiro de Sistemas Multimídia e Web - Webmedia 2011, 2011. (BITTAR et al., 2011c).

10. BITTAR, T. J.; LOBATO, L. L.; FORTES, R. P. M. e NETO, D. Accessible organizational elements in wikis with model-driven development. 28th ACM International Conference on Design of Communication, 2010, São Carlos. Proceedings of the 28th ACM International Conference on Design of Communication. New York: ACM, 2010. p. 49-56. (BITTAR et al., 2010a).

11. BITTAR, T. J.; LOBATO, L. L. e FORTES, R. P. M. Modelagem gráfica de estruturas de wikis com ganhos na arquitetura da informação e acessibilidade. Conferencia IADIS Ibero Americana. WWW/INTERNET 2010, 2010, Lagoa Algarve. Actas da Conferencia IADIS Ibero Americana. WWW/INTERNET 2010. (BITTAR et al., 2010b).

12. BITTAR, T. J.; LOBATO, L. L. e FORTES, R. P. M. Guidelines2Model2Code: uma Abordagem para incorporação de diretrizes no desenvolvimento Web orientado a modelos. In: Conferencia IADIS Ibero Americana. 
WWW/INTERNET 2010, Lagoa - Algarve. Actas da Conferencia IADIS Ibero Americana. WWW/INTERNET 2010, 2010. (BITTAR et al., 2010c).

13. BITTAR, T. J.; LOBATO, L. L.; NETO, D. e FORTES, R. P. M. Apoio à colaboração em wikis a partir de modelagem gráfica visando ganhos na arquitetura da informação e acessibilidade. Simpósio Brasileiro de Sistemas Colaborativos II, 2010, Belo Horizonte. Anais do Simpósio Brasileiro de Sistemas Colaborativos II. Washington DC: IEEE Computer Society Press, 2010. v. II. p. 12-15. (BITTAR et al., 2010d).

14. WATANABE, W. M.; NETO, D.; BITTAR, T. J. e FORTES, R. P. M. WCAG Conformance approach based on Model-Driven Development and WebML. $28^{\text {th }}$ ACM International Conference on Design of Communication, 2010, São Carlos. Proceedings of 28th ACM International Conference on Design of Communication. New York: ACM, 2010. v. 01. p. 167-174. (WATANABE et al., 2012).

15. BITTAR, T. J.; NETO, D.; LOBATO, L. L.; LUCREDIO, D. e FORTES, R. P. M. Definição de metamodelos para Web incorporando boas práticas de acessibilidade e usabilidade. In: XXXVI Conferência Latino-Americana de Informática - CLEI 2010, Assunção. Anais da XXXVI Conferência LatinoAmericana de Informática - CLEI 2010, 2010. (BITTAR et al., 2010d).

16. LUCREDIO, D.; BITTAR, T. J. e FORTES, R. P. M. Desenvolvimento Web orientado a modelos: conceitos, ferramentas e técnicas - Cap. 3. In: Mário Teixeira; Cesar Teixeira; Fernando Trinta; Pedro Porfirio. (Org.). XV Simpósio Brasileiro de Sistemas Multimídia e Web: WEBMEDIA 2009: Minicursos. 2009, p. 81-124. (LUCREDIO et al., 2009).

17. BITTAR, T. J.; FORTES, R. P. M.; LOBATO, L. L. e WATANABE, W. M. Web communication and interaction modeling using model-driven development. In: 27th ACM International Conference on Design of Communication - SIGDOC, 2009, Bloomington. Proceedings of 27th ACM International Conference on Design of Communication - SIGDOC, 2009. (BITTAR et al., 2009).

18. FREIRE, A. P.; BITTAR, T. J. e FORTES, R. P. M. An approach based on metrics for monitoring web accessibility in Brazilian municipalities web sites. In: 23rd Annual ACM Symposium on Applied Computing, 2008, Fortaleza-CE. 
Proceedings of the 2008 ACM Symposium on Applied Computing. New York, NY: ACM Press, 2008. v. 01. p. 2421-2425. (FREIRE et al., 2008).

Outras contribuições não vinculadas diretamente ao trabalho do doutorado, mas que foram importantes para a formação do autor desta tese, podem ser citadas:

1. TALARICO NETO, A.; BITTAR, T. J.; FORTES, R. P. M. e FELIZARDO, K. R. Developing and evaluating web multimodal interfaces - a case study with usability principles. In: 2009 ACM symposium on Applied Computing, 2009, Honolulu, Hawaii. Proceedings of the 2009 ACM symposium on Applied Computing, 2009. p. 116-120 (TALARICO NETO, 2009).

2. JUNQUEIRA, D. C.; BITTAR, T. J. e FORTES, R. P. M. A fine-grained and flexible version control for software artifacts. In: 26th ACM International Conference on Design of Communication (SIGDOC), 2008, Lisboa. Proceedings of the 26th ACM International Conference on Design of Communication. New York, NY, USA: ACM, 2008. v. 01. p. 185-192. (JUNQUEIRA et al., 2012).

3. BitTAR, T. J.; RIGOlin, R.; PIMENTEL, M. G. C.; FORTES, R. P. M. e MOREIRA, E. S. Uma abordagem de MDA para gerenciamento de handover ciente de contexto e embasado por feedback. Anais do XIV Simpósio Brasileiro de Sistemas Multimídia e Web. Vila Velha, ES: SBC. 2008. p. 73-79. (BITTAR et al., 2008) 



\section{Referências bibliográficas}

ABOU-ZAHRA, S. Web Accessibility Evaluation. Capítulo de Livro - Human-Computer Interaction Series, Part II. In: HARPER, S.; YESILADA, Y. Web Accessibility. 1. ed. London: Springer, 2008. p. 79-106. ISBN 978-1-84800-050-6.

ALEXANDER, C.; ISHIKAWA, S. e SILVERSTEIN, M. A Pattern Language. 7. ed. New York, NY: Oxford University Press, 1977. 1171 p. ISBN 9780195019193.

ALMEIDA, L. D. A.; SANTANA, V. F. e BARANAUSKAS, C. M. C. WARAU:Uma Proposta de Apoio ao Processo de Adequação de Websites a Requisitos de Acessibilidade e Usabilidade. Anais da $60^{a}$ Reunião Anual da SBPC (Sociedade Brasileira para o Progresso da Ciência). Campinas: [s.n.]. 2008.

AMBLER, S. W. Agile model driven development is good enough. IEEE Software, v. 20, n. 5, p. 71-73, set. 2003. ISSN 0740-7459. DOI: 10.1109/MS.2003.1231156.

ANACleto, J. C.; PENTEADO, R. A. D.; SILVA, A. C. e TAlARICO NETO, A. Padrões de Interação para Projetos Web Uma Visão Geral. In: TEIXEIRA, C. A. C.; GOULARTE, R.; (ORG.) Tópicos em Tecnologias Web \& Multimídia. Ribeirão Preto: SBC, v. 1, 2004. p. $197-221$.

APPLE. iOS Human Interface Guidelines for Web Applications, 2011. Disponível em: <http://developer.apple.com/library/ios/\#documentation/userexperience/conceptual/mobile hig/Introduction/Introduction.html> . Acesso em: maio 2011.

ATTERER, R. Model-based automatic usability validation:a tool concept for improving webbased UIs. Proceedings of the 5th Nordic conference on Human-computer interaction: building bridges. Lund, Sweden: ACM Press. 2008. p. 13-22. 
BAILEY, C. e PEARSON, E. An educational tool to support the accessibility evaluation process. Proceedings of the 2010 International Cross Disciplinary Conference on Web Accessibility (W4A). Raleigh, North Carolina: ACM. 2010. p. 4.

BAILEY, C. e PEARSON, E. An educational tool to support the accessibility evaluation process. Proceedings of the International Cross-Disciplinary Conference on Web Accessibility. Hyderabad, Andhra Pradesh, India: ACM Press. 2011. p. 2:1-2:10.

BASILI, V. R. Software Modelling and Measurement: the Goal/Question/Metric Paradigm. Relatório Técnico CS-TR-2956. University of Maryland at College Park, College Park, MD, USA, 24 p., 1992.

BERNSTEIN, M. Patterns of hypertext. Proceedings of the ninth ACM conference on Hypertext and hypermedia. Pittsburgh, Pennsylvania, United States: ACM Press. 1998. p. 21-29.

BEVAN, N. Quality in use: Meeting user needs for quality. Journal of Systems and Software, v. 49, n. 1, p. 89-96, dez. 1999. ISSN 0164-1212. DOI: 10.1016/S0164-1212(99)00070-9.

BITTAR, T. J. Abordagem para diagnóstico de problemas em aplicações de e-gov - um retrato dos municípios. Dissertação de Mestrado. Universidade Federal de São Carlos, São Carlos-SP, 118 p., 2006.

BITTAR, T. J.; AMARAL, L. A.; FARIA, F. B. e FORTES, R. P. M. Supporting the developer in an accessible edition of web communications:a study of five desktop tools. Proceedings of the Workshop on Information Systems and Design of Communication ISDOC 2012. Lisbon, Portugal: ACM. 2012. p. 3-9.

BITTAR, T. J.; RIGOLIN, R.; PIMENTEL, M. G. C.; FORTES, R. P. M. e MOREIRA, E. S. Uma abordagem de MDA para gerenciamento de handover ciente de contexto e embasado por feedback. Anais do XIV Simpósio Brasileiro de Sistemas Multimídia e Web. Vila Velha, ES: SBC. 2008. p. 73-79.

BULTERMAN, D. C. A. e HARDMAN, L. Structured multimedia authoring. ACM Transactions on Multimedia Computing, Communications, and Applications, p. 89-109, 2005. ISSN 1551-6857. DOI 10.1145/1047936.1047943. 
BUZZI, M. e LEPORINI, B. Wikipedia usable for the blind. Proceedings of the 2008 international cross-disciplinary conference on Web accessibility (W4A). Beijing, China: ACM Press. 2008. p. 15-22.

CENTENO, V. L.; KLOOS, C. D.; GAEDKE, M. e NUSSBAUMER, M. WCAG formalization with W3C standards. Poster Proceedings of the 14th International World Wide Web Conference. Chiba, Japão: ACM Press. 2005. p. 1146-1147.

CERI, S.; FRATERNALI, P. e BONGIO, A. Web modeling language (WebML): A modeling language for designing web sites. Computer Networks, Volume 33, jun. 2000. 137-157.

CEZAR, É. S.; SANTOS, N. e PRATES, R. O. O Uso de Scaffolds no Projeto de Software Educacional. Cadernos do IME. Série Informática., Rio de Janeiro, 2006. p. 1-9.

CGI.BR. Dimensões e características da Web brasileira: um estudo do.gov.br. [S.l.], 93 p., 2010.

CHEN, J.; XU, H. e WHINSTON, A. Moderated Online Communities and Quality of UserGenerated Content. J. Manage. Inf. Syst., Armonk, NY, USA, 28, 2011. 237-268.

CHISHOLM, W. A. e HENRY, S. L. Interdependent components of web accessibility. Proceedings of the 2005 International Cross-Disciplinary Workshop on Web Accessibility (W4A). Chiba, Japan: ACM. 2005. p. 31-37.

CICCHETTI, A.; DI RUSCIO, D. e DI SALLE, A. Software customization in model driven development of web applications. Proceedings of the 2007 ACM symposium on Applied computing. Seoul, Korea: ACM Press. 2007. p. 1025 - 1030.

CONSTANTINE, L. L. e LOCKWOOD, L. A. D. Usage-Centered Engineering for Web Applications. IEEE Software - Computing \& Processing (Hardware/Software), Volume 19, Issue 2, mar. 2002. 42-50.

CUNHA, J. A. O. G.; THOMAZ, J. P. C. F. e MOURA, H. P. As Conferências de Decisão na Resolução de Conflitos em Projetos de Software. Anais do VII Simpósio Brasileiro de Qualidade de Software 2008. Florianópolis - Santa Catarina: SBC. 2008. p. 12. 
DESHPANDE, Y.; MURUGESAN, S.; GINIGE, A.; HANSEN, S.; SCHWABE, D. et al. Web Engineering. Journal of Web Engineering, 1, n. 1, 2002. 15.

DOKUWIKI. DokuWiki, 2011. Disponível em: <http://www.dokuwiki.org/>. Acesso em: maio 2010.

DORN, B. e GUZDIAL, M. Learning on the job:characterizing the programming knowledge and learning strategies of web designers. Proceedings of the SIGCHI Conference on Human Factors in Computing Systems. Atlanta, Georgia, USA: ACM Press. 2010. p. 703712 .

DUTOIT, A. H.; MCCALL, R.; MISTRÍKAND, I. e PAECH, B. Rationale Management in Software Engineering: Concepts and Techniques. In: Rationale Management in Software Engineering. 1. ed. [S.1.]: Springer, 2006. Cap. 1, p. 1-48. ISBN 978-3-54030998-7.

ECLIPSE. Eclipse Platform. Eclipse Platform, 2012. Disponível em: <http://www.eclipse.org>. Acesso em: maio 2012.

E-MAG. e-MAG - Modelo de Acessibilidade de Governo Eletrônico, 2011. Disponível em: <http://www.governoeletronico.gov.br/acoes-e-projetos/e-MAG>. Acesso em: 2012.

FALESSI, D.; CANTONE, G. e BECKER, M. Documenting design decision rationale to improve individual and team design decision making:an experimental evaluation. Proceedings of the 2006 ACM/IEEE international symposium on Empirical software engineering. Rio de Janeiro, Brazil: ACM Press. 2006. p. 134-143.

FINCHER, S.; FINLAY, J.; GREENE, S.; JONES, L. e MATCHEN, P. Perspectives on HCI patterns:concepts and tools. Conference on Human Factors in Computing Systems, CHIO3. Ft. Lauderdale, Florida, USA : ACM. 2003. p. 1044 - 1045.

FOWLER, M. Model Driven Architecture, 2004. Disponível em: <http://martinfowler.com/bliki/ModelDrivenArchitecture.html>. Acesso em: mar. 2009.

FREIRE, A. Acessibilidade no desenvolvimento de sistemas web: um estudo sobre o cenário brasileiro. Dissertação de mestrado. USP, São Carlos, 154 p., 2008. 
FREIRE, A. P.; BITTAR, T. J. e FORTES, R. P. M. An approach based on metrics for monitoring web accessibility in Brazilian municipalities web sites. Proceedings of the 2008 ACM Symposium on Applied Computing. Fortaleza, Ceará, Brasil: ACM Press, New York, NY. 2008. p. 2421-2425.

FREIRE, A. P.; FORTES, R. P. M.; TURINE, M. A. e PAIVA, D. M. An evaluation of web accessibility metrics based on their attributes. Proceedings of the 26th annual ACM international conference on Design of communication. Lisbon, Portugal: ACM. 2008. p. 73-80.

FREIRE, A. P.; GOULARTE, R. e FORTES, R. P. M. Techniques for developing more accessible web applications:a survey towards a process classification. Proceedings of the 25th annual ACM international conference on Design of communication. El Paso, Texas, USA: ACM. 2007. p. 162-169.

FREIRE, A. P.; RUSSO, C. M. e FORTES, R. P. M. A survey on the accessibility awareness of people involved in web development projects in Brazil. Proceedings of the 2008 international cross-disciplinary conference on Web accessibility (W4A). Beijing, China: ACM. 2008. p. 87-96.

GAMMA, E.; JOHNSON, R.; HELM, R. e JOHN, V. Design Patterns: Elements of Reusable Object-Oriented Software. [S.1.]: Addison Wesley, 1995. 416 p. ISBN 0-20163361-2.

GARRETT, J. J. Ajax: A New Approach to Web Applications, fev. 2005. Acesso em: fev. 2009.

GARZOTTO, F.; PAOLINI, O.; BOLCHINI, D. e VALENTI, S. "Modeling-by-patterns" of Web applications. Congrès on Advances in conceptual modeling. Paris: Springer. 1999. p. 293-306.

GIBSON, B. Enabling an accessible web 2.0. Proceedings of the 2007 international crossdisciplinary conference on Web accessibility (W4A). Banff, Canada: ACM Press. 2007. p. $1-6$. 
GILBERTSON, T. D. e MACHIN, C. H. C. Guidelines, icons and marketable skills:an accessibility evaluation of 100 web development company homepages. Proceedings of the International Cross-Disciplinary Conference on Web Accessibility. Lyon, France: [s.n.]. 2012. p. 17:1-17:4.

GITZEL, R.; KORTHAUS, A. e SCHADER, M. Using established Web Engineering knowledge in model-driven approaches. Science of Computer Programming, Amsterdam, 66, n. 2, 2007. 105-124.

GOTTLIEB, S. POC, Prototype, or Pilot? When and Why, 2007. Disponível em: <http://www.contenthere.net/2007/03/poc-prototype-or-pilot-when-and-why.html>. Acesso em: abr. 2009.

GRAHAM, I. A Pattern Language for Web Usability. [S.1.]: Pearson Education, 2003. 304 p. ISBN 0201788888.

GRUBBER, T. R. e RUSSEL, D. M. Design Knowledge and Design Rationale: A Framework for Representation, Capture, and Use. Technical Report KSL 90-45. Knowledge Systems Laboratory, Stanford, California, [S.1.], 40 p., 1991.

HAAKE, A.; LUKOSCH, S. e SCHÜMMER, T. Wiki-templates:adding structure support to wikis on demand. Proceedings of the 2005 international symposium on Wikis. San Diego, California: ACM Press. 2005. p. 41-51.

HARRER, A.; MOSKALIUK, J.; KIMMERLE, J. e CRESS, U. Visualizing wiki-supported knowledge building:co-evolution of individual and collective knowledge. Proceedings of the 4th International Symposium on Wikis. Porto, Portugal: [s.n.]. 2008. p. 19:1-19:9.

HOFFMAN, D.; GRIVEL, E. e BATTLE, L. Designing software architectures to facilitate accessible web applications. IBM Syst. J., Riverton, NJ, USA, ago. 2005. 467-483.

HORNER, J. e ATWOOD, M. E. Effective Design Rationale: Understanding the Barriers. In: DUTOIT, A. H.; MCCALL, R.; MISTRÍK, I. Rationale Management in Software Engineering. [S.1.]: Springer Berlin Heidelberg, 2006. Cap. 3, p. 73-90. ISBN 978-3-54030997-0. 
HÖST, M.; REGNELL, B. e WOHLIN, C. Using students as subjects - a comparative study of students and professionals in lead-time impact assessment. Empirical Software Engineering, V. 5, N. 3, 2000. 201-214.

ISO. 9241-11 - Ergonomic requirements for office work with visual display terminals (VDTs) - Part 11: Guidance on usability, 1998.

ISO/IEC. International Standard - 9126-1: 2001 Software engineering — Product quality, 15 jun. 2001.

ISO/IEC. 12.207. Technical Committee ISO/IEC/TC JTC1, Information technology. Information technology - Software life cycle processes, Canadá, 2001. (Subcommittee SC SC7, Software and systems engineering).

ISO/IEC. 40500:2012 - Information technology. W3C Web Content Accessibility Guidelines (WCAG) 2012. 2.0, Disponível em: <http://www.iso.org/iso/iso_catalogue/catalogue_tc/catalogue_detail.htm?csnumber=5862 5>. Acesso em: 30 nov. 2012.

JACOBSON, I.; BOOCH, G. e RUMBAUGH, J. The Unified Software Development Process. 1. ed. [S.1.]: Addison Wesley, v. 1, 1999. 512 p. ISBN 978-0201571691.

JACOBSON, I.; PAN-WEI, N.; P., M.; I., S. e S., L. The Essence of Software Engineering: The SEMAT Kernel. Communications of ACM, New York, v. 55. n. 12., p. 42-49, dez. 2012.

JAZAYERI, M. Some Trends in Web Application Development. FOSE '07: 2007 Future of Software Engineering - International Conference on Software Engineering (May 23 - 25, 2007). Washington, DC, USA: IEEE Computer Society. 2007. p. 199-213.

JUNQUEIRA, D. C.; BITTAR, T. J. e FORTES, R. P. M. A fine-grained and flexible version control for software artifacts. Proceedings of the 26th annual ACM international conference on Design of communication. Lisbon, Portugal: ACM. 2008. p. 185-192.

JUZGADO, N. J. e MORENO, A. M. Basics of software engineering experimentation. 1. ed. [S.1.]: Kluwer, v. 1, 2001. 395 p. ISBN 978-0-7923-7990-4. 
KAMPENES, V. B.; DYBÅ, T.; HANNAY, J. E. e SJøBERG, D. I. K. A systematic review of quasi-experiments in software engineering. Inf. Softw. Technol., Newton, MA, USA, jan. 2009. 71-82.

KANE, S. K.; SHULMAN, J. A.; SHOCKLEY, T. J. e LADNER, R. E. A web accessibility report card for top international university web sites. Proceedings of the 2007 international cross-disciplinary conference on Web accessibility (W4A). Banff, Canada: ACM Press. 2007. p. 148-156.

KELlY, B.; SLOAN, D.; BROWN, S.; SEALE, J.; PETRIE, H. et al. Accessibility 2.0:people, policies and processes. Proceedings of the 2007 international crossdisciplinary conference on Web accessibility (W4A). Banff, Canada: ACM. 2007. p. 138147.

KELlY, B.; SLOAN, D.; PHIPPS, L.; PETRIE, H. e HAMILTON, F. Forcing standardization or accommodating diversity?:a framework for applying the WCAG in the real world. Proceedings of the 2005 International Cross-Disciplinary Workshop on Web Accessibility (W4A). Chiba, Japan: ACM. 2005. p. 46-54.

KLEPPE, A.; WARMER, J. e BAST, W. MDA Explained: The Model Driven Architecture(TM): Practice and Promise. [S.1.]: Addison-Wesley Professional, 2003. 192 p. ISBN 032119442X.

KOCH, N.; KRAUS, A. e HENNICKER, R. The Authoring Process of the UML-based Web Engineering. First International Workshop on Web-Oriented Software Technology IWWOST 2001. Valencia: [s.n.]. 2001. p. 29.

KROIB, C. e KOCH, N. UWE Metamodel and Profile: User Guide and Reference. LMU Technical Report. Ludwig-Maximilians-Universität München, Alemanha, [S.1.], 35 p., 2008.

LARA, S. M. A. D. Um suporte à captura informal de Design Rationale. Dissertação de Mestrado. Instituto de Ciências Matemáticas e de Computação - USP, São Carlos - SP, 130 p., 2005. 
LARA, S. M. A. D.; WATANABE, W. M.; DOS SANTOS, E. P. B. e FORTES, R. P. M. Improving WCAG for elderly web accessibility. Proceedings of the 28th ACM International Conference on Design of Communication. São Carlos, São Paulo, Brazil: ACM Press. 2010. p. 175-182.

LAUKE, P. H. Retrofitting case study: redesign of a university website. In: THATCHER, J., et al. Web Accessibility: Web Standards and Regulatory Compliance. 1. ed. [S.1.]: FriendsofED, 2006. Cap. 15, p. 696. ISBN 978-1590596388.

LAZAR, J.; DUDLEY-SPONAUGLE, A. e GREENIDGE, K.-D. Improving web accessibility: a study of webmaster perceptions. Computers in Human Behavior, Elsevier Ltd., v. 20, n. 2, p. 269-288, 2004. ISSN 0747-5632. DOI: 10.1016/j.chb.2003.10.018.

LAZAR, J.; FENG, J. H. e HOCHHEISER, H. Research Methods in Human-Computer Interaction. 1. ed. [S.1.]: Wiley, v. 1, 2010. 448 p.

LEE, J. Design Rationale Systems: Understanding the Issues. IEEE Expert, v. 12, n. 3, p. 7885, 1997.

LEE, K.; KANG, K. C. e LEE, J. Concepts and guidelines of feature modeling for product line software engineering. 7th International Conference on Software Reuse (ICSR): Methods, Techniques, and Tools. Austin, Texas: [s.n.]. 2002. p. 62-77.

LOBATO, L. L. An Approach for Risk Management in Software Product Lines. Tese de Doutorado. Universidade Federal de Pernambuco, Recife, 328 p., 2012.

LÓPEZ, M. AWA, Marco metodológico específico en el dominio de la accesibilidad para el desarrollo de aplicaciones web. Tese de Doutorado. Universidad Carlos III de Madrid, Madrid, 395 p., 2010.

LUCRÉDIO, D. Uma abordagem orientada a modelos para reutilização de software. Tese de Doutorado. ICMC - USP, São Carlos-SP, 270 p., 2009.

LUCRÉDIO, D.; BITTAR, T. J. e FORTES, R. P. M. Desenvolvimento Web orientado a modelos: conceitos, ferramentas e técnicas. In: SBC Simpósio Brasileiro de Sistemas Multimídia e Web - WebMedia 2009: Minicursos. Fortaleza: Ceará, v. 1, 2009. p. 40. 
MACLEAN, A.; YOUNG, R. M. e MORAN, T. Design rationale: the argument behind the artifact. SIGCHI Bull, 1989. 247-252.

MAHEMOFF, M. Ajax design patterns. 1. ed. Sebastopol, CA, USA: O'Reilly Media, Inc., 2006. 655 p. ISBN 0596101805.

MAIA, L. S. Um processo para o desenvolvimento de aplicações Web acessíveis. Dissertação de Mestrado. Universidade Federal de Mato Grosso do Sul, Cuiabá, 106 p., 2010.

MARTÍN, A.; CECHICH, A. e ROSSI, G. Accessibility at early stages:insights from the designer perspective. Proceedings of the International Cross-Disciplinary Conference on Web Accessibility. Hyderabad, Andhra Pradesh, India: ACM. 2011. p. 9:1-9:9.

MARTINS, J. C. C. Técnicas Para Gerenciamento de Projetos de Software. [S.1.]: Brasport, 2007. 456 p. ISBN 8574523089.

MBIPOM, G. e HARPER, S. The transition from web content accessibility guidelines 1.0 to 2.0:what this means for evaluation and repair. Proceedings of the 27th ACM international conference on Design of communication. Bloomington, Indiana, USA: ACM Press. 2009. p. 37-44.

MELO, A. M. e BARANAUSKAS, M. C. C. Design para a inclusão:desafios e proposta. Proceedings of VII Brazilian symposium on Human factors in computing systems (IHC '06). Natal: ACM, New York, NY, USA. 2006. p. 11-20.

MONTERO, F.; LOZANO, M.; GONZÁLEZ, P. e RAMOS, I. A first approach for design web sites by using patterns. First Nordic Conference on Pattern Languages of Program. Hojstrupgard, Dinamarca: 20 a 22 de setembro de 2002. 2002. p. 137-158.

MORAN, T. P. e CARROLL, J. M. Design Rationale: Concepts, Techniques, and Use Computers, Cognition, and Work. New Jersey: Lawrence Erlbaum Associates, 1996. 659 p.

MUNSON, E. V. e PIMENTEL, M. G. C. Specialized Documents. In: HARPER, S.; YESILADA, Y. Web Accessibility: A Foundation for Research (Human-computer Interaction Series). London: Springer-Verlag, v. 1, 2008. p. 273-286. 
NBR ISO/IEC. 9126-1 - Engenharia de software - Qualidade de produto - Parte 1: Modelo de qualidade, 2003.

NIELSEN NORMAN GROUP. Usability Reports, User Research, and Design Guidelines by Nielsen Norman Group, 2009. Disponível em: <http://www.nngroup.com/reports/>. Acesso em: maio 2009.

NIELSEN, J. Designing Web Usability: The Practice of Simplicity. Indianapolis: New Riders Publishing, 2000. 432 p. ISBN 1-56205-810-X.

NIELSEN, J. Breadcrumb Navigation Increasingly Useful. Jakob Nielsen's Alertbox. [S.1.], 1 p., 2007.

NIETZIO, A.; OLSEN, M. G.; EIBEGGER, M. e SNAPRUD, M. Accessibility of eGovernment web sites:towards a collaborative retrofitting approach. Proceedings of the 12th international conference on Computers helping people with special needs: Part I (ICCHP'10). Berlin, Heidelberg: Springer-Verlag. 2010. p. 468-475.

OMG. Meta Object Facility Core Specification Version 1.4, 2002. Disponível em: <http://www.omg.org/cgi-bin/doc?formal/2002-04-03>. Acesso em: fev. 2009.

OMG. MDA Guide Version 1.0.1, 2003. Disponível em: <http://www.omg.org/cgibin/doc?omg/03-06-01>. Acesso em: jan. 2009.

OMG. Software Process Engineering Metamodel - Version 1.1. Object Managment Group, 2005. Disponível em: <http://www.omg.org/technology/documents/formal/spem.htm>. Acesso em: 03 out. 2010.

OMG. Meta Object Facility Core Specification Version 2.0, 2006. Disponível em: <http://www.omg.org/spec/MOF/2.0/HTML/>. Acesso em: jan. 2009.

OMG. XML Metadata Interchange (XMI) Specification Version 2.1.1, 2007. Disponível em: <http://www.omg.org/technology/documents/formal/xmi.htm>. Acesso em: jan. 2009.

OMG. Unified Modeling Language (UML) Version 2.2, 2009. Disponível em: <http://www.omg.org/technology/documents/formal/uml.htm>. Acesso em: maio 2009. 
OPENARCHITECTUREWARE. openArchitectureWare - The leading platform for professional model-driven software development, 2011. Disponível em: <http://www.openarchitectureware.org>. Acesso em: 2011.

PAIVA, D. M. B. e FORTES, R. P. M. Design Rationale in Software Engineering:A Case Study. Proceedings of the 17th International Conference on Software Engineering \& Knowledge Engineering. Taipei - Taiwan: United Daily News Digital Co. and Tung Tai University. 2005. p. 342-348.

PARMANTO, B. e ZENG, X. Metric for Web accessibility evaluation. Journal of the American Society for Information, v. 56, n. 33, 2005. 1394-1404.

PATEL, M.; BORG, A. e SANDAHL, K. A case study in assessing and improving capacity using an anatomy of good practice. Proceedings of the the 6th joint meeting of the European software engineering conference and the ACM SIGSOFT symposium on The foundations of software engineering. Dubrovnik, Croatia: ACM Press. 2007. p. 509-512.

PLESSERS, P.; CASTELEYN, S.; YESILADA, Y.; DE TROYER, O.; STEVENS, R. et al. Accessibility:a Web engineering approach. Proceedings of the 14th international conference on World Wide Web. Chiba, Japan: ACM. 2005. p. 353-362.

POWER, C. e PETRIE, H. Accessibility in non-professional web authoring tools:a missed web 2.0 opportunity? Proceedings of the 2007 international cross-disciplinary conference on Web accessibility (W4A). New York, NY, USA: ACM Press. 2007. p. 116-119.

PRESSMAN, R. e LOWE, D. Web Engineering: A Practioner's Approach. 1a. ed. [S.1.]: McGraw-Hill Science/Engineering/Math, v. 1, 2008. 472 p. ISBN 978-0073523293.

PRESSMAN, R. S. Engenharia de Software. 6a. ed. [S.1.]: McGraw-Hill, 2006. 720 p. ISBN 8586804576.

QUINTANA, C.; KRAJCIK, J. e SOLOWAY, E. A Case Study to Distill Structural Scaffolding Guidelines for Scaffolded Software Environments. Proceedings of the SIGCHI Conference on Human Factors in Computing Systems. Minneapolis, Minnesota, USA: ACM Press. 2002. p. 81-88. 
REGLI, W. C.; HU, X.; ATWOOD, M. e SUN, W. A Survey of Design Rationale Systems: Approaches, Representation, Capture and Retrival. Engineering with Computers (16), 2000. 209-235.

REID, L. G. e SNOW-WEAVER, A. WCAG 2.0:a web accessibility standard for the evolving web. Proceedings of the 2008 international cross-disciplinary conference on Web accessibility (W4A). Beijing, China: ACM. 2008. p. 109-115.

ROR. Ruby on Rails, 2012. Disponível em: <http://rubyonrails.org/>. Acesso em: 01 mar. 2012.

ROSSI, G.; SCHWABE, D. e LYARDET, F. Improving Web information systems with navigational patterns. Toronto, Canada: Elsevier North-Holland. 1999. p. 1667 - 1678.

SANDIM, H. C. Pantaneiro: Framework de Aplicações Web Para Plataformas E-Gov. Dissertação de Mestrado. Universidade Federal de Mato Grosso do Sul - DCT/UFMS, [S.1.], 145 p., 2009.

SCHULZ, M. e PIEPER, M. Web compliance management:barrier-free websites just by simply pressing the button? accessibility and the use of content-management-systems. Proceedings of the 9th conference on User interfaces for all (ERCIM'06). Königswinter (Bonn), Germany: Springer-Verlag. 2006. p. 419-426.

SLOAN, D. The Effectiveness of the Web Accessibility Audit as a Motivational and Educational Tool in Inclusive Web Design. Tese de Doutorado. University of Dundee, Scotland, 218 p., 2006.

SLOAN, D.; KELlY, B.; PETRIE, H.; HAMILTON, F. e PHIPPS, L. Using context to support effective application of web content accessibility guidelines. J. Web Eng., Paramus, NJ, 5, dez. 2006. 367-386.

SOMMERVILLE, I. Engenharia de Software. 8a. ed. [S.1.]: Pearson, v. 1, 2007. 568 p. ISBN 9788588639287.

SOMMERVILLE, I. e SAWYER, P. Requirements Engineering: A Good Practice Guide. 1. ed. [S.1.]: Wiley, v. 1, 1997. 404 p. ISBN 978-0471974444. 
SPIESSER, J. e KITCHEN, L. Optimization of html automatically generated by wysiwyg programs. Proceedings of the 13th international conference on World Wide Web. Manhattan: ACM. 2004. p. 355-364.

TAKAGI, H.; KAWANAKA, S.; KOBAYASHI, M.; SATO, D. e ASAKAWA, C. Collaborative web accessibility improvement:challenges and possibilities. Proceedings of the 11th international ACM SIGACCESS conference on Computers and accessibility. Pittsburgh, Pennsylvania, USA: ACM. 2009. p. 195-202.

TALARICO NETO, A.; ANACLETO, J. C. e NERIS, V. P. D. A. Padrões para Apoiar o Projeto de Material Instrucional para EAD. Latin American Conference on Pattern Languages of Programming. Campos do Jordão: Hillside. 2005. p. 1-16.

THATCHER, J.; BURKS, M. R.; C., H.; HENRY, S.; KIRKPATRICK, A. et al. Web Accessibility: Web Standards and Regulatory Compliance. 1. ed. [S.1.]: FriendsofED, 2006. $696 \mathrm{p}$.

THATCHER, J.; CYNTHIA, W.; HENRY, S.; SWIERENGA, S.; URBAN, M. et al. Constructing Accessible Web Sites. 1a. ed. [S.1.]: Glasshaus, 2002. 415 p. ISBN 1904151000 .

TREWIN, S.; CRAGUN, B.; SWART, C.; BREZIN, J. e RICHARDS, J. Accessibility challenges and tool features:an IBM Web developer perspective. Proceedings of the 2010 International Cross Disciplinary Conference on Web Accessibility (W4A). Raleigh, North Carolina: ACM. 2010. p. 32:1-32:10.

TRUJILlO, S.; BATORY, D. e DIAZ, O. Feature Oriented Model Driven Development:A Case Study for Portlets. Proceedings of the 29th International Conference on Software Engineering. Minneapolis: IEEE Computer Society. 2007. p. 44-53.

VAN DER DUIM, L.; ANDERSSON, J. e SINNEMA, M. Good Practices for Educational Software Engineering Projects. Proceedings of the 29th international conference on Software Engineering. Minneapolis: IEEE Computer Society. 2007. p. 698-707. 
VAN WELIE, M. e VAN DER VEER, G. C. Pattern Languages in Interaction Design:Structure and Organization. INTERACT 2003 - 1 a 5 de setembro. Zürich, Switzerland: [s.n.]. 2003. p. 8.

VENKATESAN, D. M. Generation of Diagram editors, taking the Enterprise Application Integration Patterns as Case study. Dissertação de mestrado. Technische Universität Hamburg-Harburg, Hamburg, Alemanha, 83 p., 2006.

W3C. Web Content Accessibility Guidelines (WCAG) 1.0, 5 maio 1999. Disponível em: <http://www.w3.org/TR/1999/WAI-WEBCONTENT-19990505/>. Acesso em: mar. 2009.

W3C. Authoring Tool Accessibility Guidelines (ATAG), 3 fev. 2000. Disponível em: <http://www.w3.org/TR/WAI-AUTOOLS/>. Acesso em: abr. 2009.

W3C. User Agent Accessibility Guidelines 1.0, dez. 2002. Disponível em: <http://www.w3.org/TR/WAI-USERAGENT/>. Acesso em: abr. 2009.

W3C. Techniques for Authoring Tool Accessibility Guidelines 1.0. ATAG10-TECHS. W3C Note., dez. 2002b. Disponível em: <http://www.w3.org/TR/ATAG10-TECHS/>. Acesso em: 17 maio 2009.

W3C. Inaccessibility of CAPTCHA, 23 nov. 2005. Disponível em: <http://www.w3.org/TR/turingtest/>. Acesso em: abr. 2009.

W3C. Web Content Accessibility Guidelines (WCAG) 2.0, 11 dez. 2008. Disponível em: <http://www.w3.org/TR/WCAG20/>. Acesso em: mar. 2009.

W3C. WAI Guidelines and Techniques, 2008b. Disponível em: <http://www.w3.org/WAI/guid-tech.html>. Acesso em: 10 dez. 2008.

W3C. W3C Technical Reports and Publications, 2009. Disponível em: <http://www.w3.org/TR/\#Recommendations>. Acesso em: jul. 2009.

W3C. Authoring Tool Accessibility Guidelines 2.0 (Working Draft), 2012. Disponível em: <http://www.w3.org/TR/ATAG20/>. Acesso em: 2012 abr. 10. 
WALD, M.; DRAFFAN, E. A.; SKUSE, S.; NEWMAN, R. e PHETHEAN, C. Southampton accessibility tools. Proceedings of the International Cross-Disciplinary Conference on Web Accessibility. Hyderabad, Andhra Pradesh, India: ACM Press. 2011. p. 1-2.

WANG, W. e BURGE, J. E. Using rationale to support pattern-based architectural design. Proceedings of the 2010 ICSE Workshop on Sharing and Reusing Architectural Knowledge. Cape Town, South Africa: ACM Press. 2010. p. 1-8.

WELIE. A Pattern Library for Interaction Design, 2009. Disponível em: <http://www.welie.com>. Acesso em: 20 abr. 2009.

WEST, J. A. e WEST, M. L. Using Wikis for Online Collaboration: The Power of the ReadWrite Web. 1a. ed. [S.1.]: Jossey-Bass;, 2008. 160 p. ISBN 978-0-470-34333-3.

WHITEHEAD, J. Collaboration in Software Engineering:A Roadmap. Proceedings of Future of Software Engineering (FOSE 2007). [S.1.]: IEEE Computer Society. 2007. p. 214-225.

WILDE, E. Structuring namespace descriptions. Proceedings of the 15th international Conference on World Wide Web. Edinburgh, Scotland: ACM Press. 2006. p. 881-882.

WOHLIN, C.; RUNESON, P.; HOST, M.; OHLSSON, M. C.; REGNELL, B. et al. Experimentation in software engineering: an introduction. 1. ed. Norwell, MA, USA: Kluwer Academic Publishers, 2000. 232 p. ISBN 0-7923-8682-5.

WOHLIN, C.; RUNESON, P.; HOST, M.; OHLSSON, M. C.; REGNELL, B. et al. Experimentation in Software Engineering. 1. ed. [S.1.]: Springer, v. 1, 2012. 236 p. ISBN 9783642290435.

WRIGHT, J. M. e DIETRICH, J. B. Requirements for Rich Internet Application Design Methodologies. Proceedings of the 9th international conference on Web Information Systems Engineering. Auckland, New Zealand: Springer-Verlag. 2008. p. 106-119.

YIN, R. K. Estudo de Caso: Planejamento e Métodos. 3. ed. Porto Alegre: Bookman, 2005. 212 p. ISBN 8536304626. 


\section{Glossário}

Agentes de usuário: qualquer software que recupera, processa e facilita a interação do usuário final com o conteúdo Web. Como exemplo desses agentes, podem ser citados navegadores, reprodutores multimídia e tecnologias assistivas.

ATAG: Authoring Tool Accessibility Guidelines ou Diretrizes de acessibilidade para ferramentas de autoria. É um conjunto de diretrizes para desenvolvedores de qualquer ferramenta de criação para Web, como: simples editores HTML, ferramentas para exportar conteúdo para Web, ferramentas multimídia e sistemas de gerenciamento de conteúdo.

Blog: é um sistema Web que permite que o usuário faça atualizações frequentes chamadas de posts ou postagens que geralmente são organizadas em categorias e ordenadas cronologicamente. Uma característica importante dos blogs é a possibilidade de permitir que usuários deixarem comentários sobre as postagens, criando uma interação entre o blogueiro (autor do blog) e o seu público.

CAPTCHA: Completely Automated Public Turing test to tell Computers and Humans Apart ou teste de Turing público completamente automatizado para diferenciação entre computadores e humanos. É um teste para impedir que softwares automatizados executem ações que degradem a qualidade do serviço de um sistema fornecido, devido a abusos no acesso a algum recurso. Para esse teste é apresentado um desafio que um computador não consegue resolver, sendo assim, todo usuário que apresenta uma solução correta é presumidamente humano.

CMS: Content Management System ou Sistema de gerenciamento de conteúdo. É um sistema que possibilita que o conteúdo de um site como notícias, eventos, imagens e itens de menu possam ser manipulados de maneira simples e objetiva pelo próprio usuário. 
Deficiência de aprendizagem: refere-se a problemas cognitivos em um indivíduo, fazendo com que ele apresente dificuldades em aprender efetivamente, podendo ser em termos de aquisição, processamento ou retenção da informação.

Disléxicos: são as pessoas que possuem dislexia que é um distúrbio genético e neurobiológico prejudicando (em diferentes graus) o funcionamento do cérebro em relação ao processamento linguístico, afetando assim na área da leitura, escrita e soletração.

DOM: Document Object Model ou Modelo de Objetos de Documentos. É uma especificação do W3C para organizar objetos de um documento em que se pode, dinamicamente, alterar e editar sua estrutura, conteúdo e estilo.

GMF: Graphic Modeling Framework. É uma estruturação com um conjunto de ferramentas disponíveis na plataforma do ambiente de programação Eclipse para a modelagem gráfica utilizando de componentes e de uma estrutura de execução.

Javascript: é uma linguagem de script para desenvolvimento de certos tratamentos que ocorrem lado do cliente, geralmente o navegador Web. Ela é utilizada geralmente quando é inconveniente ou impossível para o servidor para fazer esse tratamento.

IDE: Integrated Development Environment ou Ambiente Integrado de Desenvolvimento. É um conjunto integrado de softwares que permitem e facilitam o desenvolvimento de aplicações.

OMG: Object Management Group ou Grupo de Gerenciamento de Objetos. É um consórcio internacional da indústria de software fundado em maio de 1989 com o objetivo de criar padrões para possibilitar a interoperabilidade e portabilidade das aplicações distribuídas utilizando a tecnologia de objetos.

Relação de contraste: taxa estabelecida entre duas cores para estabelecer suas diferenciações em termos de contraste. Uma relação de contraste baixa dificulta ao ser humano a distinção das formas que contém as cores, prejudicando a leitura, por exemplo.

RIA: Rich Internet Application ou Aplicações de Internet Rica. São aplicações Web que melhoram as funcionalidades de páginas HTML por meio de tecnologias no lado do cliente possibilitando se ter características de aplicações do tipo desktop. 
Stakeholder: qualquer indivíduo ou entidade que afete nas atividades de uma organização. Alguns exemplos possíveis de stakeholders de uma organização são: acionistas, proprietários, clientes, investidores e colaboradores.

Tag: ou etiqueta, é uma palavra-chave ou termo associado com uma informação que a descreve, funcionando como uma marcação em linguagens como o HTML e XML.

Tecnologia assistiva: são recursos para facilitar ou viabilizar o desenvolvimento de atividades por pessoas com algum tipo de deficiência. Procuram aumentar as capacidades funcionais e assim promover a autonomia de quem as utiliza. Tais recursos podem ser metodologias, estratégias, práticas e serviços que de alguma forma auxiliam essas pessoas. No âmbito da acessibilidade na Web é possível citar: leitores e aumentadores de tela, navegadores alternativos e teclado virtual.

Transformações de software: são mecanismos que fazem a leitura de um determinado artefato de software e, por meio de regras específicas, realizam a sua conversão em outro artefato.

UAAG: User Agent Accessibility Guidelines ou Diretrizes de acessibilidade para agentes de usuário. Conjuntos de diretrizes para desenvolvedores de agentes de usuário (por exemplo: navegadores e reprodutores de mídia) com a finalidade de fazer com que tais agentes permitam sua utilização adequada por pessoas com algum tipo de deficiência.

URL amigável: é um endereço um conteúdo Web fácil de ler e inclui palavras que descrevem o conteúdo da página. Este tipo de URL pode ser "amigável” de duas maneiras: i) ajudando visitantes a lembrar e manipular o endereço; e ii) descrevendo a página para motores de busca.

W3C: o World Wide Web Consortium (W3C) é um consórcio internacional formado por empresas, órgãos governamentais e organizações independentes que visa desenvolver padrões para a criação e a interpretação de conteúdos da Web.

WAI: Web Accessibility Initiative ou Iniciativa de Acessibilidade na Web. É a iniciativa do W3C no que tange a desenvolver estratégias, diretrizes e outros recursos para se ter uma Web mais acessível para pessoas com deficiências.

WAI-ARIA: Web Accessibility Initiative - Accessible Rich Internet Applications ou Iniciativa de Acessibilidade na Web - Aplicações Ricas Acessíveis de Internet. Define uma 
forma de tornar o conteúdo mais acessível em aplicações ricas, contribuindo especialmente em relação ao conteúdo dinâmico e interface de controles de usuário avançadas desenvolvidos com Ajax, HTML, JavaScript e tecnologias relacionadas.

WCAG: Web Content Accessibility Guidelines ou Diretrizes de Acessibilidade para Conteúdo Web. É um conjunto de diretrizes criado pelo W3C para auxílio na elaboração de conteúdo acessível, que atualmente está em sua versão 2.0 desde 2008 sendo subdividido em quatro princípios: 1 - Perceptível, 2 - Operável, 3 - Entendível e 4 - Robusto.

Wiki: ferramenta colaborativa que permite aos usuários editar, adicionar ou revisar conteúdos por meio de um navegador Web. A criação de conteúdo segue a premissa de criação de links que aguardam a inserção de algum conteúdo, que pode ser revisado por outros usuários. É a forma de manipulação de informação que é usada pela Wikipédia, uma enciclopédia livre na Web que contém uma quantidade expressiva de informação.

WYSIWYG: "What You See Is What You Get" ou "O que você vê é o que você obtém”. Recurso tem por objetivo permitir que um documento, enquanto manipulado na tela, tenha a mesma aparência de sua utilização, usualmente sendo considerada final. Isso facilita para o desenvolvedor que pode trabalhar visualizando a aparência do documento sem precisar salvar em vários momentos e abrir em um software separado de visualização. 


\section{Detalhes da ferramenta AccessibilityUtil}

\section{A.1 Lista de casos de uso}

Área para usuários não registrados.

Quadro A.1 - Lista de casos de uso para usuários não registrados

\begin{tabular}{|l|l|l|}
\hline Código & Pacote & Nome \\
\hline \hline 1 & Conteúdo Dinâmico Aberto & Fazer registro de conta de usuário \\
\hline 2 & Acessibilidade & Pular para o conteúdo \\
\hline 3 & Acessibilidade & Aumentar o tamanho da fonte \\
\hline 4 & Acessibilidade & Ativa o modo de contraste aumentado \\
\hline 5 & Conteúdo Estático & Quem somos \\
\hline 6 & Conteúdo Estático & Objetivo deste projeto \\
\hline 7 & Conteúdo Estático & Conceitos envolvidos \\
\hline 8 & Conteúdo Estático & Gestão de projetos \\
\hline 9 & Conteúdo Estático & Material para divulgação \\
\hline 10 & Conteúdo Estático & Publicações \\
\hline
\end{tabular}




\begin{tabular}{|l|l|l|}
\hline 11 & Conteúdo Estático & Na imprensa \\
\hline 12 & Conteúdo Dinâmico Aberto & Listar avaliações por diretriz \\
\hline 13 & Conteúdo Dinâmico Aberto & Listar artefatos e avaliações \\
\hline 14 & Conteúdo Dinâmico Aberto & Busca avançada \\
\hline 15 & Ambiente & Mudar o idioma da ferramenta \\
\hline
\end{tabular}

Área para usuários registrados - participantes colaboradores.

Quadro A.2 - Lista de casos de uso para usuários registrados

\begin{tabular}{|l|l|l|}
\hline Código & Pacote & Nome \\
\hline \hline 1 & Artefatos & Cadastrar artefato Web \\
\hline 2 & Artefatos & Listar artefatos \\
\hline 3 & Artefatos & Visualizar estatística de número de artefatos por tipo \\
\hline 4 & Artefatos & Buscar artefato \\
\hline 5 & Artefatos & Visualizar o número de avaliações realizadas \\
\hline 6 & Artefatos & Visualizar o número de comentários realizados \\
\hline 7 & Projetos & Cadastrar um projeto Web \\
\hline 8 & Projetos & Visualizar o número de projetos que é administrador \\
\hline 9 & Projetos & Visualizar o número de projetos que é colaborador \\
\hline 10 & Artefatos & Listar artefatos por tipo \\
\hline 11 & Artefatos & Visualizar dados de um dado artefato \\
\hline 12 & Artefatos & Inserir uma imagem que ilustra a utilização de um dado artefato \\
\hline 13 & Artefatos & Comentar avaliações (em português e inglês) \\
\hline 14 & Artefatos & Avaliar este artefato em relação à acessibilidade \\
\hline 15 & Usuários & Visualização dos dados de usuário \\
\hline 16 & Usuários & Alteração de dados pessoais \\
\hline 17 & Usuários & Alteração ou inclusão de foto de usuário \\
\hline 18 & Usuários & Alteração de senha \\
\hline 19 & Usuários & Esqueci a senha \\
\hline & & \\
\hline
\end{tabular}

Área para usuários registrados - administradores.

Quadro A.3 - Lista de casos de uso para administradores

\begin{tabular}{|l|l|l|}
\hline Código & Pacote & Nome \\
\hline \hline 1 & Artefatos & Cadastrar artefato Web \\
\hline 2 & Artefatos & Listar artefatos \\
\hline 3 & Artefatos & Visualizar estatística de número de artefatos por tipo \\
\hline 4 & Artefatos & Buscar artefato \\
\hline 5 & Artefatos & Visualizar o número de avaliações realizadas \\
\hline 6 & Artefatos & Visualizar o número de comentários realizados \\
\hline 7 & Projetos & Cadastrar um projeto Web \\
\hline
\end{tabular}




\begin{tabular}{|c|c|c|}
\hline 8 & Projetos & Visualizar o número de projetos que é administrador \\
\hline 9 & Projetos & Visualizar o número de projetos que é colaborador \\
\hline 10 & Artefatos & Listar artefatos por tipo \\
\hline 11 & Artefatos & Visualizar dados de um dado artefato \\
\hline 12 & Artefatos & Inserir uma imagem que ilustra a utilização de um dado artefato \\
\hline 13 & Artefatos & Comentar avaliações (em português e inglês) \\
\hline 14 & Artefatos & Avaliar este artefato em relação à acessibilidade \\
\hline 15 & Artefatos & Cadastrar tipo de artefato \\
\hline 16 & Artefatos & Visualizar o total de avaliações \\
\hline 17 & Artefatos & Visualizar o total de imagens \\
\hline 18 & Artefatos & Listar avaliações em ordem cronológica \\
\hline 19 & Usuários & Visualizar o número de usuários \\
\hline 20 & Usuários & Listar os usuários \\
\hline 21 & Usuários & Detalhar os dados de um usuário e suas contribuições \\
\hline 22 & Projetos & Visualizar o número de projetos \\
\hline 23 & Projetos & Listar os projetos \\
\hline 24 & Usuários & Visualização dos dados de usuário \\
\hline 25 & Usuários & Alteração de dados pessoais \\
\hline 26 & Usuários & Alteração ou inclusão de foto de usuário \\
\hline 27 & Usuários & Alteração de senha \\
\hline
\end{tabular}

\section{A.2 Dicionário de dados}

Quadro A.4 - artefact: artefatos Web

\begin{tabular}{|l|l|l|}
\hline Campo & Tipo & Comentários \\
\hline \hline id_artefact & int(11) & Identificador único e sequencial \\
\hline id_artefact_type & int(11) & Tipo \\
\hline name & varchar(255) & Nome em inglês \\
\hline name_pt & varchar(255) & Nome em português \\
\hline description & text & Descrição em inglês \\
\hline description_pt & text & Descrição em português \\
\hline literature_references & text & Referências para outros materiais \\
\hline inserted_by_id_user & int(11) & Identificador do usuário que fez a criação \\
\hline timestamp_ins & datetime & Data e horário da criação \\
\hline
\end{tabular}

Quadro A.5 - artefact_images: imagens relacionadas aos artefatos Web

\begin{tabular}{|l|l|l|}
\hline Campo & Tipo & Comentários \\
\hline \hline id_image & $\operatorname{int}(11)$ & Identificador único e sequencial \\
\hline id_artefact & $\operatorname{int}(11)$ & Identificador do artefato ao qual faz parte \\
\hline name & $\operatorname{varchar}(255)$ & Nome \\
\hline
\end{tabular}




\begin{tabular}{|l|l|l|}
\hline label_pt & varchar(255) & Rótulo em português \\
\hline label_en & varchar(255) & Rótulo em inglês \\
\hline is_example & int(11) & Flag se é (1) - exemplo e (-1) - contra exemplo \\
\hline
\end{tabular}

Quadro A.6 - artefact_type: tipos de artefatos

\begin{tabular}{|l|l|l|}
\hline Campo & Tipo & Comentários \\
\hline \hline id_artefact_type & $\operatorname{int}(11)$ & Identificador único e sequencial \\
\hline name & varchar(255) & Nome em inglês \\
\hline name_pt & varchar(255) & Nome em português \\
\hline description & text & Descrição em inglês \\
\hline description_pt & text & Descrição em português \\
\hline
\end{tabular}

Quadro A.7 - comments_evaluation_success_criteria: comentários para cada avaliação de um critério de sucesso ligada a um artefato

\begin{tabular}{|l|l|l|}
\hline Campo & Tipo & Comentários \\
\hline$\underline{\text { id_comment_evaluation_success_criteri }}$ & int(11) & Identificador único e sequencial \\
\hline comments & text & Comentários em português \\
\hline comments_en & text & Comentários em inglês \\
\hline id_user & int(l1) & Identificador do usuário \\
\hline timestamp_ins & datetime & Data e hora de inserção \\
\hline id_evaluation_success_criteria & int(11) & Chave estrangeira para qual avaliação é \\
\hline
\end{tabular}

Quadro A.8 - content_analysis: análise de conteúdo, onde um usuário pode reportar um abuso

\begin{tabular}{|l|l|l|}
\hline Campo & Tipo & Comentários \\
\hline \hline id_content_analysis & $\operatorname{int}(11)$ & Identificador único e sequencial \\
\hline type & $\operatorname{varchar(200)}$ & Tipo \\
\hline reference & $\operatorname{int}(11)$ & Referência \\
\hline message & text & Mensagem \\
\hline datetime_ins & datetime & Data e hora de criação \\
\hline id_user & int(11) & Identificador do usuário (caso exista) \\
\hline email_user & varchar(255) & E-mail do usuário \\
\hline name_user & varchar(255) & Nome do usuário \\
\hline status_analysis & int(11) & $\begin{array}{l}0 \text { - não foi analisado, -1 - foi visto, mas nada } \\
\text { foi feito e 1 - foi visto e alterado }\end{array}$ \\
\hline ip & & Endereço IP \\
\hline
\end{tabular}

Quadro A.9 - evaluation: avaliação de um artefato

\begin{tabular}{|l|l|l|}
\hline Campo & Tipo & Comentários \\
\hline \hline id_evaluation & $\operatorname{int}(11)$ & Identificador único e sequencial \\
\hline id_user & $\operatorname{int}(11)$ & Identificador do usuário \\
\hline id_artefact & $\operatorname{int}(11)$ & Identificador do artefato \\
\hline date_time_evaluation & datetime & Data e horário da criação \\
\hline
\end{tabular}


Quadro A.10 - evaluation_success_criteria: avaliação de um artefato em relação a um critério de sucesso

\begin{tabular}{|l|l|l|}
\hline Campo & Tipo & Comentários \\
\hline \hline id_evaluation_success_criteria & int(11) & Identificador único e sequencial \\
\hline date_time_evaluation_success_criteria & datetime & Data e horário da criação \\
\hline id_evaluation & $\operatorname{int}(11)$ & Identificador da avaliação \\
\hline id_success_criteria & $\operatorname{int}(11)$ & Identificador do critério de sucesso \\
\hline general_comments & text & Comentários gerais em inglês \\
\hline general_comments_pt & text & Comentários gerais em português \\
\hline difficulty_in_developing & $\operatorname{int}(11)$ & Dificuldade no desenvolvimento \\
\hline
\end{tabular}

Quadro A.11 - evaluation_success_criteria_util: se um usuário acha útil uma determinada avaliação

\begin{tabular}{|l|l|l|}
\hline Campo & Tipo & Comentários \\
\hline \hline id_evaluation_success_criteria_util & $\operatorname{int}(11)$ & Identificador único e sequencial \\
\hline id_evaluation_success_criteria & $\operatorname{int}(11)$ & Identificador da avaliação \\
\hline id_user & $\operatorname{int}(11)$ & Identificador do usuário \\
\hline datetime_ins & datetime & Data e horário da criação \\
\hline
\end{tabular}

Quadro A.12 - guideline: diretrizes do conjunto WCAG 2.0

\begin{tabular}{|l|l|l|}
\hline Campo & Tipo & Comentários \\
\hline \hline id_guideline & $\operatorname{int}(11)$ & Identificador único e sequencial \\
\hline id_principle & $\operatorname{int}(11)$ & Identificador do princípio \\
\hline code & $\operatorname{varchar}(20)$ & Código \\
\hline name & $\operatorname{varchar}(255)$ & Nome em inglês \\
\hline description & text & Descrição em inglês \\
\hline name_pt & $\operatorname{varchar}(255)$ & Nome em português \\
\hline description_pt & text & Descrição em português \\
\hline
\end{tabular}

Quadro A.13 - invitation: convite para colaborar em um projeto

\begin{tabular}{|l|l|l|}
\hline Campo & Tipo & Comentários \\
\hline \hline id_invitation & $\operatorname{int}(11)$ & Identificador único e sequencial \\
\hline id_project & $\operatorname{int}(11)$ & Identificador do projeto \\
\hline email & varchar(255) & E-mail \\
\hline name & varchar(255) & Nome \\
\hline date_time_creation & datetime & Data e horário de criação \\
\hline status & int(11) & Status do convite \\
\hline
\end{tabular}

Quadro A.14 - principle: princípios do conjunto de diretrizes WCAG 2.0

\begin{tabular}{|l|l|l|}
\hline Campo & Tipo & Comentários \\
\hline \hline id_principle & $\operatorname{int}(11)$ & Identificador único e sequencial \\
\hline code & $\operatorname{varchar}(20)$ & Código \\
\hline name & $\operatorname{varchar}(255)$ & Nome em inglês \\
\hline
\end{tabular}




\begin{tabular}{|l|l|l|}
\hline description & text & Descrição em inglês \\
\hline name_pt & varchar(255) & Nome em português \\
\hline description_pt & text & Descrição em português \\
\hline
\end{tabular}

Quadro A.15 - project: projetos

\begin{tabular}{|l|l|l|}
\hline Campo & Tipo & Comentários \\
\hline \hline id_project & $\operatorname{int}(11)$ & Identificador único e sequencial \\
\hline name & $\operatorname{varchar}(255)$ & Nome \\
\hline description & text & Descrição \\
\hline opened & int(11) & Se o projeto é aberto para leitura de todos. \\
\hline date_time_creation & datetime & Data e horário de criação \\
\hline id_user & int(11) & Identificador do usuário \\
\hline
\end{tabular}

Quadro A.16 - session: sessão de acesso ao sistema

\begin{tabular}{|l|l|l|}
\hline Campo & Tipo & Comentários \\
\hline \hline id_session & $\operatorname{int}(11)$ & Identificador único e sequencial \\
\hline id_user & $\operatorname{int}(11)$ & Identificador do usuário \\
\hline ip & varchar(16) & Endereço IP \\
\hline datetime & datetime & Data e horário da criação \\
\hline
\end{tabular}

Quadro A.17 - status: status de cada projeto

\begin{tabular}{|l|l|l|}
\hline Campo & Tipo & Comentários \\
\hline \hline id_status & $\operatorname{int}(11)$ & Identificador único e sequencial \\
\hline Name & varchar(256) & Nome \\
\hline Color & varchar(20) & Código hexadecimal RGB da cor desejada \\
\hline
\end{tabular}

Quadro A.18 - success_criteria: critérios de sucesso do conjunto de diretrizes WCAG 2.0

\begin{tabular}{|l|l|l|}
\hline Campo & Tipo & Comentários \\
\hline \hline id_success_criteria & $\operatorname{int}(11)$ & Identificador único e sequencial \\
\hline id_guideline & $\operatorname{int}(11)$ & Identificador da diretriz \\
\hline name & $\operatorname{varchar}(255)$ & Nome em inglês \\
\hline code & varchar(45) & Código \\
\hline name_pt & varchar(255) & Nome em português \\
\hline description & text & Descrição em inglês \\
\hline description_pt & text & Descrição em português \\
\hline level & varchar(5) & Nível \\
\hline level_pt & varchar(5) & Nível em português \\
\hline
\end{tabular}

Quadro A.19 - topic: tópicos de discussão para cada projeto

\begin{tabular}{|l|l|l|}
\hline Campo & Tipo & Comentários \\
\hline \hline id_topic & $\operatorname{int}(11)$ & Identificador único e sequencial \\
\hline id_project & $\operatorname{int}(11)$ & Identificador do projeto \\
\hline Title & $\operatorname{text}$ & Título \\
\hline
\end{tabular}




\begin{tabular}{|l|l|l|}
\hline Description & text & Descrição \\
\hline Keywords & varchar(200) & Palavras chave \\
\hline date_time_creation & datetime & Data e horário de inserção \\
\hline id_user & $\operatorname{int}(11)$ & Identificador do usuário \\
\hline id_status & $\operatorname{int}(11)$ & Status \\
\hline
\end{tabular}

Quadro A.20 - topic_comment: comentários para cada tópico de um projeto

\begin{tabular}{|l|l|l|}
\hline Campo & Tipo & Comentários \\
\hline \hline id_topic comment & $\operatorname{int}(11)$ & Identificador único e sequencial \\
\hline id_topic & $\operatorname{int}(11)$ & Identificador do tópico \\
\hline description & text & Descrição \\
\hline date_time_creation & datetime & Data e horário da criação \\
\hline id_user & $\operatorname{int}(11)$ & Identificador do usuário que criou o tópico \\
\hline id_status & $\operatorname{int}(11)$ & Status (se está concluído ou não) \\
\hline
\end{tabular}

Quadro A.21 - user: dados dos usuários do sistema

\begin{tabular}{|l|l|l|}
\hline Campo & Tipo & Comentários \\
\hline \hline id_user & $\operatorname{int}(11)$ & Identificador único e sequencial \\
\hline email & varchar(255) & E-mail \\
\hline password & varchar(100) & Senha \\
\hline name & varchar(255) & Nome \\
\hline institution & varchar(80) & Instituição \\
\hline expertise & int(11) & Nível de expertise \\
\hline admin & tinyint(1) & Se é administrador \\
\hline
\end{tabular}

Quadro A.22 - user_project: associa cada usuário a um projeto

\begin{tabular}{|l|l|l|}
\hline Campo & Tipo & Comentários \\
\hline \hline id_user_project & $\operatorname{int}(11)$ & Identificador único e sequencial \\
\hline id_user & $\operatorname{int}(11)$ & Identificador do usuário \\
\hline id_project & $\operatorname{int}(11)$ & Identificador do projeto \\
\hline user_type & $\operatorname{int}(11)$ & Tipo do usuário: 1 - colaborador, 2 - admin \\
\hline
\end{tabular}

\section{A.3 Listagem de organizações e número de usuários}

Quadro A.23 - Listagem de organizações e números de usuários

\begin{tabular}{|l|r|}
\hline Nome da organização & Quantidade de usuários \\
\hline \hline Agência WebSocorro & 1 \\
\hline Aptor Software & 2 \\
\hline Centro de Ensino Superior de Catalão (CESUC) & 1 \\
\hline Centro Universitário de Araraquara - Uniara & 2 \\
\hline
\end{tabular}




\begin{tabular}{|c|c|}
\hline Digital Acesso & 1 \\
\hline E. M. Professora Clarisse Toledo & 1 \\
\hline E.M.E. Bilíngue para Surdos & 1 \\
\hline Escola de Ensino Médio Aprendizagem e Cidadania & 1 \\
\hline Escola SENAI Catalão & 1 \\
\hline Fatec São José dos Campos & 1 \\
\hline Fundação de Economia e Estatística Siegfried Emanuel Heuser (FEE) & 1 \\
\hline Governo do Estado de São Paulo & 1 \\
\hline Governo do Estado do Rio Grande do Sul & 1 \\
\hline Instituto Federal de Educação, Ciência e Tecnologia Baiano & 1 \\
\hline Instituto Federal de Educação, Ciência e Tecnologia de São Paulo (IFSP) & 2 \\
\hline Instituto Federal de Goiás (IFG) & 1 \\
\hline Interagi Tecnologia & 1 \\
\hline Midiamix Editora Digital & 1 \\
\hline Museu do Judiciário Catarinense & 1 \\
\hline Prefeitura Municipal de Engenheiro Coelho & 1 \\
\hline Revista Espaço Aberto - USP & 1 \\
\hline Rochester Institute of Technology & 1 \\
\hline TV Pirapitinga & 1 \\
\hline Universidade de São Paulo (USP) & 25 \\
\hline Universidade Estatual de Goiás (UEG) & 1 \\
\hline Universidade Federal de Goiás (UFG) & 66 \\
\hline Universidade Federal de Pernambuco (UFPE) & 1 \\
\hline Universidade Federal de São Carlos (UFSCar) & 3 \\
\hline Universidade Federal de Uberlândia (UFU) & 1 \\
\hline Universidade Federal do Ceará (UFC) & 1 \\
\hline Universidade Federal do Espírito Santo (UFES) & 1 \\
\hline Universidade Federal do Rio Grande do Sul (UFRGS) & 2 \\
\hline Universidade Federal do Tocantins (UFT) & 1 \\
\hline Universidade Federal Rural da Amazônia (UFRA) & 1 \\
\hline Universidade Tecnológica Federal do Paraná (UTFPR) & 1 \\
\hline University of York & 1 \\
\hline W3C - Brasil & 1 \\
\hline
\end{tabular}




\section{Detalhes sobre o experimento realizado}

\section{B.1 Modelo de dados proposto para o sistema}

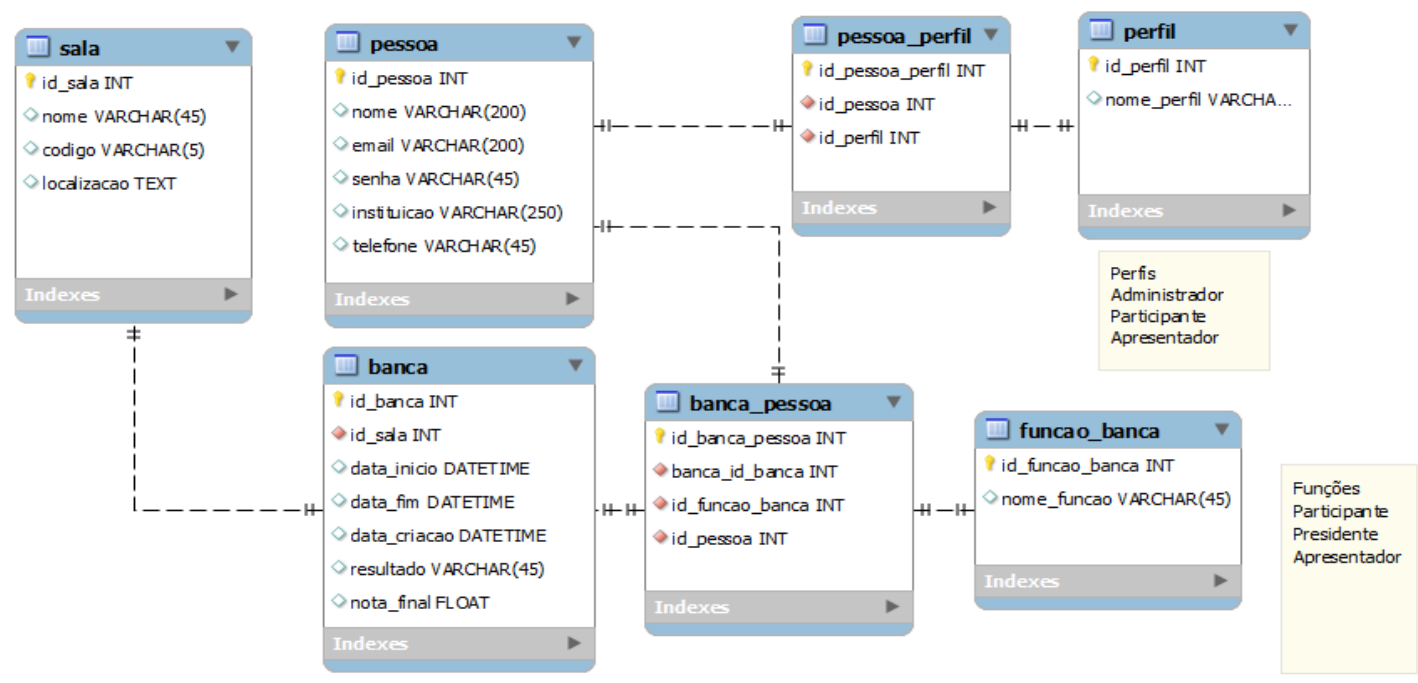

Figura B.1 - Modelo de dados proposto para o sistema 


\section{B.2 Questionário 1 - Dados pessoais (background)}

\section{1 - Nome}

Não são divulgados nesta pesquisa os nomes dos respondentes.

\section{2 - Gênero}

Tabela B.1 - Respondentes por gênero

\begin{tabular}{|l|r|r|}
\hline Masculino & 19 & $79,0 \%$ \\
\hline Feminino & 5 & $21,0 \%$ \\
\hline
\end{tabular}

\section{3 - Pontue sua experiência em desenvolvimento Web}

Tabela B.2 - Experiência em desenvolvimento Web

\begin{tabular}{|l|r|r|}
\hline 0 - Nenhuma & 0 & $0 \%$ \\
\hline 1 & 3 & $12,5 \%$ \\
\hline 2 & 5 & $20,8 \%$ \\
\hline 3 & 13 & $54,2 \%$ \\
\hline 4 & 3 & $12,5 \%$ \\
\hline 5 - Muita & 0 & $0 \%$ \\
\hline
\end{tabular}

\section{4 - Detalhe sua experiência em desenvolvimento Web}

"Pequenas aplicações em HTML"

"Alguns sites em algumas disciplinas da faculdade."

"Pequenas aplicações em HTML."

"Desenvolvi pequenos projetos bem simples na matéria de multimídia."

"Não possuo experiência em Web, apenas em pequenos trabalhos acadêmicos."

"Pequenos sites para empresas, sistema de controle de estoque online, sistema de cadastro de documentos. PHP-OO e MySQL intermediário."

"Alguns serviços prestados."

"Desenvolvi dois Web sites para duas disciplinas na UFG." 
"Eu já trabalhei com desenvolvimento Web somente na parte de design, trabalhei com Dreamweaver, fiz sites utilizando essas ferramentas mais ainda não fiz sites utilizando PHP+SQL (nível avançado). Esse ano estou aprendendo."

"Criação de alguns projetos Web para empresas, apresentações em CDs contendo conteúdo Web."

"Nunca desenvolvi um Web site, mas já fiz protótipos de páginas e design. Mas no desenvolvimento em si não, em multimídia foram feitas algumas páginas Web, e para o evento Enacomp dois sites foram feitos.”

"Fui instrutor de informática, no qual meu objetivo era ensinar desenvolvimento Web básico, utilizando ferramentas para facilitar o desenvolvimento como, Fireworks, Dreamweaver, flash, e também o uso de HTML básico. Também sou estagiário do DEPECAC e minha função é trabalhar no desenvolvimento e gerenciamento do site do departamento."

"Não tive muita experiência com desenvolvimento Web, o desenvolvimento que fiz foi em um curso de ASP e quando estudei um pouco de FLASH. Não cheguei a construir uma pagina que chegou a ser colocada na Web."

"Bom, minha experiência com desenvolvimento Web é bem básica, apenas algumas tags e controles, nunca cheguei a desenvolver um site sozinho, acredito que com a prática posso aguçar essa técnica."

"Somente na universidade."

“Conhecimento básico em HTML.”

"Fiz um minicurso, no Instituto Federal Goiano Campus-Morrinhos, em desenvolvimento Web, usando Joomla."

"Antes de entrar na faculdade não tinha nenhum conhecimento com o desenvolvimento Web, porém fiz algumas matérias que me proporcionaram alguns conhecimentos sobre o desenvolvimento como, por exemplo, a disciplina de Multimídia para a qual desenvolvemos alguns trabalhos."

"Já trabalhei como Web Designer por um breve período." 


\section{6 - Pontue sua experiência sobre acessibilidade na Web}

Tabela B.3 - Experiência em acessibilidade na Web

\begin{tabular}{|l|r|r|}
\hline 0 - Nenhuma & 9 & $37,5 \%$ \\
\hline 1 & 11 & $45,8 \%$ \\
\hline 2 & 3 & $12,5 \%$ \\
\hline 3 & 0 & $0,0 \%$ \\
\hline 4 & 1 & $4,2 \%$ \\
\hline 5 - Muita & 0 & $0,0 \%$ \\
\hline
\end{tabular}

\section{7 - Detalhe sua experiência em acessibilidade na Web}

“Tecnicamente não sei como tornar um site acessível, nem analisar se um site é realmente acessível para certos tipos de deficiência."

"Nenhuma."

“Sobre acessibilidade eu já ouvi falar, porém nunca trabalhei ou desenvolvi nada pensando na acessibilidade."

"Já pesquisei sobre o assunto, para desenvolvimento de artigo. E me interesso bastante pelo tema, por isso pesquiso sobre isso."

"Apesar de ter uma noção sobre o tema, não tenho experiência alguma."

"Pouca experiência na área."

"Utilização básica em smartphones, em especial iPhone."

"Somente leituras em revista e internet."

"Minha experiência com acessibilidade na Web é pouca, mas na criação de alguns projetos, sempre coloco o site mais limpo, com poucas opções na página inicial, botões maiores."

“Já estudei em outras matérias como em Interação Humano Computador e Engenharia de Software, mas só teoria, nunca tive contato com nenhuma ferramenta que auxilia a acessibilidade."

"Em acessibilidade já li alguns artigos, mas nunca trabalhei." 
"Não tenho muita experiência com a acessibilidade na Web, apenas conhecimento sobre o tema de uma disciplina."

"Primeira vez que vejo, apesar de que em algumas matérias como Engenharia de Software sempre foi falado sobre alguns requisitos para que os softwares fossem no mínimo acessíveis para uma maior quantidade de usuários."

"Existe um certo problema a ser sanado em relação a acessibilidade na Web, pois são poucas as entidades que priorizam essa técnica hoje em dia, com isso é difícil dizer sobre minha experiência sobre acessibilidade na Web, porque é difícil encontrar sites que disponibiliza tal recurso, mas mesmo assim os sites acessíveis que encontro falham em muitos aspectos."

“Somente na Universidade."

"Nenhuma."

"Pouca experiência."

"Já me informei a respeito através de disciplina, mas não desenvolvi algo a respeito."

"Tenho algum conhecimento sobre o assunto, pouco conhecimento porque no meu caso é um assunto muito recente que só tive contato logo após a minha entrada na faculdade, logo após ter o primeiro contato com o assunto pesquisei um pouco sobre o mesmo."

"Não tenho experiência em acessibilidade na Web."

8 - Conhece alguma pessoa que tem dificuldade ou que enfrenta barreiras em acessar algum site.

Tabela B.4 - Se o respondente conhece alguém com dificuldade ou que enfrenta barreiras em acessar algum site

\begin{tabular}{|l|r|r|}
\hline Sim & 10 & $41,7 \%$ \\
\hline Não & 14 & $58,3 \%$ \\
\hline
\end{tabular}

9 - Caso sim na questão anterior, detalhe as experiências sentidas por essa pessoa.

"A pessoa sempre precisa de ajuda para acessar site, o que a torna dependente de outras pessoas, limitando seu acesso a informação, pois nem sempre tem alguém disponível para ajudá-la." 
"Dificuldade para navegar sozinho, dificuldade para lembrar o que foi feito anteriormente, medo de usar o computador."

"Dificuldade na utilização de PC's e Celulares."

"Dificuldade em encontrar conteúdos em determinados sites."

"Meus próprios pais, sabem digitar, mas na hora de navegar tem dificuldades de enxergar menus ou localizar algumas informações."

"Minha colega diz que sente muita dificuldade na visualização dos sites, pois em muitos deles os botões são muito pequenos e como ela tem problema de visão ela força muito pra ler."

"Dificuldade em entender o que o clicar em um link faz, muitas das vezes não encontra a informação que deseja chegando ao ponto de se irritar. Também tem certa dificuldade em decorar os passos necessários para ter acesso a informação.”

"Pessoas mais de idade têm problemas ao trabalhar com o mouse e ficam sem saber onde clicar. Estão mais acostumadas com alguém auxiliando nessa tarefa de interagir com computador e internet. Às vezes são muitos passos que eles têm que fazer e acabam desistindo."

"Em meu caso a dificuldade encontrada foi de um idoso que não conseguia acessar uma página na internet, pois não tinha o hábito de ver a internet como uma ferramenta útil para seu cotidiano, posso dizer que o sentimento que ele teve foi de incapacidade de não poder acessar o site."

\section{B.3 Questionário 2 - Sobre o desenvolvimento}

1 - Houve alguma dificuldade adicional em desenvolver com preocupação em garantir acessibilidade?

Tabela B.5 - Dificuldade adicional em desenvolver com preocupação em garantir acessibilidade

\begin{tabular}{|l|r|r|}
\hline \multicolumn{1}{|c|}{ Opção } & $\begin{array}{c}\text { Respondentes que } \\
\text { usaram a abordagem }\end{array}$ & $\begin{array}{c}\text { Respondentes que não } \\
\text { usaram a abordagem }\end{array}$ \\
\hline \hline 1 (pouco) & $2(16,7 \%)$ & $0(00,0 \%)$ \\
\hline 2 & $1(08,3 \%)$ & $1(08,3 \%)$ \\
\hline 3 & $6(50,0 \%)$ & $8(66,7 \%)$ \\
\hline
\end{tabular}




\begin{tabular}{|l|l|r|}
\hline 4 & $3(25,0 \%)$ & $3(25,0 \%)$ \\
\hline 5 (alta) & $0(00,0 \%)$ & $0(00,0 \%)$ \\
\hline
\end{tabular}

\section{2 - Explique as dificuldades encontradas}

\section{Respondentes que usaram a abordagem}

"A dificuldade maior foi com o tempo, pois para garantir a acessibilidade, um tempo maior é gasto. O restante foi tranquilo, com o conhecimento das tags e a ajuda dada, o trabalho era somente aplicá-las em nosso projeto."

"Existe a necessidade de se atentar para procedimentos, que muitas vezes nem seriam citados, na hora do desenvolvimento. Ex.: colocar o caption ou o label, verificar o tabIndex, cuidados com abreviaturas, etc...

Além da dificuldade encontrada nas ferramentas de autoria, que na maioria dos casos, não ajuda neste tipo de desenvolvimento."

"Por estarmos iniciando no quesito acessibilidade, faltou-nos material de apoio, que realmente ajudasse, como foi discutido em sala de aula, ate mesmo as diretrizes WCAG não são tão claras..."

"Falta de costume com as tags específicas."

"Falta de técnica em desenvolver aplicativos mais acessíveis e o tempo foi um fator determinante."

"A maioria das vezes fazemos algo com intuito de funcionar, mas agora além de funcionar ficando bonito na tela precisa estar adequado com uma lista grande de padrões."

"Não foram encontradas dificuldades."

"Tem que preocupar com muitos detalhes, mas não houve dificuldades pra fazer as alterações."

"São muitas atividades e considerações para desenvolver com acessibilidade. Aparentemente pode estar tudo certo, mas se for avaliar a acessibilidade em algum site você verá diversos problemas." 
"Para desenvolver de forma acessível tudo é um pouco mais rígido, há regras que devem ser cumpridas. Mas acredito que com o tempo a gente vai obtendo mais experiência. Eu não sabia a importância do texto alternativo para imagens, agora que sei para que serve, isso nos anima mais para preenchermos corretamente."

"Sim, não é fácil desenvolver garantindo a acessibilidade. São muitas regras que devem ser vistas. Precisa ter um acompanhamento muito bom para que a gente faça um trabalho bom."

"Sim é necessário maior atenção no desenvolvimento e mais conhecimento de regras pelo desenvolvedor. O trabalho com isso aumenta. E, assim, temos mais dificuldades para fazer tudo acessível de acordo com os padrões e diretrizes ensinadas."

\section{Respondentes que não usaram a abordagem}

“O tempo gasto na produção de material acessível é algo a se pensar, além disso tentar agradar a vários tipos de deficientes é algo muito relativo."

"Falta de ferramentas adequadas."

"Falta de conhecimento em desenvolvimento Web dificultou aos alunos envolvidos a prover acessibilidade."

“O tempo, foi curto então para desenvolver o sistema acessível foi um problema. Tive que realizar pesquisar para ver como fazer os tratamentos afim de que todos pudessem prover do sistema."

"Na verdade não é bem uma dificuldade, mas um obstáculo encontrado é a questão de demorar mais o desenvolvimento por conta d colocar dentro dos padrões."

"Muitas vezes o material disponibilizado na rede não leva em conta a acessibilidade, com isso acabamos aprendendo coisas novas da maneira errada."

“Aplicar todas as diretrizes, são muitas."

“As dificuldades que encontrei ao desenvolver conteúdo acessível estão baseadas na falta de ferramentas que auxiliem essa prática. As poucas ferramentas que tentam ajudar o desenvolvedor ainda são muito fracas."

"Umas das dificuldades encontradas foi a falta de ferramentas para auxiliar o desenvolvimento que garanta à acessibilidade." 
“Achei difícil por não termos exemplos rápidos de como fazer o código de forma acessível. Existem muitos jeitos de desenvolver e são várias possibilidades para o código, e o HTML não dá nenhum erro quando desenvolvemos com erros de acessibilidade.”

"Para desenvolver bem, com preocupação em acessibilidade, nós tivemos a dificuldade de encontrar rapidamente o que fazer de melhor. Eu já tenho experiência no desenvolvimento, mas a parte de acessibilidade exige outros detalhes que dificultam um pouco."

"A grande dificuldade encontrada foi nas ferramentas de autoria, pois a grande maioria delas não oferecem suporte de acessibilidade para o programador. Como foi estudado, as ferramentas de autoria que oferecem suporte, ainda não são adequadas de acordo com a acessibilidade, pois falta muitas características da WCAG."

3 - Você acredita que componentes acessíveis podem melhorar os desenvolvimentos?

Tabela B.6 - Se componentes acessíveis podem melhorar os desenvolvimentos

\begin{tabular}{|l|r|r|}
\hline \multicolumn{1}{|c|}{ Opção } & $\begin{array}{c}\text { Respondentes que } \\
\text { usaram a abordagem }\end{array}$ & $\begin{array}{c}\text { Respondentes que não } \\
\text { usaram a abordagem }\end{array}$ \\
\hline \hline Sim & $11(91,7 \%)$ & $10(83,3 \%)$ \\
\hline Não & $0(00,0 \%)$ & $1(08,3 \%)$ \\
\hline Não sei & $1(08,3 \%)$ & $1(08,3 \%)$ \\
\hline
\end{tabular}

Observação: as porcentagens acima somadas não totalizam $100 \%$ por causa de dízimas periódicas encontradas.

4 - Sobre a apresentação sobre as diretrizes do conjunto WCAG 2.0, você achou fácil e viável aplicá-las?

Tabela B.7 - Se achou fácil e viável aplicar as diretrizes WCAG 2.0

\begin{tabular}{|l|r|r|}
\hline \multicolumn{1}{|c|}{ Opção } & $\begin{array}{c}\text { Respondentes que } \\
\text { usaram a abordagem }\end{array}$ & $\begin{array}{c}\text { Respondentes que não } \\
\text { usaram a abordagem }\end{array}$ \\
\hline \hline Sim & $4(33,3 \%)$ & $3(25,0 \%)$ \\
\hline Não & $7(58,3 \%)$ & $9(75,0 \%)$ \\
\hline Não sei & $1(08,3 \%)$ & $0(00,0 \%)$ \\
\hline
\end{tabular}


Observação: as porcentagens acima somadas não totalizam 100\% por causa de dízimas periódicas encontradas.

\section{5 - Explique sua resposta anterior em relação ao uso da WCAG 2.0}

\section{Respondentes que usaram a abordagem}

"Sim a maioria delas sim. Algumas das diretrizes da WCAG 2.0 são um pouco difíceis de aplicar. Apesar de não usadas no nosso projeto em um trabalho futuro talvez daria de trabalho, principalmente as recomendações de Mídias com base em tempo.”

"Boa parte a WCAG 2.0 não pode ser aplicada, pois exigem muito processamento ou a sua aplicação é muito complicada. Também deve-se ter em mente que a aplicação de todas as diretrizes pode sobrecarregar de informação o sistema impedindo o usuário de ter acesso a informação."

"As diretrizes da WCAG2.0 não estão claras na sua integridade, até mesmo algumas delas não são fácil uso, e algumas ate impossíveis de serem aplicadas na prática. Acho que deveriam ser mais claras e objetivas, um texto/diretriz simples talvez falaria e transmitiria mais informação palpável.”

"Na grande maioria das diretrizes, a apresentação é bem clara, requisitando pequeno esforço para implementar, desde que haja tempo e pessoas suficientes."

“Alguns são até possíveis e diretas, porém outras são muito difíceis de entender e de aplica na prática. Definitivamente não da pra seguir todas as normativas da WCAG 2.0, mas existem metas que podem ser compridas e ajudam na acessibilidade."

"Não, pois existe algumas normas na WCAG 2.0 que não estão claras quanto ao que se deve ser feito."

“Tem algumas diretrizes que eu não acho viáveis, mas muitas são sim bem viáveis".

"Algumas diretrizes sim, a maioria conseguimos usar. Com ajuda de materiais adicionais buscando no Google, por exemplo."

"Não é simples de aplicar não. Tem muitas partes que não fazem sentido para todos os sites. Mas com exemplos de código e componentes que já estão corretos com essas diretrizes fica mais fácil. E também tem que ter um tempo para fazer correções sempre, pois são muitos detalhes que temos que ver." 
“Achei confusas as diretrizes. Poderiam ser mais práticas."

"Não é fácil e viável aplicá-las, são muitas considerações. Poderia haver um jeito de saber o que realmente é útil em cada momento, e assim facilitar ao desenvolvedor. Simplesmente falar para a gente ler as diretrizes não quer dizer que as seguiremos, pois na hora do desenvolvimento é diferente. É difícil fazer funcionar em algumas situações, e agora temos que preocupar com essas regras. Eu sei da importância, mas também é preciso ver o lado do desenvolvedor que precisa entregar o resultado funcionando.”

\section{Respondentes que não usaram a abordagem}

"Apesar do material ser extenso é bem autoexplicativo."

"Existem alguns quesitos impossíveis de se implementar."

“É fácil e viável por serem bem explicadas e terem exemplos de aplicações práticas."

"Ao meu modo de ver $80 \%$ das diretrizes da WCAG são de grande dificuldade, e algumas praticamente impossíveis de ser atingida."

"Não é bem fácil assim, porque depende muito também das ferramentas, se elas oferecem suporte facilita bastante."

"As diretrizes falam o que fazer, a dificuldade está em como fazer."

"São muitas diretrizes, e algumas envolvem um trabalho mais minucioso."

“As diretrizes da WCAG 2.0 não estão em linguagem de fácil entendimento e às vezes não guia o desenvolvedor a fazer diretamente determinada tarefa, apenas as apresenta em determinadas categorias. Acredito que o uso de uma linguagem simples poderia tornar as tarefas mais fáceis."

“As diretrizes são fáceis de entender, porém não é fácil de aplicá-las.”

“A versão em português é boa, ajuda muito. Mas tem várias partes que não dá para aplicar facilmente no site que está sendo feito."

“Algumas são difíceis de entender e aplicar na prática, como, por exemplo, a parte de ser robusto. É um pouco subjetivo isso em minha opinião.”

"O uso da WCAG 2.0 é bastante viável, mas o principal fator que compromete seu uso são os próprios programadores (talvez o profissional não tenha conhecimento das 
diretrizes e acaba não usando, ou também porque o tempo de projeto é pequeno e para agilizar o projeto ele acaba não fazendo nos padrões adequados) e pelas empresas (pois elas necessitam do termino do projeto o mais rápido possível, fazendo com que os programadores não usem tais diretrizes para agilizar o projeto)."

\section{6 - O registro de decisões de projeto sob a forma de Design Rationale foi} importante?

Tabela B.8 - Se o registro de decisões usando DR foi importante

\begin{tabular}{|l|r|r|}
\hline & $\begin{array}{c}\text { Respondentes que } \\
\text { usaram a abordagem }\end{array}$ & $\begin{array}{c}\text { Respondentes que não } \\
\text { usaram a abordagem }\end{array}$ \\
\hline \hline Sim & $8(66,7 \%)$ & $6(66,7 \%)$ \\
\hline Não & $2(16,7 \%)$ & $2(16,7 \%)$ \\
\hline Não sei & $2(16,7 \%)$ & $4(16,7 \%)$ \\
\hline
\end{tabular}

Observação: as porcentagens acima somadas não totalizam 100\% por causa do número de casas decimais utilizado em todas as tabulações.

\section{7 - Quais ferramentas de desenvolvimento Web foram utilizadas por seu grupo?}

\section{Respondentes que usaram a abordagem}

Tabela B.9 - Ferramentas utilizadas pelos grupos que usaram a abordagem

\begin{tabular}{|l|l|}
\hline "Somente a IDE Web Builder versão 2010." & "Dreamweaver." \\
\hline $\begin{array}{l}\text { "As ferramentas utilizadas por nosso grupo } \\
\text { foram: Eclipse e Netbeans." }\end{array}$ & $\begin{array}{l}\text { "Dreamweaver e phpMyAdmin para } \\
\text { trabalhar com o MySQL." }\end{array}$ \\
\hline "Netbeans com linguagem PHP." & "Dreamweaver." \\
\hline "Netbeans." & "Usamos o Netbeans para fazer o código." \\
\hline "Dreamweaver." & "Netbeans." \\
\hline "Netbeans." & \\
\hline
\end{tabular}

\section{Respondentes que não usaram a abordagem}

Tabela B.10 - Ferramentas utilizadas pelos grupos que não usaram a abordagem

\begin{tabular}{|l|l|}
\hline "PHP.” & "O ambiente de programação NetBeans." \\
\hline "NVU." & "NetBeans e NVU." \\
\hline "Bloco de notas e Google." & "Dreamweaver." \\
\hline "Não usei nenhuma." & "Netbeans." \\
\hline $\begin{array}{l}\text { "Usamos a ferramenta "Nvu 1.0", um editor } \\
\text { opensource." }\end{array}$ & $\begin{array}{l}\text { "Umas das ferramentas utilizadas foi o } \\
\text { Netbeans e o Eclipse." }\end{array}$ \\
\hline "Notepad++." & "Joomla e Microsoft Word." \\
\hline
\end{tabular}


8 - Houve alguma ajuda dessas ferramentas de desenvolvimento para auxílio ao trabalho em acessibilidade?

Tabela B.11 - Se as ferramentas apoiaram no desenvolvimento com acessibilidade

\begin{tabular}{|l|r|r|}
\hline \multicolumn{1}{|c|}{ Opção } & $\begin{array}{c}\text { Respondentes que } \\
\text { usaram a abordagem }\end{array}$ & $\begin{array}{c}\text { Respondentes que não } \\
\text { usaram a abordagem }\end{array}$ \\
\hline \hline Sim - ajudou bastante & $2(16,7 \%)$ & $1(08,3 \%)$ \\
\hline Sim - parcialmente & $8(66,7 \%)$ & $7(58,3 \%)$ \\
\hline Não & $2(16,7 \%)$ & $3(25,0 \%)$ \\
\hline Não sei & $0(00,0 \%)$ & $1(08,3 \%)$ \\
\hline
\end{tabular}

9 - Você acredita que as ferramentas podem apoiar mais no desenvolvimento com acessibilidade?

Tabela B.12 - Se as ferramentas podem apoiar mais no desenvolvimento com acessibilidade

\begin{tabular}{|l|r|r|}
\hline \multicolumn{1}{|c|}{ Opção } & $\begin{array}{c}\text { Respondentes que } \\
\text { usaram a abordagem }\end{array}$ & $\begin{array}{c}\text { Respondentes que não } \\
\text { usaram a abordagem }\end{array}$ \\
\hline \hline Sim & $12(100,0 \%)$ & $11(91,7 \%)$ \\
\hline Não & $0(00,0 \%)$ & $0(00,0 \%)$ \\
\hline Não sei & $0(00,0 \%)$ & $1(08,3 \%)$ \\
\hline
\end{tabular}

10 - Explique sua resposta anterior em relação apoio das ferramentas de desenvolvimento Web.

\section{Respondentes que usaram a abordagem}

"Poderiam integrar demonstrações de algumas recomendações de acessibilidade, assim como a documentação das mesmas.

Poderiam criticar também mais, alguns auxílios que essas ferramentas dão, são somente recomendações, elas poderiam ser obrigatórias."

"Muitas ferramentas poderiam ajudar o desenvolvimento com acessibilidade usando, por exemplo, um auto completar em tags de formulário que já inserisse no código os parâmetros como caption, tabindex, label, etc... já pré preenchidos ou informando o desenvolvedor a falta de algum deles.

Esta ideia não forçaria o desenvolvedor a desenvolver com acessibilidade, pois isso depende do desenvolvedor, mas ajudaria os desenvolvedores que quisesse trabalhar usando acessibilidade." 
"Provavelmente com mais apoio no que diz respeito à acessibilidade, mais sites acessíveis teríamos.”

"As ferramentas deveriam exigir os requisitos de acessibilidade em todos os projetos."

"Verificação de algumas regras básicas em acessibilidade, por exemplo fechamento de tags, caso uma tag de imagem verificar se existe algum texto auxiliar e etc..."

“Oferecer auxílios fáceis em tempo real de desenvolvimento."

"Ferramentas apoiando o programador em acessibilidade, incentiva a classe a desenvolver de forma acessível."

"As ferramentas auxiliam bastante informando possíveis erros e completando alguns códigos."

"Sim, poderiam ter mais alertas, informações em geral."

"Com certeza as ferramentas precisam evoluir para apoiar mais o desenvolvimento de sites acessíveis."

"Elas poderiam ser mais fáceis de usar e ajudar os usuários com recursos específicos para acessibilidade."

"Sim, tudo que for possível para ajudar é bem vindo. E fica mais fácil se tiver apoio de ferramentas."

\section{Respondentes que não usaram a abordagem}

"Interagindo-se mais com as questões da WCAG e colocando muitas das alternativas viáveis na prática."

“Obvio que sim. Desenvolver algo acessível não é fácil logo tem que haver ferramentas que ajudem."

"As ferramentas de apoio não auxiliam o desenvolvedor a prover acessibilidade e na maioria das vezes, não é acessível nem ao próprio desenvolvedor."

"Não vi nenhuma que fosse útil em um ambiente de trabalho, talvez a criação de framework fosse mais viável."

"Elas poderiam ajudar com uma espécie de banco de dados de acessibilidade, informando os padrões da WCAG." 
"Se as todas as ferramentas sugerissem ideias para acessibilidade, as aplicações se tornariam acessíveis, por exemplo, inserção de imagens, quando uma tag <img> fosse inserida, atributos para texto alternativo deveriam ser inseridos automaticamente. Algumas IDEs já usam parcialmente essa ideia.”

“Acho que elas deveriam avaliar a acessibilidade durante a produção de páginas Web."

"Acredito que se as ferramentas já tivessem algumas coisas prontas, os desenvolvedores seriam motivados a usá-las."

"Se as ferramentas auxiliassem os desenvolvedores a incrementar seus projetos de desenvolvimento seria mais fácil para o desenvolvedor o uso da acessibilidade."

"Poderia dizer onde estamos falhando em como arrumar o código fonte."

"As ferramentas poderiam facilitar o trabalho do desenvolvedor mostrando como fazer de forma correta os códigos HTML... Elas já ajudam a preencher um pouco do código, mas poderiam fazer mais."

"Sim, pois com o auxílio da ferramenta o usuário acaba sendo forçado, mostrando padrões de projetos com o uso de acessibilidade de forma correta."

11 - Quais utilidades você acredita serem importantes em ferramentas de desenvolvimento para apoio em acessibilidade?

Tabela B.13 - Utilidades importantes consideradas importantes em ferramentas de desenvolvimento para apoio em acessibilidade

\begin{tabular}{|l|r|r|}
\hline \multicolumn{1}{|c|}{ Opção } & $\begin{array}{c}\text { Respondentes que } \\
\text { usaram a } \\
\text { abordagem }\end{array}$ & $\begin{array}{c}\text { Respondentes que } \\
\text { não usaram a } \\
\text { abordagem }\end{array}$ \\
\hline Documentação integrada à ferramenta & $7(58,3 \%)$ & $6(50,0 \%)$ \\
\hline $\begin{array}{l}\text { Validações de código em tempo real informando } \\
\text { ao desenvolvedor possíveis erros e } \\
\text { esquecimentos }\end{array}$ & $11(91,7 \%)$ & $10(83,3 \%)$ \\
\hline $\begin{array}{l}\text { Possibilidade de arrastar e soltar componentes } \\
\text { acessíveis }\end{array}$ & $7(58,3 \%)$ & $6(50,0 \%)$ \\
\hline $\begin{array}{l}\text { Integração com os modelos de planejamento } \\
\text { feitos (documento de requisitos, por exemplo) }\end{array}$ & $8(66,7 \%)$ & $5(21,0 \%)$ \\
\hline
\end{tabular}

Como as opções não são excludentes, as porcentagens somadas excedem 100\%. 


\section{B.4 Reprodução da entrevista}

A seguir é apresentada, na íntegra, a entrevista realizada como parte do estudo empírico envolvendo o desenvolvimento de uma aplicação para o agendamento de bancas científicas.

P1 - Você considerou útil o uso da abordagem na orientação de atividades a serem seguidas?

R1 - Eu achei útil porque a abordagem dá um norte para a gente, sobre o que fazer, quais os passos que a gente deve fazer para se ter um desenvolvimento melhor. A maioria das atividades foi viável sim, mas há algumas coisas difíceis de fazer.

P2 - Comente sobre o Eixo 1 - Treinamento em Acessibilidade: importância, como foi feito, dentre outas impressões que achar conveniente?

R2 - Ele foi importante, pois deixa a gente tomar decisões sobre o que fazer. A conscientização sobre o tema melhorou bastante, apesar do tempo curto para ser desenvolvido o treinamento. Isso leva um tempo a mais se comparado ao que normalmente é feito. São muitas diretrizes da WCAG, tem bastante. É importante, pois educa a todos do grupo também, se um trabalhar usando esse treinamento e outros não, nessa abordagem, pode ocorrer um conflito depois.

\section{P3 - Foi fácil encontrar materiais?}

R3 - Tem muito coisa que foi fácil encontrar, mas a maioria das coisas está em inglês. Então houve uma dificuldade por estar em inglês. A WCAG pelo menos tinha a sua tradução, mas que não é oficial.

\section{P4 - Você já tinha experiência em acessibilidade para o desenvolvimento Web?}

R4 - Não tinha, dessa forma em que foi feito não. Utilizava algumas coisas. Talvez eu até utilizasse algumas técnicas corretas, mas não sabia que ajudava na acessibilidade. Um exemplo, o uso de labels em formulários. Com o treinamento que foi feito agora ficou melhor.

P5 - A avaliação de conhecimento da equipe é importante?

R5 - É bom avaliar para ver se está tudo certo. Se o treinamento funcionou ou não. 
P6 - Você acredita que se houver esse treinamento e discussões numa empresa será interessante?

R6 - Em uma empresa seria importante, mas o problema é o tempo. A gente tem que entregar o produto em um prazo específico e poderia ser muito oneroso.

P7 - O uso do AccessibilityUtil para buscas e registros foi importante?

R7 - É interessante buscar lá sim. Tem várias coisas que a gente pode usar lá, mas tem coisas que não tem. Mas usamos várias coisas que foram úteis.

P8 - Comente sobre o Eixo 2 - Gerência de Decisões: importância, como foi feito, dentre outas impressões que achar conveniente? Foi fácil fazer essa gerência? Você achou útil isso?

R8 - É interessante fazer porque a gente inseria as dúvidas que a gente tinha. Por exemplo: layout. A gente definia questões e discutíamos. É bom para todos do grupo saberem o que está acontecendo e ajudarem na decisão do que íamos fazer. Por exemplo, sobre a linguagem de programação, a gente discutiu quais seriam utilizadas, a gente utilizou uma lá, pois não tínhamos tempo de aprender uma nova. E a gente sabia que precisava entregar o produto no final.

P9 - Você acredita que a difusão dessas decisões contribuirá como conhecimento útil para outras equipes.

R9 - Com certeza, pois pode ter muita gente que pode ter as mesmas dúvidas que a gente teve. Pode ajudar eles embasarem algumas decisões de acordo com as decisões que nós tivemos.

P10 - O uso do AccessibilityUtil para essa gerência de decisões foi interessante?

R10 - Sim, muitas decisões feitas e registradas com auxílio da ferramenta foram válidas, deram certo depois na prática com a execução do que foi decidido.

P11 - As decisões envolveram escolha de lay-out e itens dinâmicos, linguagens para se utilizar, dentre outras?

R11 - Sim, foram esses os assuntos. A gente começou a escolher a linguagem de programação. Depois discutimos em relação ao lay-out, dúvidas sobre cores. Ai cada um 
colocou as opiniões que tinham e a gente decidiu o esquema de cores do site. Se tem contraste, se é acessível, de acordo com o que sabíamos.

P12 - Comente sobre o Eixo 3 - Desenvolvimento e ferramentas: importância, como foi feito, dentre outas impressões que achar conveniente? Foi fácil fazer um desenvolvimento com preocupações em acessibilidade? Você achou útil isso?

R12 - É importante termos ferramentas que nos auxiliem, por exemplo, a fazer formulários corretamente, acessível. Fica bem mais fácil para a gente fazer, porque nem sempre nos lembramos de todas as tags e de outras informações que aprendemos.

P13 - A documentação contínua de acessibilidade foi difícil, atrasou o desenvolvimento?

R13 - Sim, foi complicado, pois toma um pouco do tempo. E tínhamos pouco tempo. Mas é importante fazer sim. Apesar de ser um pouquinho difícil.

P14 - Você achou importante e útil já ter a disposição uma base de componentes acessíveis para uso? Foi fácil aplica-los no código fonte Web?

R14 - É importante porque o tempo que a gente ia gastar desenvolvendo essa base seria muito maior. Tendo esse repositório de código com funções já prontas a gente inclui em nosso código e a gente já sabe que ele fica acessível. Foi tranquilo aplicar os elementos em nosso código fonte. Um exemplo disso foi o menu acessível por tab, geralmente os menus com submenus não são acessíveis. Conseguimos mudar a cor do menu, fonte, tínhamos opções para parametrizá-lo, sem mudar a funcionalidade oferecida por ele e sendo acessível. Tivemos vários recursos obtendo códigos Javascript prontos para controles de aumentar fonte e alterar o modo de contraste.

P15 - Foi usado algum método de gerência de configuração?

R15 - Não foi possível fazer por uma questão de tempo. Tínhamos um prazo curto para ser feito.

P16 - As ferramentas utilizadas proveram todos os recursos que você esperava para auxílio em acessibilidade?

R16 - Sobre as ferramentas que a gente utilizou, algumas tinham mais recursos, outras não. Por exemplo, o auxílio para colocar texto alternativo foi uma função que a maioria das 
ferramentas fazem, mas essa é uma ajuda simples, porém importante. Seria interessante colocar mais ajudas sim.

P17 - Sobre validação em tempo real, você acredita ser importante e útil para o desenvolvimento?

R17 - Seria muito bom a validação em tempo de desenvolvimento. A gente esquece muito de fechar tags e outras coisas, pequenos detalhes, que poderia haver uma ajuda na hora para nos lembrar. O provimento de esqueletos de código seria muito importante, pois tendo uma base inicial, facilitaria muito o desenvolvimento correto.

P18 - Sobre monitoramento contínuo de acessibilidade, acredita ser importante e como foi realizado em seu desenvolvimento?

R18 - A gente até começou a fazer uma avaliação após cada desenvolvimento, por partes, para saber se estava dando tudo certo. Para a avaliação do código usamos um validador do W3C. Mas essa avaliação não foi continuada após a entrega do produto, pois não houve manutenção posterior desse sistema. Acredito ser importante sim ter esse monitoramento. 



\section{Técnicas, critérios de sucesso e checkpoints de documentos do W3C}

\section{C.1 Técnicas para atendimento às diretrizes WCAG 2.0}

A seguir é apresentada a seleção de técnicas para atendimento às diretrizes WCAG 2.0 referenciados de forma específica nesta tese. A lista completa dessas técnicas está disponível em: http://www.w3.org/TR/WCAG20-TECHS/.

Quadro C.1 - Seleção de técnicas para atendimento às diretrizes WCAG 2.0

\begin{tabular}{|c|l|}
\hline Código & Descrição \\
\hline \hline G134 & Validando páginas Web. \\
\hline
\end{tabular}




\begin{tabular}{|c|l|}
\hline G141 & Organizando uma página usando cabeçalhos. \\
\hline H28 & $\begin{array}{l}\text { Provendo definiçães para abreviatura usando os elementos } a b b r \text { (para abreviaturas) e } \\
\text { acronym (para acrônimos). }\end{array}$ \\
\hline H37 & Usando atributos alt em elementos do tipo imagem. \\
\hline H39 & Usando elementos caption para associar data table captions em dados de tabelas. \\
\hline H42 & Usando $h 1$ - $h 6$ para identificar cabeçalhos. \\
\hline H44 & Usando elementos do tipo label para associar rótulos de texto em controles de formulário. \\
\hline H51 & Usando marcação de tabela para apresentar informação tabular. \\
\hline H67 & $\begin{array}{l}\text { Usando texto alternativo nulo (alt text) e sem atributo title em imagens para que sejam } \\
\text { ignorados pelas ferramentas de autoria (imagens decorativas). }\end{array}$ \\
\hline H73 & $\begin{array}{l}\text { Usando o atributo sumário (summary) no elemento tabela para fornecer uma descrição geral } \\
\text { desse elemento. }\end{array}$ \\
\hline H75 & Garantindo que as páginas Web são bem formadas. \\
\hline
\end{tabular}

\section{C.2 Critérios de sucesso das diretrizes WCAG 2.0}

A seguir é apresentada a seleção de critérios de sucesso das diretrizes WCAG 2.0 referenciados de forma específica nesta tese. A lista completa desses critérios de sucesso está disponível em: http://www.w3.org/TR/WCAG/.

Quadro C.2 - Seleção de critérios de sucesso das diretrizes WCAG 2.0

\begin{tabular}{|c|c|}
\hline Código & Descrição \\
\hline 1.1 .1 & $\begin{array}{l}\text { Conteúdo Não Textual: todo o conteúdo não textual que é apresentado ao usuário tem uma } \\
\text { alternativa em texto que serve um propósito equivalente, exceto para as situações indicadas } \\
\text { abaixo. }\end{array}$ \\
\hline 1.3 .1 & $\begin{array}{l}\text { Informações e Relações: as informações, a estrutura e as relações transmitidas através de } \\
\text { apresentação podem ser determinadas de forma programática ou estão disponíveis no texto. }\end{array}$ \\
\hline 1.4 .3 & $\begin{array}{l}\text { Contraste (Mínimo): a apresentação visual de texto e imagens de texto tem uma relação de } \\
\text { contraste de, no mínimo, } 4.5: 1 \text {. }\end{array}$ \\
\hline 4.1 .2 & $\begin{array}{l}\text { Nome, Função, Valor: para todos os componentes de interface de usuário (incluindo, mas } \\
\text { não se limitando a: elementos de formulário, links e componentes gerados por scripts), o } \\
\text { nome e a função podem ser determinados de forma programática; os estados, as propriedades } \\
\text { e os valores que podem ser definidos pelo usuário podem ser definidos de forma } \\
\text { programática; e a notificação sobre alterações a estes itens está disponível para agentes de } \\
\text { usuário, incluindo tecnologias assistivas. }\end{array}$ \\
\hline 3.3 .2 & $\begin{array}{l}\text { Etiquetas ou Instruções: etiquetas ou instruções são fornecidas quando o conteúdo exigir a } \\
\text { entrada de dados por parte do usuário. }\end{array}$ \\
\hline 2.4 .2 & Página com Título: as páginas Web têm títulos que descrevem o tópico ou a finalidade. \\
\hline 3.2 .3 & $\begin{array}{l}\text { Navegação Consistente: os mecanismos de navegação que são repetidos em várias páginas } \\
\text { Web ocorrem pela mesma ordem relativa a cada vez que são repetidos, a menos que seja } \\
\text { iniciada uma alteração pelo usuário. }\end{array}$ \\
\hline 2.4 .10 & Cabeçalhos da sessão: os cabeçalhos da sessão são utilizados para organizar o conteúdo. \\
\hline
\end{tabular}




\section{C.3 Checkpoints das diretrizes ATAG 1.0}

A seguir é apresentada a seleção de checkpoints da ATAG 1.0 referenciados de forma específica nesta tese. A lista completa desses checkpoints está disponível em: http://www.w3.org/TR/WAI-AUTOOLS/atag10-chktable.html.

Quadro C.3 - Seleção de checkpoints das diretrizes ATAG 1.0

\begin{tabular}{|c|l|}
\hline Código & Descrição \\
\hline \hline 1.1 & $\begin{array}{l}\text { Assegura que o autor possa produzir conteúdo acessível nas linguagens de marcação } \\
\text { suportadas pela ferramenta de autoria. }\end{array}$ \\
\hline 1.3 & $\begin{array}{l}\text { Assegura que quando a ferramenta automaticamente gera conteúdo de marcação esse esteja } \\
\text { em conformidade com as diretrizes de acessibilidade WCAG. }\end{array}$ \\
\hline 3.1 & $\begin{array}{l}\text { Solicita ao autor o fornecimento de informações de alternativas equivalentes para elementos } \\
\text { não textuais (por exemplo, legendas, descrições auditivas, e transcrições de texto agregadas } \\
\text { para vídeo). }\end{array}$ \\
\hline 4.1 & Provê maneiras de checagem e correção de conteúdo inacessível. \\
\hline 4.4 & Integra soluções de acessibilidade em seu modo de ver e sentir "look and feel". \\
\hline 6.2 & $\begin{array}{l}\text { Assegura que a criação do conteúdo acessível é naturalmente integrado como uma parte da } \\
\text { documentação, incluindo exemplos. }\end{array}$ \\
\hline
\end{tabular}

